\title{
Ein Knockout-Mausmodell für Congenital Disorder of Glycosylation-IIc: Defizienz des Golgi-GDP-Fucose-Transporters
}

\author{
Dissertation \\ zur Erlangung des Doktorgrades \\ der Mathematisch-Naturwissenschaftlichen Fakultäten \\ der Georg-August-Universität zu Göttingen
}

\author{
vorgelegt von \\ Christina Hellbusch \\ aus Delmenhorst
}

Göttingen 2006 
D7

Referent: Prof. Dr. Dr. h.c. K. von Figura

Korreferent: Prof. Dr. G. Braus

Tag der mündlichen Prüfung: 03. Mai 2006 
Meinen Eltern 


\section{Inhaltsverzeichnis}

1

1.1

1.1.1

1.1 .2

1.1 .3

1.1.4

1.2

1.2.1

1.2.2

1.2.2.1

1.2.2.2

1.2.2.3

1.3

2

3

3.1

3.1.1

3.1 .2

3.1 .3

3.1 .4

3.1 .5

3.1 .6
Einleitung

Vorkommen, Bedeutung und Mechanismen der

1

Proteinglykosylierung

Vorkommen und Bedeutung der Glykosylierung von Proteinen

1

Fucosylierung von Glykoproteinen

2

6

Mechanismen der Proteinglykosylierung

8

der Solute carrier family 35

Vererbbare Defekte der Proteinglykosylierung: Congenital

10

Disorders of Glycosylation (CDG)

CDG-Typen

CDG-IIc / LAD II

Symptomatik von CDG-IIC

Fucose-Therapie von CDG-IIc-Patienten

CDG-IIc: Ein Defekt des Golgi-GDP-Fucose-Transporters

Verwendung von genetisch manipulierten Mausmodellen zur

\section{Untersuchung molekularer Mechanismen}

Die Maus als Modell: Eigenschaften, Eignung und Vorgehensweise

17

Der Golgi-GDP-Fucose-Transporter der Maus

Vorhandene Mausmodelle mit Defekten der Proteinfucosylierung

Problemstellung

21

Material und Methoden

Material

Geräte

EDV

24

Verbrauchsmaterial

25

Chemikalien

26

Puffer und Lösungen

28

Zellkulturmedien, Medienzusätze und Lösungen zur Arbeit mit

28 
3.1.7 Enzyme und Reagenzien für molekularbiologische, zellbiologische und proteinbiochemische Methoden

3.1.8 Antikörper und Selektin-Fc-Fusionsproteine

3.1.9 Lektine und Streptavidin-Konjugate 31

3.1.10 Oligonukleotide 31

3.1.11 Radioaktive Substanzen 31

3.1.12 Hormone und Anästhetika zur Arbeit mit Mäusen 32

3.1.13 Embryonale Stammzellen 32

3.1.14 Neomycin-resistente embryonale Mausfibroblasten (Feeder) 32

3.1.15 Mausstämme 32

$3.2 \quad$ Molekularbiologische Methoden 34

3.2.1 Standardbedingungen und -methoden der Molekularbiologie 34

3.2.2 Isolierung genomischer DNA

3.2.3 Isolierung von RNA 35

3.2.4 Konzentrationsbestimmung von Nukleinsäuren 35

3.2.5 Spaltung von DNA mit Restriktionsendonukleasen 35

3.2.6 Auftrennung von DNA-Fragmenten in Agarosegelen 36

3.2.7 Isolierung von DNA-Fragmenten aus Agarosegelen 37

3.2.8 Transfer von DNA auf Hybond N-Filter (Southern-Blot) 37

3.2.9 Transfer von RNA auf Hybond N-Filter (Northern-Blot) 39

3.2.10 Markierung einer DNA-Sonde mit $\left[\alpha{ }^{32} \mathrm{P}\right] \mathrm{dCTP} \quad 39$

3.2.11 Hybridisierung der an Hybond N-Filter gebundenen DNA bzw. RNA 40

3.2.12 Polymerase-Ketten-Reaktion 41

3.2.12.1 Allgemeines 41

3.2.12.2 Primer-Design 41

3.2.12.3 Standard-PCR 42

3.2.12.4 Genotypisierungs-PCR mit der Taq DNA-Polymerase E (Genaxxon) 43

3.2.13 Sequenzierung von DNA 43

3.3 Methoden zur Arbeit mit Mäusen und Blastozysten 44

3.3.1 Maushaltung 44

3.3.2 Superovulation von Mäusen 44

3.3.3 Gezielte Verpaarung von Mäusen 45

3.3.3.1 Vaginalpfropfkontrolle $\quad 45$ 
3.3.3.2 Weibchen zur Blastozystenspende 45

3.3.3.3 Weibchen zum Austragen der Blastozysten (Foster-Mäuse) 45

3.3.4 Gewinnung von Blastozysten aus trächtigen Mäusen 46

3.3.5 Mikroinjektion von ES-Zellen in Maus-Blastozysten 46

3.3.6 Transfer injizierter Blastozysten in pseudoschwangere Foster- 46

$\begin{array}{lll}\text { 3.3.7 Identifizierung von Chimären } & 47\end{array}$

3.3.8 Weitere Zucht zur Etablierung von Knockout-Mauslinien $\quad 47$

3.3.9 Embryonentransfer zur Etablierung einer SPF-Zucht 48

3.3.10 Differentialblutbild 48

3.3.11 Untersuchung psychomotorischer Fähigkeiten anhand des "Screen- 48

$3.4 \quad$ Methoden zur Zellpräparation und -kultur 49

3.4.1 ES-Zellkultur 49

3.4.1.1 Kultivierung von embryonalen Stammzellen 49

3.4.1.2 Trypsinieren von ES- und Feeder-Zellen 50

3.4.1.3 Mitotische Inaktivierung von Fibroblasten 50

3.4.1.4 Kryokonservierung von ES-Zellen 50

3.4.1.5 Auftauen und Revitalisieren von Zellen 51

3.4.1.6 Vorbereitung von ES-Zellen für die Mikroinjektion 51

3.4.2 Präparation von primären embryonalen Fibroblasten 51

3.4.3 Präparation von murinen Hepatozyten 52

3.4.3.1 Lineare in situ Perfusion einer Mausleber und Gewinnung einer 52

3.4.3.2 Abtrennung der vitalen Hepatozyten von nicht-parenchymalen 55

3.4.3.3 Aussaat und Kultur von Hepatozyten 56

3.4.4 Präparation von murinen Mesangialzellen 56

3.4.5 Präparation von Knochenmarkszellen $\quad 57$

3.4.6 Präparation von Milzzellen 58

3.4.7 Fucose-Behandlung verschiedener Zelltypen 58

$3.5 \quad$ Proteinbiochemische Methoden $\quad 59$

3.5.1 Bestimmung der GDP-[ $\left[{ }^{14} \mathrm{C}\right]$ Fucose- und UDP- $\left[{ }^{3} \mathrm{H}\right]$ Galactose-Import- $\quad 59$ Aktivität in Golgi-angereicherten Fraktionen aus Lebergewebe 
3.5.1.1 Aufschluss von Lebergewebe $\quad 59$

3.5.1.2 Präparation Golgi-angereicherter Vesikel aus Lebergewebe 59

3.5.1.3 Bestimmung der GDP- $\left[{ }^{14} \mathrm{C}\right]$ Fucose- und UDP- $\left[{ }^{3} \mathrm{H}\right]$ Galactose-Import- $\quad 60$ Aktivität

3.5.2 Bestimmung der Galactosyltransferase-Aktivität in Leberhomogenaten, postnukleären Überständen und Golgi-angereicherten Vesikeln

3.5.3 Bestimmung der Protein-Fucosylierung durch Lens culinaris-LektinAffinitätschromatographie von metabolisch markierten Glykopeptiden

3.5.3.1 Metabolische Markierung mit 2-[ $\left[{ }^{3} \mathrm{H}\right]$ Mannose 62

3.5.3.2 Präparation der Glykoproteine 63

3.5.3.3 Pronase-Behandlung der Glykoproteine 64

3.5.3.4 Lens culinaris-Lektin-Affinitätschromatographie 64

3.6 Histologische, histochemische und zytochemische Methoden 65

3.6.1 Anfertigung, Färbung und Auswertung histologischer Präparate aus 65

3.6.1.1 Organentnahme und Fixierung 65

3.6.1.2 Entwässerung und Einbettung in Paraffin 65

3.6.1.3 Schneiden der Präparate $\quad 66$

3.6.1.4 Hämatoxylin-Eosin-Färbung 66

3.6.1.5 Kombinierte Elastica- und Trichrom-Färbung nach Masson-Goldner 67

3.6.1.6 Morphometrische Analyse des Lungengewebes 68

3.6.2 Zytochemische Färbung fucosylierter Zellbestandteile in MEF mit $\quad 69$ Aleuria aurantia-Lektin

3.6.3 Fluoreszenzfärbung histologischer Präparate mit Lektinen 70

3.7 Methoden zur Charakterisierung der Fucosylierung und 72

\section{Selektin-Liganden-Expression und -Funktion auf Leukozyten}

3.7.1 Durchflusszytometrische Analysen 72

3.7.1.1 Fucosylierung und Selektin-Bindung von Knochenmarkszellen 72

3.7.1.2 Fucosylierung von Milzzellen 73

3.7.2 Untersuchung der Selektin-Liganden-Funktion durch 73 Intravitalmikroskopie an Peyer'schen Plaques 
4.1 Etablierung eines Knockout-Mausmodells für den Golgi-GDP-

Fucose-Transporter

4.1.1 Generierung von Chimären durch Retransfer der transgenen ES-

Zellen

Verpaarungsstrategie

76

4.1.3 Genotypisierung durch PCR, Sequenzierung und Southern-Blot 76 Klinischer Phänotyp der GFT ${ }^{-I-}$-Maus

4.2.1 Geburts- und Überlebensraten 81

4.2.1.1 Konventionelle Tierhaltung 81

4.2.1.2 SPF-Tierhaltung 83

4.2.1.3 Zucht auf Bl6- bzw. 129Sv-Stammhintergrund 84

4.2.2 Gewichtsentwicklung 85

4.2.3 Äußere Merkmale, Verhalten und motorische Fähigkeiten 86

4.2.4 Fertilität 88

$\begin{array}{lll}4.2 .5 & \text { Blutbild } & 89\end{array}$

4.3 Nachweis des Knockouts auf Ebene der RNA und GDP-Fucose- $\quad 90$

4.3.1 Expressionsanalyse durch Northern-Blot 90

4.3.2 Zuckernukleotid-Import-Aktivität in Golgi-angereicherten Vesikeln 91

4.4 Charakterisierung der Fucosylierung in primären Zellkulturen $\quad 93$

4.4.1 Markierung fucosylierter Strukturen in primären embryonalen 93

4.4.2 Quantitative Analyse der Fucosylierung durch Lens culinaris-Lektin- $\quad 94$ Affinitätschromatographie

4.4.2.1 Primäre embryonale Fibroblasten 94

4.4.2.2 Primäre Hepatozyten 96

4.4.2.3 Primäre Mesangialzellen 98

4.5 Fucosylierung und Selektin-Liganden-Funktion auf Leukozyten 100

4.5.1 FACS-Analyse isolierter Leukozyten aus dem Knochenmark 100

$\begin{array}{lll}\text { 4.5.2 } & \text { FACS-Analyse von Milzzellen } & 102\end{array}$

4.5.3 Leukozyten-Rollen in HEV der Peyer'schen Plaques 103

$\begin{array}{lll}4.6 & \text { Histologie der Organe } & 105\end{array}$ 
4.6.1 Übersichtsfärbung der histologischen Präparate 105

4.6.2 Morphometrische Analyse des Lungengewebes 115

4.6.3 Fluoreszenz-Markierung glykosylierter Strukturen in histologischen 116 Präparaten

5

Diskussion

5.1 Die Insertion einer Neomycin-Resistenzkassette in das SLC35C1-Gen führt zu einem konstitutiven Total-Knockout des murinen Golgi-GDP-Fucose-Transporters

5.2 Der Phänotyp des GFT $^{-l-}$-Mausmodells ist mit dem Krankheitsbild von CDG-Ilc vergleichbar

5.3 $\mathrm{GFT}^{-1-}$-Mäuse weisen einen Defekt der Expression und Funktion 131 von Selektin-Liganden auf

$5.4 \quad$ Lymphknoten und Lunge GFT-defizienter Mäuse zeigen histopathologische Veränderungen

$5.5 \quad \mathrm{GFT}^{-l-}$-Zellen und -Gewebe weisen eine ausgeprägte Hypofucosylierung auf

5.6 Die Fucosylierungsrate in $\mathrm{GFT}^{-1-}$-Zellen lässt sich durch Fucose-Supplementation normalisieren

$5.7 \quad$ Ausblick

8.1 Nukleotid- und Aminosäuresequenzen des GFT

8.1.1 Partielle Nukleotidsequenz der cDNA des murinen GDP-Fucose-

Transporters (ohne 3'-Ende)

8.1.2 Aminosäuresequenz des murinen Golgi-GDP-Fucose-Transporters 


\section{Verzeichnis der Abkürzungen}

\begin{tabular}{|c|c|}
\hline A & Adenin \\
\hline Abb. & Abbildung \\
\hline AP & Alkalische Phosphatase \\
\hline ATP & Adenosintriphosphat \\
\hline bp & Basenpaare \\
\hline BSA & Rinderserumalbumin \\
\hline bzw. & beziehungsweise \\
\hline C & Cytosin \\
\hline${ }^{\circ} \mathrm{C}$ & Grad Celsius \\
\hline${ }^{14} \mathrm{C}$ & Kohlenstoff 14 \\
\hline CDG & Congenital Disorders of Glycosylation \\
\hline cDNA & komplementäre DNA \\
\hline $\mathrm{Ci}$ & Curie \\
\hline $\mathrm{cpm}$ & counts per minute \\
\hline СTP & Cytidintriphosphat \\
\hline d & $\operatorname{Tag}(e)$ \\
\hline $\mathrm{Da}$ & Dalton \\
\hline $\mathrm{dd}_{2} \mathrm{O}$ & doppelt destilliertes Wasser \\
\hline d.h. & das heißt \\
\hline DMEM & Dulbecco's Modified Eagle Medium \\
\hline DMSO & Dimethylsulfoxid \\
\hline DNA & Desoxyribonukleinsäure \\
\hline dNTPs & Desoxyribonukleotide \\
\hline Dol & Dolichol \\
\hline ER & Endoplasmatisches Retikulum \\
\hline et al. & et alii (lat. und andere) \\
\hline f.c. & final concentration \\
\hline FKS & fötales Kälberserum \\
\hline Fuc & Fucose \\
\hline G & Guanin \\
\hline G418 & Geneticin $® 418$ \\
\hline
\end{tabular}




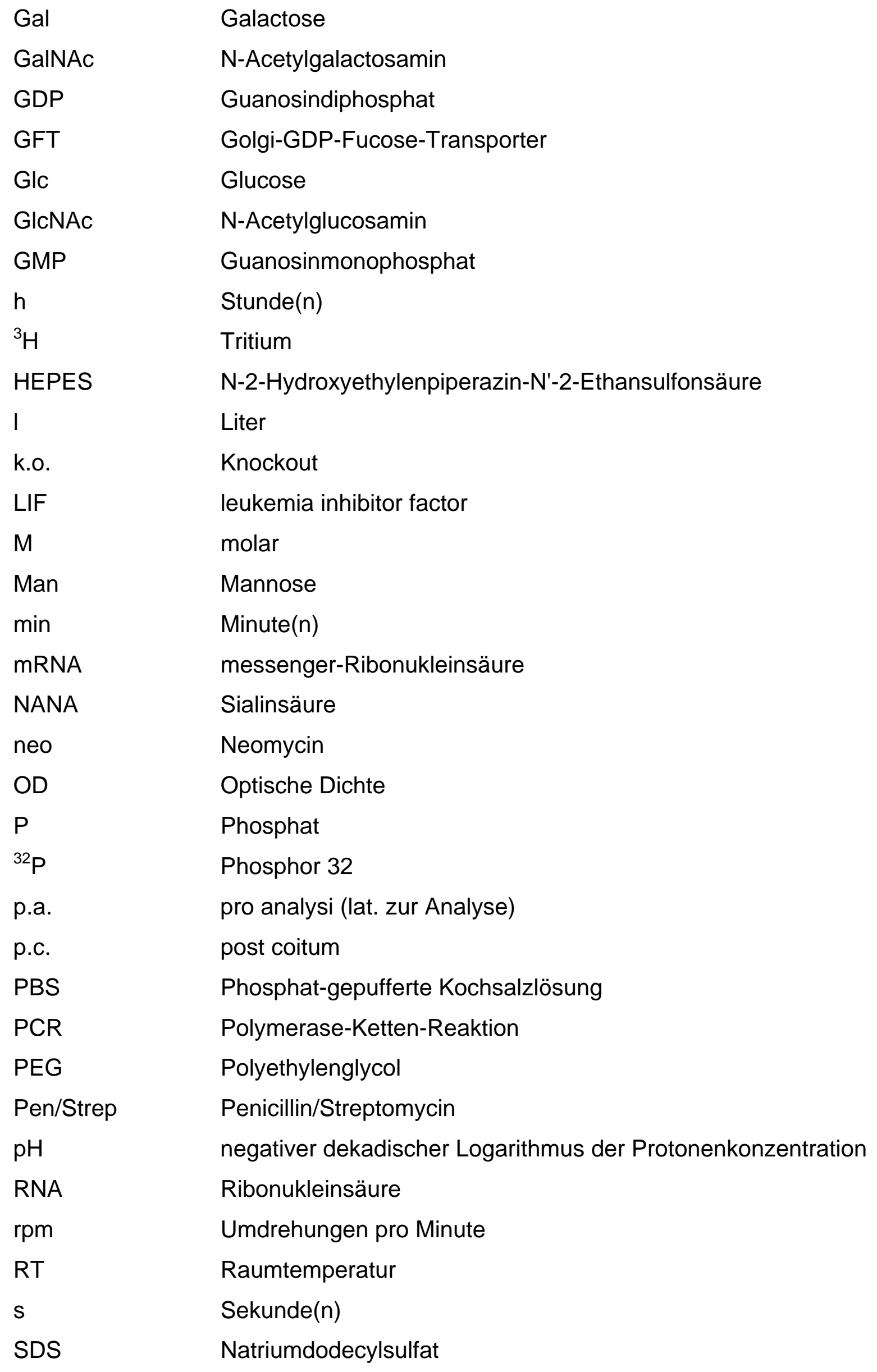




$\begin{array}{ll}\text { SSC } & \text { standard saline citrate } \\ \text { T } & \text { Thymin } \\ \text { Tab. } & \text { Tabelle } \\ \text { Taq } & \text { Thermophilus aquaticus } \\ \text { TE } & \text { Tris-EDTA } \\ \text { Tris } & \text { Tris(hydroxymethyl)-aminoacetat } \\ \text { u } & \text { Unit } \\ \text { U } & \text { Uridin } \\ \text { UDP } & \text { Uridindiphosphat } \\ \text { ü.N. } & \text { über Nacht } \\ \text { UTR } & \text { untranslated region (nicht-codierender Bereich) } \\ \text { UV } & \text { ultraviolett } \\ \text { V } & \text { Volt } \\ \text { Vol. } & \text { Volumen } \\ \text { vs. } & \text { versus } \\ \text { v/v } & \text { Volumen zu Volumen } \\ \text { w/v } & \text { Gewicht zu Volumen } \\ \text { WT } & \text { Wildtyp } \\ \text { xg } & \text { z-fache Erdbeschleunigung Beispiel } \\ \text { z.B. } & \end{array}$

Verwendete Vorsilben für Potenzen der Zahl Zehn:

$\begin{array}{lll}\mathrm{p} & \text { Pico } & \left(1 \times 10^{-12}\right) \\ \mathrm{n} & \text { Nano } & \left(1 \times 10^{-9}\right) \\ \mu & \text { Mikro } & \left(1 \times 10^{-6}\right) \\ \mathrm{m} & \text { Milli } & \left(1 \times 10^{-3}\right) \\ \mathrm{k} & \text { Kilo } & \left(1 \times 10^{3}\right) \\ \mathrm{M} & \text { Mega } & \left(1 \times 10^{6}\right)\end{array}$

Die chemischen Elemente wurden mit den üblichen Symbolen abgekürzt. Die Aminosäuren wurden entweder im Drei- oder Ein-Buchstabencode angegeben.

Bei einigen Begriffen wurden die englischen Fachtermini verwendet, da auch in der deutschsprachigen Fachliteratur eine Übersetzung diese Begriffe unüblich und unzureichend ist. 
$1 \quad$ Einleitung

\subsection{Vorkommen, Bedeutung und Mechanismen der Proteinglykosylierung}

\subsubsection{Vorkommen und Bedeutung der Glykosylierung von Proteinen}

Die ko- und posttranslationale Modifikation von Proteinen durch kovalente Verknüpfung mit Saccharidbausteinen ist für alle lebenden Organismen von Eubakterien bis hin zu Säugetieren beschrieben worden. Der Prozess ist gekennzeichnet durch eine hohe Komplexität der möglichen Zuckerstrukturen, die unter Beteiligung einer Vielzahl von Enzymen aus 13 unterschiedlichen Monosacchariden aufgebaut und mit acht verschiedenen Aminosäuren verknüpft werden können (Spiro, 2002).

Auch in Bezug auf die Art der Bindung zwischen Zucker und Protein lassen sich Glykoproteine in mehrere Gruppen untergliedern. Seit der ersten Beschreibung einer N-Acetylglucosamin- $\beta$-Asparagin-Verknüpfung in Ovalbumin im Jahr 1961 (Johansen et al., 1961) wurde die N-Glykosylierung als ein hochkonservierter Prozess bisher am eingehendsten charakterisiert. Eine weitere Bindungsart stellt die O-glykosidische Verknüpfung des Zuckers mit Hydroxylgruppen von Aminosäuren dar. 1994 wurde außerdem ein Bindungstyp beschrieben, der keine funktionelle Gruppe einer Aminosäure involviert und in einer C-C-Bindung zwischen einem a-Mannosylrest und dem C-2-Atom von Tryptophan besteht (Hofsteenge et al., 1994).

Oligosaccharid-Ketten können die Eigenschaften von Glykoproteinen in vielfältiger Weise beeinflussen. Sie verändern beispielsweise physikalische Eigenschaften wie die Hydrophilizität und die Faltungseffizienz und -stabilität. Der Glykosylierungsstatus eines Proteins kann darüber hinaus für die intrazelluläre Verteilung sowie die Proteinstabilität in Bezug auf Proteolyse entscheidend sein (Sears und Wong, 1998). 
Die Proteinglykosylierung erfüllt im Rahmen vieler biochemischer und zellbiologischer Prozesse entscheidende Funktionen. Ihre Bedeutung wird nicht zuletzt durch die stetig wachsende Zahl von beschriebenen Erkrankungen deutlich, deren Ursachen mit der Glykoprotein-Biosynthese in Zusammenhang stehen.

Rezeptor-Ligand-Interaktionen stellen eine bedeutende Funktion von N-Glykanen dar. Sie vermitteln Zell-Zell-Wechselwirkungen zum Zwecke der Erkennung und Adhäsion und sind für den rezeptorvermittelten Transport von Proteinen sowohl innerhalb der Zelle als auch zu spezifischen Zielzellen verantwortlich (Varki, 1993).

Die Bedeutung der O-Glykosylierung wird zum Beispiel anhand der Glykoproteine

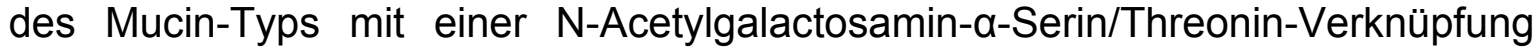
deutlich. Sie bewirken die visköse Beschaffenheit von mukösem Schleim als Schutzfaktor auf epithelialen Oberflächen des Gastrointestinal-, Respirations- und Genitaltraktes. Auch die auf nahezu allen identifizierten Kollagenen vorhandene Galactose- $\beta$-Hydroxylysin-Bindung ist diesem Glykosylierungstyp zuzurechnen (Spiro, 1969). Verschiedene Erkrankungen aus der Gruppe der Muskeldystrophien wie z.B. das Walker-Warburg-Syndrom oder die 'Muscle-eye-brain disease' werden durch Defekte in der Synthese von O-Mannosylglykanen verursacht (Beltran-Valero de Bernabe et al., 2002; Yoshida et al., 2001).

\subsubsection{Fucosylierung von Glykoproteinen}

Diese Arbeit befasst sich mit der Fucosylierung von Proteinen. Der Zucker Fucose trägt aufgrund seiner Vielfalt an möglichen Bindungstypen und -partnern insbesondere zur Mikroheterogenität von Oligosaccharidstrukturen bei. In NGlykanen des Säugerorganismus ist die Desoxyhexose L-Fucose durch eine $\alpha$ 1,2-glykosidische Bindung mit Galactose oder durch $\alpha-1,3-$, $\alpha-1,4-$ oder $\alpha-1,6-$ glykosidische Bindungen mit N-Acetylglucosamin verknüpft. An Serin oder Threonin O-glykosidisch verknüpfte Fucose wurde bisher allein oder als Basis für eine elongierte Struktur aus bis zu vier Zuckern beschrieben (Moloney et al., 2000a; s. Abb.1). 
Im Gegensatz zu den meisten anderen Zuckern sind Fucosereste in proteinverknüpften Oligosaccharidstrukturen vor allem Bestandteil der peripheren Abschnitte. Als solcher verleihen sie den jeweiligen Proteinen eine charakteristische Oberflächenstruktur und spielen somit bei intra- und interzellulären Erkennungsprozessen und Interaktionen eine bedeutende Rolle.

L-Fucose gehört zu den vier Sacchariden, aus denen sich die determinante Gruppe von Kohlenhydrat-Blutgruppenantigenen zusammensetzt. Je nach Art und Lokalisation der Bindung eines Fucoserestes an das Grundgerüst der Blutgruppenantigene entstehen Substanzen mit $\mathrm{H}-$, Lewis a $\left(\mathrm{Le}^{\mathrm{a}}\right)$ - oder $\mathrm{Le}^{\mathrm{b}}$ Spezifität (s. Abb. 1).

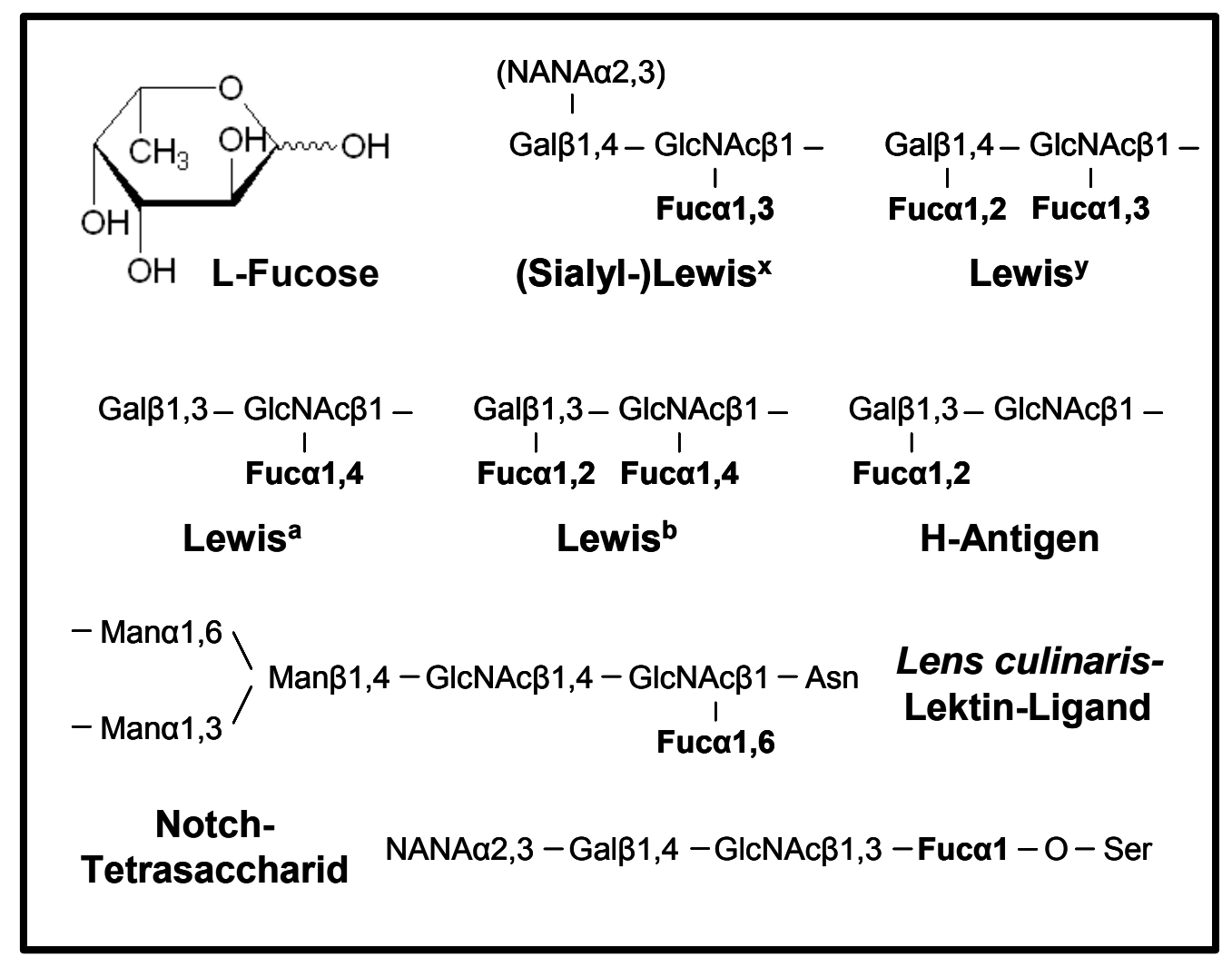

Abb. 1: $\quad$ L-Fucose und fucosylierte Strukturen von besonderer Bedeutung.

Als Liganden von Selektinen, einer Familie von Adhäsionsrezeptoren mit terminalen Lektin-Domänen, erfüllen fucosylierte Sialyl-Le ${ }^{\mathrm{x}}-$ Moleküle bei dem Rollen von Leukozyten auf der Oberfläche der kapillären Endothelzellen eine entscheidende Funktion. Dieser Prozess ist im Verlauf von LymphozytenRezirkulation sowie entzündlichen Gewebsreaktionen Voraussetzung für die 
anschließende, feste Adhäsion der Leukozyten an die Endothelzellen (Vestweber und Blanks, 1999), bevor ihre Migration durch die Gefäßwand in das lymphatische bzw. entzündete Gewebe (Diapedese) erfolgen kann (Lowe, 1994, 1997).

Glykanstrukturen auf Krebszellen zeigen charakteristische und tumorspezifische Muster in Bezug auf Anzahl und Art der Verknüpfung mit Fucosyl- und Sialylresten, die wertvolle Informationen über die Malignität des Tumors und sein Potential zur Metastasierung enthalten. Die Glykane sind sowohl an der Immunantwort des Organismus als auch an der Zelladhäsion bei der Metastasis und der Modulation der Funktion von Proteinen beteiligt (Fukuda, 1996).

Darüber hinaus spielt Fucose als relevanter Bestandteil von Liganden bei einer Vielzahl von Erkennungsprozessen auch bei anderen pathologischen Vorgängen eine wichtige Rolle (Kobata, 1998; Brockhausen et al., 1998). Neben Autoimmunerkrankungen (Delves, 1998), Diabetes (Yorek und Dunlap, 2002) und Zystischer Fibrose (Scanlin und Glick, 1999) seien an dieser Stelle die Erkennungsmechanismen im Rahmen der Invasion von Viren, Bakterien und Parasiten, beispielsweise der Bindung von Helicobacter pylori an Epithelzellen der Magenschleimhaut, genannt (Falk et al., 1995).

Doch auch nicht pathologische Interaktionen mit Mikroorganismen werden durch fucosylierte Glykane vermittelt, wie beispielsweise die Symbiose mit dem kommensalen Darmbakterium Bacteroides thetaiotaomicron, das seinerseits sogar in der Lage ist, eine Expression dieser Glykane, die inm als Nahrungsquelle dienen, auf den Wirtszellen zu induzieren (Bry et al., 1996).

Fucosylierten Epitopen werden Funktionen im Rahmen der Apoptose (Hiraishi et al., 1993), der Fertilisation (Sinowatz et al., 1998) und der embryonalen (Fenderson et al., 1986) sowie postnatalen Entwicklung (Bendahmane und AbouHaila, 1997) zugeschrieben.

In neuronalem Gewebe erfüllen fucosylierte Strukturen wichtige Funktionen. Histochemische Analysen haben Fucose als eines der Monosaccharide identifiziert, die als Lektin-Liganden bei ontogenetischen Prozessen im Nervensystem im Rahmen des axonalen Wachstums und der Faszikulation, der Neuronenwanderung, Synaptogenese und Myelinisierung eine essentielle Rolle spielen (Zanetta, 1998). Bei Interaktionen zwischen den verschiedenen Zelltypen des Nervensystems im sich entwickelnden Cerebellum junger Ratten (SajdelSulkowska, 1998) und bei kultivierten Zellen des fötalen, menschlichen Gehirns 
(Satoh und Kim, 1994) wurde eine Beteiligung des Le ${ }^{\mathrm{x}}$-Antigens gefunden. Wird die Proteinfucosylierung bei Ratten durch Behandlung mit 2-Desoxy-D-Galactose, die keine glykosidische Bindung mit Fucose ausbilden kann, vorübergehend gehemmt, ist das Erinnerungsvermögen der Tiere reversibel eingeschränkt (Jork et al., 1986). Neueste Erkenntnisse zeigen, dass das Fuc- $\alpha(1,2)$ Gal-Disaccharid ein Bestandteil von O-Glykanen auf Synapsin la und $\mathrm{lb}$ ist und $\mathrm{zu}$ deren Stabilisierung und somit zu einer korrekten Synapsenfunktion beiträgt (Murrey et al., 2006).

Obwohl bereits 1975 von Hallgren et al. zum ersten Mal beschrieben, ist die OFucosylierung vor allem in den letzten Jahren in den Mittelpunkt des Interesses gerückt. Diese Art der Proteinglykosylierung wurde bisher vorwiegend in einer Konsensus-Sequenz innerhalb von EGF-Repeats (Kentzer et al., 1990) sowie kürzlich auch auf Thrombospondin-Repeats (Hofsteenge et al., 2001) gefunden. Das konservierte EGF-Motiv aus etwa 40 Aminosäuren wurde ursprünglich in dem Protein Epidermal Growth Factor identifiziert und ist in einer Reihe von sezernierten und Zelloberflächen-Proteinen $\mathrm{zu}$ finden, für deren ProteinInteraktionen es von Bedeutung ist. Darunter sind beispielsweise Faktoren der Blutgerinnung und Fibrinolyse (Harris et al., 1991) sowie Rezeptoren und deren Liganden der Nodal- und Notch-Signaltransduktionswege. Nodal gehört der TGF $\beta$ Superfamilie an und reguliert gemeinsam mit seinem Kofaktor Cripto Prozesse der frühen Embryogenese, wie die Gastrulation und die Ausbildung der Links-RechtsAsymmetrie während der Mesoderm-Bildung. Die Kooperation mit Cripto hängt von dessen O-Fucosylierung eines EGF-Repeats ab (Schiffer et al., 2001). Der membranständige Notch-Rezeptor trägt ebenfalls einen regulatorisch bedeutsamen O-Fucose-Rest auf EGF-Repeats in seiner extrazellulären Domäne.

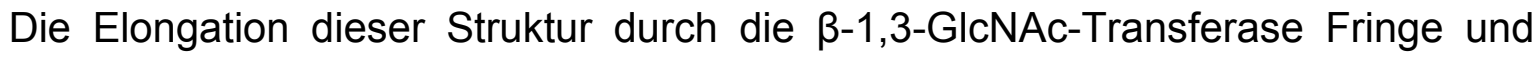
eine weitere Verlängerung zu einem Tetrasaccharid (s. Abb. 1) entscheiden über die Bindungsmöglichkeit der Notch-Liganden Delta oder Serrate, die ihrerseits Transmembranproteine auf Nachbarzellen sind (Moloney et al., 2000b). Ihre Bindung an Notch aktiviert den Rezeptor und induziert eine proteolytische Kaskade, an deren Ende eine Genregulation steht, die im Rahmen vieler Entwicklungsprozesse über das Zellschicksal in Bezug auf Differenzierung, Proliferation oder auch Apoptose entscheidet (Artavanis-Tsakonas et al., 1999). 


\subsubsection{Mechanismen der Proteinglykosylierung}

Die Biosynthese von N-Glykanen beginnt auf der zytoplasmatischen Seite des ER mit der Übertragung eines GlcNAc-P-Rests auf den Lipid-Carrier DolicholPhosphat. Weitere spezifische Glykosyltransferasen, deren Substrate Nukleotidaktivierte oder Dolichol-verknüpfte Zucker darstellen, elongieren dieses Zwischenprodukt zu einer biantennären Struktur, die zwischenzeitlich durch die Flippase auf die luminale Seite des ER wechselt und schließlich aus insgesamt zwei GlcNAc-, neun Man- und drei Glc-Resten besteht (Kornfeld und Kornfeld, 1985; s. Abb. 2). Diese wird durch den Oligosaccharyltransferase-Komplex auf die Amidgruppe von Asn in der Konsensus-Sequenz Asn-X-Ser/Thr (X stellt jede beliebige Aminosäure außer Pro und Asp dar) in naszierenden Proteinen übertragen. Nach weiteren Prozessierungsschritten im Rahmen einer ChaperonKontrolle der korrekten Proteinfaltung findet der vesikuläre Transport des Glykoproteins zum Golgi-Apparat statt (Tatu und Helenius, 1997).

In Abhängigkeit von der Bestimmung des Glykoproteins finden in den GolgiKompartimenten weitere Prozessierungs- und Elongationsschritte statt, die beispielsweise zur Freisetzung der Man-6-P-Erkennungssequenz auf lysosomalen Proteinen oder zur Generierung von Oligosaccharidketten des sogenannten hybriden, mannosereichen oder des in Vertebraten am häufigsten vertretenen komplexen Typs führen. Letzterer (als eine von mehreren Möglichkeiten in Abbildung 2 dargestellt) enthält auch die Zucker Fucose, Sialinsäure und Galactose, deren Addition wiederum durch spezifische Glykosyltransferasen katalysiert und durch Import Nukleotid-aktivierter Zucker als Substrate ermöglicht wird (s. Abb. 2).

Im Gegensatz zu diesem hochkonservierten, bis zu einem gemeinsamen Zwischenprodukt für alle betroffenen Glykoproteine sehr einheitlichen und eingehend charakterisierten Prozess sind andere Proteinglykosylierungstypen in Bezug auf ihre intrazelluläre Lokalisation, Konsensussequenzen innerhalb des Proteins, beteiligte Enzyme und deren Substrate noch weitaus weniger verstanden. 


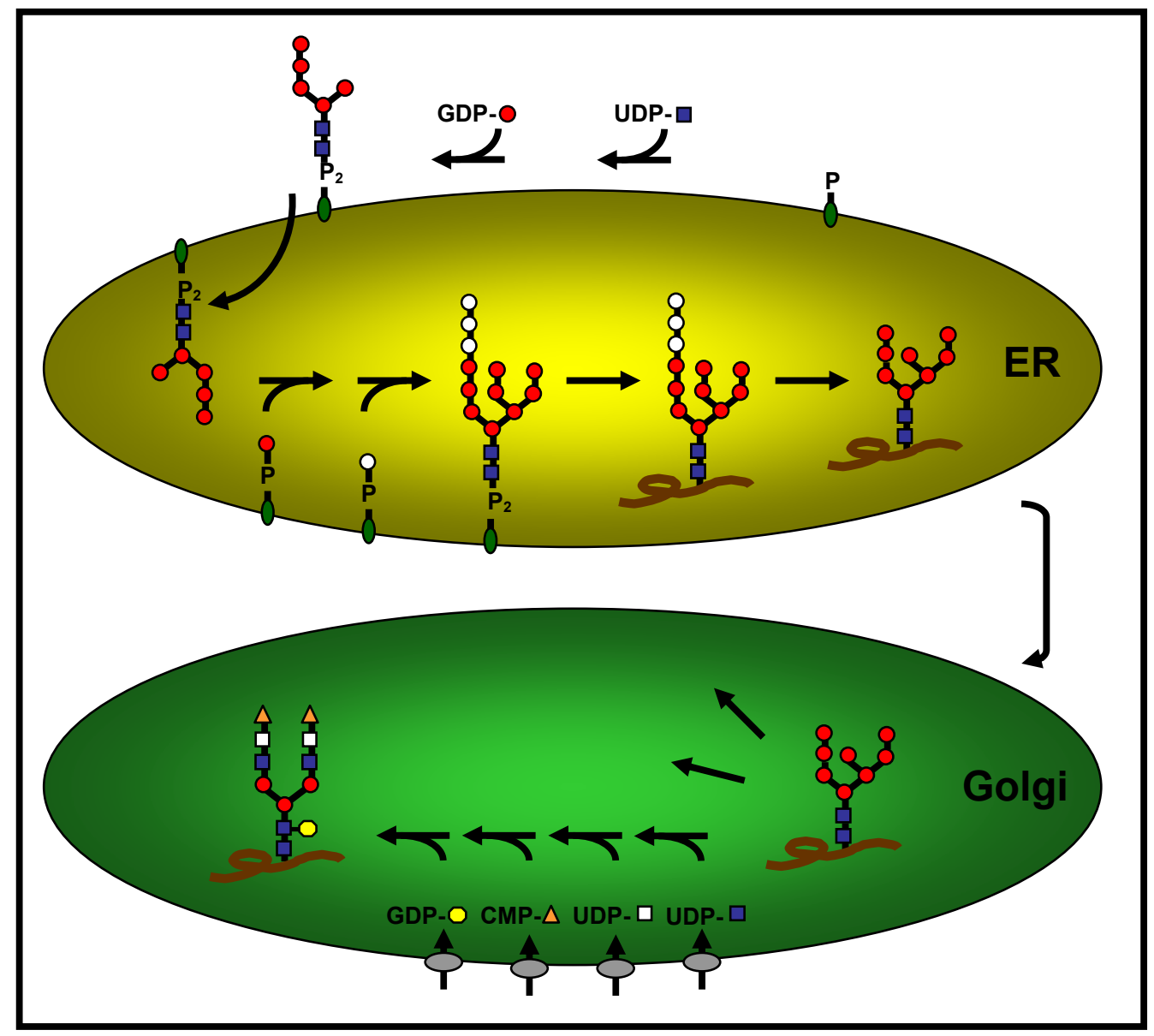

Abb. 2: $\quad$ Prozess der N-Glykosylierung. In ER und Golgi-Apparat erfolgt der Aufbau von Oligosaccharidstrukturen für die N-Glykosylierung von Proteinen aus NAcetylglucosamin (blaues Quadrat), Mannose (roter Kreis), Glucose (weißer Kreis), Galactose (weißes Quadrat), Sialinsäure (Dreieck) und Fucose (gelber Kreis).

So sind für die C-Mannosylierung zwar die Erkennungssequenz WXXW, das ER als Lokalisation und Dol-P-Man als Zuckerdonor identifiziert worden (Doucey et al., 1998). Enzyme, die eine entsprechende Reaktion katalysieren, sind jedoch noch gänzlich unbekannt.

Die O-Glykosylierung umfasst eine Reihe verschiedener Verknüpfungen der Hydroxylgruppe von Serin oder Threonin mit dem Zuckeranteil, der wiederum als einzelner Zucker oder in einer elongierten Struktur vorliegen kann. Diese Vielfalt sei verdeutlicht am Beispiel der Biosynthese der GalNAc-a-Ser/Thr-Bindung in Glykoproteinen des Mucin-Typs (s. 1.1.1). Sie wird durch mindestens vierzehn GalNAc-Transferasen katalysiert (Wang et al., 2003), die gewebespezifisch differentiell exprimiert werden und möglicherweise in einer hierarchischen Art und 
Weise an dem selben, mehrfach O-glykosylierten Protein zusammenarbeiten (Ten Hagen et al., 2001). Die Suche nach einer gemeinsamen Konsensus-Sequenz war bisher erfolglos. Ebenso ist die Lokalisation noch ungeklärt, auch wenn einige Ergebnisse für das cis-Golgi-Kompartiment sprechen (Hirschberg et al., 1998). Eine Elongation führt zu den Core-Strukturen 1 bis 4 , welche ihrerseits zu einer Vielzahl von O-Glykanen modifiziert werden können.

Über die O-Fucosylierung konnten vor allem im Zusammenhang mit dem NotchRezeptor, für dessen Regulation sie essentiell ist (s. 1.1.2), in den vergangenen Jahren zunehmend Erkenntnisse gewonnen werden. Zwei Enzyme mit hoher Homologie, die O-Fucosyltransferasen 1 und 2, katalysieren den Transfer von Fucose von ihrem Substrat GDP-Fucose auf die Hydroxylgruppe von Ser oder Thr in den Konsensussequenzen $C^{2} X_{4-5}(S / T) C^{3}$ bzW. $W X_{5} C^{1} X_{2 / 3} S / T C^{2} X_{2} G$ in EGFbzw. Thrombospondin-Repeats (Martinez-Duncker et al., 2003; Shao et al., 2003; Gonzalez de Peredo et al., 2002; Luo et al., 2006a und 2006b). Beide Module sind durch sechs konservierte Cys-Reste, die in einem bestimmten Muster Disulfidbrücken untereinander ausbilden, gekennzeichnet, welche für den Transfer der Fucose von Bedeutung sind (Campbell und Bork, 1993; Adams und Tucker, 2000). Aufgrund der Annahme einer N-terminalen Transmembran-Sequenz, welche typisch für Typ II-Membranproteine und somit für fast alle in Säugern identifizierten Golgi-Glykosyltransferasen ist (Kleene und Berger, 1993; Paulson und Colley, 1989), wurde bisher von einer Golgi-Lokalisation der OFucosyltransferasen ausgegangen (Wang et al., 2001). Kürzlich konnte jedoch gezeigt werden, dass beide O-Fucosyltransferasen im Gegensatz zu allen anderen bekannten Fucosyltransferasen im ER lokalisiert und aktiv sind (Luo und Haltiwanger, 2005; Luo et al., 2006a und 2006b).

\subsubsection{Bereitstellung von Nukleotid-aktivierten Zuckern durch Transporter der Solute carrier family 35}

Nukleotid-aktivierte Zucker, die im ER und Golgi-Apparat den Glykosyltransferasen als Substrate dienen, werden zunächst, abgesehen von CMP-NANA, deren Syntheseort der Zellkern ist (Münster et al., 1998), im Zytoplasma synthetisiert. Ihr Import in das Lumen der Organellen wird durch eine 
Familie von Nukleotidzucker-Transportern gewährleistet, die als Solute carriers 35 (SLC35) zusammengefasst werden (s. Abb. 3) und deren Homologe in Bakterien, Pflanzen und Säugern zu finden sind.

SLC35-Vertreter sind sehr hydrophobe Proteine mit einer Länge von 320 bis 400 Aminosäuren (Ishida et al., 2004). Sie liegen als Transmembranproteine mit zehn Transmembrandomänen innerhalb der ER- und Golgi-Membranen vor, wobei sich die C- und N-terminalen Regionen auf zytosolischer Seite befinden (Eckhardt et al., 1999). Der Import des jeweilige Zuckernukleotids erfolgt energiefrei und im Austausch gegen das entsprechende Nukleosidmonophosphat, welches nach dem Transfer des Zuckerrestes und (mit Ausnahme von CMP-NANA) anschließender Dephosphorylierung durch eine Nukleosid-Diphosphatase freigesetzt wird (Hirschberg et al., 1998).

Die ursprüngliche Annahme einer hohen Spezifität jedes Transporters für einen bestimmten Nukleotidzucker (Hirschberg et al., 1998) musste nach der Identifizierung von bifunktionalen bzw. Multisubstrat-Transportern revidiert werden (Muraoka et al., 2001; Segawa et al., 2002; Suda et al., 2004; Ashikov et al., 2005).

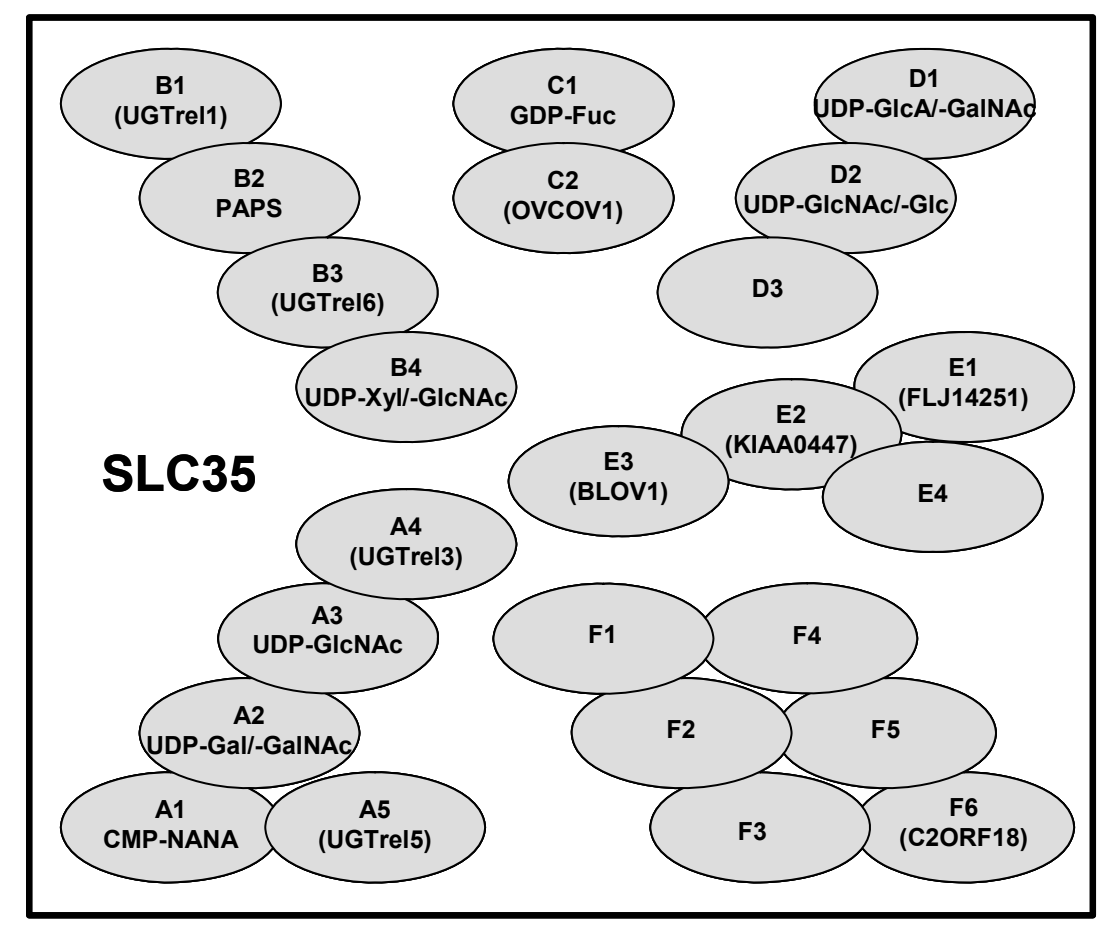

Abb. 3: Die Mitglieder der SLC35-Familie. Angegeben sind die Substrate, soweit bekannt, sowie gegebenenfalls Synonyme. 


\subsection{Vererbbare Defekte der Proteinglykosylierung: Congenital Disorders of Glycosylation (CDG)}

\subsubsection{CDG-Typen}

Die Congenital Disorders of Glycosylation (CDG) stellen eine Gruppe autosomal rezessiv vererbter Erkrankungen dar, welche die Glykosylierung von Glykoproteinen betreffen (Jaeken et al., 1991; McDowell und Gahl, 1997). Die Glykosylierungsdefekte können durch einen Mangel an Nukleotid-aktivierten oder Lipid-verknüpften Zuckern, Defekte des Transfers von Zuckerresten oder Oligosacchariden auf Glykoproteine oder durch Defekte in der Prozessierung von Protein-verknüpften Oligosacchariden verursacht werden. Je nach ihrer Lokalisation werden die Defekte zwei Untergruppen zugeordnet: Unter römisch I werden all diejenigen zusammengefasst, die die Synthese der Lipid-verknüpften Oligosaccharide im Zytosol und im ER und ihren Transfer auf naszierende Proteine betreffen. Defekte der nachfolgenden Prozessierung im ER und GolgiApparat und damit verbundener Vorgänge werden mit römisch II gekennzeichnet. Bisher wurden 18 unterschiedliche CDG-Typen charakterisiert (s. Tab. 1).

Vor kurzem wurden Fälle mit multiplen Glykosylierungsdefekten beschrieben, die sich nicht durch einzelne Enzymdefekte der bisher bekannten Glykosylierungsmaschinerie erklären lassen und die klassische Einteilung der CDG-Typen in Frage stellen. So führt bei dem kürzlich aufgeklärten CDG-Typ Ile ein Defekt des COG7-Proteins zu einem Verlust von sowohl $\mathrm{N}$ - als auch OGlykanen (Wu et al., 2004). Es ist Bestandteil des Conserved oligomeric Golgi(COG-)Komplexes, der mit der zytoplasmatischen Seite des Golgi-Apparates assoziiert und für den Transport von Komponenten der Glykosylierungsmaschinerie essentiell ist. 
Tab. 1: $\quad$ Publizierte CDG-Typen, molekulare und biochemische Defekte, Autoren und OMIM-Referenznummern. ${ }^{*}$ OMIM = online Mendelian inheritance in man (www.ncbi.nlm.nih.gov/).

\begin{tabular}{|c|c|c|c|c|}
\hline $\begin{array}{l}\text { CDG- } \\
\text { Typ }\end{array}$ & Gen & Enzym & Referenz & OMIM \\
\hline la & $P M M 2$ & $\begin{array}{l}\text { Phosphomannomutase II } \\
\text { (PMM2) }\end{array}$ & $\begin{array}{l}\text { van Schaftingen und } \\
\text { Jaeken, } 1995\end{array}$ & 212065 \\
\hline Ib & $M P I$ & $\begin{array}{l}\text { Phosphomannoseisomerase } \\
\text { (PMI) }\end{array}$ & Niehues et al., 1998 & 602579 \\
\hline Ic & hALG6 & $\begin{array}{l}\text { Dol-P-Glc:Man }{ }_{9} \mathrm{GlcNAc}_{2} \text {-PP- } \\
\text { Dol-Glucosyltransferase }\end{array}$ & $\begin{array}{l}\text { Burda et al., 1998; } \\
\text { Körner et al., 1998; } \\
\text { Imbach et al., 1999 }\end{array}$ & 603147 \\
\hline Id & hALG3 & $\begin{array}{l}\text { Dol-P-Man:Man }{ }_{5} \mathrm{GlcNAc}_{2^{-}} \\
\text {PP-Dol-Mannosyltransferase }\end{array}$ & Körner et al., 1999a & 601110 \\
\hline le & DPM1 & Dol-P-Man-Synthase I & $\begin{array}{l}\text { Kim et al., 2000; } \\
\text { Imbach et al., } 2000\end{array}$ & 608799 \\
\hline If & MPDU1 & $\begin{array}{l}\text { (Dol-P-Man utilization defect } \\
\text { 1) }\end{array}$ & $\begin{array}{l}\text { Kranz et al., 2001; } \\
\text { Schenk et al., } 2001\end{array}$ & 609180 \\
\hline Ig & hALG12 & $\begin{array}{l}\text { Dol-P-Man:Man }{ }_{7} \mathrm{GlcNAc}_{2-} \\
\text { PP-Dol-Mannosyltransferase }\end{array}$ & $\begin{array}{l}\text { Thiel et al., 2002; } \\
\text { Chantret et al., } 2002\end{array}$ & 607143 \\
\hline Ih & hALG8 & $\begin{array}{l}\text { Dol-P-Glc:Glc }{ }_{1} \text { Man }_{9} \mathrm{GlcNAc}_{2-} \\
\text { PP-Dol-Glucosyltransferase }\end{array}$ & Chantret et al., 2003 & 608104 \\
\hline li & hALG2 & $\begin{array}{l}\text { GDP-Man:Man }{ }_{1} \mathrm{GlcNAc}_{2} \text {-PP- } \\
\text { Dol-Mannosyltransferase }\end{array}$ & Thiel et al., 2003 & 607906 \\
\hline lj & DPAGT1 & $\begin{array}{l}\text { UDP-GlcNAc:Dol-P-GIcNAc- } \\
\text { 1-Phosphotransferase }\end{array}$ & Wu et al., 2003 & 608093 \\
\hline $\mathbf{I k}$ & hALG1 & $\begin{array}{l}\text { GDP-Man:GlcNAc }{ }_{2}-\text { PP-Dol- } \\
\text { Mannosyltransferase }\end{array}$ & $\begin{array}{l}\text { Grubenmann et al., } \\
2004\end{array}$ & 608540 \\
\hline IL & hALG9 & $\begin{array}{l}\text { Dol-P-Man:Man } \\
6 \text { und } \\
8 \text { GlcNAc }_{2}-\text { PP-Dol- } \\
\text { Mannosyltransferase }\end{array}$ & Frank et al., 2004 & 608776 \\
\hline IIa & MGAT2 & GlcNAc-Transferase II & \begin{tabular}{|l} 
Jaeken et al., 1994; \\
Tan et al., 1996 \\
\end{tabular} & 212066 \\
\hline Illb & GCS1 & a-1,2-Glucosidase I & $\begin{array}{l}\text { De Praeter et al., } \\
2000\end{array}$ & 606056 \\
\hline IIC & SLC35C1 & GDP-Fucose-Transporter & $\begin{array}{l}\text { Lübke et al., 1999; } \\
\text { Lübke et al., 2001; } \\
\text { Lühn et al., 2001 }\end{array}$ & 266265 \\
\hline IId & B4GALT1 & \begin{tabular}{|l|} 
UDP-Gal:GlcNAc- $\beta-1,4-$ \\
Galactosyltransferase I
\end{tabular} & $\begin{array}{l}\text { Peters et al., 2002; } \\
\text { Hansske et al., } 2002\end{array}$ & 607091 \\
\hline Ile & COG7 & $\begin{array}{l}\text { COG-Komplex, Untereinheit } \\
7\end{array}$ & Wu et al., 2004 & 608779 \\
\hline IIf & SLC35A1 & CMP-Sialinsäure-Transporter & $\begin{array}{l}\text { Martinez-Duncker et } \\
\text { al., } 2005\end{array}$ & 605634 \\
\hline
\end{tabular}


CDG tritt mit einer Inzidenz von 1:20.000 auf, die mit Abstand häufigste Form ist der Typ CDG-la. Fast alle Erkrankungen sind klinisch durch mehr oder weniger schwere Entwicklungsstörungen, psychomotorische Retardierung, Muskelhypotonie, Hirnatrophie und Krampfanfälle geprägt. Zusätzlich treten bei einzelnen Typen weitere Symptome wie z.B. Strabismus oder Blindheit, invertierte Brustwarzen oder häufige Infektionen auf (Freeze, 2001).

Im Fall eines CDG-Verdachts aufgrund der Symptome eines Patienten wird zunächst das Serumtransferrin durch isoelektrische Fokussierung untersucht. Bei CDG-I-Typen sowie CDG-Ila, -Ild und -Ilf kommt es zu einem partiellen oder vollständigen Verlust der vier Zuckerketten auf diesem Protein. Der damit einhergehende Verlust der negativ geladenen terminalen NANA-Reste führt zu einer detektierbaren Ladungsveränderung des Proteins (Jaeken et al., 1997). Darüber hinaus können für einzelne Enzyme gezielt Aktivitätsmessungen durchgeführt werden. Eine abschließende Bestätigung einer Diagnose erfolgt in der Regel durch eine molekularbiologische Analyse des entsprechenden Gens.

\subsubsection{CDG-IIc / LAD II}

\subsubsection{Symptomatik von CDG-IIc}

Der CDG-Typ Ilc ist erstmals im Jahr 1992 bei zwei Jungen arabischer Abstammung beschrieben worden (Frydman et al., 1992; Etzioni et al., 1992). Zu den auffälligsten Symptomen zählen eine ausgeprägte, persistierende Leukozytose und eine Immundefizienz aufgrund einer Störung des LeukozytenRollens auf Endothelzellen. Deshalb wurde die Erkrankung zunächst als 'Leukocyte adhesion deficiency II' (LAD II) bezeichnet, in Anlehnung an den LADTyp I, bei dem ein Defekt der Integrin-Untereinheit $\beta 2$ (CD18) zu ähnlichen Symptomen aufgrund eines Verlustes der Leukozyten-Adhäsion führt (Anderson und Springer, 1987).

Seitdem wurden fünf weitere CDG-Ilc-Patienten identifiziert: zwei Kinder aus arabischen Familien (Etzioni und Tonetti, 2000), ein türkisches (Marquardt et al., 1999a) und ein brasilianisches Kind (Hidalgo et al., 2003) sowie kürzlich ein Patient pakistanischer Abstammung (Helmus et al., 2006). 
Zu den Symptomen von CDG-Ilc zählen neben der Immundefizienz Dysmorphien wie eine breite, flache Nasenwurzel, eine lange Ober- und eine herausgekehrte Unterlippe, lange Wimpern, Mikrocephalie und kurze Extremitäten. Die pränatale Entwicklung war bei fast allen Patienten unauffällig, postnatal manifestierten sich jedoch innerhalb der ersten Lebensmonate eine deutliche Wachstumsverzögerung und eine mentale und psychomotorische Retardierung. Die Patienten leiden unter Muskelhypotonie, häufig wiederkehrenden Infektionen und z.T. Periodontitis. Die Leukozytenspiegel steigen während Infektionen auf bis zu 70.000/ $\mu \mathrm{l}$, in einem Fall

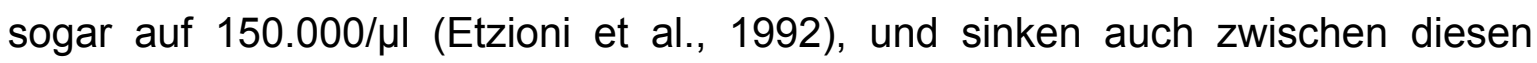

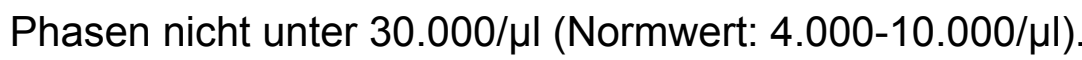

Die Erklärung für die Leukozytose und die Immundefizienz erbrachten Untersuchungen der Leukozyten-Oberflächenantigene mittels Fluoreszenzaktivierter Zellsortierungsanalyse (Fluorescence activated cell sorting, FACS). Es konnten keine sLe $\mathrm{e}^{\mathrm{x}}$-Reste nachgewiesen werden, die für das Leukozyten-Rollen auf Endothelzellen als Voraussetzung für eine lokale Entzündungsbekämpfung essentiell sind (s. 1.1.2). Auch konnten die $\alpha-1,4$-fucosylierten Lewis A- und $\mathrm{H}$ Antigene (s. Abb. 1) nicht auf der Erythrozyten-Oberfläche detektiert werden (Marquardt et al., 1999a). Das Fehlen des H-Antigens charakterisiert die in Westeuropa seltene, als Bombay-Phänotyp bezeichnete Blutgruppe.

\subsubsection{Fucose-Therapie von CDG-IIc-Patienten}

Eine Erhöhung der Fucose-Konzentration im Kulturmedium von Fibroblasten des türkischen Patienten führte zu einer Normalisierung der Fucosylierung von Proteinen (Lübke et al., 1999; Marquardt et al., 1999b). Daraufhin wurde bei einigen Patienten eine Therapie in Form einer oralen L-Fucose-Gabe bis zu einer maximalen Dosis von $2.460 \mathrm{mg}$ pro kg Körpergewicht und Tag angewandt (Marquardt et al., 1999b).

Zwei der arabischen Patienten zeigten nach Angaben der behandelnden Ärzte keine Verbesserungen unter der Behandlung (Etzioni und Tonetti, 2000), allerdings wurden im ersten Ansatz über den Großteil der Therapiedauer nur vergleichbar niedrige Tagesdosen von $400 \mathrm{mg} / \mathrm{kg}$ gegeben. Doch auch eine 
Wiederholung mit höheren Dosen erbrachte keine positive Wirkung (Sturla et al., 2001).

Der türkische Patient sprach auf die Therapie mit steigenden Dosen von bis zu $2.460 \mathrm{mg} / \mathrm{kg}$ sehr gut an: Die Zahl der Neutrophilen konnte innerhalb weniger Tage auf Werte innerhalb des Normbereichs gesenkt werden, die P-SelektinExpression stieg auf 50\%, die E-Selektin-Expression auf 20\% der Kontrollwerte. Es traten keine weiteren Infektionen auf, und es zeigte sich sogar eine leichte Verbesserung der psychomotorischen Fähigkeiten (Marquardt et al., 1999b).

Im Fall des brasilianischen Patienten war eine Fucose-Therapie mit Tagesdosen von bis zu 1.000 mg/kg Körpergewicht in Bezug auf die Neutrophilenzahl und die P-Selektin-Expression ebenfalls erfolgreich. Die psychomotorische Retardierung blieb jedoch unverändert. Die Gefahr einer Hämolyse aufgrund der Re-Expression des H-Antigens und der Präsenz von anti-H-Antikörpern sowie das Auftreten einer Autoimmun-Neutropenie erforderten eine Senkung der Tagesdosis auf 570 mg/kg (Hidalgo et al., 2003).

\subsubsection{CDG-IIc: Ein Defekt des Golgi-GDP-Fucose-Transporters}

Da die Hypofucosylierung bei CDG-Ilc nicht nur das Produkt einer einzelnen Fucosyltransferase sondern Fucoseanteile in verschiedenen Verknüpfungen zu Saccharidstrukturen betraf, war bei der Suche nach der molekularen Ursache vom Defekt eines zentraleren Elements des Fucose-Metabolismus auszugehen.

Die Bereitstellung von GDP-Fucose im Zytosol kann über zwei Wege erfolgen: Ein kleiner Anteil stammt aus einem sogenannten "Salvage-Pathway", der direkt aufgenommene Fucose sowie Fucosereste aus lysosomalen Abbauprozessen nutzt. Etwa 90\% der für Glykosylierungsreaktionen verwendeten GDP-Fucose wird jedoch de novo über GDP-Mannose aus Glucose und Mannose synthetisiert.

Aufgrund von Ergebnissen aus in vitro-Untersuchungen an Patientenzellen mit einer erfolgreichen Fucose- und erfolglosen Glucose-Behandlung wurde zunächst die Hypothese aufgestellt, die de novo-Synthese von GDP-Fucose sei betroffen (Karsan et al., 1998). Sturla et al. ermittelten eine erniedrigte Aktivität des ersten Enzyms dieses Synthesewegs, der GDP-Mannose-4,6-Dehydratase, in Lymphozyten eines der arabischen Patienten (Sturla et al., 1998). 
Nach Messung normaler Aktivitäten der Enzyme der de novo-Synthese in Zellen des türkischen Patienten (Körner et al., 1999b) sowie eines stark verminderten GDP-Fucose-Imports in den Golgi-Apparat (Lübke et al., 1999) haben im Jahr 2001 Lübke et al. durch retrovirale Komplementations-Klonierung in PatientenFibroblasten den Defekt eines Golgi-GDP-Fucose-Transporters (GFT) als Ursache für CDG-Ilc identifiziert. Parellel dazu konnten Lühn et al. (2001) durch Expression von Proteinen aus Caenorhabditis elegans mit Homologie zu bekannten NukleotidZucker-Transportern dieses Ergebnis bestätigen.

Das identifizierte Gen besteht aus zwei Exons und codiert ein stark hydrophobes Protein, welches 364 Aminosäuren umfasst. Nach Analyse der Protein-Topologie werden zehn Transmembran(TM)-Domänen angenommen (s. Abb. 4). Diese Eigenschaften stimmen mit anderen Mitgliedern der SLC35-Familie (s. 1.1.4) überein, in die der Transporter als SLC35C1 eingeordnet wurde.

Puglielli und Hirschberg haben 1999 das Orthologe der Ratte identifiziert und aufgereinigt. Das Protein weist eine Größe von 39 kDa auf und und liegt in der Golgi-Membran als funktionelles Homodimer vor.

Die Sequenzierung des entsprechenden Gens (SLC35C1) der Patienten erwies vier verschiedenen, homozygot vorliegenden Mutationen. Drei der vier arabischen Patienten wurden untersucht und wiesen eine Punktmutation (C923GTransversion) auf, die zu einem Aminosäureaustausch in der neunten TMDomäne(T308R) führt. Bei dem türkischen Patienten wurde eine Punktmutation (C439T-Transition) gefunden, welche einen Aminosäureaustausch in der vierten TM-Domäne (R147C) zur Folge hat (Lübke et al., 2001). Im Fall des brasilianischen Patienten verursacht eine Nukleotid-Deletion ( $\Delta \mathrm{G} 588)$ eine Verschiebung des Leserahmens, die zur Einführung von 34 weiteren zufälligen Codons und einem vorzeitigen Stop-Codon und somit zu einem Verlust der letzten fünf TM-Domänen führt (Hidalgo et al., 2003). Der letzte beschriebene Patient weist eine Punktmutation (G969A) auf, die ein vorzeitiges Stop-Codon generiert und den Verlust der zehnten TM-Domäne zur Folge hat (Helmus et al., 2006; s. Abb. 4). 


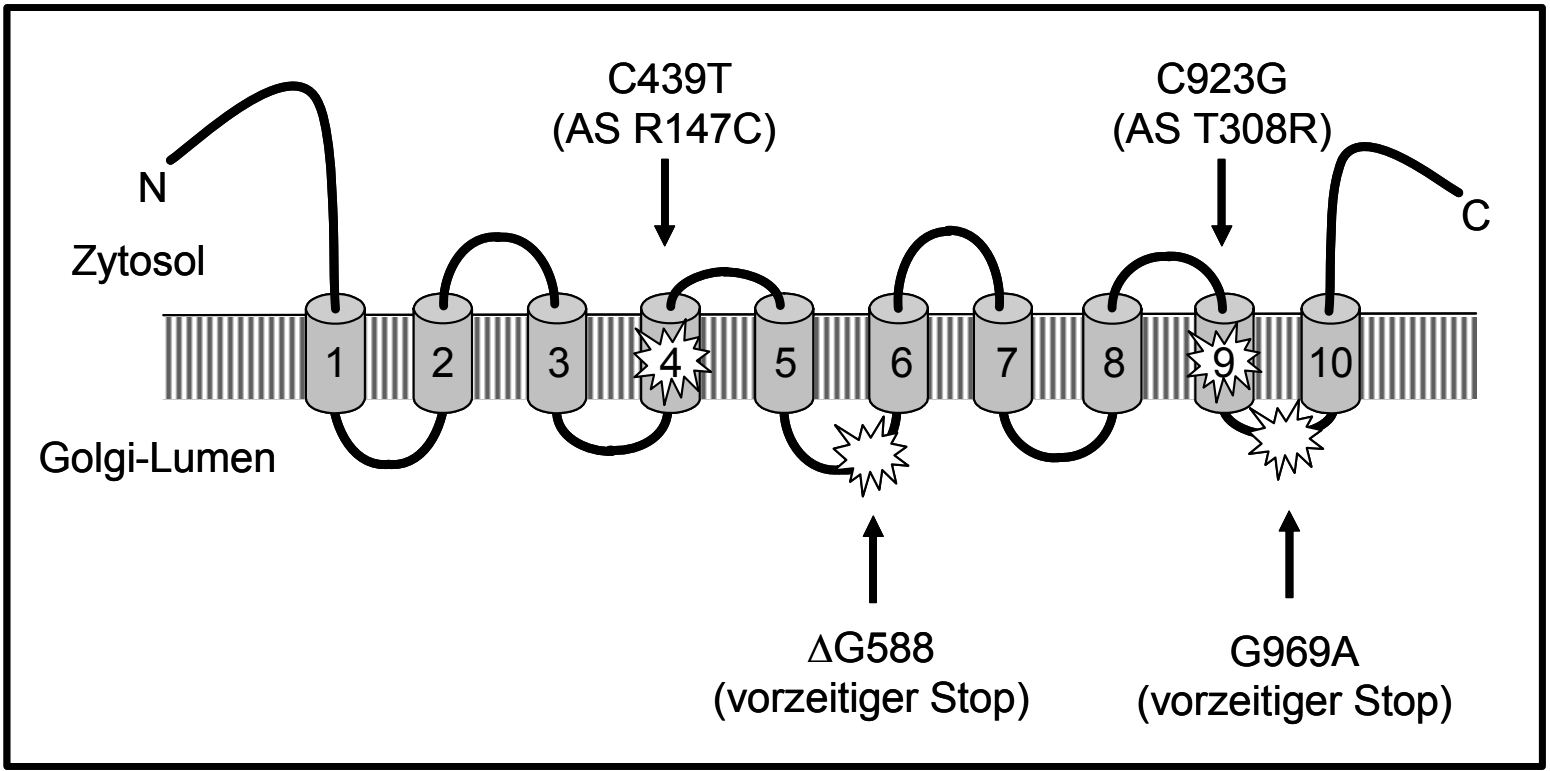

Abb. 4: Topologie des GDP-Fucose-Transporters in der Golgi-Membran und Lokalisation der bisher identifizierten Mutationen in CDG-IIc-Patienten. 
1.3

$\begin{array}{lll}\text { Verwendung } & \text { von } & \text { genetisch } \\ \text { Mausmodellen } & \text { zur } & \text { Untersuchung } \\ \text { Mechanismen } & & \end{array}$

manipulierten

molekularer

Mechanismen

\subsubsection{Die Maus als Modell: Eigenschaften, Eignung und Vorgehensweise}

Das 'Human Genome Project' hat zur Sequenzierung von mehr als 20.000 humanen Genen geführt (International Human Genome Sequencing Consortium, 2004), wobei jedoch nur für einen kleinen Teil dieser Gene Informationen über ihre Expression und Funktion zur Verfügung stehen (Van der Weyden et al., 2002). Gleichzeitig werden für viele neue monogenetische Erberkrankungen die entsprechenden mutierten Gene identifiziert, deren Zusammenhang mit der jeweiligen Pathogenese jedoch noch unklar ist.

Viele mechanistische Informationen und Antworten auf einfache Fragestellungen, die ein überschaubares Modell erfordern, können aus niedrigen Organismen wie der Hefe, Drosophila melanogaster oder Caenorhabditis elegans gewonnen werden. Aufgrund ihrer verhältnismäßig hohen anatomischen, physiologischen und genetischen Ähnlichkeit zum Menschen ist jedoch die Maus Mus musculus bislang das beste experimentelle Modell, um die Funktion menschlicher Gene im Kontext des gesamten Organismus zu definieren. Im Gegensatz zu höheren Säugetieren, auf die diese Eigenschaften ebenfalls zutreffen, weist dieses Modell weitere entscheidende Vorteile auf. Die Maus hat einen relativ kurzen Lebenszyklus: Die Tragezeit beträgt im Durchschnitt nur 19 Tage, die Wurfgrößen liegen zwischen fünf und zehn Jungen, die Nachkommen sind nach vier Wochen geschlechtsreif und nach sechs bis acht Wochen zuchtreif.

Darüber hinaus stehen etablierte Protokolle zur Mutagenese zur Verfügung. Eine Reihe von Linien embryonaler Stammzellen wurden etabliert, ebenso wie In- und Auszuchten vieler Stämme, die jeweils besondere Eignungen für bestimmte Fragestellungen haben.

Neben der klassischen Mutagenese auf physikalischem oder chemischem Wege zur Generierung zufälliger Mutationen wurden in den vergangenen dreißig Jahren 
Techniken für die gezielte Manipulation des Mausgenoms entwickelt. Linearisierte DNA mit dem gentechnisch veränderten Zielgen wird beispielsweise durch Elektroporation in kultivierte, totipotente embryonale Stammzellen eingebracht, wo sie mit einer Wahrscheinlichkeit von etwa 1\% durch homologe Rekombination anstelle des Wildtyp-Gens in das Mausgenom integriert wird. Mit Hilfe von Selektionsmarkern können Zellen mit einem positiven Rekombinationsereignis selektiert werden (Capecchi, 1989). Nach ihrer Mikroinjektion in Blastozysten werden diese in hormonell vorbehandelte, pseudoschwangere Weibchen implantiert. Die Nachkommen der injizierten Zellen können in der Embryonalentwicklung aufgrund ihrer Totipotenz zu allen Geweben beitragen, wodurch chimäre Tiere zur Welt kommen (Gossler et al., 1986). Sofern eine Keimbahnbeteiligung vorliegt, kann die eingeführte genetische Modifikation von der Chimäre an nachfolgende Generationen vererbt werden (Bradley et al., 1984).

\subsubsection{Der Golgi-GDP-Fucose-Transporter der Maus}

Diese Arbeit befasst sich mit dem Knockout des GFT in der Maus und den daraus entstehenden Konsequenzen. Die cDNA des murinen GFT wurde im Rahmen eigener Vorarbeiten zunächst mit Hilfe des humanen Orthologs aus einer Cosmidbank isoliert und charakterisiert. Die Aminosäuresequenz ist im Vergleich zum humanen GFT zu 87\% konserviert, einschließlich der konserviert und semikonservativ substituierten Reste ergibt sich sogar ein Anteil von 95\%. Hydrophilizitäts-Plots nach Kyte-Doolittle und Voraussagen zur Topologie der Transporter in der Golgi-Membran führen zu sehr ähnlichen Ergebnissen. Die Expressionsmuster in verschiedenen Geweben unterscheiden sich ebenfalls kaum.

\subsubsection{Vorhandene Mausmodelle mit Defekten der Proteinfucosylierung}

Die Verknüpfung von Fucoseresten mit neusynthetisierten Glykoproteinen wird durch mehrere Fucosyltransferasen katalysiert, die für den jeweiligen Akzeptor 
spezifisch sind und GDP-Fucose als Substrat benötigen. Bisher wurden elf verschiedene Fucosyltransferasen identifiziert, die nach ihrem Akzeptor-Substrat sowie der Art der Verknüpfung in vier verschiedene Familien gegliedert werden (Martinez-Duncker et al., 2003).

Die Fucosyltransferasen Fut1 und Fut2 katalysieren die Verknüpfung von Fucose in $\alpha-1,2-S t e l l u n g$ mit terminalen Galactoseresten in N- oder O-Glykanen. Für beide Enzyme konnten Expression und Aktivität in Geweben des Magens und Darms nachgewiesen werden. Außerdem wird Fut1 im Epithel der Epididymis exprimiert, Fut2 dagegen im Uterus-Epithel. Domino et al. (2001) haben Untersuchungen an Fut1- bzw. Fut2-defizienten Mäusen durchgeführt, um insbesondere die Bedeutung der Transferasen bzw. ihrer Produkte für die Fertilisationskompetenz von Spermatozoen sowie für die Blastozystenadhäsion an und Implantation in das Uterusepithel zu untersuchen. Histochemisch konnte das Fehlen der entsprechenden Produkte in den Geweben des männlichen und weiblichen Reproduktionstraktes nachgewiesen werden. Die Mäuse zeigten jedoch keine auffälligen Abnormalitäten bezüglich Morphologie und Verhalten und waren in ihrer Fertilität nicht beeinträchtigt.

Die Fucosyltransferasen Fut4 und Fut7 gehören neben Fut3, Fut5, Fut6 und Fut9 zur Familie der a-3/4-Fucosyltransferasen und katalysieren die Verknüpfung von Fucose mit dem Asn-verknüpften GlcNAc-Rest in $\alpha-1,3-S t e l l u n g$ und somit einen Schritt der Synthese des Le $e^{\mathrm{x}}$-Antigens, einem Strukturelement von E-, P- und LSelektin-Liganden. Ist nur jeweils eine der beiden Fucosyltransferasen Fut4 bzw. Fut7 ausgeschaltet, zeigt sich eine deutliche, jedoch nicht vollständige Defizienz des Lymphozyten-Homings bzw. der Leukozyten-Rekrutierung (Weninger et al., 2000; Maly et al., 1996). Homeister et al. (2001) haben ein Mausmodell mit einer Doppeldefizienz der Fucosyltransferasen Fut4 und Fut7 generiert. In diesem Fall sind beide Prozesse vollständig ausgeschaltet. Daraus folgerten die Autoren, dass Fut4 und Fut7 kooperativ beide Selektin-Liganden-abhängige Prozesse kontrollieren.

Fut9-defiziente Mäuse exprimieren kein SSEA-1 (Stage-specific embryonic antigen 1; Kudo et al., 2004). Dieses $\alpha-1,3-f u c o s y l i e r t e ~ L e^{x}-E p i t o p$ wird in der frühen Embryonalentwicklung sowie in Primordialfollikeln exprimiert und wurde bisher mit der Morula-Kompaktion in Zusammenhang gebracht (Fenderson et al., 1984). SSEA-1-defiziente Mäuse entwickeln sich jedoch normal und sind fertil. 
Die sogenannte Core-Fucosylierung, die Verknüpfung von Fucose mit dem ersten GIcNAc-Rest in N-Glykanen in $\alpha-1,6-S t e l l u n g$, wird in Vertebraten durch die Fucosyltransferase Fut8 katalysiert (Yanagidani et al., 1997). Ein Total-Knockout des Enzyms führt in der Maus zu einer schweren Wachstumsretardierung und einer hohen postnatalen Letalität (Wang et al., 2005). Emphysem-ähnliche Veränderungen der Lunge werden auf eine Überexpression von MatrixMetalloproteinasen und eine negative Regulation von Proteinen der extrazellulären Matrix, verursacht durch eine gestörte Regulation des TGF- $\beta 1$ Signalwegs, zurückgeführt. Darüber hinaus berichten Wang et al. (2006) von einer Störung des EGF-Rezeptor-vermittelten Signalwegs in embryonalen Fibroblasten dieses Mausmodells.

Die Verknüpfung von Fucose mit den Hydroxylgruppen von Ser oder Thr wird durch die Familie der O-Fucosyltransferasen, bestehend aus den Protein-OFucosyltransferasen 1 und 2 (O-Fuc-T-1 und -2), katalysiert. Ein Knockout von OFuc-T-1 führt zum Tod der Embryonen am Tag E10 (Shi und Stanley, 2003). Sie weisen schwerwiegende Defekte in der Somitogenese, Vaskulogenese, Kardiogenese und Neurogenese auf.

Smith et al. haben 2002 Untersuchungsergebnisse von einem FX-defizienten Mausmodell präsentiert. Das FX-Protein ist mit seiner 3,5-Epimerase/4Reduktase-Funktion neben der GDP-Mannose-4,6-Dehydratase (GMD) an der Umwandlung von GDP-Mannose zu GDP-Fucose im Rahmen der de novoSynthese beteiligt. Die Autoren berichten über einen partiell embryonal letalen Phänotyp des $\mathrm{FX}^{-1-}$-Genotyps und einen nahezu vollständigen Verlust fucosylierter Strukturen bei normaler Ernährung, der durch eine Fucose-Diät aufgehoben werden kann. Homozygote Tiere zeigen ohne Fucose-Behandlung eine retardierte körperliche Entwicklung, persistierende Diarrhoe mit degenerativen Erscheinungen im Darmepithel, Infertilität sowie eine akute Leukozytose. Becker et al. haben 2003 nach Rückkreuzung auf drei verschiedene Mausstämme über eine signifikante Abhängigkeit der Letalität des Phänotyps dieser Maus vom jeweiligen Stamm berichtet. 


\section{$2 \quad$ Problemstellung}

Vor kurzem konnte u.a. durch unsere Arbeitsgruppe die molekulare Ursache der Erberkrankung Congenital Disorder of Glycosylation-IIc (CDG-IIc) als ein Defekt des Golgi-GDP-Fucose-Transporters idenfiziert werden (Lübke et al., 2001; Lühn et al., 2001). Dennoch ist die molekulare Pathologie dieser multisystemischen Stoffwechselkrankheit, die auf das Fehlen von Fucoseresten als Bestandteil der Zuckerketten von Glykoproteinen durch die stark reduzierte Verfügbarkeit von GDP-Fucose im Golgi-Apparat bei CDG-IIc-Patienten zurückzuführen ist, weitgehend unverstanden. Darüber hinaus ist unklar, ob das Ansprechen einiger Patienten auf eine Fucose-Therapie auf eine Restaktivität des Transporters oder auf das Vorhandensein eines alternativen Transportmechanismus zurückzuführen ist (Hirschberg, 2001; Helmus et al., 2006).

Gegenstand dieser Dissertation ist die Generierung und Charakterisierung eines Mausmodells mit einer Defizienz des Golgi-GDP-Fucose-Transporter, welches tiefere Einblicke sowohl in die Pathogenese von CDG-Ilc als auch in die generelle Bedeutung der Fucosylierung von Glykoproteinen im Säugerorganismus ermöglichen soll.

Eigene Vorarbeiten führten zur Klonierung des Gens des murinen Golgi-GDPFucose-Transporters sowie zur Generierung von embryonalen Stammzellen der Maus mit Heterozygotie für ein Knockout-Allel des Gens. Diese Zellklone sollen in Maus-Blastozysten injiziert und resultierende Chimären gezielt verpaart werden, um Mäuse mit Homozygotie bezüglich der genetischen Modifikation zu erhalten.

Die Knockout-Mutanten sollen zunächst in Bezug auf ihre Geburts- und Überlebensrate untersucht werden. Sofern die Tiere überlebensfähig sind, sollen die Fucosylierung in verschiedenen Zelltypen und Geweben sowie die SelektinLiganden-Funktion auf Leukozyten charakterisiert werden. Hierbei sollen vor allem auch die Möglichkeiten einer Korrektur der Fucosylierungsdefizienz durch FucoseBehandlung untersucht werden, um Hinweise auf die Existenz eines alternativen Transportmechanismus für GDP-Fucose zu gewinnen. Histologische Studien sollen Aufschluss über potentielle Veränderungen der Organe infolge einer Fehlfunktion fucosylierungsabhängiger Entwicklungsprozesse geben. 


\section{$3 \quad$ Material und Methoden}

\subsection{Material}

\subsubsection{Geräte}

Analysenwaagen Typ M5P und CP3202P

Autoklav Typ 5075ELV

Brutschrank Typ 2771

Brutschrank Typ MCO-20AIC

CCD-Kamera Typ VE-1000CD

Digitalkamera Typ DFC320

Digitalkamera Typ AxioCam MRc

DNA-Sequencer Typ 310

Durchlicht-Mikroskop Typ ID03

Durchflusszytometer Typ FACSCalibur

Eismaschine

Elektrophoresekammern für Agarosegele

Eppendorfzentrifugen Typ 5402, 5414, $5415 \mathrm{D}$

Eraser für Phosphoimager-Screens

Filmentwicklungsmaschine Typ X-OMAT2000 Kodak, Stuttgart

Fujix Bio Imaging Analyzer Typ BAS 1000

Gefrierschrank $-80^{\circ} \mathrm{C}$

GeneAmp PCR System 9700

GeneAmp PCR System 2700

Handcounter Typ LB122

Heizblock Typ Thermostat 5320
Sartorius, Göttingen

Tuttnauer Systec, Wettenberg

Köttermann, Häningsen

Sanyo, Bad Nenndorf

Dage-MTI, Michigan City, USA

Leica, Bensheim

Zeiss, Göttingen

ABI Applied Biosystems, Foster City, USA

Zeiss, Oberkochen

BD Biosciences, Heidelberg

Ziegra, Isernhagen

Eigenbau, Werkstatt des Instituts

Eppendorf, Hamburg

Raytest, Straubenhardt

Fuji, Elmsford, USA

Colora Messtechnik, Lorch

Perkin Elmer, Wellesley, USA

ABI Applied Biosystems, Foster City, USA

Berthold, Bad Wildbad

Eppendorf, Hamburg 
Inkubationsschüttler Typ G25

Inkubator mit Drehrad

Kühlplatte Typ EG1150C

Kühlzentrifuge Typ Rotina 48R

Kühlzentrifuge Typ Biofuge Fresco

Liquid-Szintillation-Counter Typ LS6500

Magnetrührer Typ MR3001

Micro-Pipetten (10, 20, 200, $1000 \mu \mathrm{l})$

Mikroskop Typ Axioskop plus 2

Mikroskop Typ Axiovert

Mikroskop Typ DM LS2

Mikrotiterplatten-Zentrifuge Typ Varifuge 3.0R Heraeus, Hanau

Mikrotom Typ RM2165

Mikrowellenherd

Oxygenator

Paraffinausgießstation Typ EG1150

Paraffin-Strecktisch Typ HI1220

pH-Meter Typ InoLab

Pipettierhilfe Typ Pipet Aid XP

Rührmotor Typ RZR 2050

Schüttelwasserbad

Schlauchpumpe

Spannungsgeräte

Spektralphotometer Typ Spectra max plus 384Molecular Devices, Chicago, USA

Sterilbank Typ Lamin Air HLB2448

Sterilbank Typ SG400

Stickstofftank Typ Biosafe Chronos

Stroboskop Typ Strobex 236

Thermomixer Typ compact und 5436

Ultraschall-Desintegrator Typ Sonifier 450

Ultrazentrifuge Typ Optima LE-80K

Ultrazentrifuge Typ Optima TLX
New Brunswick Scientific, Edison, USA

Schütt Labortechnik, Göttingen

Leica, Bensheim

Hettich, Tuttlingen

Heraeus, Hanau

Beckman Coulter, Krefeld

Heidolph, Schwabach

Eppendorf, Hamburg

Zeiss, Göttingen

Zeiss, Göttingen

Leica, Bensheim

Leica, Bensheim

Siemens, München

Glasgerätebau Ochs, Bovenden

Leica, Bensheim

Leica, Bensheim

WTW, Weilheim

Drummond, Broomall, USA

Heidolph, Schwabach

Köttermann, Häningsen, Göttingen

Ismatec, Zürich

Hölzel, München

Heraeus, Hanau

Baker Company, Sanford, USA

Messer, Griesheim

Chadwick-Helmuth, Mountain View, USA

Eppendorf, Hamburg

Branson, Dietzenbach

Beckman Coulter, Krefeld

Beckman Coulter, Krefeld 
Velocimeter Typ OD-RT

Video-Drucker

Video-Kamera

Video-Recorder

Vortex-Genie 2

Waage Typ 1265MP

Wärmeschrank

Wasserbad Typ 1003

Wasserbad Typ HI1210

Wipptisch Typ Rocky

Zentrifuge Typ Labofuge
Circusoft Instrumentation, Hockessin, USA Intas, Göttingen Intas, Göttingen Panasonic, Hamburg Bender \& Hobein, Zürich, Schweiz Sartorius, Göttingen Memmert, Schwabach Gesellschaft für Labortechnik, Burgwedel Leica, Bensheim Itf Labortechnik, Wasserburg Heraeus, Hanau

\subsubsection{EDV}

Hardware:

PC Pentium IV, 2,8 GHz, 512 MB RAM

Apple Macintosh Typ Power 7300/200

Canon i865 Tintenstrahldrucker

Kyocera FS-800 Laserdrucker

Software:

Windows 2000 Professional

Windows Office 2002

Adobe-Photoshop 6.0

DNAStar (MegAlign, MapDraw,

Protean, EditSeq)

Image Reader

Image Gauge 3.0

Leica QWin-Software für Mikroskopie
G-DAS Datenservice $\mathrm{GmbH}$, Hockenheim

Apple Macintosh, Cupertino, USA

Canon, Krefeld

Kyocera, Meerbusch

Microsoft, Bellevue, USA

Microsoft, Bellevue, USA

Adobe, San Jose, USA

DNAStar, Madison, USA

Fuji, Elmsford, USA

Fuji, Elmsford, USA

Leica, Bensheim 


\subsubsection{Verbrauchsmaterial}

6/24/96well-Platten

Biopsiekassetten

Deckgläser 24x50 mm

Einbettformen

Einfrierkästen

Färbeküvetten und -kästen
Greiner, Nürtingen

Laborservice Brenzinger, Walldorf Laborservice Brenzinger, Walldorf Leica, Bensheim

National Lab, Mölln

Laborservice Brenzinger, Walldorf

Gewebekulturschalen $(3,6,10,15 \mathrm{~cm})$ Sarstedt, Nümbrecht

Gewebekulturflaschen T25, T75

Sarstedt, Nümbrecht

Glaskolben

Schott, Mainz

Glasperlen ( $\varnothing 4-5 \mathrm{~mm}$ )

Schütt, Göttingen

Hybond-N Filter $(82 \mathrm{~mm}, 132 \mathrm{~mm}$ )

Amersham, Freiburg

Kanülen Sterican

Braun, Melsungen

Kanülen Vasofix Braunüle

Braun, Melsungen

Kryoröhrchen

Mikrotom-Einmalklingen Typ A 35

Nunc, Wiesbaden

Neubauer-Zählkammer

PFM, Köln

Objektträger Typ Superfrost plus

Brand, Wertheim

Objektträger mit Mattrand

Laborservice Brenzinger, Walldorf

Laborservice Brenzinger, Walldorf

Objektträger-Kästen

Parafilm

Neolab, Heidelberg

American National, Chicago, USA

Pasteurpipetten

Schütt, Göttingen

PCR-Gefäße Multiply-Pro (0,2 ml)

Sarstedt, Nümbrecht

Phosphoimager-Screen

Fuji, Elmsford, USA

Pipettenspitzen

Sarstedt, Nümbrecht

Plastiknetz $70 \mu \mathrm{m}$

Schütt, Göttingen

Plastikpipetten, steril (2, 5, 10, $25 \mathrm{ml})$

Sarstedt, Nümbrecht

Plastik-Reaktionsgefäße $(1,5,2 \mathrm{ml})$

Sarstedt, Nümbrecht

Plastikröhrchen (10, 15, $50 \mathrm{ml})$

Sarstedt, Nümbrecht

Plastik-Spritzen, steril

BD Biosciences, Heidelberg

Präparierbesteck

Neolab, Heidelberg

Polyallomer-Zentrifugenröhrchen 
Röntgenfilme XAR-5

Metallsiebe Größen $25 \mu \mathrm{m}, 40 \mu \mathrm{m}$

Skalpelle, steril

Sterilfilter $(0,2$ und $0,45 \mu \mathrm{m})$

Whatman-Papier (3 $\mathrm{mm})$
Kodak, Stuttgart

Schütt, Göttingen

Braun, Melsungen

Sarstedt, Nümbrecht

Whatman-Vertrieb, Göttingen

\subsubsection{Chemikalien}

Alle Chemikalien wurden von den Firmen Amersham, Freiburg; Carl Roth, Karlsruhe; Grandpair, Heidelberg; Merck, Darmstadt; Perkin Elmer, RodgauJügesheim; Sigma, Taufkirchen und Serva, Heidelberg im Reinheitsgrad pro analysi bezogen.

\begin{tabular}{ll} 
Aceton & Roth \\
Agarose & Sigma \\
Azophloxin & Merck \\
$\mathrm{BCIP}$ & Sigma \\
$\mathrm{CaCl}_{2}$ & Merck \\
Carbogen-Gas $\left(95 \% \mathrm{O}_{2} / 5 \% \mathrm{CO}_{2}\right)$ & Grandpair \\
Chloroform & Merck \\
Denhardt's & Sigma \\
Dextransulfat & Amersham \\
DL-Lactat & Sigma \\
EDTA & Merck \\
Eosin B & Sigma \\
Eukitt & Merck \\
Essigsäure & Carl Roth \\
Ethanol & Carl Roth \\
Ethidiumbromid & Serva \\
Formaldehyd & Sigma \\
Glucose & Merck \\
Hämalaun nach Mayer & Merck \\
HCl & Merck \\
\hline
\end{tabular}




\begin{tabular}{|c|c|}
\hline HEPES & Sigma \\
\hline $\mathrm{H}_{2} \mathrm{O}$ HPLC-Reinheitsgrad & Carl Roth \\
\hline $\mathrm{KCl}$ & Merck \\
\hline $\mathrm{KHCO}_{3}$ & Merck \\
\hline $\mathrm{KH}_{2} \mathrm{PO}_{4}$ & Merck \\
\hline Levamisol & Sigma \\
\hline L-Fucose & Sigma \\
\hline Lichtgrün & Merck \\
\hline Methanol & Carl Roth \\
\hline Methyl-a-D-mannopyranosid & Sigma \\
\hline $\mathrm{MgCl}_{2}$ & Merck \\
\hline $\mathrm{MnCl}_{2}$ & Merck \\
\hline $\mathrm{MgSO}_{4}$ & Merck \\
\hline MOPS & Sigma \\
\hline Na-Acetat & Merck \\
\hline Na-Azid & Sigma \\
\hline $\mathrm{NaCl}$ & Merck \\
\hline $\mathrm{NaHCO}_{3}$ & Merck \\
\hline $\mathrm{Na}_{2} \mathrm{HPO}_{4}$ & Merck \\
\hline $\mathrm{NaH}_{2} \mathrm{PO}_{4}$ & Merck \\
\hline $\mathrm{NaOH}$ & Merck \\
\hline $\mathrm{NH}_{4} \mathrm{Cl}$ & Sigma \\
\hline $95 \% \mathrm{~N}_{2} / 5 \% \mathrm{CO}_{2}$-Gas & Grandpair \\
\hline Orange G & Merck \\
\hline Paraffin & Carl Roth \\
\hline Phosphormolybdänsäure & Merck \\
\hline Phosphowolframsäure & Merck \\
\hline p-Nitrotetrazoliumblau & Sigma \\
\hline Ponceau S & Merck \\
\hline Pyruvat & Sigma \\
\hline Resorcin-Fuchsin & Carl Roth \\
\hline Säurefuchsin & Merck \\
\hline SDS & Sigma \\
\hline Sucrose & Sigma \\
\hline
\end{tabular}




$\begin{array}{ll}\text { Szintillationsflüssigkeit Ultima Gold } & \text { Perkin Elmer } \\ \text { Trichloressigsäure } & \text { Merck } \\ \text { Tris } & \text { Merck } \\ \text { Triton X-100 } & \text { Sigma } \\ \text { Weigert Eisenhämatoxylin } & \text { Merck } \\ \text { Xylol } & \text { Carl Roth }\end{array}$

\subsubsection{Puffer und Lösungen}

Gebräuchliche Puffer und Lösungen wurden nach Vorschriften aus dem Laborhandbuch von Sambrook et al. (1989) angesetzt. Spezielle Puffer und Lösungen sind bei der entsprechenden Methode aufgeführt.

\subsubsection{Zellkulturmedien, Medienzusätze und Lösungen zur Arbeit mit eukaryontischen Zellen}

Zellkulturmedien, Medienzusätze und Lösungen wurden von den Firmen Amersham, Freiburg; BD Biosciences, Heidelberg; Biochrom, Berlin; Carl Roth, Karlsruhe; Chemicon, München; Invitrogen, Karlsruhe; Merck, Darmstadt; PAA, Cölbe; Roche, Mannheim; PAN Biotech, Aidenbach; Serva, Heidelberg und Sigma, Taufkirchen bezogen.

BSA

$\beta$-Mercaptoethanol

Cellfix-Lösung

Collagen

Collagenase

Dexamethason

DMSO

DMEM

DMEM mit L-Val

DMEM Glucose-frei
Serva

Sigma

BD Biosciences

Serva

Biochrom

Sigma

Merck

PAA

PAA

PAN Biotech 
FKS

Formamid

Gentamycin

HBSS

Insulin

Knockout-DMEM

LIF

L-Glutamin

MEM/HEPES

Mitomycin C

Na-Pyruvat

Non-essential amino acids

PBS

Penicillin/Streptomycin

Percoll

Trypsin/EDTA

Williams E-Medium
PAA

Carl Roth

PAA

Biochrom

Sigma

Invitrogen

Chemicon

Invitrogen

Invitrogen

Sigma

Invitrogen

Invitrogen

PAA

PAA

Amersham

Invitrogen

PAA

Weitere spezielle Medien und Lösungen sind bei der entsprechenden Methode aufgeführt.

3.1.7 Enzyme und Reagenzien für molekularbiologische, zellbiologische und proteinbiochemische Methoden

Reagenzien für molekularbiologische, zellbiologische und proteinbiochemische Methoden wurden von den Firmen ABI Applied Biosystems, Foster City, USA; Amersham, Freiburg; Biochrom, Berlin; Bio-Rad, München; Carl Roth, Karlsruhe; Genaxxon, Biberach; Invitrogen, Karlsruhe; MBI Fermentas, St. Leon-Rot; NEB, Frankfurt; Qiagen, Hilden; Roche, Mannheim und Sigma, Taufkirchen bezogen. 
ABI PRISM Sequencing Kit

ATP

DC Protein Assay Kit

DNA-Ladder

DNA-Loading Dye

dNTP-Mix

Omniscript RT Kit

Ovalbumin

Pronase

Proteinase $\mathrm{K}$

QIAquick Gel Extraction Kit

Restriktionsendonukleasen

RediPrime II DNA Labeling Kit

Rhodamin 6G

RNeasy Mini Kit

RNA-Ladder

RNA-Loading Dye

Salmon Sperm DNA

Taq DNA-Polymerase E

Ultrapure dNTP Set
$A B I$

Sigma

Bio-Rad

MBI Fermentas

MBI Fermentas

Invitrogen

Qiagen

Sigma

Roche

Carl Roth

Qiagen

NEB; MBI

Amersham

Sigma

Qiagen

MBI Fermentas

MBI Fermentas

Invitrogen

Genaxxon

Invitrogen

\subsubsection{Antikörper und Selektin-Fc-Fusionsproteine}

$\begin{array}{ll}\text { P-Selektin-Antikörper RB40.34 } & \text { Prof. Dr. D. Vestweber, Münster } \\ \text { L-Selektin-Antikörper MEL-14 } & \begin{array}{l}\text { ATCC, Manassas, USA (Hybridom- } \\ \text { Überstand) }\end{array} \\ \alpha_{4} \text {-Integrin-Antikörper PS/2 } & \begin{array}{l}\text { ATCC, Manassas, USA (Hybridom- } \\ \text { Überstand) }\end{array} \\ \text { Maus-E-Selektin-Fc } & \text { Prof. Dr. D. Vestweber, Münster } \\ \text { Maus-P-Selektin-Fc } & \text { Prof. Dr. D. Vestweber, Münster } \\ \text { Fc-Block anti-CD16/32 Antikörper } & \text { BD, Heidelberg }\end{array}$




\subsubsection{Lektine und Streptavidin-Konjugate}

Aleuria aurantia-Lektin, biotinyliert Vector Laboratories, Burlingham, USA

Lotus tetragonolobus-Agglutinin, Vector Laboratories, Burlingham, USA biotinyliert

Lens culinaris-Agglutinin, biotinyliert Vector Laboratories, Burlingham, USA Maackia amurensis-Lektin II, biotinyliert Vector Laboratories, Burlingham, USA Maackia amurensis-Lektin I, Vector Laboratories, Burlingham, USA

Fluorescein-gekoppelt

Lens culinaris-Lektin, Agarose-

Sigma, Taufkirchen

gekoppelt

Streptavidin-AP-Konjugat

Amersham, Freiburg

Streptavidin-PE Jackson-Dianova, Hamburg

Streptavidin-FITC

Vector Laboratories, Burlingham, USA

\subsubsection{Oligonukleotide}

Oligonukleotide (Primer) wurden von den Firmen IBA-Naps, Göttingen, und Invitrogen, Karlsruhe bezogen.

\subsubsection{Radioaktive Substanzen}

$\begin{array}{ll}{\left[\alpha-{ }^{32} \mathrm{P}\right] \mathrm{dCTP}, \text { Redivue }} & \text { Amersham, Freiburg } \\ \text { GDP- }\left[{ }^{14} \mathrm{C}\right] \text { Fucose } & \text { Amersham, Freiburg } \\ \text { UDP- }\left[{ }^{3} \mathrm{H}\right] \text { Galactose } & \text { Amersham, Freiburg } \\ 2-\left[{ }^{3} \mathrm{H}\right] \text { Mannose } & \text { Amersham, Freiburg }\end{array}$




\subsubsection{Hormone und Anästhetika zur Arbeit mit Mäusen}

menschl. Choriongonadotropin (hCG) Sigma, Taufkirchen

Pregnant Mare's Serum (PMS) Sigma, Taufkirchen

Ketavet

Pfizer, Karlsruhe

Rompun

Bayer, Leverkusen

\subsubsection{Embryonale Stammzellen}

Die Stammzellinie E-14 stammt aus Blastozysten von 129/Ola-Mäusen und wurde von der Arbeitsgruppe von K. Rajewsky, Köln bezogen (Hooper et al., 1987).

\subsubsection{Neomycin-resistente embryonale Mausfibroblasten (Feeder)}

Die embryonalen Stammzellen wurden auf einem Feederrasen aus G418(Neomycin)-resistenten murinen Embryonalfibroblasten kultiviert. Diese wurden von der Transgenic Research Facility der Universität Stanford bezogen.

\subsubsection{Mausstämme}

Blastozysten wurden nach natürlichen Verpaarungen aus folgendem Mausstamm (Mus musculus) isoliert:

C57 BL/6J Inzuchtstamm, schwarz BRL, Basel, Schweiz (eigene Weiterzucht)

Als Ammen-Mütter dienten Mäuse des folgenden Stammes:

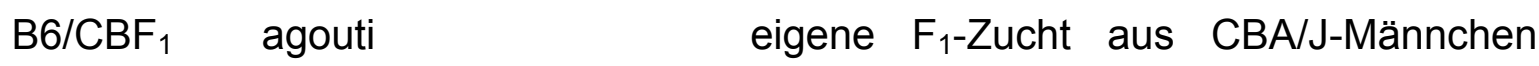
(Inzuchtstamm, agouti; BRL, Basel, Schweiz) und C57BL/6J-Weibchen 
Sterile Männchen für die Bereitstellung pseudoträchtiger $\mathrm{B} 6 / \mathrm{CBF}_{1}$-Weibchen (Foster-Mäuse) wurden durch Vasektomierung von Männchen des folgenden Stammes generiert:

Moro Inzuchtstamm, weiß BRL, Basel, Schweiz

Die weitere Verpaarung der Chimären und folgenden Generationen erfolgte mit Tieren der folgenden Stämme:

C57BL/6

Harlan Winkelmann, Borchen

129S2/SvHsd

Harlan Winkelmann, Borchen 


\subsection{Molekularbiologische Methoden}

\subsubsection{Standardbedingungen und -methoden der Molekularbiologie}

Alle gentechnologischen Arbeitsschritte wurden nach molekularbiologischen Standardmethoden unter Beachtung entsprechender Sicherheitsvorschriften (z.B. Gentechnikgesetz) durchgeführt. Reagenzien und Proben für die Vorbereitung enzymatischer Reaktionen wurden grundsätzlich auf Eis gekühlt. Verwendete Medien, Puffer und sonstige Lösungen wurden, sofern nicht käuflich erworben, mit bidestilliertem Wasser angesetzt und ggf. durch Autoklavieren oder Filtrieren sterilisiert.

Alle folgenden Methoden und Vorschriften wurden, soweit nicht anders angegeben, dem Laborhandbuch "Molecular cloning" (Sambrook et al., 1989) entnommen.

\subsubsection{Isolierung genomischer DNA}

Zellen aus Kulturen wurden von den Zellkulturplatten abgeschabt, pelletiert und in $0,3 \mathrm{ml}$ Lysispuffer überführt. Dieser Ansatz wurde mit $30 \mu \mathrm{l}$ frisch angesetzter Proteinase K-Stammlösung (10 $\mathrm{mg} / \mathrm{ml}$ Proteinase $\mathrm{K}$ in Lysispuffer) versetzt und für mindestens $3 \mathrm{~h}$ bei $56^{\circ} \mathrm{C}$ im Schüttelinkubator bzw. Schüttelwasserbad inkubiert. Im Falle von Schwanzbiopsien erfolgte dieser Verdau unter Verwendung von 0,5 $\mathrm{ml}$ Lysispuffer und $50 \mu \mathrm{l}$ Proteinase K-Stammlösung. Die Proteinase K sorgt für die Inaktivierung endogener Nukleasen, so dass die DNA intakt bleibt. Nach 15 min Zentrifugation bei $13.000 \mathrm{rpm}$ (16.000xg) in der Eppendorf-Zentrifuge wurde zum Überstand $1 \mathrm{ml}$ bzw. 1,4 ml Ethanol gegeben. Die dabei ausgefallene DNA wurde mit einer Glaspipette mit abgerundeter Spitze aufgenommen, nach einem Waschschritt in 70\% Ethanol getrocknet, in $100 \mu \mathrm{l} \mathrm{TE-Puffer} \mathrm{oder} \mathrm{Wasser} \mathrm{gelöst}$ und bis zur weiteren Verwendung bei $4^{\circ} \mathrm{C}$ gelagert. 
Lysispuffer:

$\begin{array}{rl}50 \mathrm{mM} & \text { Tris/HCl, pH 8,0 } \\ 50 \mathrm{mM} & \text { EDTA } \\ 100 \mathrm{mM} & \mathrm{NaCl} \\ 0,5 \% & \text { SDS }\end{array}$

\subsection{3}

Isolierung von RNA

Zur Isolierung von RNA aus eukaryontischen Zellen und Gewebeproben wurde das RNeasy-System der Firma Qiagen, Hilden verwendet. Die Präparation erfolgte nach dem Herstellerprotokoll (RNeasy Handbook, 2001).

\subsubsection{Konzentrationsbestimmung von Nukleinsäuren}

Die Konzentration von DNA bzw. RNA wurde photometrisch ermittelt. Die Messung erfolgte bei einer Wellenlänge von $260 \mathrm{~nm}$ gegen TE oder $\mathrm{H}_{2} \mathrm{O}$ in einer Quarzküvette. $\mathrm{OD}_{260}=1$ entspricht einer Konzentration von $50 \mu \mathrm{g} / \mathrm{ml}$ doppelsträngiger DNA bzw. $40 \mu \mathrm{g} / \mathrm{ml}$ RNA.

\subsubsection{Spaltung von DNA mit Restriktionsendonukleasen}

(Lehrach und Frischauf, 1982)

Die Aktivität von Restrikitonsendonukleasen wird in Units $(u)$ angegeben. Eine Unit entspricht der Menge an Restriktionsenzym, die benötigt wird, um 1 Mg LambdaDNA in einer Stunde vollständig zu verdauen. Um sicherzustellen, dass der Verdau quantitativ abläuft, wurden die Enzymmenge und die Inkubationszeit im Vergleich zum Herstellerprotokoll verdoppelt. Der Verdau genomischer DNA erfolgte ü.N. 
Reaktionsansatz: $\quad x \mu g \quad$ DNA

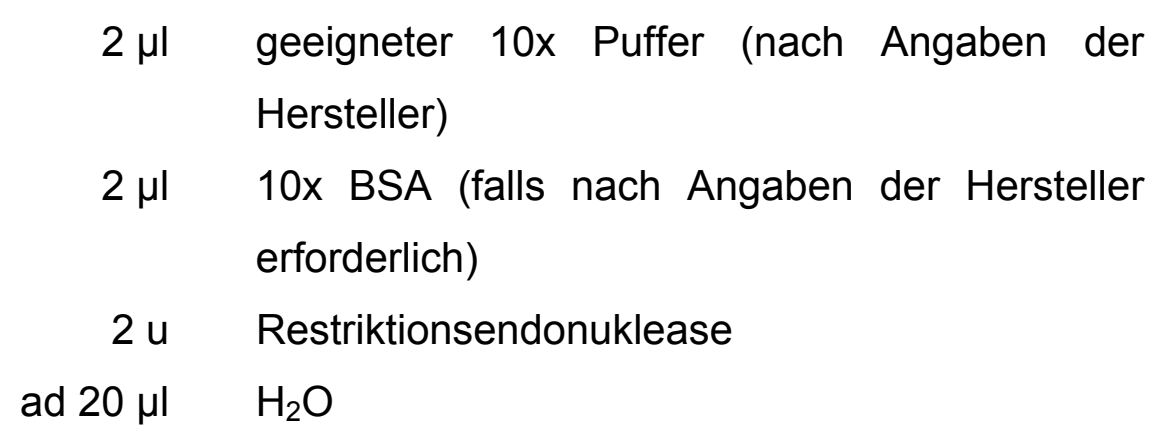

Der Ansatz wurde $2 \mathrm{~h}$ bei $37^{\circ} \mathrm{C}$ (bzw. dem jeweiligen Temperaturoptimum des Enzyms) inkubiert und anschließend im Agarosegel analysiert. Präparative Verdauungen wurden in größeren Volumina und mit entsprechend größerer Enzymmenge durchgeführt. Die Reaktionspuffer wurden gemäß dem NEB- bzw. dem MBI Fermentas-Puffersystem verwendet.

\subsubsection{Auftrennung von DNA-Fragmenten in Agarosegelen}

Zur Auftrennung von DNA-Fragmenten sowie PCR-Produkten wurden Agarosegele verwendet, deren Agarosekonzentration sich nach der Größe der zu trennenden DNA-Fragmente richtete:

$\begin{array}{cc}\text { Agarosekonzentration [\%] } & \text { Trennbereich [kb] } \\ 0,6 & 1-20 \\ 0,9 & 0,5-7 \\ 1,2 & 0,4-6 \\ 1,5 & 0,2-4 \\ 2,0 & 0,1-3\end{array}$

Die erforderliche Agarosemenge wurde in $400 \mathrm{ml}$ 1x TAE im Mikrowellenherd aufgekocht und nach Abkühlen auf $65^{\circ} \mathrm{C}$ mit Ethidiumbromid versetzt (Endkonzentration: 0,5 $\mu \mathrm{g} / \mathrm{ml}$ ). Die Lösung wurde in eine Gelform gegossen und bei RT abgekühlt. Das erstarrte Gel wurde in eine mit 1x TAE gefüllte Elektrophoresekammer überführt, die Proben wurden mit 10\% DNA-Loading buffer 
versetzt und in die vorgeformten Geltaschen pipettiert. Die Elektrophorese wurde mit einer Spannung von 3-4 V/cm ${ }^{2}$ durchgeführt. Durch das in die DNADoppelhelix interkalierende Ethidiumbromid werden die DNA-Fragmente unter UVLicht sichtbar, so dass das Gel auf dem UV-Transilluminator analysiert werden kann. Zur Dokumentation wurde das Agarosegel auf dem UV-Transilluminator mit einem Videosystem aufgenommen und ein Ausdruck des Bildes erstellt.

TAE-Puffer:

$$
\begin{aligned}
40 \mathrm{mM} & \text { Tris/Acetat } \\
2 \mathrm{mM} & \text { EDTA } \\
& \text { mit Eisessig pH 8,0 einstellen }
\end{aligned}
$$

\subsubsection{Isolierung von DNA-Fragmenten aus Agarosegelen}

Zur Isolierung von DNA-Fragmenten aus Agarosegelen wurde das QIAquick Gel Extraction Kit der Firma Qiagen, Hilden verwendet. Die Präparation erfolgte nach dem Herstellerprotokoll (QIAquick Gel Extraction Kit, Handbook, 1999).

\subsubsection{Transfer von DNA auf Hybond N-Filter (Southern-Blot)}

(Southern, 1975; Alwine et al., 1977)

Nach einem geeigneten Restriktionsverdau und der Auftrennung im Agarosegel wurde die zu analysierende DNA denaturiert. Dazu wurde das Gel zweimal 15 min in Denaturierungs-Lösung und anschließend zweimal 15 min in NeutralisierungsLösung auf einem Wipptisch geschwenkt. Nach 10 min Äquilibrieren in 20x SSC erfolgte der Transfer ü.N. mit 20x SSC als Transferpuffer mit dem in Abb. 5 dargestellten Aufbau. Der Pfeil zeigt die Richtung des Flüssigkeitsstromes an, durch den die DNA aus dem Agarosegel auf den darüberliegenden Hybond-NylonFilter (Membran) übertragen wird. 


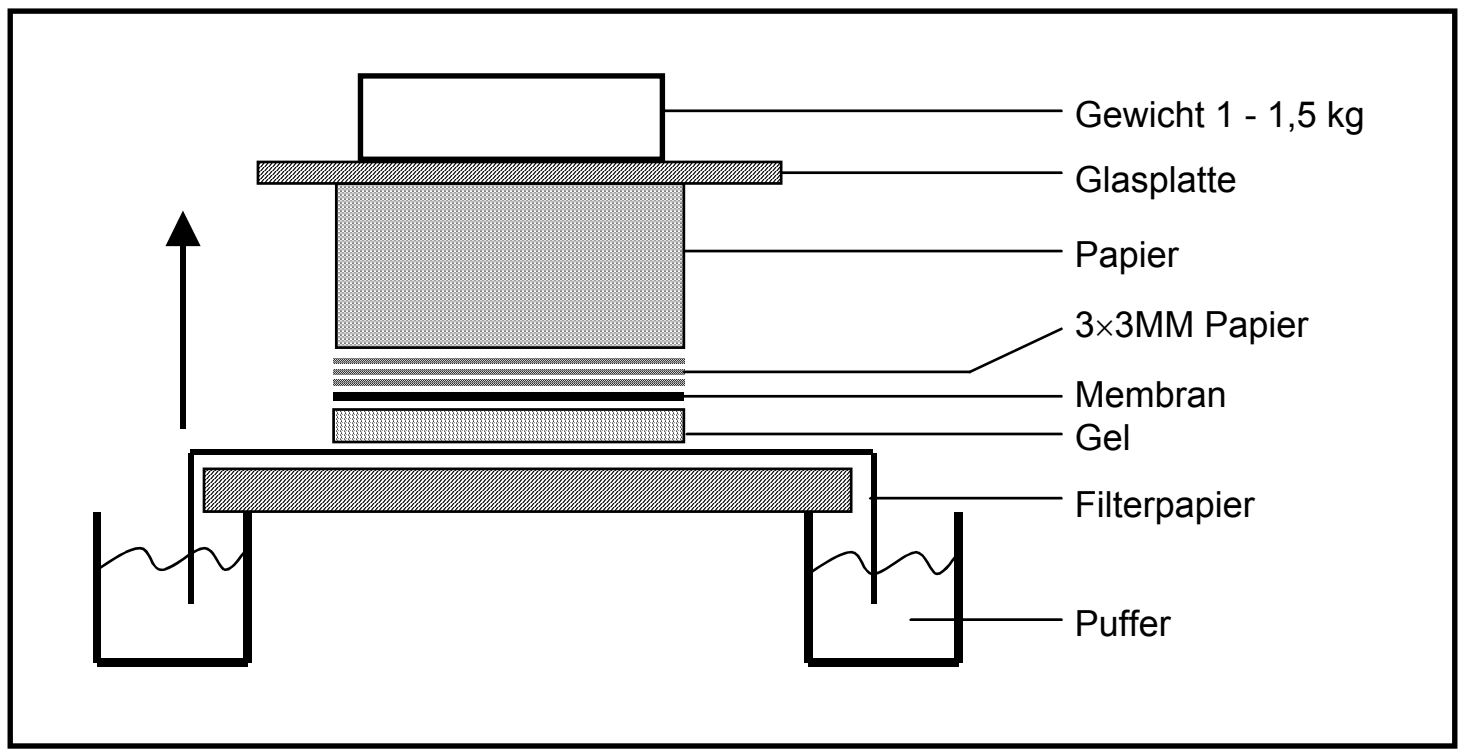

Abb. 5: $\quad$ Transfer von Nukleinsäuren aus Agarosegelen auf Hybond N-Filter

Der Filter wurde im Wärmeschrank bei $37^{\circ} \mathrm{C}$ getrocknet und die DNA-Seite markiert. Durch UV-Bestrahlung (15 s) der DNA-Seite auf dem UVTransilluminator wurde die DNA fest an die Filteroberfläche gebunden.

$\begin{array}{lrl}\text { Denaturierungs-Lösung: } & 1,5 \mathrm{M} & \mathrm{NaCl} \\ & 0,5 \mathrm{M} & \mathrm{NaOH} \\ & & \\ \text { Neutralisierungs-Lösung: } & 1,5 \mathrm{M} & \mathrm{NaCl} \\ & 0,5 \mathrm{M} & \text { Tris/HCl, pH 7,2 } \\ & 1 \mathrm{mM} & \text { EDTA } \\ & & \\ & 3 \mathrm{M} & \mathrm{NaCl} \\ \text { 20x SSC: } & 0,3 \mathrm{M} & \mathrm{Na}-\mathrm{C} \text { itrat, pH 7,0 }\end{array}$




\subsubsection{Transfer von RNA auf Hybond N-Filter (Northern-Blot)}

Die aus den Zellen bzw. Gewebeproben isolierte RNA wurde mit 2x RNA-Loading buffer versetzt und im Formaldehyd-Agarosegel elektrophoretisch bei 50-70 V aufgetrennt. Im Anschluss erfolgten die Behandlung des Gels und der Transfer auf den Hybond-Nylon-Filter wie unter 3.2.8 beschrieben.

10x Gelpuffer:

$\begin{aligned} 200 \mathrm{mM} & \text { MOPS } \\ 50 \mathrm{mM} & \text { Na-Acetat } \\ 10 \mathrm{mM} & \text { EDTA } \\ & \text { pH } 7,0 \text { mit } \mathrm{NaOH}\end{aligned}$

Agarosegel:

$\begin{aligned} 1 \mathrm{x} & \text { Gelpuffer } \\ 1,2 \% & \text { Agarose } \\ & \text { aufkochen, nach Abkühlen auf } 65^{\circ} \mathrm{C}: \\ 0,25 \mathrm{M} & \text { Formaldehyd } \\ 0,1 \mu \mathrm{g} / \mu \mathrm{l} & \text { Ethidiumbromid }\end{aligned}$

Laufpuffer:

1x Gelpuffer

$0,25 \mathrm{M} \quad$ Formaldehyd

\subsubsection{Markierung einer DNA-Sonde mit $\left[\alpha-{ }^{32} \mathrm{P}\right] \mathrm{dCTP}$}

$25 \mathrm{ng}$ der zu markierenden DNA-Sequenz wurden in $45 \mu \mathrm{l} \mathrm{H}_{2} \mathrm{O}$ verdünnt, 5 min bei $95^{\circ} \mathrm{C}$ denaturiert, auf Eis abgekühlt und zu einem Aliquot des RediPrime II DNA Labeling Lyophilisats (Amersham) gegeben, welches vorsichtig darin gelöst wurde. Auf die Zugabe von $5 \mu \mathrm{l}\left[\alpha^{32} \mathrm{P}\right] \mathrm{dCTP}(50 \mu \mathrm{Ci})$ folgten $15 \mathrm{~min}$ Inkubation bei $37^{\circ} \mathrm{C}$. Um die markierte Sonde von freien Nukleotiden zu trennen, erfolgte eine Aufreinigung über eine QIAquick-Mini-Säule aus dem QIAquick Gel Extraction Kit. Dazu wurde der Ansatz mit $250 \mu$ I PN-Puffer versetzt auf eine QIAquick-Minisäule gegeben. Darauf folgten eine kurze Zentrifugation, zwei Waschschritte mit jeweils $500 \mu \mathrm{l}$ PE-Puffer und die Elution der Sonde mit $200 \mu$ l EB-Puffer. 


\subsubsection{Hybridisierung der an Hybond N-Filter gebundenen DNA bzw. RNA mit radioaktiv markierten Sonden}

Zur Hybridisierung wurde der Filter mit dem Hybridisierungsmix $\left(1 \mathrm{ml} / 10 \mathrm{~cm}^{2}\right)$ in einem Plastikröhrchen vorinkubiert. Nach ca. $10 \mathrm{~min}$ wurde die radioaktiv markierte DNA-Sonde, die vorher zusammen mit Lachsspermien-DNA $(100 \mu \mathrm{g} / \mathrm{ml})$ 5 min bei $95^{\circ} \mathrm{C}$ denaturiert worden war, zum Filter in den Hybridisierungsmix

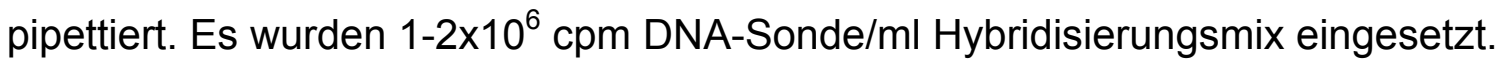

Der Filter wurde ü. $\mathrm{N}$. in der Hybridisierungslösung bei $42^{\circ} \mathrm{C}$ inkubiert, indem das Plastikröhrchen im Wärmeschrank gerollt wurden. Anschließend wurde der Filter aus dem Röhrchen mit der radioaktiven Hybridisierungslösung genommen und zunächst mit 2x SSC/0,1\% SDS 10 min bei RT, dann mehrfach mit 0,2x SSC/0,1\% SDS 10 min bei $65^{\circ} \mathrm{C}$ im Schüttelwasserbad gewaschen, bis mit dem Handcounter nach Möglichkeit weniger als $40 \mathrm{cpm}$ messbar waren.

Der Filter wurde feucht in Folie eingeschweißt und mit einem PhosphoimagerScreen und einem Kodak-XAR-5-Röntgenfilm autoradiographiert.

Für eine Hybridisierung derselben Membran mit einer anderen Sonde konnte die erste Sonde durch zweimaliges Waschen für 5 min bei $95^{\circ} \mathrm{C}$ in $0,2 x \mathrm{SSC} / 0,1 \%$ SDS entfernt werden.

$\begin{array}{rrl}\text { Hybridisierungsmix: } & 48 \% & \text { Formamid } \\ 24 \% & 20 x \text { SSC } \\ 10 \mathrm{mM} & \text { Tris/HCl, pH 7,5 } \\ 35 \mathrm{mM} & \text { SDS } \\ 2 \% & 50 x \text { Denhardts } \\ 10 \% \mathrm{w} / \mathrm{v} & \text { Dextransulfat }\end{array}$

Das Dextransulfat wurde in $\mathrm{H}_{2} \mathrm{O}$ bei $80^{\circ} \mathrm{C}$ gelöst. Anschließend wurden die anderen Substanzen zugesetzt und mit $\mathrm{H}_{2} \mathrm{O}$ aufgefüllt. Die Lagerung erfolgte bei $4^{\circ} \mathrm{C}$. 


\subsubsection{Polymerase-Ketten-Reaktion}

\subsubsection{Allgemeines}

(Saiki et al., 1986; Saiki et al., 1988)

Die Polymerase-Ketten-Reaktion (PCR) ist eine Methode, mit der definierte DNABereiche amplifiziert werden können. Sie basiert auf drei Schritten, die für die Synthese der DNA notwendig sind:

1) Denaturierung der Ausgangs-DNA (Template) in Einzelstränge

2) Annealing: Bindung von Oligonukleotiden (Primer) an beide Einzelstränge

3) Extension/Elongation: Synthese der DNA durch die Polymerase, ausgehend von den gebundenen Primern

Auswahl und Konzentration der Primer, Qualität (genomisch, Plasmid, lineares Fragment) und Menge des Templates, Pufferbedingungen, Zeiten und Temperaturen der einzelnen Zyklusschritte beeinflussen die Synthese der DNA.

\subsubsection{Primer-Design \\ (HotStarTaq PCR Handbuch, März 1999)}

Das Design von Primer-Paaren ist für die PCR von entscheidender Bedeutung und wurde nach folgenden Grundregeln durchgeführt: Die Länge eines Primers sollte zwischen 17 und 27 Basen liegen. Die Schmelztemperaturen $T_{m}$ beider Primer eines Primer-Paares sollten nach Möglichkeit identisch sein. Die Kenntnis von $T_{m}$ ist für die Festlegung der Annealing-Temperatur $T_{a n n}$, bei der ein Primer spezifisch mit einer DNA-Matrize hybridisiert, notwendig. $T_{m}$ eines Primers in einer PCR ist von den Salz- und Tris/HCl-Konzentrationen im Reaktionspuffer sowie von der Länge, der Konzentration und der Sequenz des Primers abhängig. Als Faustregel zur vereinfachten Berechnung diente jedoch folgende Formel:

$$
\mathrm{T}_{\mathrm{m}}=4 \times(\mathrm{G}+\mathrm{C})+2 \times(\mathrm{A}+\mathrm{T})
$$

Dabei stehen G, C, A und T für die Anzahl der jeweiligen Base im Primer. $T_{\text {ann }}$ sollte 5 bis $10^{\circ} \mathrm{C}$ unter $\mathrm{T}_{\mathrm{m}}$ liegen und maximal gleich der optimalen Synthesetemperatur der verwendeten, thermostabilen DNA-Polymerase $\left(68-72^{\circ} \mathrm{C}\right)$ 
sein. Weiterhin ist bei dem Design von Primern zu beachten, dass Dimerisierungen durch komplementäre Sequenzen innerhalb eines Primers oder eines Primer-Paares zu vermeiden sind und die Termini zur stabileren MatrixBindung möglichst aus einem oder zwei $G$ oder $C$ bestehen sollten.

\subsubsection{Standard-PCR}

Standard-PCR-Anwendungen wurden nach Protokollen aus dem Handbuch von McPherson et al. (1991) durchgeführt. Die Reaktionen erfolgten in einem Gesamtvolumen von 25 oder $50 \mu \mathrm{l}$. Ein Standard-PCR-Ansatz setzte sich folgendermaßen zusammen:

$\begin{aligned} \text { x ng } & \text { Template-DNA } \\ 250 \mathrm{nM} & \text { sense(5')-Primer } \\ 250 \mathrm{nM} & \text { antisense(3')-Primer } \\ \text { jeweils } 0,2 \mathrm{mM} & \text { dNTPs } \\ 1 \mathrm{x} & \text { Reaktionspuffer } \\ 0,025 \mathrm{u} / \mu \mathrm{l} & \text { Thermus aquaticus (Taq)-DNA-Polymerase }\end{aligned}$

Die eingesetzte DNA-Menge variierte, lag aber üblicherweise im Bereich zwischen 50 und 100 ng. Ein Standard-Thermocycler-Programm gestaltet sich folgendermaßen:

\begin{tabular}{|c|c|c|c|}
\hline $1 \mathrm{~min}$ & $94^{\circ} \mathrm{C}$ & & \\
\hline $0,5 \mathrm{~min}$ & $94^{\circ} \mathrm{C}$ & & Denaturierung der DNA \\
\hline $0,5 \min$ & $55^{\circ} \mathrm{C}$ & $30-35 x$ & Annealing der Primer \\
\hline $1 \mathrm{~min}$ pro $\mathrm{kb}+1 \mathrm{~min}$ & $72^{\circ} \mathrm{C}$ & & Elongation \\
\hline $1 \mathrm{~min}$ & $72^{\circ} \mathrm{C}$ & & finale Elongation \\
\hline$\infty$ & $4^{\circ} \mathrm{C}$ & & \\
\hline
\end{tabular}




\subsubsection{Genotypisierungs-PCR mit der Taq DNA-Polymerase E (Genaxxon)}

Das Taq DNA-Polymerase E-System beinhaltet eine Pufferkombination, welche für eine hohe Effizienz optimiert ist und auch bei Amplifikationen auf Basis genomischer DNA häufig eine nested-PCR, also zwei aufeinanderfolgende PCRReaktionen mit einem äußeren und einem inneren Primerpaar, überflüssig macht. Der Ansatz wurde nach Angaben der Hersteller gestaltet. Das ThermocyclerProgramm wurde im Vergleich zu 3.2.12.3 folgendermaßen modifiziert: Durch sukzessive Zyklusverlängerung wird ein Aktivitätsverlust der Polymerase nach jedem Zyklus kompensiert; die Polymerase benötigt einen initialen Aktivierungsschritt von 5 min bei $94^{\circ} \mathrm{C}$; die Annealing-Temperatur wurde für die spezielle Primer-Kombination optimiert. Das Programm setzte sich aus folgenden Zeiten und Temperaturen zusammen:

\begin{tabular}{|c|c|c|c|}
\hline $5 \min$ & $94^{\circ} \mathrm{C}$ & & \\
\hline $20 \mathrm{~s}$ & $94^{\circ} \mathrm{C}$ & & Denaturierung \\
\hline $30 \mathrm{~s}$ & $62^{\circ} \mathrm{C}$ & $10 x$ & Annealing \\
\hline $3 \min$ & $72^{\circ} \mathrm{C}$ & & Elongation \\
\hline $20 \mathrm{~s}$ & $94^{\circ} \mathrm{C}$ & & Denaturierung \\
\hline $20 \mathrm{~s}$ & $62^{\circ} \mathrm{C}$ & $25 x$ & Annealing \\
\hline $3 \mathrm{~min}+10 \mathrm{~s} /$ Zyklus & $72^{\circ} \mathrm{C}$ & & Elongation \\
\hline $5 \min$ & $72^{\circ} \mathrm{C}$ & & finale Elongation \\
\hline & $4^{\circ} \mathrm{C}$ & & \\
\hline
\end{tabular}

\subsubsection{Sequenzierung von DNA}

Für die Sequenzierung von DNA-Abschnitten wurde zunächst mit dem ABI PRISM Dye Terminator Cycle Sequencing Ready Reaction Kit nach Protokoll des Herstellers eine spezielle PCR durchgeführt. Als Template dienten entweder PCRProdukte oder Plasmid-DNA, nicht jedoch genomische DNA. Das PCR-Produkt wurde mittels Ethanol-Fällung aufgereinigt, in $25 \mu \mathrm{l} \mathrm{H}_{2} \mathrm{O}$ aufgenommen und in einem kapillarelektrophoretischen Verfahren in einem DNA-Sequenzierer automatisch sequenziert. 


\subsection{Methoden zur Arbeit mit Mäusen und Blastozysten}

Die folgenden Schritte wurden in Kooperation mit dem Max-Planck-Institut für experimentelle Medizin, Göttingen, der Zentralen Tierexperimentellen Einrichtung (ZTE), Göttingen, und der Interfakultären Biomedizinischen Forschungseinrichtung (IBF), Heidelberg durchgeführt.

\subsubsection{Maushaltung}

Die Mäuse wurden im MPI und der ZTE unter konventionellen Bedingungen (Hogan et al., 1986), im IBF unter spezifiziert pathogenfreien (SPF-) Bedingungen gehalten. Die Temperatur in den Mausräumen betrug $21-23^{\circ} \mathrm{C}$, die Luftfeuchtigkeit 45-60\%. Es wurde ein Tag-Nacht-Rhythmus von $12 \mathrm{~h}$ Licht (6-18 Uhr) und $12 \mathrm{~h}$ Dunkelheit eingehalten.

\subsubsection{Superovulation von Mäusen}

Gonadotropin-Gaben an fertile Mäuseweibchen können die Anzahl der ovulierten Eizellen sehr stark erhöhen (bis zu Faktor 5; Hogan et al., 1994). Im Rahmen dieser Arbeit wurden Weibchen des Stammes C57 BL/6J superovuliert. Es wurden die folgenden zwei Gonadotropine verwendet:

1) Pregnant Mare's Serum (PMS) als Ersatz für das follikelstimulierende Hormon (FSH);

2) menschliches Choriongonadotropin ( $\mathrm{hCG}$ ) als Ersatz für das luteinisierende Hormon (LH).

Es wurden jeweils $5 \mathrm{IU}$ intraperitoneal injiziert, um eine schnelle Aufnahme in den Blutkreislauf der Maus zu gewährleisten. Zwischen der Injektion von PMS und der von hCG wurde ein 46-48 h-Intervall geschoben. Direkt im Anschluss erfolgte die Verpaarung. 


\subsubsection{Gezielte Verpaarung von Mäusen}

\subsubsection{Vaginalpfropfkontrolle}

Am Morgen nach der Verpaarung (etwa 7-9 h nach dem angenommenen Verpaarungszeitpunkt) wurden die weiblichen Mäuse untersucht. Mittels einer abgerundeten Pasteurpipette wurde die Vagina leicht geweitet, so dass auch tiefer liegende Spermapfropfen registriert werden konnten. Das Sperma bildet einen gelblich-weißen Pfropf im Ausgang der Vagina.

\subsubsection{Weibchen zur Blastozystenspende}

Vier Tage vor der Gewinnung der Blastozysten zur Mikroinjektion wurden 40 C57BL/6J-Männchen gegen 16 Uhr verpaart. Weibliche Mäuse haben eine mittlere Zyklusdauer von vier Tagen; durchschnittlich waren also zehn Weibchen zur Aufnahme bereit.

Am nächsten Morgen (7 Uhr; Tag 0,5 p.c.) wurden die Weibchen einer Vaginalpfropfkontrolle unterzogen und die positiven Tiere bis zur Präparation der Blastozysten gesondert gehalten.

Es wurde mit zwei Gruppen von Männchen gearbeitet, so dass ein Männchen jeweils mindestens vier Tage vor der folgenden Verpaarung pausierte, um eine ausreichende Spermienproduktion zu gewährleisten.

\subsubsection{Weibchen zum Austragen der Blastozysten (Foster-Mäuse)}

$24 \mathrm{~h}$ nach der Verpaarung der Blastozystenspender wurden 20 B6/CBF 1 (agouti) ${ }^{-}$ Weibchen (Alter: 10-20 Wochen) mit zehn vasektomierten Moro-Männchen verpaart. Die Verpaarung wurde am nächsten Morgen (7 Uhr) durch Vaginalpfropfkontrolle überprüft. Weibchen mit Pfropf wurden bis zum Blastozystentransfer gesondert gehalten. 


\subsubsection{Gewinnung von Blastozysten aus trächtigen Mäusen}

Die Blastozysten wurden aus den nach 3.3.3.2 verpaarten C57 BL/6J-Weibchen, die am Tag 0,5 einen Vaginalpfropfen aufwiesen, am Tag 3,5 p.c. isoliert. Die genaue Vorgehensweise wurde von Hogan et al. (1994) beschrieben.

Es konnten im Schnitt etwa 5-9 injizierbare Blastozysten pro Maus isoliert werden.

\subsubsection{Mikroinjektion von ES-Zellen in Maus-Blastozysten}

Die Herstellung von Injektions- und Haltekapillaren, der Aufbau der Mikroinjektionsanlage sowie die Durchführung der Mikroinjektion der nach 3.4.1.6 präparierten ES-Zellen in die Blastozysten erfolgten nach den Angaben von Hogan et al. (1994).

Während der Injektion wurden die Zellen auf einer Temperatur von etwa $10^{\circ} \mathrm{C}$ gehalten. Nach der Manipulation wurden die Blastozysten noch etwa eine Stunde bei $37^{\circ} \mathrm{C}$ und $10 \% \mathrm{CO}_{2}$ im Brutschrank inkubiert. Daran schloss sich unmittelbar der Transfer in pseudoträchtige Mäuse an.

\subsubsection{Transfer injizierter Blastozysten in pseudoschwangere Foster- Mäuse}

Nach erfolgreicher Verpaarung wurden die Reproduktionstrakte des Weibchens hormonell auf die Aufnahme von befruchteten Eizellen vorbereitet. Ein pseudoträchtiges Weibchen würde nach nicht erfolgter Implantation von befruchteten Eizellen erst nach etwa elf Tagen wieder in den normalen Zyklus kommen. Für den Blastozysten-Transfer wurden pseudoträchtige Weibchen am Tag 2,5 oder 3,5 p.c. verwendet. Der Embryo-Transfer wurde wie in Hogan et al. (1994) beschrieben durchgeführt. 


\subsubsection{Identifizierung von Chimären}

Chimären wurden anhand des Agouti-Fellmarkers identifiziert. Männliche Mäuse mit einem Chimärismus von mindestens 70\% wurden mit C57BL/6-Weibchen verpaart. Agoutifarbene Nachkommen wurden im Alter von drei Wochen mittels PCR genotypisiert. Dadurch wurden chimäre Männchen mit Keimbahnbeteiligung identifiziert, d.h. zumindest ein Teil ihrer Keimzellen trägt das mutagenisierte Allel, so dass dies weitervererbt werden kann.

\subsubsection{Weitere Zucht zur Etablierung von Knockout-Mauslinien}

Der C57BL/6-Stamm ist aufgrund positiver Zuchteigenschaften wie z.B. relativ großer Wurfgrößen bei der Zucht gentechnisch manipulierter Mäuse ein häufig verwendeter Stamm. Zur Auszucht auf den C57BL/6-Stamm ausgehend vom 129Stammhintergrund der manipulierten ES-Zellen wurden die agoutifarbenen, heterozygoten Nachkommen mit C57BL/6-Tieren verpaart. Es folgte eine weitere Verpaarung jeweils heterozygoter Nachkommen mit C57BL/6-Tieren über insgesamt mindestens sieben Generationen. Nach dieser Generationszahl kann ein statistisch betrachtet reiner Stammhintergrund angenommen werden.

Parallel dazu wurden die chimären Männchen mit Keimbahnbeteiligung mit 129S2/SvHsd-Weibchen verpaart. Der 129-Stamm zeichnet sich zwar durch kleine Wurfgrößen, aber auch durch eine höhere Vitalität und Resistenz gegenüber äußeren sowie genetischen Einflüssen aus. Um auch hier eine statistisch reinen Stammhintergrund für exakt den zur Verpaarung gewählten Stamm 129S2/SvHsd zu gewährleisten, erfolgte eine Verpaarung mit 129S2/SvHsd-Tieren über mindestens sieben Generationen.

Um sofort mit der Charakterisierung von Knockout-Tieren beginnen zu können und gleichzeitig einen möglichst einheitlichen Stammhintergrund zu gewährleisten, wurde folgende Strategie gewählt: Heterozygote Nachkommen aus 129Sv/C57BL/6-Verpaarungen, also 50/50-Hybriden der beiden Stämme, wurden untereinander verpaart. Sie stellten somit die Elterngeneration für Nachkommen dar, für die zu 25\% der Knockout-Genotyp zu erwarten war. 


\subsubsection{Embryonentransfer zur Etablierung einer SPF-Zucht}

Im Verlauf dieser Arbeit wurden Tiere aus der konventionellen Haltung in der ZTE Göttingen für einen Embryonentransfer im IBF Heidelberg eingesetzt, um eine Zucht unter SPF-Bedingungen zu etablieren.

Zu diesem Zweck wurden heterozygote Männchen mit superovulierten WildtypWeibchen verpaart. Die Embryonen wurden 24 h p.c. präpariert und in FosterMäuse transferiert. Die Vorbereitung der Foster-Mäuse sowie der Transfer erfolgten wie unter 3.3.3.3 und 3.3.6 beschrieben nach Hogan et al. (1994).

\subsubsection{Differentialblutbild}

Das Alter der verwendeten Tiere lag zwischen neun und 16 Wochen. Die Entnahme der Blutproben erfolgte unter vorübergehender HalothanInhalationsbetäubung und mit Hilfe einer Blutkapillare aus dem retrobulbären Venenplexus. Der Blutausstrich, die Färbung der Zellen sowie das Auszählen der verschiedenen Spezies erfolgte nach der Methode von Pappenheim (1912).

\subsubsection{Untersuchung psychomotorischer Fähigkeiten anhand des "Screen-Tests" \\ (modifiziert nach Coughenour et al., 1977)}

Die Tiere wurden auf ein horizontales Drahtgitter mit einem $\mathrm{cm}$ Abstand zwischen den Gitterstäben gesetzt. Das Gitter wurde in etwa 0,5 m Höhe über eine weiche Unterlage gehalten. Im Verlauf des Tests wurde das Gitter fortwährend vertikal mit einer Geschwindigkeit von $180^{\circ}$ pro $10 \mathrm{~s}$ gedreht. Dabei wurde die Haltezeit der Tiere bis maximal $60 \mathrm{~s}$ erfasst. Es wurden ausschließlich adulte Tiere, also mit einem Mindestalter von drei Monaten, verwendet. 


\subsection{Methoden zur Zellpräparation und -kultur}

\subsubsection{ES-Zellkultur}

\subsubsection{Kultivierung von embryonalen Stammzellen}

Sämtliche Methoden lehnen sich an Protokolle an, wie sie in "Teratocarcinomas and Embyonic Stem Cells" (Robertson, 1987), "Gene Targeting" (Joyner, 1993), "Manipulating the Mouse Embryo" (Hogan et al., 1994).und "Gene targeting by Homologous Recombination in Embryonic Stem Cells" (Mansouri, 1998) beschrieben sind.

Die embryonalen Stammzellen (ES-Zellen) wurden in wassergesättigter Atmosphäre unter $5 \% \mathrm{CO}_{2}$ bei $37^{\circ} \mathrm{C}$ auf einem Rasen aus mitotisch inaktivierten Maus-Embryonen-Fibroblasten (MEF; "Feeder-Zellen") kultiviert. Medien und Lösungen wurden auf $37^{\circ} \mathrm{C}$ vorgewärmt, wenn nicht anders angegeben.

Die Zellen wuchsen in scharf abgerundeten Kolonien und wurden täglich mikroskopisch kontrolliert. Je nach Ansäuerung durch die ES-Zellen wurde das Medium regelmäßig gewechselt. Diesem wurde unter anderem LIF (Leukemia Inhibitor Factor) zugesetzt, welcher eine Differenzierung der ES-Zellen verhindert. Eine erneute Passagierung wurde, je nach Dichte der Zellen, alle zwei bis vier Tage durchgeführt. Alle Zentrifugationsschritte erfolgten, soweit nicht anders angegeben, für 5 min bei $500 x g$ in der Labofuge.

ES-Medium:

Knock Out-DMEM

$\begin{aligned} 15 \% & \text { FKS } \\ 2 \mathrm{mM} & \text { L-Glutamin } \\ 1 \mathrm{mM} & \text { Na-Pyruvat } \\ 1 \mathrm{x} & \text { non-essential amino acids } \\ 100 \mathrm{u} / \mathrm{ml} & \text { Penicillin/Streptomycin } \\ 1.000 \mathrm{u} / \mathrm{ml} & \text { LIF } \\ 0,1 \mathrm{mM} & \beta \text {-Mercaptoethanol }\end{aligned}$




\subsubsection{Trypsinieren von ES- und Feeder-Zellen}

Nach Absaugen des Mediums von der Gewebekulturschale wurden die Zellen einmal mit PBS gewaschen und dann ca. 5 min mit Trypsin/EDTA bei $37^{\circ} \mathrm{C}$ bis zur Abrundung (mikroskopische Kontrolle) inkubiert. Die Reaktion wurde durch Zugabe von ES-Medium gestoppt und die Zellsuspension in ein Plastikröhrchen überführt. Die Zellen wurden durch Zentrifugation pelletiert, in ES-Medium resuspendiert und in der gewünschten Dichte auf neue Gewebekulturschalen ausgesät.

\subsubsection{Mitotische Inaktivierung von Fibroblasten}

Konfluente Mausfibroblasten wurden unmittelbar vor Benutzung als Feederzellen durch Behandlung mit dem Zytostatikum Mitomycin C mitotisch inaktiviert. Dazu wurden dem Medium $10 \mu \mathrm{g} / \mathrm{ml}$ Mitomycin C zugesetzt. Nach einer Inkubation über $3 \mathrm{~h}$ bei $37^{\circ} \mathrm{C}$ wurde das Medium abgesaugt. Die Zellen wurden dreimal mit PBS gewaschen, trypsiniert und auf neue Gewebekulturschalen ausgesät.

Nach mindestens 2 h Inkubation, während der sich die Fibroblasten absetzen, konnten ES-Zellen auf dem Feederrasen ausgesät werden.

\subsubsection{Kryokonservierung von ES-Zellen}

Die Zellen wurden mit PBS gewaschen, trypsiniert, in ES-Medium aufgenommen, pelletiert und schließlich in $4^{\circ} \mathrm{C}$ kaltem ES-Medium resuspendiert. Nun wurde tropfenweise unter leichtem Schütteln dieselbe Menge Einfriermedium zugefügt. Je $1 \mathrm{ml}$ Zellsuspension wurde in ein Kryoröhrchen gefüllt, bei $-80^{\circ} \mathrm{C}$ eingefroren und am nächsten Tag in Stickstoff überführt.

$\begin{array}{lll}\text { Einfriermedium (2x): } & 60 \% & \text { DMEM } \\ & 20 \% & \text { FKS } \\ & 20 \% & \text { DMSO }\end{array}$




\subsubsection{Auftauen und Revitalisieren von Zellen}

Nach der Entnahme des Kryoröhrchens aus dem Stickstofftank wurde es etwa 1 min bei RT gehalten und dann im $37^{\circ} \mathrm{C}$-Ethanolbad unter Schwenken aufgetaut, bis nur noch ein kleiner Eiskern vorhanden war. Die Zellsuspension wurde in $5 \mathrm{ml}$ eiskaltes ES-Medium überführt und zentrifugiert. Der Überstand wurde abgesaugt, das Zellpellet in ES-Medium aufgenommen und ausplattiert. Am nächsten Tag erfolgte ein Mediumwechsel, um die für die Zellwand schädlichen DMSO-Reste zu entfernen.

\subsubsection{Vorbereitung von ES-Zellen für die Mikroinjektion}

Als Vorbereitung für die Mikroinjektion der ausgewählten ES-Klone in Blastozysten wurde eine dünn bewachsene $6 \mathrm{~cm}$-Platte einmal mit PBS gewaschen. Nach dem Trypsinieren wurden die Zellen in $5 \mathrm{ml}$ ES-Medium resuspendiert und $15 \mathrm{~min}$ auf der Platte bei $37^{\circ} \mathrm{C}$ ruhig stehen gelassen. In dieser Zeit setzen sich die schwereren Fibroblasten auf den Boden ab. Die leichteren ES-Zellen wurden anschließend mit dem Überstand in ein $15 \mathrm{ml}$-Plastikröhrchen überführt und abzentrifugiert. Das Pellet wurde zum Waschen in $5 \mathrm{ml} 4^{\circ} \mathrm{C}$ kaltem PBS resuspendiert, erneut abzentrifugiert und schließlich in $5 \mathrm{ml} 4^{\circ} \mathrm{C}$ kaltem MEM/HEPES/5\% FKS aufgenommen.

\subsubsection{Präparation von primären embryonalen Fibroblasten}

Eine trächtige Maus (Tag 11-13 p.c.) wurde durch Zervikaldislokation getötet. Das Abdomen wurde eröffnet, der Uterus wurde freipräpariert, entnommen und in einer Petrischale mit PBS gewaschen. Die Embryonen wurden aus Uterus und Amnionhöhle herausgelöst und mit PBS gewaschen. Der Kopf wurde abgetrennt, Herz und Leber wurden entfernt. Die Embryonen wurde zerschnitten und wiederum in PBS gespült. 
Das Embryonengewebe wurde in einem sterilen Erlenmeyerkolben mit $5 \mathrm{ml}$ 0,25\% Trypsin-EDTA und sterilen Glasperlen $\left(\varnothing 4-5 \mathrm{~mm}\right.$ ) $15 \mathrm{~min}$ bei $37^{\circ} \mathrm{C}$ gerührt. Nach Abstoppen der Trypsinierung durch Zugabe von $5 \mathrm{ml}$ Medium wurden die Zellen durch 5 min Zentrifugation bei 500xg pelletiert, in DMEM resuspendiert, auf $6 \mathrm{~cm}$ Gewebekulturschalen ausgesät und kultiviert.

Die weitere Kultivierung (Trypsinieren, Einfrieren, Auftauen) erfolgte wie unter 3.4.1 beschrieben unter Verwendung folgender Medien:

MEF-Medium:

DMEM

$\begin{aligned} 10 \% & \text { FKS } \\ 100 \mathrm{u} / \mathrm{ml} & \text { Penicillin/Streptomycin }\end{aligned}$

$\begin{array}{lll}\text { Einfriermedium (1x): } & 80 \% & \text { MEF-Medium } \\ & 10 \% & \text { FKS } \\ & 10 \% & \text { DMSO }\end{array}$

\subsubsection{Präparation von murinen Hepatozyten}

(modifiziert nach Meredith, 1988)

Zur Isolierung von Hepatozyten der Maus wurde eine Collagenase-unabhängige, lineare in situ Leberperfusion angewandt. Die Desintegration des Lebergewebes beruht bei dieser Methode auf Lösung Calcium-abhängiger Zell-Zell-Kontakte durch Calcium-Depletion mittels EDTA.

Soweit nicht anders angegeben, wurden alle Lösungen auf $37^{\circ} \mathrm{C}$ vortemperiert.

\subsubsection{Lineare in situ Perfusion einer Mausleber und Gewinnung einer Leberzellsuspension}

Die Perfusionsapparatur bestand im Wesentlichen aus einem Oxygenator, in dem der Perfusionspuffer auf $37^{\circ} \mathrm{C}$ temperiert und mit Carbogen $\left(\begin{array}{llll}95 \% & \mathrm{O}_{2} / 5 \% & \mathrm{CO}_{2}\end{array}\right)$ begast wurde. Über eine Peristaltikpumpe zirkulierte der Puffer durch einen 
Kreislauf, aus dem ein Teil, reguliert durch eine Schlauchklemme, mit einer Flussrate von $10 \mathrm{ml} / \mathrm{min}$ zur Leberperfusion abfließen konnte (s. Abb. 6).

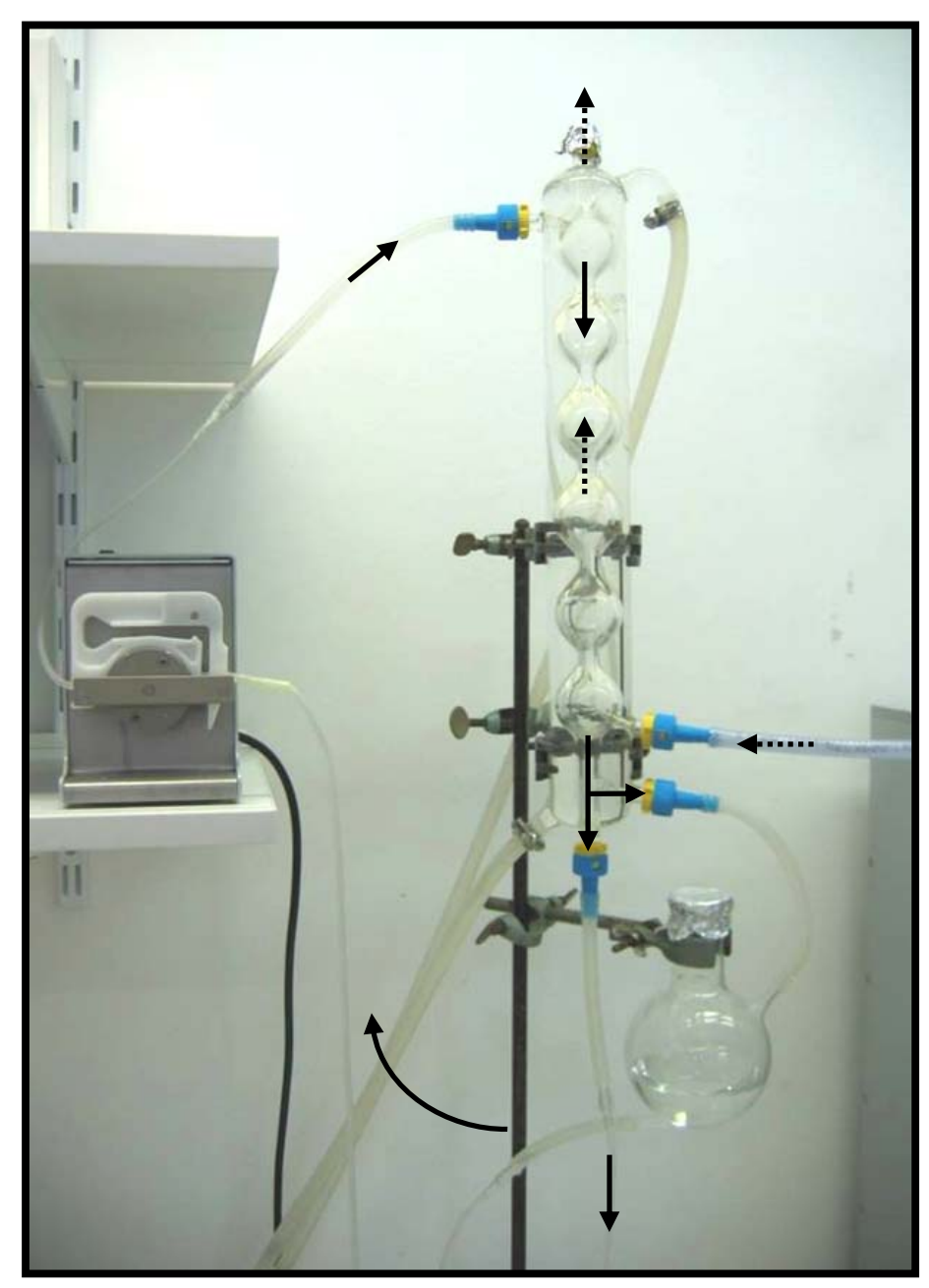

Abb. 6: Perfusionsapparatur. Die Flussrichtung des Perfusionspuffers ist mit durchgehenden Pfeilen, der Gasstrom mit unterbrochenen Pfeilen markiert. Der Puffer wird im Oxygenator begast und auf $37^{\circ} \mathrm{C}$ temperiert, bevor er zur Leberperfusion abfließt. Überschüssiger Puffer wird zurück in den Vorratskolben und erneut durch den Oxygenator geleitet.

Die Maus wurde durch intraperitoneale Injektion von 8,6 $\mu$ Anästhetikum pro $g$ Körpergewicht narkotisiert und nach Einsetzen der Narkose auf dem Präpariertisch fixiert. Das Abdomen wurde mit $70 \%$ igem Ethanol sterilisiert und nach Entfernen der Bauchhaut durch eine Längsinzision entlang der Linea alba bis zum Processus xiphoideus eröffnet. Die Pfortader wurde durch Rechtsverlagerung der Eingeweide freipräpariert. Eine Braunüle wurde vorsichtig in die Pfortader bis 
kurz vor das Leberhilum geschoben. Das Kunststoffteil der Braunüle wurde durch eine zuvor gelegte Ligatur fixiert und, nachdem es durch ausströmendes Blut gefüllt war, an den Pufferkreislauf angeschlossen. Zur Druckentlastung wurde sofort danach die untere Hohlvene eröffnet. Die Leber sollte nun deutlich blutleer gelaufen sein, erkennbar am Verlust der blutroten Farbe. Nach Anschluss der Braunüle und beginnender Perfusion wurde der Thorax durch Längsinzisionen durch das Diaphragma eröffnet. Das Diaphragma wurde vorsichtig von der Leber getrennt, wodurch die Leber frei in der Bauchhöhle zu liegen kam, um ein Abknicken der Leberläppchen zu vermeiden. Die Leber wurde 20 min perfundiert. Nach Abschluss der Perfusion wurde die Leber entnommen und in eine mit Williams E-Medium gefüllte Petrischale überführt. Es erfolgte die vorsichtige Entfernung der Gallenblase. Die Leberkapsel wurde mit einer Pinzette zerrissen, die Zellen wurden mit einem kleinen Spatel aus den Gewebestücken geschabt. Um Bindegewebsreste zu entfernen, wurde die Zellsuspension anschließend durch eine sterile Gaze in in ein steriles 50 ml-Reaktionsgefäß filtriert.

$\begin{array}{lrl}\text { 10x Perfusionspuf- } & 1400 \mathrm{mM} & \mathrm{NaCl} \\ \text { fer-Stammlösung: } & 50 \mathrm{mM} & \mathrm{KCl} \\ 8 \mathrm{mM} & \mathrm{MgCl}_{2} \cdot 6 \mathrm{H}_{2} \mathrm{O} \\ 16 \mathrm{mM} & \mathrm{Na}_{2} \mathrm{HPO}_{4} \cdot 2 \mathrm{H}_{2} \mathrm{O} \\ 4 \mathrm{mM} & \mathrm{KH}_{2} \mathrm{PO}_{4} \\ & \mathrm{pH} 7,4 \\ & & \\ \text { Perfusionpuffer: } & 1 \mathrm{x} & \text { Perfusionspuffer-Stammlösung } \\ & 25 \mathrm{mM} & \text { NaHCO} \\ 2 \mathrm{mM} & \text { EDTA } \\ 15 \mathrm{mM} & \text { D-Glucose } \cdot \mathrm{H}_{2} \mathrm{O} \\ 2 \mathrm{mM} & \text { DL-Lactat } \\ 0,2 \mathrm{mM} & \text { Pyruvat } \\ & \text { sterilfiltriert; } 20 \text { min Begasung mit Carbogen } \\ & \left(95 \% \mathrm{O}_{2} / 5 \% \mathrm{CO}_{2}\right) ; \mathrm{pH} 7,4\end{array}$


Anästhetikum:

$\begin{array}{ll}80 \% & \mathrm{NaCl} 0,9 \% \\ 10 \% & \text { Ketavet } 100 \mathrm{mg} / \mathrm{ml} \\ 10 \% & \text { Rompun } 20 \mathrm{mg} / \mathrm{ml} \\ & \text { sterilfiltriert }\end{array}$

\subsubsection{Abtrennung der vitalen Hepatozyten von nicht-parenchymalen Leberzellen und toten Hepatozyten}

Die Abtrennung der nicht-parenchymalen Leberzellen (Kupffer-Zellen, Ito-Zellen, Endothelzellen) erfolgte durch Zentrifugation für 3 min bei $60 x g$ im AufschwingRotor bei RT.

Das resultierende Zellpellet wurde in $8 \mathrm{ml}$ Williams E-Medium resuspendiert und zur Abtrennung vitaler Hepatozyten von toten Zellen einer PercollDichtegradienten-Zentrifugation unterworfen. Dazu wurde die Zellsuspension mit $16 \mathrm{ml}$ Percoll-Lösung gemischt (Endkonzentration Percoll: 58\%) und bei 1000xg für 5 min bei RT zentrifugiert.

Tote Hepatozyten, Zelltrümmer und Nicht-Parenchymzellen flottierten auf der Oberfläche des Gradienten und wurden zusammen mit dem überschüssigen Puffer abgesaugt. Das Hepatozyten-Pellet wurde vorsichtig in $10 \mathrm{ml}$ HepatozytenMedium resuspendiert und die Zellzahl aus einem Aliquot mittels einer NeubauerZählkammer bestimmt.

\begin{tabular}{|c|c|c|}
\hline Percoll-Lösung: & $\begin{array}{r}13,9 \mathrm{ml} \\
2,1 \mathrm{ml}\end{array}$ & $\begin{array}{l}\text { Percoll } \\
\text { 1x Perfusionspuffer-Stammlösung (sterilfiltriert) }\end{array}$ \\
\hline Hepatozyten- & & Williams E-Medium \\
\hline Medium: & $10 \%$ & FKS \\
\hline & $100 \mathrm{u} / \mathrm{ml}$ & Penicillin/Streptomycin \\
\hline & $1 \%$ & Gentamycin \\
\hline & $1 \mu \mathrm{M}$ & Insulin \\
\hline & $1 \mu \mathrm{M}$ & Dexamethason \\
\hline
\end{tabular}




\subsubsection{Aussaat und Kultur von Hepatozyten}

Die Hepatozyten wurden in einer Dichte von $7 \times 10^{4}$ Zellen/ $/ \mathrm{cm}^{2}$ auf $24 \mathrm{~h}$ zuvor collagenisierte Gewebekulturschalen ausplattiert. Nach $4 \mathrm{~h}$ hatten die Zellen an die Oberfläche der Kulturschale adhäriert und sich weitgehend abgeflacht. Nach dieser Zeitspanne wurde ein Mediumwechsel vorgenommen, bei dem die toten Zellen entfernt wurden.

\subsubsection{Präparation von murinen Mesangialzellen}

(modifiziert nach Krakower et al., 1951)

Die Glomerula der Nierenrinde, welche die Mesangialzellen enthalten, weisen einen speziesspezifischen Durchmesser auf, der bei der Maus zwischen 20 und $45 \mu \mathrm{m}$ liegt. Durch ein entsprechendes Siebverfahren können sie von Gewebetrümmern und Einzelzellen gezielt getrennt werden. Ein anschließender Collagenase-Verdau entfernt die Kapsel und ermöglicht ein Auswachsen der Mesangialzellen in Kultur. Eine Kontamination mit Fibroblasten wurde durch Verwendung eines speziellen Mediums ausgeschlossen. Es enthielt D-Val anstelle von L-Val, welches von Mesangialzellen, nicht jedoch von Fibroblasten verwertet werden kann (Gilbert und Migeon, 1975).

Nach Tötung von zwei Mäusen durch Zervikaldislokation wurden die Nieren präpariert und gegebenenfalls kurzfristig in $4^{\circ} \mathrm{C}$ kaltem PBS gelagert. Nach Entfernung der Kapseln wurden die Nieren in kleine Stücke geschnitten, auf ein mit PBS befeuchtetes Sieb mit einer Porengröße von $45 \mu \mathrm{m}$ gegeben und mit einem sterilen Messkolben zerrieben. Anschließend wurde das Sieb, welches auf einem sterilen Becherglas stand, mit Hilfe einer 50 ml-Perfusionsspritze mit einer Kanüle der Größe 16 mit PBS mit hohem Druck abgespritzt, bis eine heller Belag erschien. Durch diesen Schritt wurden die Glomerula von größeren Gewebebestandteilen getrennt. Das Filtrat wurde nun auf ein $20 \mu \mathrm{m}$-Sieb gegeben, welches die Glomerula wiederum von kleineren Bestandteilen trennte. Durch anschließendes Umdrehen des Siebes und Abspritzen mit PBS wurden die Glomerula in ein steriles Becherglas gespült. Nach Pelletieren der Glomerula durch 10 min Zentrifugation bei $500 x g$ und $4^{\circ} \mathrm{C}$ und einem Waschschritt mit PBS 
erfolgte ein Verdau des Pellets mit einer Collagenase-Lösung über 20 min bei $37^{\circ} \mathrm{C}$ im Schüttelwasserbad. Es folgte eine erneute Zentrifugation sowie ein Waschschritt mit M1-Medium, bevor das Pellet in M2-Medium resuspendiert und in eine kleinen Zellkulturflasche (T25) gegeben wurde.

Nach mindestens fünf Tagen Ruhe erfolgte die erste mikroskopische Kontrolle. Die weitere Kultivierung (Trypsinieren, Einfrieren, Auftauen) entspricht den Bedingungen zur Kultur von Fibroblasten.

M1-Medium:

DMEM (mit D-Val statt L-Val)

$$
\begin{aligned}
1 \mathrm{mM} & \text { Na-Pyruvat } \\
2 \mathrm{mM} & \text { L-Glutamin } \\
100 \mathrm{u} / \mathrm{ml} & \text { Penicillin/Streptomycin }
\end{aligned}
$$

M2-Medium:

M1-Medium

$20 \% \quad$ FKS

Collagenase-

M1-Medium

Lösung:

$600 \mathrm{u} / \mathrm{ml}$

Collagenase

sterilfiltriert

\subsubsection{Präparation von Knochenmarkszellen}

Nach Tötung der Maus durch Zervikaldislokation wurden die Knochen der Hinterextremitäten präpariert. Mit Hilfe einer Spritze mit Kanüle wurden die Knochenmarkszellen mit kaltem PBS aus Femur und Tibia herausgespült. Anschließend wurden die Zellen mit einer $10 \mathrm{ml}$-Pipette auf Eis resuspendiert, durch ein $70 \mu \mathrm{m}$-Plastiknetz filtriert und bei Raumtemperatur für 10 min bei 300xg abzentrifugiert. Zur Lyse der Erythrozyten wurde das Pellet in Erythrozyten-LysePuffer resuspendiert, 5 min bei RT inkubiert und zweimal mit PBS gewaschen. Schließlich wurde mit einer Neubauer-Zählkammer die Zellzahl bestimmt. 


$\begin{array}{lrl}\text { Erythrozyten-Lyse- } & 150 \mathrm{mM} & \mathrm{NH}_{4} \mathrm{Cl} \\ \text { Puffer: } & 10 \mathrm{mM} & \mathrm{KHCO}_{3} \\ & 0,1 \mathrm{mM} & \mathrm{EDTA} \\ & & \mathrm{pH} 7,3\end{array}$

\subsubsection{Präparation von Milzzellen}

Nach Tötung der Maus durch Zervikaldislokation wurde die Milz entnommen und zerkleinert. Zur Freisetzung der Zellen wurden die Gewebestücke durch ein 0,4 mm-Stahlnetz gedrückt. Nach Resuspension der Zellen in kaltem PBS erfolgten Filtration, Lyse der Erythrozyten, Waschen und Zellzahlbestimmung wie unter 3.4.5 beschrieben. Die Zellen wurden zur Kultivierung in Splenozyten-Medium aufgenommen und ü.N. bei $37^{\circ} \mathrm{C}$ und $10 \% \mathrm{CO}_{2}$ inkubiert.

Splenozyten-

DMEM

Medium:

$20 \% \quad$ FKS

$10 \% \quad$ Kulturüberstand von IL-3- und G-CSF-produzierenden WEHI-3B-Zellen

$2 \mathrm{mM} \quad$ L-Glutamin

$100 \mathrm{u} / \mathrm{ml} \quad$ Penicillin/Streptomycin

\subsubsection{Fucose-Behandlung verschiedener Zelltypen}

Fibroblasten, Hepatozyten, Mesangialzellen und Milzzellen wurden mit Fucose behandelt, um die Möglichkeit einer Wiederherstellung der Fucosylierung zu charakterisieren. Durch Zugabe von filtrierten Stammlösungen zum jeweiligen Kulturmedium wurde die Fucose je nach Versuch in Endkonzentrationen zwischen 0,1 und $10 \mathrm{mM}$ eingesetzt. Die Inkubationszeit variierte, betrug jedoch mindestens $18 \mathrm{~h}$. 


\subsection{Proteinbiochemische Methoden}

Bestimmung der GDP- $\left[{ }^{14} \mathrm{C}\right]$ Fucose- und UDP- $\left[{ }^{3} \mathrm{H}\right]$ Galactose-
Import-Aktivität in Golgi-angereicherten Fraktionen aus
Lebergewebe

\subsubsection{Aufschluss von Lebergewebe}

Soweit nicht anders angegeben, wurden alle Arbeitsschritte auf Eis durchgeführt und alle Lösungen auf $4^{\circ} \mathrm{C}$ gekühlt.

Nach Tötung einer Maus durch Zervikaldislokation wurde die Leber herauspräpariert und die Gallenblase vorsichtig entfernt. Das Organ wurde zerkleinert und in 3,5 ml Puffer A (0,25 M Sucrose) in das Gefäß eines PotterElvehjem-Homogenisators gegeben. Mit Hilfe eines Kolbens, der in einen Rührmotor eingespannt war, wurde für $20 \mathrm{~s}$ bei 1.500 Umdrehungen/min das Gewebe homogenisiert und die Zellen aufgeschlossen. Das Homogenat wurde bei $600 x g$ für $10 \mathrm{~min}$ bei $4^{\circ} \mathrm{C}$ zentrifugiert, um die Zellkerne und nichtaufgeschlossene Zellen von dem ersten postnukleären Überstand (PNS1) zu trennen. Das verbleibende Pellet wurde in 3,0 ml Puffer A resuspendiert und wie zuvor homogenisiert, um nach erneuter Zentrifugation einen zweiten Überstand (PNS2) zu erhalten.

\subsubsection{Präparation Golgi-angereicherter Vesikel aus Lebergewebe (modifiziert nach Leelavathi et al., 1970)}

Die beiden nach 3.5.1.1 resultierenden postnukleären Überstände wurden gepoolt und vorsichtig zur Dichtegradienten-Zentrifugation auf $5 \mathrm{ml}$ eines Sucrosekissens aus 1,3 M Sucrose in einem SW-40-Polyallomer-Röhrchen gegeben. Es folgte eine Zentrifugation bei $105.000 x g$ für $60 \mathrm{~min}$ bei $4^{\circ} \mathrm{C}$ in einem SW-40-Rotor. Die Golgi-angereicherten Vesikel sammelten sich an der 0,25/1,3 M-Sucrose- 
Interphase und wurden nach Abnehmen der oberen Fettschicht und der 0,25 M Sucrose-Phase mit einer Pasteurpipette vorsichtig als Membranfeld geerntet.

\subsubsection{Bestimmung der GDP- $\left[{ }^{14} \mathrm{C}\right]$ Fucose- und UDP- $\left[{ }^{3} \mathrm{H}\right]$ Galactose- Import-Aktivität}

(modifiziert nach Perez und Hirschberg, 1987)

Der Proteingehalt des MF wurde mit Hilfe des DC Protein Assay Kits bestimmt. Der Reaktionsansatz setzte sich folgendermaßen zusammen:

$\begin{aligned} 400 \mu \mathrm{g} & \text { Protein bzw. Membranfeld } \\ 66 \% & \text { Puffer B } \\ 3 \mu \mathrm{M} & \text { GDP- }\left[{ }^{14} \mathrm{C}\right] \text { Fucose oder } \\ 0,5 \mu \mathrm{M} & \text { UDP-[ }\left[{ }^{3} \mathrm{H}\right] \text { Galactose }\end{aligned}$

Das Gesamtvolumen variierte zwischen 100 und $130 \mu \mathrm{l}$ in Abhängigkeit von der Proteinkonzentration. Es wurden Doppelbestimmungen durchgeführt. Der mit jeweils einem der Zuckernukleotide supplementierte Puffer B wurde in 1,5 mlPolyallomer-Reaktionsgefäßen vorgelegt und auf $37^{\circ} \mathrm{C}$ temperiert. Nach Zugabe des Membranfelds wurden die Ansätze 10 min bei $37^{\circ} \mathrm{C}$ inkubiert. Zum Abstoppen der Reaktion wurden $0,8 \mathrm{ml}$ eiskalter Puffer $\mathrm{B}$ ohne radioaktiv markierte Zuckernukleotide zugegeben und sofort zum Pelletieren der Vesikel bei 100.000xg für $30 \mathrm{~min}$ bei $4^{\circ} \mathrm{C}$ im TLA-45-Rotor zentrifugiert. Um den Background unspezifisch an Vesikel gebundener, radioaktiv markierter Zuckernukleotide zu bestimmen, wurden $\mathrm{t}_{0}$-Werte mitgeführt, die direkt vor der Zentrifugation pipettiert wurden.

Das Pellet wurde dreimal mit Puffer B gewaschen und nach der letzten Zentrifugation in $0,5 \mathrm{ml}$ Lysispuffer durch viermal Ultraschall für $30 \mathrm{~s}$ resuspendiert und solubilisiert. Die freigesetzte Radioaktivität des Pellets stellt die insgesamt importierte Menge an Zuckernukleotid dar. Durch eine anschließende Säurefällung mit $50 \mu \mathrm{l}$ Säurelösung konnte die importierte Zuckernukleotidmenge in zwei Komponenten differenziert werden: Eine Säure-fällbar Komponente, die den Anteil an auf Makromoleküle transferierte Zuckernukleotide enthielt, und den Importanteil 
löslicher GDP- $\left[{ }^{14} \mathrm{C}\right]$ Fucose bzw. UDP- $\left[{ }^{3} \mathrm{H}\right]$ Galactose im Golgi, die durch die Säurefällung nicht präzipitierbar war.

Der lösliche Anteil wurde nach der Fällung ü.N. bei $4^{\circ} \mathrm{C}$ und 20 min Zentrifugation bei $16.000 x g$ als Überstand abgenommen und im Flüssigkeitsszintillationszähler gemessen. Das Pellet aus fällbarem Material wurde dreimal mit $500 \mu \mathrm{l}$ Säurelösung gewaschen, nach dem letzten Zentrifugationsschritt in $0,2 \mathrm{ml} \mathrm{2,5} \mathrm{N}$ $\mathrm{NaOH}$ aufgenommen und für 10 min bei $95^{\circ} \mathrm{C}$ resuspendiert. Nach dem Abkühlen der Proben bei RT wurden sie mit $0,6 \mathrm{ml} \mathrm{H}_{2} \mathrm{O}$ und 0,2 ml Eisessig neutralisiert und zur Bestimmung der importierten Radioaktivität quantitativ in Szintillationsflüssigkeit überführt und vermessen.

Puffer B:

$\begin{array}{rl}10 \mathrm{mM} & \text { Tris/ } \mathrm{HCl} \mathrm{pH} \mathrm{7,5} \\ 150 \mathrm{mM} & \mathrm{KCl} \\ 1 \mathrm{mM} & \mathrm{MgCl}_{2}\end{array}$

Säurelösung:

$\begin{array}{rl}20 \% & \text { TCA } \\ 1 \% & \text { Phosphowolframsäure } \\ 0,5 \mathrm{~N} & \mathrm{HCl}\end{array}$

\section{5 .2} Bestimmung der Galactosyltransferase-Aktivität in
Leberhomogenaten, postnukleären Überständen und Golgi-
angereicherten Vesikeln (modifiziert nach Brändli et al., 1988)

Um die Anreicherung von Golgi-Vesikeln aus Leberhomogenat zu bestimmen, wurde die Galactosytransferase-Aktivität im nach 3.5.1.1 und 3.5.1.2 präparierten Homogenat, PNS und Membranfeld bestimmt. Dazu wurden Aliquots der einzelnen Anreicherungsschritte mit Puffer $C$ 1:20 verdünnt und $20 \mu \mathrm{l}$ dieser Verdünnungen mit $30 \mu \mathrm{l}$ Substratmix für eine Stunde bei $37^{\circ} \mathrm{C}$ inkubiert. Die Reaktion wurde durch Zugabe von $0,5 \mathrm{ml}$ einer 10\%igen TCA-Lösung gestoppt und ü.N. bei $4^{\circ} \mathrm{C}$ gefällt.

TCA-fällbares Material der Proben wurde durch 20 min Zentrifugation bei $16.000 \times \mathrm{xg}$ und $4^{\circ} \mathrm{C}$ pelletiert und dreimal mit eiskalter 5\%iger TCA gewaschen. 
Nach dem letzten Waschschritt wurde das Pellet in 0,2 ml 2,5 N NaOH aufgenommen und für $10 \mathrm{~min}$ bei $95^{\circ} \mathrm{C}$ resuspendiert. Anschließend wurden die Proben mit $0,6 \mathrm{ml} \mathrm{H}_{2} \mathrm{O}$ und $0,2 \mathrm{ml}$ Eisessig neutralisiert und in Szintillationsflüssigkeit überführt, um die auf das Ovalbumin transferierte $\left[{ }^{3} \mathrm{H}\right]$ Galactose in den Proben zu bestimmen.

Die Galactosyltransferase-Aktivität in den Proben wurde um die eingesetzte Proteinmenge und die spezifische Radioaktivität der eingesetzten $\left[{ }^{3} \mathrm{H}\right]$ Galactose normalisiert, um die spezifische Aktivität zu berechnen.

$\begin{array}{lrl}\text { Puffer C: } & 10 \mathrm{mM} & \text { Tris/HCl pH 7,4 } \\ 0,25 \mathrm{M} & \text { Sucrose } \\ 0,5 \% & \text { Triton X-100 } \\ 1 \mathrm{mM} & \text { EDTA } \\ & & \\ \text { Substratmix: } & 83 \mathrm{mM} & \text { Tris/ } \mathrm{HCl} \mathrm{pH} \mathrm{7,4} \\ 0,83 \% & \text { Triton X-100 } \\ 33 \mathrm{mM} & \text { MnCl }_{2} \\ 6 \mu \mathrm{M} & \left.\text { UDP-[ }{ }^{3} \mathrm{H}\right] \text { Galactose } \\ 33 \mathrm{mM} & \text { ATP } \\ 12 \mathrm{mg} / \mathrm{ml} & \text { Ovalbumin }\end{array}$

3.5.3 Bestimmung der Protein-Fucosylierung durch Lens culinarisLektin-Affinitätschromatographie von metabolisch markierten Glykopeptiden

\subsubsection{Metabolische Markierung mit 2-[ $\left.{ }^{3} \mathrm{H}\right]$ Mannose}

Eine konfluente $6 \mathrm{~cm}$-Kulturschale der zu markierende Zellen wurde dreimal mit PBS gewaschen und in Abhängigkeit des Zelltyps für 6-12 $\mathrm{h}$ mit Markierungsmedium inkubiert. Soweit nicht anders angegeben wurden alle folgenden Schritte bei $4^{\circ} \mathrm{C}$ durchgeführt und alle Lösungen auf $4^{\circ} \mathrm{C}$ gekühlt. Die Zellen wurden fünfmal mit Hanks-Puffer gewaschen, in zweimal $1 \mathrm{ml}$ Methanol/10 
mM Tris/HCl, 1 mM EDTA, pH 8,0 im Verhältnis 1:1 abgeschabt und in ein 15 mlReaktionsgefäß überführt.

Markierungs-

medium:

Hanks-Puffer:

$$
\begin{array}{rl}
137 \mathrm{mM} & \mathrm{NaCl} \\
5,4 \mathrm{mM} & \mathrm{KCl} \\
0,4 \mathrm{mM} & \mathrm{MgSO}_{4} \cdot 7 \mathrm{H}_{2} \mathrm{O} \\
0,5 \mathrm{mM} & \mathrm{MgCl}_{2} \cdot 6 \mathrm{H}_{2} \mathrm{O} \\
0,35 \mathrm{mM} & \mathrm{Na}_{2} \mathrm{HPO}_{4} \cdot 2 \mathrm{H}_{2} \mathrm{O} \\
0,44 \mathrm{mM} & \mathrm{KH}_{2} \mathrm{PO}_{4} \\
2 \mathrm{mM} & \text { HEPES pH } 7,4
\end{array}
$$

\subsubsection{Präparation der Glykoproteine}

Die Suspension wurde $3 \mathrm{~min}$ bei $95^{\circ} \mathrm{C}$ im Wasserbad gekocht, auf Eis abgekühlt und bei $3.200 x g$ für 10 min bei $4^{\circ} \mathrm{C}$ zentrifugiert. Das Pellet wurde zur Extraktion der Lipidanteile in $2 \mathrm{ml}$ Chloroform/Methanol im Verhältnis 3:2 durch Ultraschall und Vortex gelöst und erneut zentrifugiert. Dies wurde zweimal wiederholt und anschließend dreimal mit Chloroform/Methanol $/ \mathrm{H}_{2} \mathrm{O}$ im Verhältnis 10:10:3 durchgeführt. Nach einer weiteren Wiederholung mit $1 \mathrm{ml}$ Methanol wurde das Pellet bei RT fast vollständig getrocknet. 


\subsubsection{Pronase-Behandlung der Glykoproteine}

Zum vollständigen Verdau des Proteinanteils der nach 3.5.3.2 angereicherten Glykoproteine wurden diese mit Pronase behandelt, einer Mischung von Endound Exoproteasen aus Streptomyces griseus.

Das Pellet wurde in 0,5 ml TBS mit Hilfe von Ultraschall, Vortex und Erwärmung auf $60^{\circ} \mathrm{C}$ gelöst. Nach Zugabe der Pronase in einer Endkonzentration von 400 $\mu \mathrm{g} / \mathrm{ml}$ erfolgte eine Inkubation ü.N. bei $50^{\circ} \mathrm{C}$ im Schüttelinkubator. Anschließend wurde die Pronase durch 5 min Erhitzung auf $95^{\circ} \mathrm{C}$ inaktiviert. Nach 10 min Zentrifugation bei 16.000xg wurde der Überstand mit den gelösten Glykopeptiden abgenommen.

TBS:

$\begin{array}{rl}10 \mathrm{mM} & \text { Tris/HCl pH 8,0 } \\ 150 \mathrm{mM} & \mathrm{NaCl} \\ 1 \mathrm{mM} & \mathrm{MgCl}_{2} \\ 1 \mathrm{mM} & \mathrm{CaCl}_{2}\end{array}$

\subsubsection{Lens culinaris-Lektin-Affinitätschromatographie}

Mit Hilfe von Agarose-gekoppeltem Lens culinaris-Lektin, welches spezifisch $\alpha-$ 1,6-verknüpfte Core-Fucose in bi- und triantennären N-Glykanen bindet, wurden die entsprechend fucosylierten Glykopeptide von den übrigen Glykanen getrennt. $1 \mathrm{ml}$ der Lektin-Agarose wurde in einer 2,5 ml Chromatographie-Säule mit TBS gewaschen, bevor die nach 3.5.3.3 präparierten Glykopeptide zugegeben und die Säule zur Bindung $1 \mathrm{~h}$ bei $4^{\circ} \mathrm{C}$ auf dem Drehrad inkubiert wurde. Ungebundenes Material wurde mit $20 \mathrm{ml}$ TBS ausgewaschen. Die Elution der spezifisch gebundenen Glykopeptide erfolgte durch Zugabe von $1 \mathrm{ml}$ Haptens Methyl-a-Dmannopyranosid (100 mM). Danach wurde die Säule wieder mit $20 \mathrm{ml}$ TBS

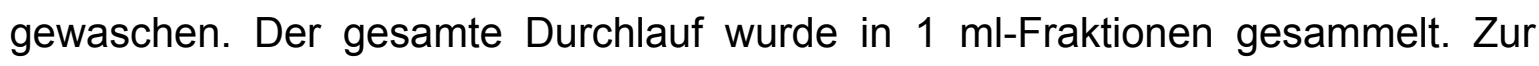
Bestimmung der Radioaktivität in den Fraktionen wurden jeweils $100 \mu \mathrm{l}$ in Szintillationsflüssigkeit überführt und gemessen. 


\title{
3.6 Histologische, histochemische und zytochemische Methoden
}

3.6.1

\author{
Anfertigung, Färbung und Auswertung histologischer Präparate \\ aus Organen der Maus
}

\subsubsection{Organentnahme und Fixierung}

Nach Tötung der Maus durch Zervikaldislokation wurden die zu untersuchenden Organe präpariert, in Biopsiekassetten gelegt und zur Fixierung in $4 \%$ Formaldeyd/0,5 M PBS überführt. Nach $24 \mathrm{~h}$ wurde die Fixierung durch Überführung der Proben in 70\% Ethanol abgeschlossen, worin sie bis zur weiteren Bearbeitung gelagert wurden.

\subsubsection{Entwässerung und Einbettung in Paraffin}

Vor der Einbettung in Paraffin mussten die fixierten Organe durch eine aufsteigende Alkoholreihe entwässert werden. Zu diesem Zweck wurden sie folgendermaßen behandelt:

$\begin{array}{ll}\text { 96\% Ethanol } & 30 \mathrm{~min}(2 \mathrm{x}) \\ 100 \% \text { Ethanol } & 45 \mathrm{~min}(2 \mathrm{x}) \\ \text { Xylol } & 45 \mathrm{~min} \\ \text { Paraffin ohne Vakuum } & 45 \mathrm{~min} \\ \text { Paraffin mit Vakuum } & 45 \mathrm{~min} \\ \text { Paraffin ohne Vakuum } & 45 \mathrm{~min}\end{array}$

Im Paraffinbad wurden die Proben einem Vakuum ausgesetzt, um ein vollständiges Eindringen des Paraffins zu ermöglichen. 
Anschließend wurden die Organe an einer Paraffinausgießstation in Gussformen in Paraffin eingeschlossen und nach Erkalten auf einer Kühlplatte als Block aus der Form herausgebrochen.

\subsubsection{Schneiden der Präparate}

Mit Hilfe eines Mikrotoms wurden von den gekühlten Paraffinblöcken $3 \mu \mathrm{m}$ Sektionen geschnitten, die nach ihrer Glättung auf einem $38^{\circ} \mathrm{C}$-Wasserbad schwimmend auf Superfrost-Objektträger aufgezogen und ü.N. im $37^{\circ} \mathrm{C}$ Wärmeschrank getrocknet wurden.

\subsubsection{Hämatoxylin-Eosin-Färbung}

Die Hämatoxylin-Eosin-Färbung (HE-Färbung) ist eine gebräuchliche Übersichtsfärbung mit wasserlöslichen Farbstoffen. Zellkerne werden durch das Hämatoxylin blau angefärbt, während das Eosin in Bindegewebe und Muskulatur zu einer intensiv roten Färbung führt. Die Eosin-Färbung erfolgt, im Gegensatz zur Hämatoxylin-Färbung, in regressiver Weise, d.h. die Intensität der Färbung wird nicht durch die Verweildauer der Objekte in der Färbelösung selbst, sondern durch die in den anschließenden, entfärbenden Bädern bestimmt. Das Färbeprotokoll gestaltet sich folgendermaßen:

$\begin{array}{lll}\text { Xylol } & 10 \mathrm{~min}(2 \mathrm{x}) & \begin{array}{l}\text { Deparaffinisierung } \\ \text { absteigende Alkoholreihe zur } \\ 100 \% \text { Ethanol }\end{array} \\ 96 \% \text { Ethanol } & 4 \mathrm{~min} & \text { Wässerung der Objekte } \\ 70 \% \text { Ethanol } & 3 \mathrm{~min} & \\ \mathrm{H}_{2} \mathrm{O} & 2 \mathrm{~min} & \\ \mathrm{Hämalaun} & 1 \mathrm{~min} & \\ \mathrm{H}_{2} \mathrm{O} & \text { kurz spülen } \\ \text { Leitungswasser } & 5 \mathrm{~min} \text { fließend wässern } \\ \mathrm{H}_{2} \mathrm{O} & \text { kurz spülen } \\ \text { Eosin } & 40 \mathrm{~s}\end{array}$




$\begin{array}{lll}\mathrm{H}_{2} \mathrm{O} & \text { kurz spülen } & \\ 70 \% \text { Ethanol } & \text { sehr kurz } & \text { aufsteigende Alkoholreihe } \\ 96 \% \text { Ethanol } & \text { sehr kurz } & \text { zur Entwässerung der } \\ 100 \% \text { Ethanol } & 30 \mathrm{~s} & \text { Objekte } \\ 100 \% \text { Ethanol } & 3 \mathrm{~min} & \\ \text { Xylol } & 5 \mathrm{~min}(2 \mathrm{x}) & \end{array}$

Jeweils zehn Objektträger wurden zusammen mit Hilfe eines Färberahmens in die Färbekästen mit den entsprechenden Bädern eingetaucht. Nach dem letzten Xylol-Bad wurden die Objekte mit Eukitt und Deckgläsern eingebettet.

Eosin:

$$
\begin{aligned}
1 \% \mathrm{w} / \mathrm{v} & \text { Eosin } \mathrm{B} \\
0,2 \% \mathrm{v} / \mathrm{v} & \text { Eisessig }
\end{aligned}
$$

\subsubsection{Kombinierte Elastica- und Trichrom-Färbung nach Masson- Goldner}

Diese Färbemethode wurde für die Darstellung elastischer Fasern in der Lunge angewandt (in Zusammenarbeit mit der Abteilung für Zelluläre und Molekulare Pathologie, DKFZ, Heidelberg, Prof. Dr. H. J. Gröne). Zellkerne werden dunkelblau, Zytoplasma rot, Bindegewebe grün, Erythrozyten hellrot und elastische Fasern violett angefärbt. Vorangehende Deparaffinisierung und anschließendes Entwässern sowie die Einbettung erfolgten gemäß 3.6.1.4. Die Färbung wurde nach folgendem Protokoll durchgeführt:

Deparaffinisierung

Resorcin-Fuchsin

$15 \min$

Leitungswasser

kurz spülen

$2 \% \mathrm{HCl} / 80 \%$ Alkohol

einige min (je nach Intensität)

Leitungswasser

5 min fließend wässern

Eisenhämatoxylin

1-2 $\min$

Leitungswasser

5 min fließend wässern

$\mathrm{H}_{2} \mathrm{O}$

kurz spülen 


$\begin{array}{ll}\begin{array}{l}\text { Ponceau S } \\ 1 \% \text { Essigsäure }\end{array} & 5 \text { min } \\ \text { Phosphormolybdän- } & 10-15 \mathrm{~s} \\ \text { säure-Goldorange } & \\ 1 \% \text { Essigsäure } & \text { kurz spülen } \\ \text { Lichtgrün } & 10-15 \text { s } \\ \mathrm{H}_{2} \mathrm{O} & \text { kurz spülen } \\ \text { Entwässerung } & \end{array}$

Ponceau S/ $\quad 0,1 \% \mathrm{w} / \mathrm{v} \quad$ Säurefuchsin

Säurefuchsin: $\quad 0,2 \% \mathrm{w} / \mathrm{v} \quad$ Ponceau S

$\begin{aligned} 0,01 \% & \text { Azophloxin } \\ 0,6 \% \mathrm{v} / \mathrm{v} & \text { Eisessig }\end{aligned}$

Phosphormolyb- $\quad 2 \% \mathrm{w} / \mathrm{v} \quad$ Phosphormolybdänsäure

dänsäure- $\quad 2 \% \mathrm{w} / \mathrm{v} \quad$ Orange $\mathrm{G}$

Goldorange:

Lichtgrün: $\quad 0,5 \% \mathrm{w} / \mathrm{v} \quad$ Lichtgrün

$0,2 \% \mathrm{v} / \mathrm{v} \quad$ Eisessig

\subsubsection{Morphometrische Analyse des Lungengewebes}

Zur Ermittlung der Fläche von Lungenalveolen wurden jeweils drei repräsentative Ausschnitte aus Präparaten von drei Tieren pro Genotyp ausgewertet. Nach der Erfassung eines mikroskopischen Bildes von dem entsprechenden Ausschnitt (200fache Vergrößerung) wurde mit Hilfe der Leica QWin-Software die Fläche der Alveoli ausgemessen. Insgesamt wurden 150 Alveoli jedes Genotyps, d.h. 50 pro Lunge, vermessen. 


\subsubsection{Zytochemische Färbung fucosylierter Zellbestandteile in MEF mit Aleuria aurantia-Lektin}

Um die Fucosylierung in MEF qualitativ darzustellen, wurden diese nach ihrer Fixierung mit Biotin-gekoppeltem Aleuria aurantia-Lektin ( $A A L)$ behandelt, welches spezifisch an N-Glykane mit $\alpha-1,2-, \alpha-1,3-$ oder $\alpha-1,6$-verknüpfter Fucose bindet. Darauf folgte eine indirekte Färbung durch Behandlung mit an alkalische Phosphatase (AP) gekoppeltem Streptavidin, welches an das Biotin bindet, sowie mit einem Färbesubstrat für die AP.

Alle Schritte wurden bei Raumtemperatur durchgeführt. Die Zellen, in 24wellPlatten auf gelatinisierten Deckgläschen kultiviert, wurden dreimal mit PBS gewaschen und zur Fixierung für 3 min mit Methanol/Aceton 1:1 überschichtet und vorsichtig geschwenkt. Nach dem Absaugen der Fixierungslösung wurden die Zellen für 10 min an der Luft getrocknet und im Anschluss dreimal mit PBS gewaschen. Unspezifische Bindungsstellen wurden durch Inkubation der Zellen mit filtriertem (0,2 $\mu \mathrm{m}$-Filter) PBS/1\% BSA für 45 min unter leichtem Schwenken auf einer Wippe blockiert. Die Markierung der Zellen erfolgte durch eine 30minütige Inkubation mit $4 \mu \mathrm{g} / \mathrm{ml}$ biotinyliertem $\mathrm{AAL}$ in PBS/1\% BSA. Im Anschluss an die Markierung wurden die Zellen viermal für 2 min mit PBS gewaschen, um nicht gebundenes Lektin zu entfernen.

Zum Nachweis des Lektins wurden die Zellen für $30 \mathrm{~min}$ mit $2 \mu \mathrm{g} / \mathrm{ml} \mathrm{AP}$ gekoppeltem Streptavidin in PBS/1\% BSA inkubiert. Zum Farbnachweis markierter Zellen wurden die Ansätze wiederum viermal für 2 min mit PBS sowie dreimal für 2 min mit TBS gewaschen, dann $10 \mathrm{~min}$ in AP-Puffer äquilibriert und unter mikroskopischer Kontrolle je nach Farbentwicklung für 5-10 min mit der Entwicklungslösung inkubiert. Die Reaktion wurde durch mehrmaliges Waschen mit PBS abgestoppt. Durch die Umsetzung des Nachweissubstrats bilden sich violett-bräunliche Präzipitate an AAL-markierten Strukturen.

Zur Konservierung wurden die Deckgläschen nach dem Abstoppen der Reaktion mehrere Male in $\mathrm{H}_{2} \mathrm{O}$ und einmal in $100 \%$ Ethanol getaucht und nach dem Trocknen auf Objektträgern mit Dako eingebettet. 
PBS:

$10 \mathrm{mM} \quad \mathrm{Na}_{2} \mathrm{HPO}_{4} \mathrm{pH} 7,4$

$150 \mathrm{mM} \quad \mathrm{NaCl}$

TBS:

$20 \mathrm{mM} \quad$ Tris/ $\mathrm{HCl} \mathrm{pH} \mathrm{7,4}$

$150 \mathrm{mM} \quad \mathrm{NaCl}$

AP-Puffer:

$100 \mathrm{mM} \quad$ Tris/ $\mathrm{HCl} \mathrm{pH} \mathrm{9,5}$

$100 \mathrm{mM} \quad \mathrm{NaCl}$

$5 \mathrm{mM} \quad \mathrm{MgCl}_{2}$

Entwicklungs-

AP-Puffer

lösung:

$0,4 \mathrm{mM}$

p-Nitrotetrazoliumblauchlorid (NBT)

0,4 mM 5-Brom-4-chlor-3-indolylphosphat-p-toluidinsalz $(\mathrm{BCIP})$

$2 \mathrm{mM}$ Levamisol (zur Reduktion endogener APAktivität)

\subsubsection{Fluoreszenzfärbung histologischer Präparate mit Lektinen}

Für die Anfärbung von Zuckerstrukturen in histologischen Präparaten wurden diese zunächst deparaffinisiert und dann mit Lektinen behandelt. Das Maackia amurensis-Lektin I (MAL I), welches an Glykokonjugate mit Gal- $\beta-1,3-L a c N A c-$ Strukturen bindet, wurde als Kontroll-Lektin verwendet und war direkt an das Fluorochrom Fluorescein (FITC) gekoppelt. Die übrigen verwendeten Lektine wie das Aleuria aurantia-Lektin (AAL, $\alpha-1,2-, \alpha-1,3-$ oder $\alpha-1,6$-verknüpfte Fucose), das Lotus tetragonolobus-Agglutinin (LTA, a-verknüpfte Fucose) und das Lens culinaris-Agglutinin (LCA, a-1,6-verknüpfte Core-Fucose in bi- und triantennären $\mathrm{N}$-Glykanen) waren biotinyliert und wurden mit Streptavidin-gekoppeltem FITC nachgewiesen. Die Färbung erfolgte nach folgendem Protokoll: 


$\begin{array}{ll}\text { Xylol } & 10 \mathrm{~min}(2 \mathrm{x}) \\ 100 \% \text { Ethanol } & 5 \mathrm{~min} \\ 90 \% \text { Ethanol } & 5 \mathrm{~min} \\ 70 \% \text { Ethanol } & 5 \mathrm{~min} \\ 50 \% \text { Ethanol } & 5 \mathrm{~min} \\ \mathrm{H}_{2} \mathrm{O} & 3 \mathrm{~min}(2 \mathrm{x}) \\ \text { PBS } & 5 \mathrm{~min} \\ \text { Lektin } & 1 \mathrm{~h} \\ \text { PBS } & 5 \mathrm{~min}(3 \mathrm{x}) \\ \text { Str.-FITC } & 1 \mathrm{~h} \\ \text { PBS } & 5 \mathrm{~min}(3 \mathrm{x})\end{array}$

Nach den Inkubationen in $\mathrm{H}_{2} \mathrm{O}$ wurden die Objektträger leicht getrocknet und die Objekte mit einem PAP-Pen umkreist. Durch die enthaltene hydrophobe Substanz können die für die folgenden Inkubationen einzusetzenden Volumina gering gehalten werden. Die Inkubationen nach Zugabe der Fluorochrom-haltigen Substanzen erfolgten im Dunkeln. Bei Verwendung von MAL I-FITC entfiel entsprechend die Behandlung mit Streptavidin-FITC. Die Lektine wurden jeweils in einem Volumen von $100 \mu$ l pro Präparat in einer 1:50-Verdünnung $(40 \mu \mathrm{g} / \mathrm{ml}$ aktives Konjugat), Streptavidin-FITC in einer $1: 20$-Verdünnung $(5 \mu \mathrm{g} / \mathrm{ml})$ in PBS eingesetzt. Die Einbettung erfolgte mit Vectashield-HardSet Mounting Medium mit DAPI, welches an DNA bindet und die Zellkerne anfärbt. 


\subsection{Methoden zur Charakterisierung der Fucosylierung und Selektin-Liganden-Expression und -Funktion auf Leukozyten}

\subsubsection{Durchflusszytometrische Analysen}

Die Fucosylierung sowie die Selektin-Bindung von Leukozyten wurde in Zusammenarbeit mit Dr. Martin Wild, Yvonne Helmus und Sviatlana Yakubenia in der Abteilung von Prof. Dr. Dietmar Vestweber am Max-Planck-Institut für Molekulare Biomedizin Münster mit Hilfe von Durchflusszytometrie bzw. FACS (Fluorescence activated cell sorting) untersucht. Das Prinzip dieser Methode beruht auf der Emission von optischen Signalen seitens einer Zelle, wenn diese einen Laserstrahl passiert. Durch Markierung bestimmter Oberflächenmerkmale mit Fluoreszenz-markierten Molekülen, wie in diesem Fall beispielsweise von Selektin-Liganden mit Selektinen oder fucosylierten Strukturen mit Lektinen, können die Zellen aufgrund der entsprechenden Merkmale unterschieden werden.

\subsubsection{Fucosylierung und Selektin-Bindung von Knochenmarkszellen}

Die Zellen wurden wie unter 3.4 .5 beschrieben präpariert. Die Markierung der Zellen erfolgte in 96well-V-bottom-Platten. Pro Napf wurden 600.000 Zellen eingesetzt.

Vor der Markierung durch Selektine wurden die Zellen für 30 min bei $4^{\circ} \mathrm{C}$ mit 50 $\mu \mathrm{l} / \mathrm{well} 10 \mu \mathrm{g} / \mathrm{ml}$ Fc-Block in FACS-Puffer inkubiert, um unspezifische Bindungsstellen zu blockieren. Anschließend wurden die Zellen in einer Mikrotiterplatten-Zentrifuge pelletiert und für weitere $30 \mathrm{~min}$ bei $4^{\circ} \mathrm{C}$ mit jeweils 50 $\mu \mathrm{l}$ der verschiedenen Fc-Fusionsproteine (mE-Selektin-Fc, mP-Selektin-Fc) in einer Konzentration von $100 \mu \mathrm{g} / \mathrm{ml}$ inkubiert. Darauf folgten zwei Waschschritte mit FACS-Puffer und eine dritte 30 minütige Inkubation bei $4^{\circ} \mathrm{C}$ mit einer 1:50Verdünnung eines Sekundärantikörpers, der mit dem Fluoreszenzmarker Phycoerythrin gekoppelt ist. Nach zweimaligem Waschen mit FACS-Puffer wurden 
die Zellen mit Cellfix fixiert und mit einem Durchflusszytometer des Typs FACSCalibur analysiert.

Entsprechend erfolgte die Lektin-Markierung der Zellen, allerdings entfiel der erste Inkubationsschritt. In diesem Fall wurden die Zellen direkt mit $100 \mu \mathrm{l}$ der jeweiligen Lektine (Maackia amurensis-Lektin II, Aleuria aurantia-Lektin) in einer Konzentration von $10 \mu \mathrm{g} / \mathrm{ml}$ in FACS-Puffer inkubiert. Die Markierung der gebundenen Lektine erfolgte durch eine letzte Inkubation mit einer 1:50Verdünnung eines Streptavidin-Phycoerythrin-Konjugats.

Parallel wurden Negativ-Kontrollen angefertigt, deren Behandlung sich im ersten Inkubationsschritt von den übrigen Proben unterschied. Die Selektin-Bindung wurde durch Inkubation mit Fc-Block in PBS/5 mM EDTA, die Lektin-Bindung durch vorige Inkubation des Lektins mit 75 mM Fucose in FACS-Puffer blockiert.

FACS-Puffer:

$\begin{array}{rl}1 \mathrm{x} & \mathrm{HBSS} \mathrm{pH} 7,5 \\ 4,2 \mathrm{mM} & \mathrm{NaHCO}_{3} \\ 6,2 \mathrm{mM} & \text { Natriumazid } \\ 3 \% & \text { FKS }\end{array}$

\subsubsection{Fucosylierung von Milzzellen}

Die Zellen der Milz wurden wie unter 3.4.6 beschrieben präpariert. Die Zellen wurden $18 \mathrm{~h}$ in Medium, das gegebenenfalls mit $10 \mathrm{mM}$ Fucose supplementiert war, inkubiert, bevor sie geerntet und gezählt wurden. Pro Well wurden 600.000 Zellen eingesetzt und vor ihrer Analyse im Durchflusszytometer wie unter 3.7.1.1 beschrieben mit Aleuria aurantia-Lektin behandelt.

\subsubsection{Untersuchung der Selektin-Liganden-Funktion durch Intravitalmikroskopie an Peyer'schen Plaques}

In Zusammenarbeit mit Dr. Markus Sperandio, Klinik für Kinder- und Jugendmedizin Heidelberg, Abt. IV Neonatologie, wurde das L- und P-Selektin- 
abhängige Leukozytenrollen in hochendothelialen Venolen der Peyer'schen Plaques der Darmwand intravitalmikroskopisch untersucht.

Nach Narkotisierung der Maus (s. 3.4.3.1) wurden ein Trachealtubus und ein Katheter in die Aorta carotis für Blutentnahmen und Injektionen gelegt. Zur Präparation der Peyer'schen Plaques wurde die Peritonealhöhle mittels Medianschnitt eröffnet. Die Maus wurde nun auf der Seite liegend auf einem Präpariertisch positioniert. Unter konstanter Superfusion mit einer auf $35^{\circ} \mathrm{C}$ temperierten Bicarbonat-gepufferten Lösung wurde eine Dünndarmschlinge aus der Peritonealhöhle mobilisiert und nach Peyer'schen Plaques untersucht. Nach Auffinden eines geeigneten Plaques wurde dieser mit Hilfe von Silikonfett und einem transparenten Deckglas für die intravitalmikroskopische Betrachtung fixiert. Um intravaskuläre Leukozyten in vivo durch Epifluoreszenz sichtbar zu machen, erhielt die Maus eine Injektion von 0,15 ml einer $2 \mathrm{mg} / \mathrm{ml}$ Rhodamin 6G-Lösung. Die entsprechende Epifluoreszenz-Beleuchtung erfolgte durch ein Stroboskop (60/s). Das Intravitalmikroskop war mit einem Salzwasser-Immersionsobjektiv (SW 63) ausgestattet. Venolen mit einem Durchmesser zwischen 12 und $35 \mu \mathrm{m}$ wurden für jeweils $60 \mathrm{~s}$ beobachtet und mit einem CCD-Kamera-System und einem VHSRekorder aufgezeichnet.

Für die spezifische Blockade von Selektin- und Integrin-vermitteltem Leukozytenrollen wurden verschiedene Antikörper über den Katheter injiziert. Pro Maus wurden gegebenenfalls $30 \mu \mathrm{g}$ des P-Selektin-Antikörpers RB40.34, $50 \mu \mathrm{g}$ des L-Selektin-Antikörpers MEL-14 bzw. $30 \mu \mathrm{g}$ des Antikörpers PS/2, der die $\alpha_{4}{ }^{-}$ Integrin-Kette bindet, appliziert.

Superfusionspuffer: $132 \mathrm{mM} \quad \mathrm{NaCl}$

$4,7 \mathrm{mM} \quad \mathrm{KCl}$

2,7 $\mathrm{mM} \quad \mathrm{CaCl}_{2}$

2,1 $\mathrm{mM} \quad \mathrm{MgCl}_{2}$

$18 \mathrm{mM} \quad \mathrm{NaHCO}_{3} \mathrm{pH} 7,4$

Begasung mit 95\% $\mathrm{N}_{2} / 5 \% \mathrm{CO}_{2}$ 
$4 \quad$ Ergebnisse

\subsection{Etablierung eines Knockout-Mausmodells für den Golgi-GDP-Fucose-Transporter}

Durch eigene Vorarbeiten im Rahmen der Diplomarbeit wurde das murine Gen für den Golgi-GDP-Fucose-Transporter (GFT, Gen: SLC35C1) kloniert. Es wurde ein entsprechender Gene targeting-Vektor (GTV) für einen Total-Knockout konstruiert, in dem der offene Leserahmen durch die Insertion einer NeomycinResistenzkassette (Neo-Kassette) in das erste Exon unterbrochen ist. Durch Einbringen dieses GTV in embryonale Stammzellen und homologe Rekombination wurden Klone generiert, die heterozygot für das transgene Allel sind (s. Abb. 7).

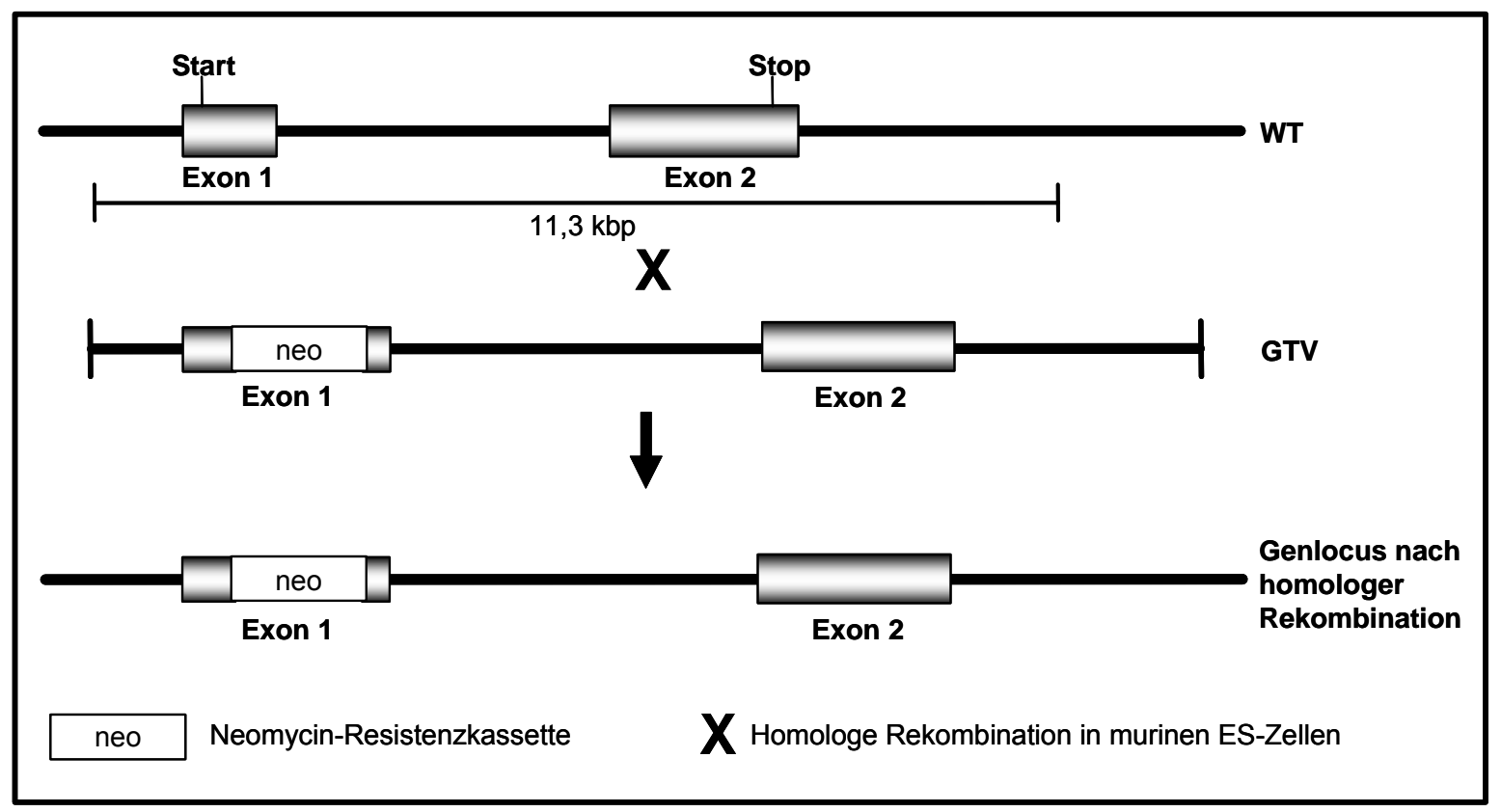

Abb. 7: Schematische Darstellung der homologen Rekombination mit dem GTV zur Generierung eines Total-Knock-Outs des GDP-Fucose-Transporters. 


\subsubsection{Generierung von Chimären durch Retransfer der transgenen ES- Zellen}

ES-Zellen von zwei verschiedenen Klonen (Klon 72 und Klon 96) mit einem Knockout-Allel wurden aufgetaut, kultiviert und zur Mikroinjektion in MausBlastozysten aufgearbeitet.

Nach Injektion der Zellen erfolgte der Transfer der Blastozysten in insgesamt vier pseudoschwangere Foster-Weibchen für Klon 72 und zwei Weibchen für Klon 96. Unter den Nachkommen waren bei Klon 72 insgesamt zwölf chimäre Männchen und sechs chimäre Weibchen, bei Klon 96 waren es fünf Männchen und drei Weibchen. Nach Beurteilung der Fellfarbe wiesen diese Tiere einen Chimärismus zwischen 10 und $90 \%$ auf.

\subsubsection{Verpaarungsstrategie}

Von den chimären Männchen wurden insgesamt neun Tiere mit einem Chimärismus zwischen 40 und $85 \%$ ausgewählt und mit C57BL/6-Weibchen verpaart. Fünf dieser verpaarten Chimären hatten agoutifarbene Nachkommen, was auf eine Keimbahnbeteiligung der mikroinjizierten ES-Zellen schließen ließ, da nur diese den Agouti-Fellmarker des 129Sv-Stamms in sich tragen. Die Genotypisierung dieser agoutifarbenen Nachkommen zeigte, dass wie erwartet $50 \%$ der Tiere heterozygot für das Knockout-Allel sind.

Für die weitere Zucht erfolgte die Verpaarung heterozygoter Nachkommen eines Männchens mit $85 \%$ Chimärismus aus der Linie des Klons 72 wie unter 3.3.8 beschrieben.

\subsubsection{Genotypisierung durch PCR, Sequenzierung und Southern-Blot}

Nach dem Absetzen vom Muttertier wurden zur Genotypisierung der Nachkommen Biopsien der Schwanzspitzen genommen. Parallel erfolgte zur Unterscheidung eine Markierung mit einem Ohrlochsystem, welches eine Nummerierung von eins bis 99 ermöglicht. Vor dem Absetzen verstorbene Tiere 
wurden möglichst schnell eingefroren, um auch in diesem Fall eine Genotypisierung durch spätere Entnahme einer Biopsie des Kadavers zu ermöglichen.

Aus den Biopsien wurde nach deren Lyse und Proteinase K-Verdau die genomische DNA durch Ethanol-Präzipitation isoliert. Diese wurde einer Genotypisierungs-PCR mit der Taq DNA-Polymerase E sowie den Primern GFTF1, -R1 und R2 unterworfen (s. Abb. 8).

Anhand der Größen der PCR-Produkte ließ sich der jeweilige Genotyp +/+, +/oder -/- feststellen (entsprechende Tiere werden im Folgenden als $\mathrm{GFT}^{+/+}, \mathrm{GFT}^{+/-}$ bzw. GFT ${ }^{-/-}$bezeichnet). Mit den Primern F1 und R2, die jeweils 5' bzw. 3' des ersten Exons liegen, wurde ein 2,3 kb umfassender Abschnitt des Wildtyp-Alles amplifiziert. Das Vorliegen mindestens eines Knockout-Allels führte zur Amplifikation eines Produktes von 1,8 kb Länge. Dies entspricht dem ersten Abschnitt des ersten Exons sowie dem Beginn der inserierten Neo-Kassette bis zur Sequenz des Primers R1. Eine Amplifikation des Abschnitts zwischen F1 und R2 vom Knockout-Allel erfolgte nur in geringem Maß, da dieses Produkt eine Größe von 3,4 kb hat und somit bei der verwendeten Elongationszeit von drei Minuten von der Taq-Polymerase, welche etwa eine min pro kb Elongation benötigt, nicht vollständig bearbeitet werden kann.

Im Anschluss an die PCR wurden die Ansätze zur Analyse auf ein 1\%-Agarosegel aufgetragen und die Größen der PCR-Produkte durch Vergleich mit den Banden der DNA-Ladder ermittelt (s. Abb. 9). 


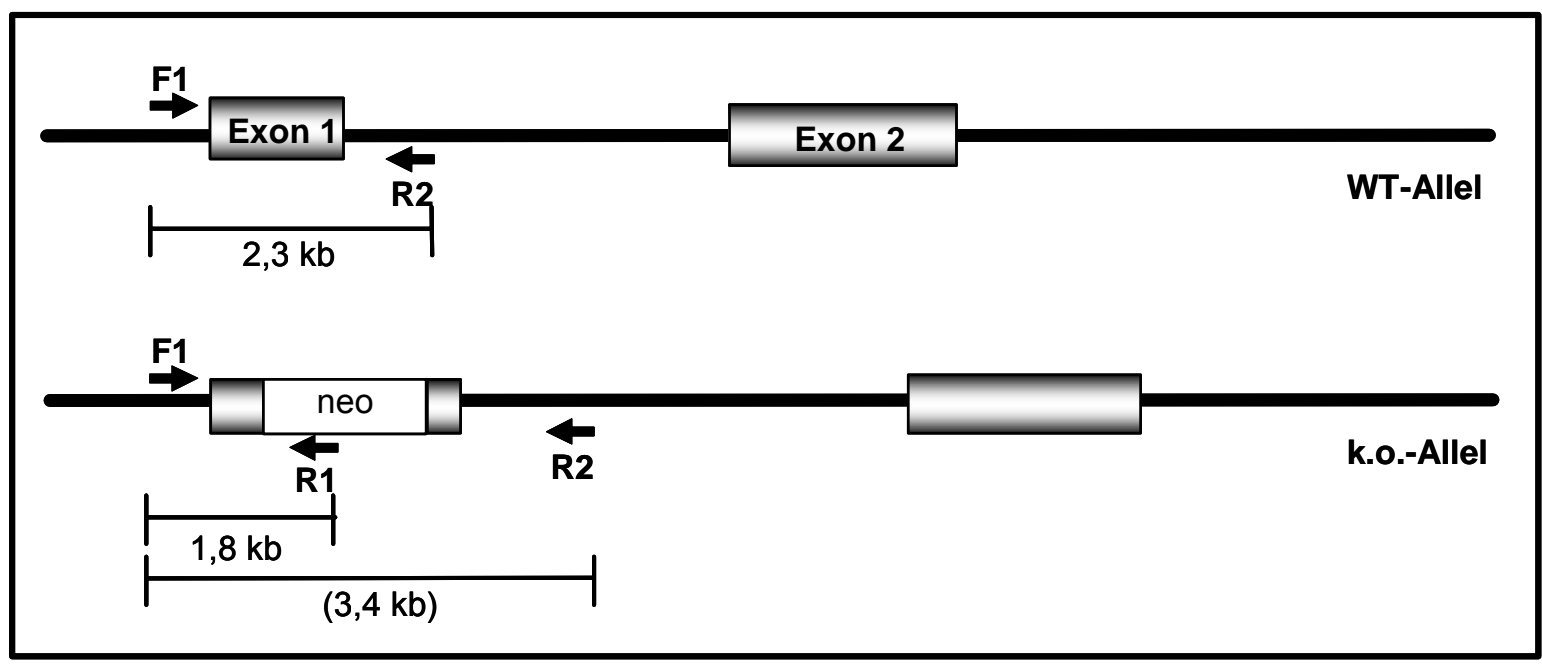

Abb. 8:

Position der Genotypisierungs-Primer und Größe der möglichen PCRProdukte für das Wildtyp- und das Knockout-Allel.

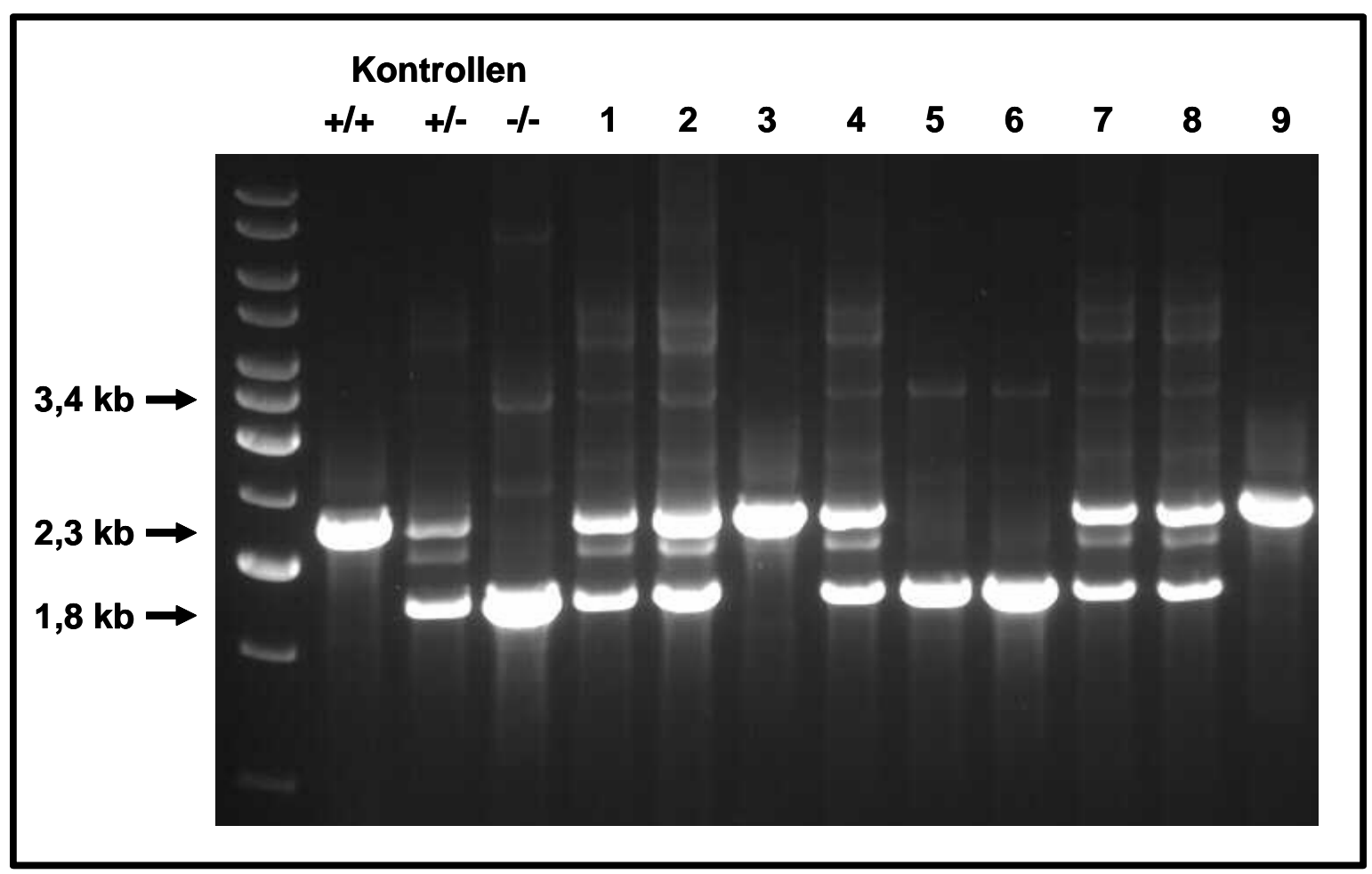

Abb. 9: $\quad$ Analytisches Agarose-Gel nach einer Genotypisierungs-PCR. Eingesetzt wurden Kontroll-DNA und genomische DNA aus Schwanzbiopsien eines Wurfs aus einer Verpaarung von zwei heterozygoten Tieren. 
Für eine weitere Kontrolle der ersten DNA-Proben wurden diese darüber hinaus einer Sequenzierung sowie einer Southern-Blot-Analyse unterworfen.

Zur Sequenzierung wurden die Banden aus dem Gel ausgeschnitten, die DNA aus dem Gel extrahiert und für eine Sequenzierungs-PCR mit den oben genannten Primern eingesetzt. Die kapillarelektrophoretische Analyse erbrachte für das Knockout-Allel die erwartete Sequenz der Neo-Kassette, welche in das erste Exon inseriert ist.

Für eine Analyse durch DNA-Hybridisierung nach Southern wurden jeweils $6 \mu \mathrm{g}$ der genomischen DNA mit dem Restriktionsenzym Hincll verdaut. In der Region des ersten Exons befinden sich Hincll-Restriktionsschnittstellen, die im Fall des Wildtyp-Gens zur Generierung eines 4,25 kb großen Fragments führen. Innerhalb der Neo-Kassette ist eine zusätzliche Schnittstelle lokalisiert, so dass bei Verdau des Knockout-Allels ein 1,85 kb-Fragment entsteht (s. Abb. 10).

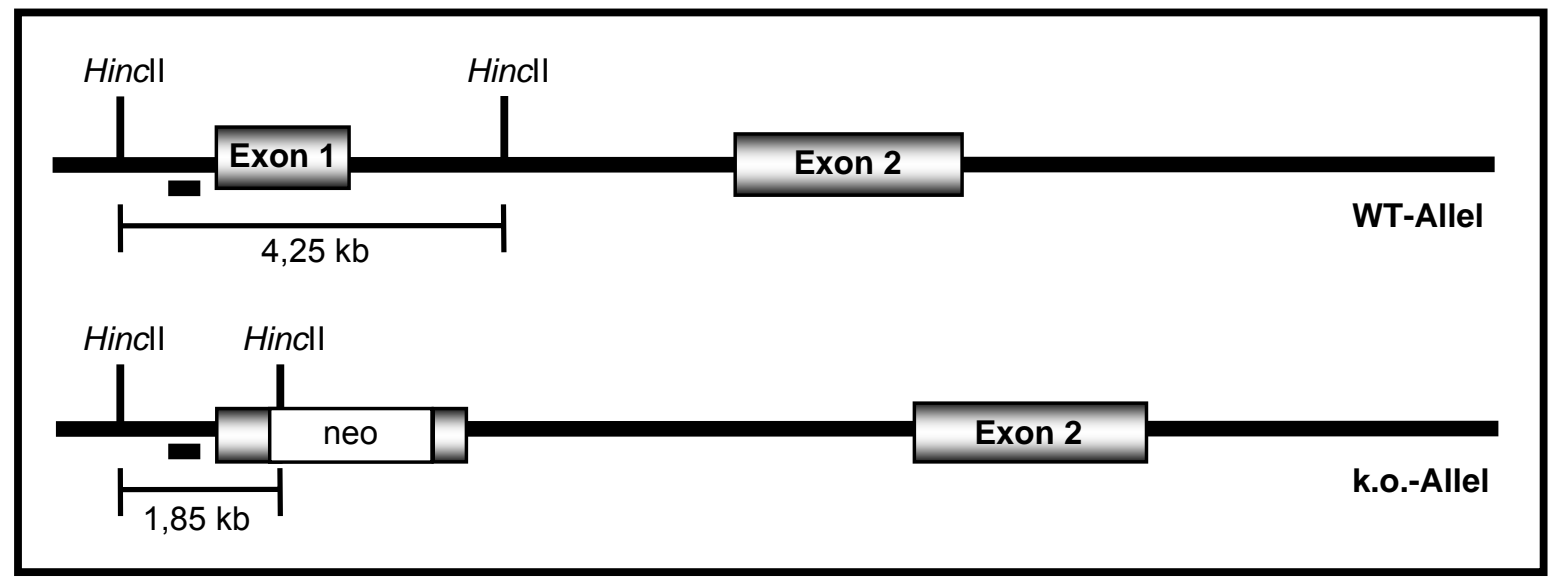

Abb. 10: Hincll-Restriktionsschnittstellen und resultierende Fragmentgrößen nach Hincll-Verdau. Der schwarze Balken vor dem ersten Exon stellt die Sonde dar, mit der die entsprechenden Fragmente detektiert wurden.

Die Hincll-verdaute DNA wurde gelelektrophoretisch aufgetrennt, auf eine Hybond $\mathrm{N}-$ Membran transferiert und mit einer radioaktiv markierten DNA-Sonde hybridisiert. Diese Sonde entspricht einer 693 bp langen Sequenz 5' des ersten Exons und wurde zuvor durch PCR von genomischer DNA amplifiziert (Primer: GFT-F1 und -R3). Den verschiedenen Fragmentgrößen entsprechend zeigten sich nach Autoradiographie der Membran unterschiedliche Banden, mit denen die Sonde hybridisiert hatte (s. Abb. 11). 


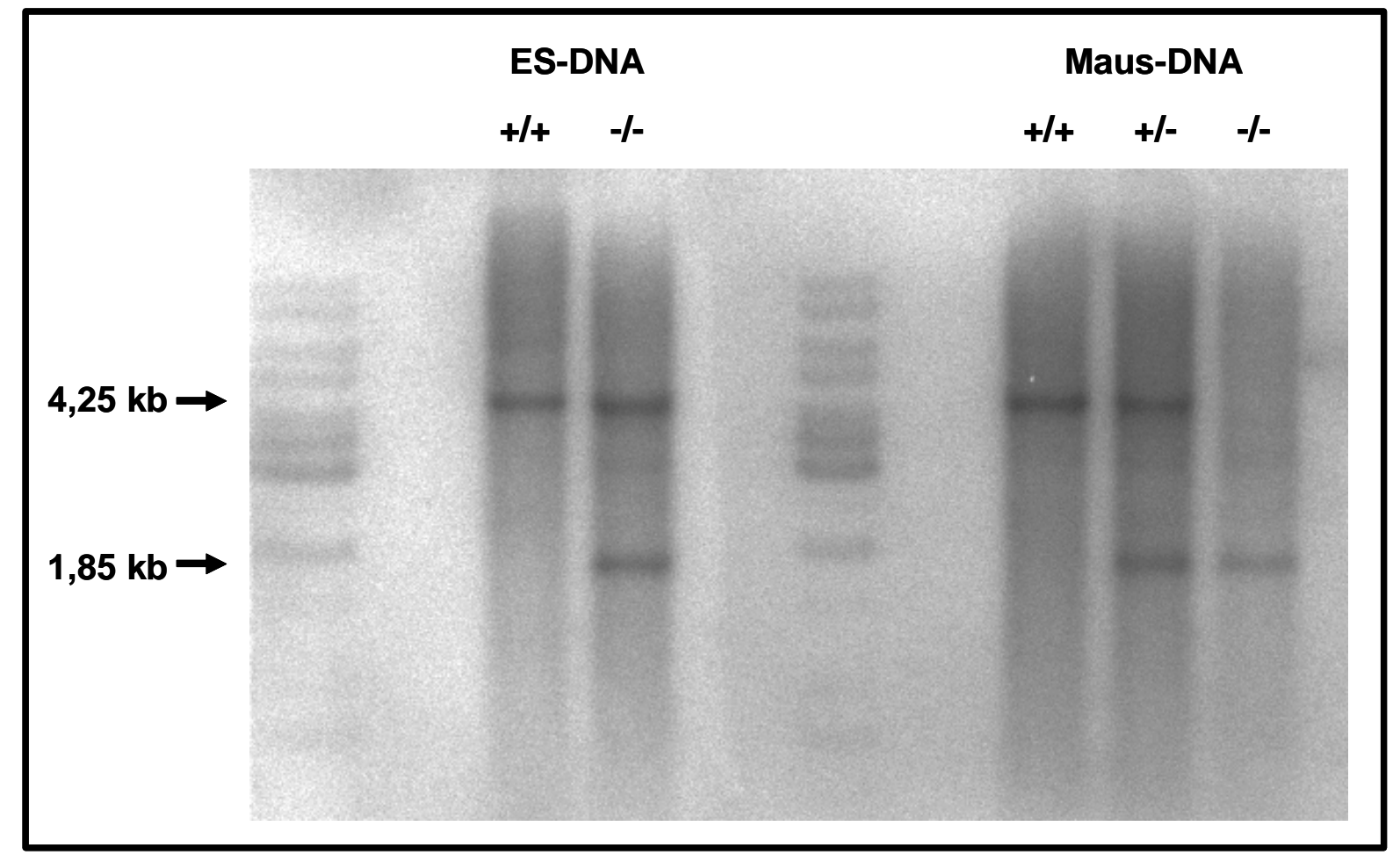

Abb. 11: Bandenmuster nach Southern-Blot. Eingesetzt wurde genomische DNA aus zwei ES-Zell-Klonen (links) und drei Schwanzbiopsien. 


\subsection{Klinischer Phänotyp der GFT $^{-1-}$-Maus}

\subsubsection{Geburts- und Überlebensraten}

Wie unter 3.3.8 beschrieben wurden heterozygote Nachkommen aus Verpaarungen zwischen Bl6- und 129Sv-Tieren, also 50/50-Hybriden der beiden Stämme, untereinander verpaart. Ihre Nachkommenschaft (als Linie ko72SB bezeichnet), für die nach Mendel zu 25\% der Knockout-Genotyp zu erwarten ist, wurde für die Ermittlung von Geburts- und Überlebensraten sowie alle nachfolgend beschriebenen Experimente eingesetzt.

Parallel dazu erfolgte durch Verpaarung mit Wildtyp-Tieren die Rückkreuzung auf den Bl6- bzw. 129Sv-Stamm (Linien ko72B6 bzw. ko72SV) über sieben Generationen. Da dies ein sehr zeitaufwendiger Prozess ist, konnten erst gegen Ende dieser Arbeit Verpaarungen zwischen den resultierenden $\mathrm{GFT}^{+/-}$-Tieren angesetzt und dementsprechend bisher vergleichsweise wenig Daten zu Geburtsund Überlebensraten gewonnen werden, die jedoch das Abschätzen einer Tendenz ermöglichen.

Für die Ermittlung der Geburtsraten wurden nur Würfe berücksichtigt, aus denen alle Jungtiere genotypisiert werden konnten. Dies war nicht immer der Fall, da die Mütter oft die verstorbenen Jungtiere auffressen, bevor sie im Käfig gefunden werden. Die Überlebensrate wurde für die ersten fünf Lebenswochen ermittelt und setzte voraus, dass keines der Tiere bis zu diesem Zeitpunkt für Versuchszwecke getötet wurde.

\subsubsection{Konventionelle Tierhaltung}

Aus der konventionellen Tierhaltung wurden 246 Tiere aus 30 Würfen, welche die oben genannten Kriterien erfüllten, berücksichtigt. Tabelle 2 zeigt die Verteilung der Genotypen und Geschlechter, welche weitgehend den Mendelschen Regeln entspricht. Etwa 25\% der Nachkommen hatten den GFT $^{-/-}$-Genotyp, so dass nicht von einer pränatalen Letalität des Phänotyps auszugehen ist. 
Tab. 2: Verteilung der Genotypen und Geschlechter in der konventionellen Tierhaltung. Für die unter n.e. (nicht ermittelt) aufgeführten Tiere konnte aufgrund des Todeseintritts vor der Ausprägung von erkennbaren Geschlechtsmerkmalen oder der nur teilweisen Erhaltung der Kadaver kein Geschlecht bestimmt werden.

\begin{tabular}{|c|c|c|c|c|}
\hline Genotyp & Geschlecht & Anzahl & $\begin{array}{c}\text { Anteil } \\
\text { (Geschlecht) }\end{array}$ & $\begin{array}{c}\text { Anteil } \\
\text { (Genotyp) }\end{array}$ \\
\hline \multirow[t]{3}{*}{$\mathrm{GFT}^{+/+}$} & $\mathrm{m}$ & 29 & $47,5 \%$ & \multirow[t]{3}{*}{$24,8 \%$} \\
\hline & w & 32 & $52,5 \%$ & \\
\hline & n.e. & 0 & $0,0 \%$ & \\
\hline \multirow[t]{3}{*}{$\mathrm{GFT}^{+/-}$} & $\mathrm{m}$ & 67 & $54,5 \%$ & \multirow[t]{3}{*}{$50,0 \%$} \\
\hline & $w$ & 50 & $40,7 \%$ & \\
\hline & n.e. & 6 & $4,9 \%$ & \\
\hline \multirow[t]{3}{*}{$\mathrm{GFT}^{-1-}$} & $m$ & 24 & $38,7 \%$ & \multirow[t]{3}{*}{$25,2 \%$} \\
\hline & $w$ & 26 & $41,9 \%$ & \\
\hline & n.e. & 12 & $19,4 \%$ & \\
\hline
\end{tabular}

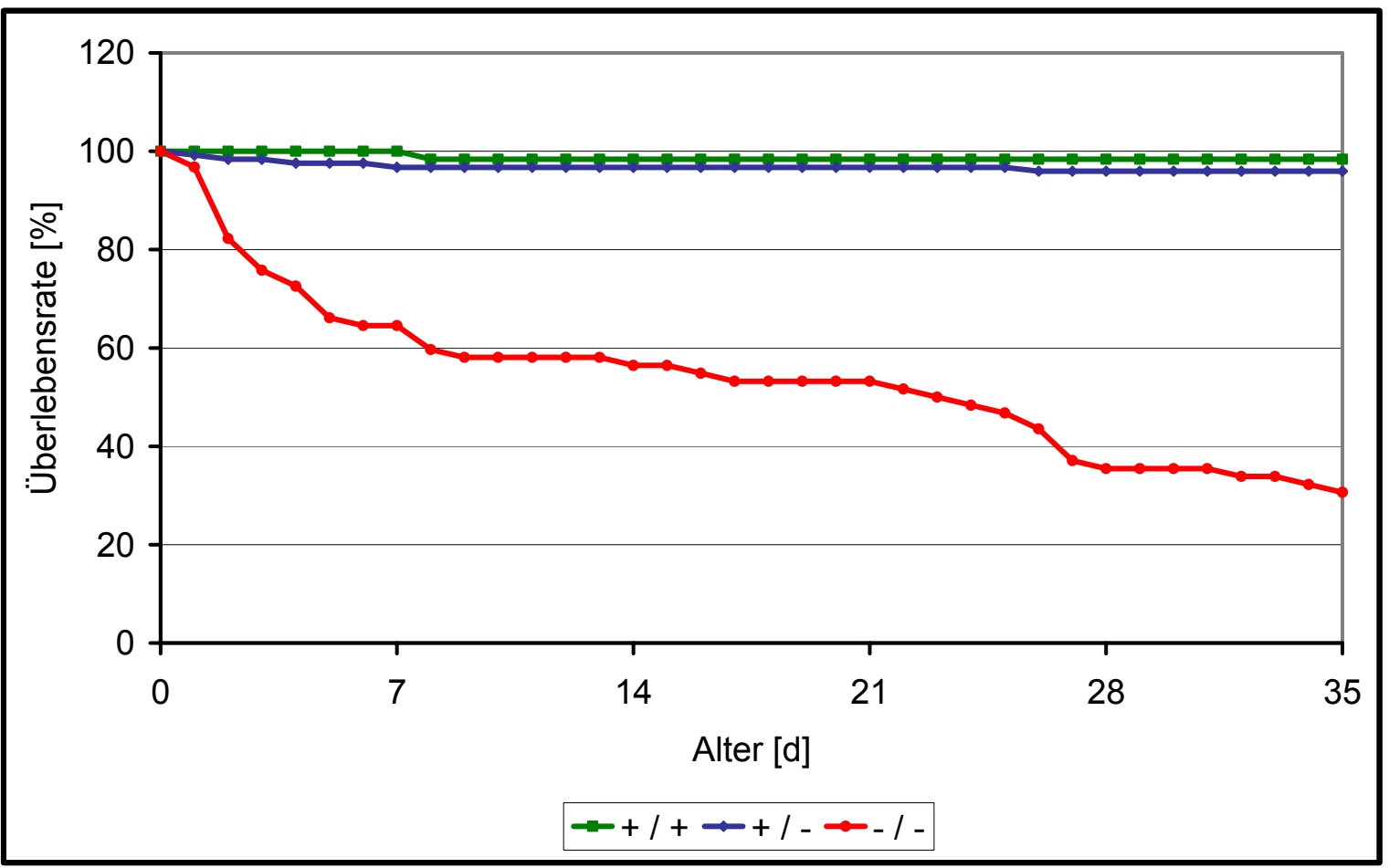

Abb. 12: Überlebensraten der Nachkommen in konventioneller Tierhaltung während der ersten fünf Lebenswochen. 
Abbildung 12 stellt die Überlebensrate der Tiere aus den berücksichtigten 30 Würfen dar. Es zeichnete sich sehr schnell ab, dass ein Großteil der GFT ${ }^{-/-}$-Tiere früh verstirbt. Nach der ersten Woche lebten noch $64,5 \%$ der Jungtiere dieses Genotyps, nach zwei Wochen 56,5\% und nach drei Wochen 53,2\%. Im Verlauf der vierten Woche sank der Anteil der Überlebenden nochmals auffallend deutlich auf $35,5 \%$. In dieser Phase erfolgt das Absetzen von der Mutter.

\subsubsection{SPF-Tierhaltung}

Für die Beurteilung der Geburts- und Überlebensraten in der im Verlauf dieser Arbeit etablierten SPF-Zucht wurden 128 Tiere aus 17 Würfen berücksichtigt. Wie aus Tabelle 3 ersichtlich ist, ergaben sich auch hier keine signifikanten Abweichungen von den gemäß Mendel zu erwartenden Verhältnissen.

Tab. 3:

Verteilung der Genotypen und Geschlechter in SPF-Tierhaltung.

\begin{tabular}{|c|c|c|c|c|}
\hline Genotyp & Geschlecht & Anzahl & $\begin{array}{c}\text { Anteil } \\
\text { (Geschlecht) }\end{array}$ & $\begin{array}{c}\text { Anteil } \\
\text { (Genotyp) }\end{array}$ \\
\hline \multirow[t]{3}{*}{$\mathrm{GFT}^{+/+}$} & $\mathrm{m}$ & 18 & $52,9 \%$ & \multirow[t]{3}{*}{$26,6 \%$} \\
\hline & $w$ & 16 & $47,1 \%$ & \\
\hline & n.e. & 0 & $0,0 \%$ & \\
\hline \multirow[t]{3}{*}{$\mathrm{GFT}^{+/-}$} & $\mathrm{m}$ & 24 & $38,7 \%$ & \multirow[t]{3}{*}{$48,4 \%$} \\
\hline & $w$ & 38 & $61,3 \%$ & \\
\hline & n.e. & 0 & $0,0 \%$ & \\
\hline \multirow[t]{3}{*}{$\mathrm{GFT}^{-1-}$} & $\mathrm{m}$ & 12 & $38,7 \%$ & \multirow[t]{3}{*}{$25,0 \%$} \\
\hline & $w$ & 9 & $29,0 \%$ & \\
\hline & n.e. & 11 & $32,3 \%$ & \\
\hline
\end{tabular}

In Abbildung 13 ist die Überlebensrate der in SPF-Haltung zur Welt gekommenen Jungtiere dargestellt. Sieben Tage nach der Geburt lebten noch 68,8\% der GFT ${ }^{-{ }^{-}}$Tiere, nach der zweiten Woche 65,6\%, nach drei Wochen 59,4\%. Auch hier sank der Anteil der Überlebenden während der vierten Woche auffallend stark auf 43,8\%. Der Verlauf gleicht damit sehr der Entwicklung in konventioneller Tierhaltung, jedoch überleben bis zum Ende des erfassten Zeitraums etwa $8 \%$ mehr. 


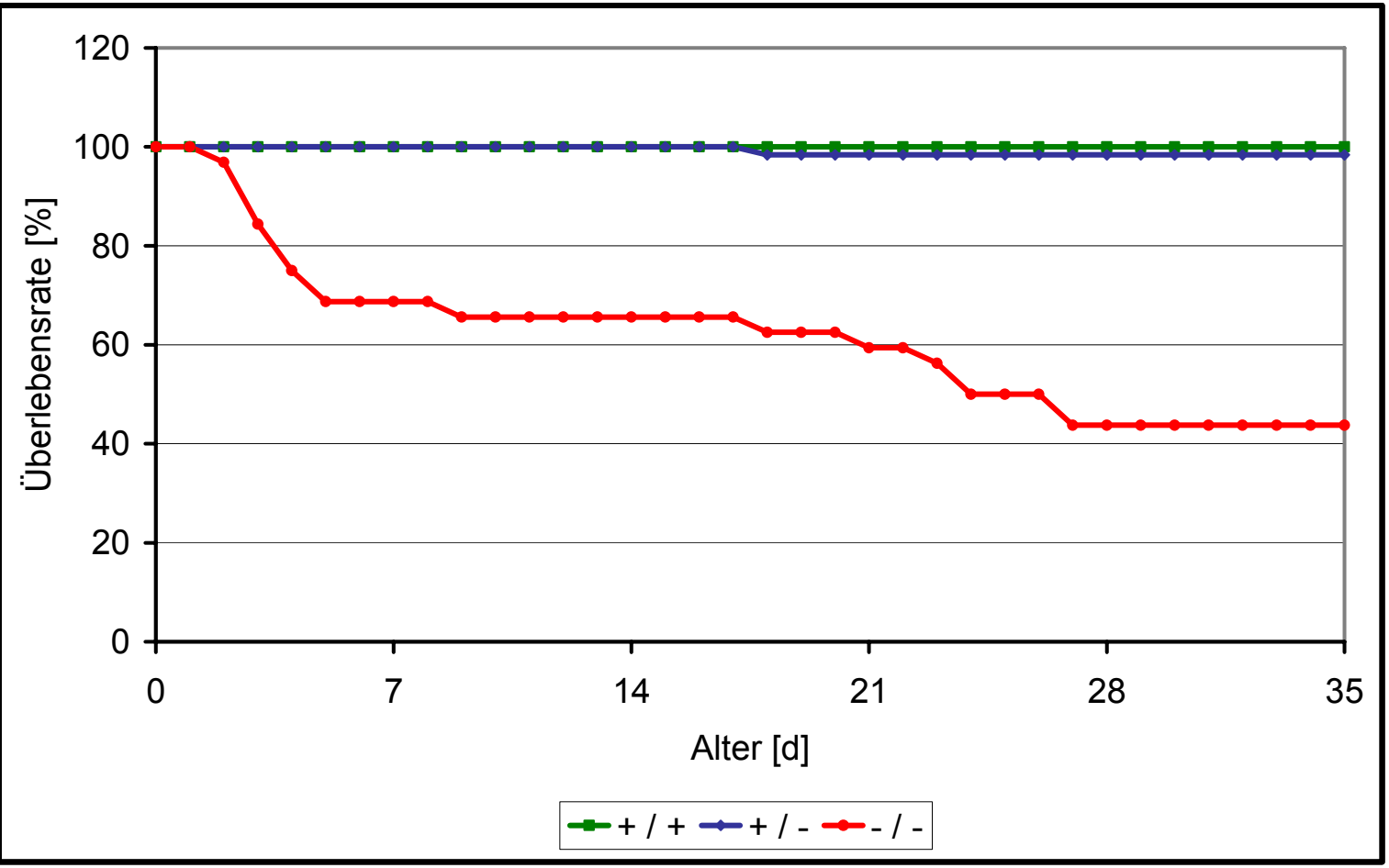

Abb. 13: Überlebensraten der Nachkommen in SPF-Tierhaltung während der ersten fünf Lebenswochen.

\subsubsection{Zucht auf BI6- bzw. 129Sv-Stammhintergrund}

Aus Verpaarung von $\mathrm{GFT}^{+/-}$-Tieren der 129Sv-Zucht (F7) untereinander gingen 40 Nachkommen in sieben Würfen hervor, $20 \%$ davon waren $\mathrm{GFT}^{-/-}$, das älteste davon verstarb nach 27 Tagen. Die Darstellung einer Überlebensrate ist bei dieser Gruppengröße noch nicht sinnvoll. Für die Bl6-Zucht stehen zwölf entsprechende Würfe zur Auswertung zur Verfügung. Von insgesamt 94 Jungtieren wurden 23\% als $\mathrm{GFT}^{-/-}$genotypisiert. Keines dieser Tiere wurde älter als 28 Tage (s. Abb. 14). Zusammenfassend lässt sich nach der bisherigen Datenlage sagen, dass die Geburtsraten von $\mathrm{GFT}^{-/-}$-Nachkommen auf 129Sv- bzw. BI6-Stammhintergrund im Vergleich zu der ko72SB-Zucht leicht erniedrigt sind. Darüber hinaus zeichnet sich eine deutlich geringere Lebenserwartung ab. Die meisten der $\mathrm{GFT}^{-/-}$-Nachkommen verstarben innerhalb der ersten Lebenswoche, keines davon hat das kritische Alter des Absetzens von der Mutter und der damit verbundenen Nahrungsumstellung in den folgenden Tagen überwunden. 


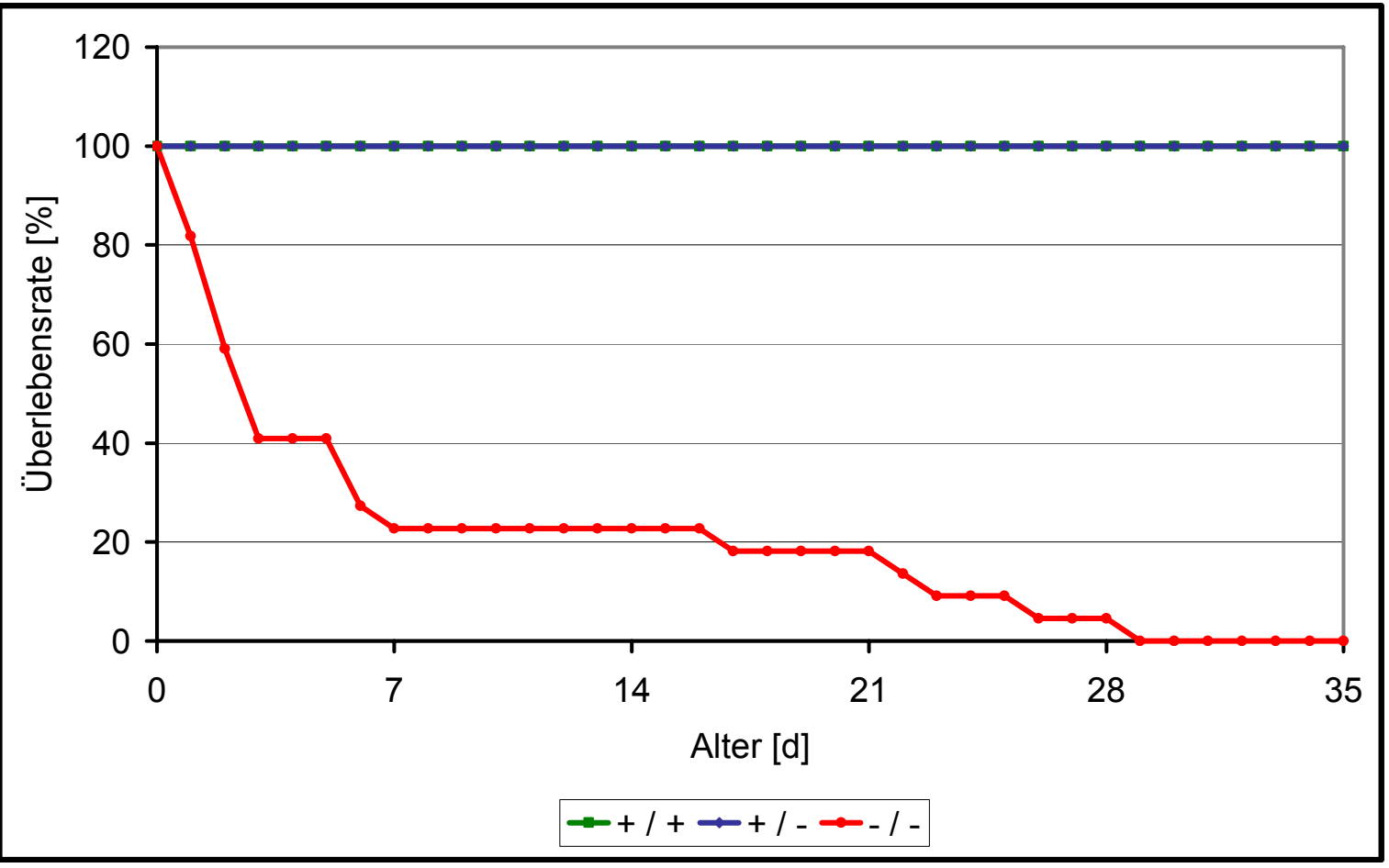

Abb. 14: Überlebensraten der Nachkommen aus $\mathrm{GFT}^{+/}$-Verpaarungen der BI6-Zucht in SPF-Tierhaltung während der ersten fünf Lebenswochen.

\subsubsection{Gewichtsentwicklung}

Die Gewichtsentwicklung der $\mathrm{GFT}^{-/}$-Tiere und ihrer Geschwister wurde am Beispiel von acht Würfen in konventioneller Tierhaltung verfolgt. Die Jungtiere wurden ab dem dritten Lebenstag im Abstand von drei Tagen gewogen. In die Auswertung miteinbezogen wurden nur Tiere, die bis zum Ende der Beobachtungszeit überlebt haben, um eine Verfälschung der Datenreihen zu vermeiden. Dabei ist zu beachten, dass auf diese Weise jedoch zwangsläufig eine gewisse Auswahl zugunsten der stabileren und damit sich in Bezug auf das Gewicht besser entwickelnden $\mathrm{GFT}^{-/-}$-Tiere getroffen wird.

Die Gewichtsentwicklungen von $\mathrm{GFT}^{+/+}$- und $\mathrm{GFT}^{+/-}$-Tieren unterschieden sich kaum voneinander. Die $\mathrm{GFT}^{-/}$-Tiere hingegen wiesen über den gesamten Beobachtungszeitraum ein deutlich geringeres Gewicht auf (s. Abb. 15). Diese Entwicklung setzte sich tendenziell auch in den folgenden Wochen fort. Während 
gesunde Tiere nach etwa zwei bis drei Monaten $30 \mathrm{~g}$ wiegen, erreichen ausgewachsene GFT $^{-/}$-Tiere in der Regel ein Höchstgewicht von nur etwa $20 \mathrm{~g}$.

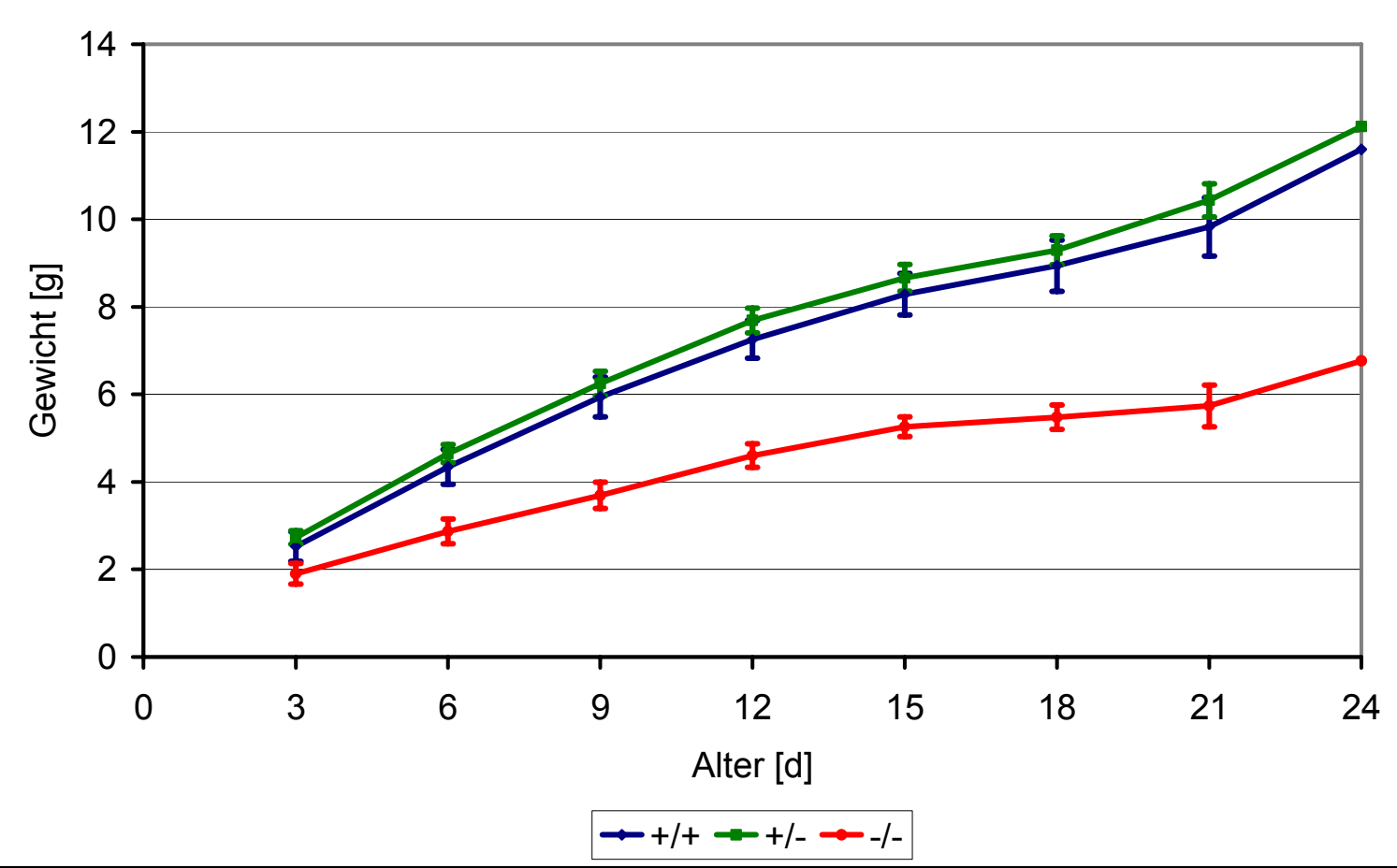

Abb. 15: Gewichtsentwicklung während der ersten 24 Lebenstage. In die Auswertung miteinbezogen wurden alle Tiere aus acht Würfen, die bis zum 24. Tag überlebt haben (Mittelwert \pm SEM; $n\left(\mathrm{GFT}^{+/+}\right)=12, \mathrm{n}\left(\mathrm{GFT}^{+-}\right)=23, \mathrm{n}\left(\mathrm{GFT}^{-/}\right)=11$ ).

\subsection{3 Äußere Merkmale, Verhalten und motorische Fähigkeiten}

Entsprechend der Gewichtsentwicklung wiesen die $\mathrm{GFT}^{-1}$-Tiere eine geringere Körpergröße auf (Abb. 16). Probleme mit der Nahrungsaufnahme oder Verdauung waren nicht festzustellen. Eine mikrobielle Analyse der Keime im Gastrointestinaltrakt durch Dr. Alexander Dalpke (Abt. Hygiene und Medizinische Mikrobiologie, Universität Heidelberg) ergab eine regelrechte Keimverteilung und keine Auffälligkeiten. 


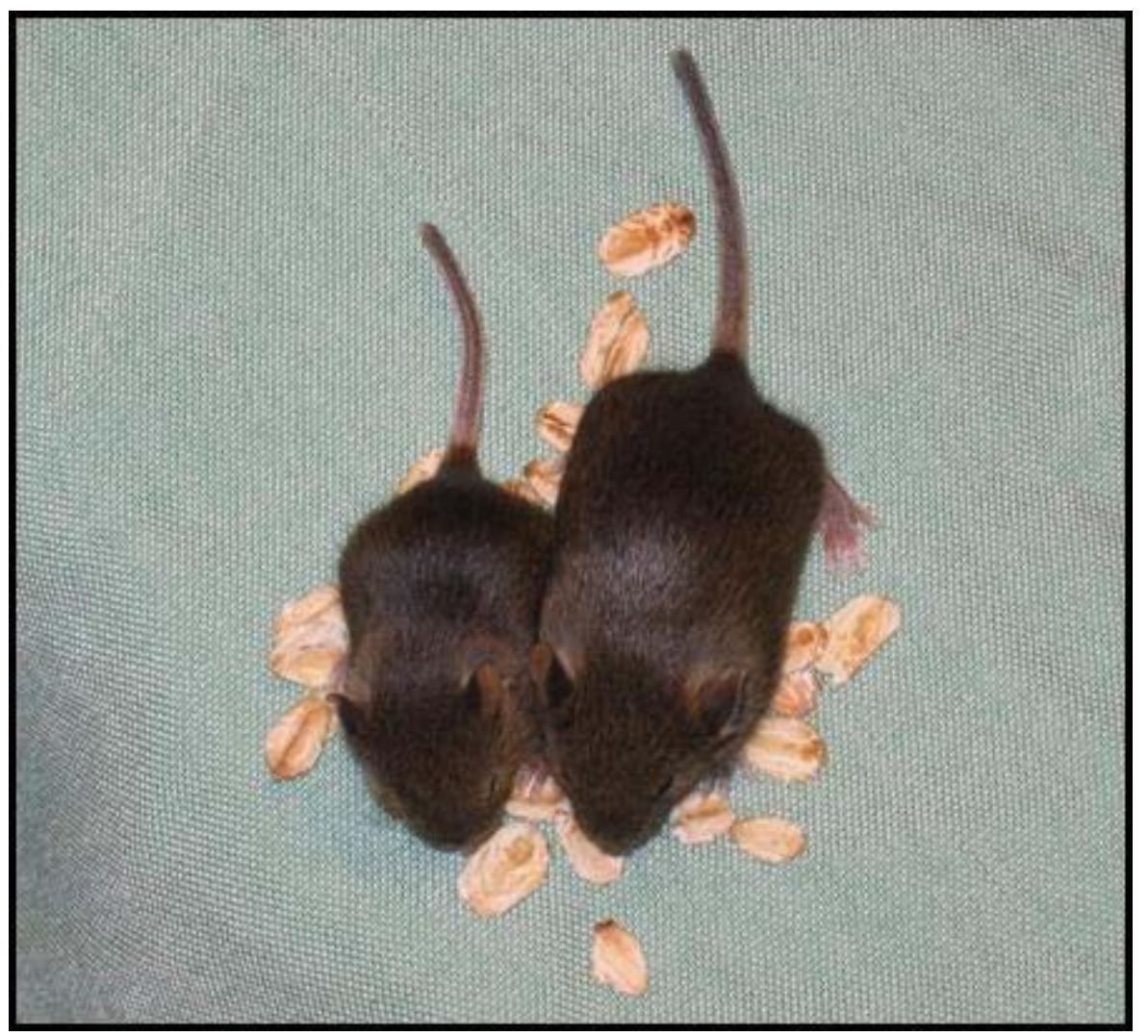

Abb. 16: Geschwister im Alter von acht Wochen. Links im Bild ist ein $\mathrm{GFT}^{-1-}$-Tier, rechts ein $\mathrm{GFT}^{+/+}$-Tier.

Das Fell der Tiere war häufig gesträubt und ungepflegt, was physischen oder psychischen Stress signalisiert. Selten wurde auch ein vorzeitiges Ergrauen der Fellfarbe beobachtet. Darüber hinaus wiesen die Tiere keine besonderen äußeren Merkmale wie etwa eine Abweichung der Proportionen der Extremitäten oder andere Dysmorphien auf.

Weitere Hinweise für Stress bzw. ein vermindertes Wohlbefinden der $\mathrm{GFT}^{-1-}$-Tiere gaben eine vorwiegend gekrümmte Körperhaltung sowie eine zumeist deutlich geringere Aktivität im Vergleich zu gesunden Geschwistern. Die psychomotorischen Fähigkeiten wurden anhand eines modifizierten "ScreenTests" (Coughenour et al., 1977) untersucht. Die GFT ${ }^{-1}$-Tiere konnten sich dabei deutlich schlechter am Gitter festhalten und fielen nach durchschnittlich $29 \pm 7 \mathrm{~s}$ herunter $(\mathrm{n}=8)$, während sich $\mathrm{GFT}^{+/+}$- und $\mathrm{GFT}^{+/-}$-Geschwister (jeweils $\mathrm{n}=11$ ) bis zum Ende des Tests nach $60 \mathrm{~s}$ ohne Probleme festhalten konnten.

Das Verhalten der $\mathrm{GFT}^{-/}$-Tiere fiel durch Zwanghaftigkeit und Wiederholungen der Bewegungen auf. Sofern die Tiere in einer hinreichend guten körperlichen 
Verfassung waren, sprangen sie häufig ohne ersichtlichen Grund in einer Ecke des Käfigs minutenlang an der Käfigwand hoch. Bei der Erkundung beispielsweise eines neuen Käfigs kehrten sie häufig wiederholt an die gleichen Stellen zurück, während die Geschwister immer neue, noch unbekannte Winkel der neuen Umgebung untersuchten.

Eine darüber hinausgehende Charakterisierung neurologisch-motorischer Fähigkeiten, emotionaler Aspekte oder neurokognitiver Fähigkeiten wie Lernen und Gedächtnis durch Verhaltenstests erfordert für eine hinreichende statistische Relevanz der Ergebnisse größere als die bisher verfügbaren Versuchsgruppen (mindestens n=10 pro Genotyp; Crawley, 1999) mit Standardisierung in Bezug auf Geschlecht, Alter und Lebensbedingungen. Da die $\mathrm{GFT}^{-/-}$-Tiere bisher nur aus Verpaarung heterozygoter Tiere erhalten werden konnten, also nur $25 \%$ der Nachkommenschaften ausmachen und darüber hinaus wie bereits dargestellt zu einem Großteil früh versterben, konnten diese Untersuchungen im Rahmen dieser Arbeit nicht durchgeführt werden.

\subsubsection{Fertilität}

Zur Untersuchung der Fertilität der $\mathrm{GFT}^{-/-}$-Tiere wurden diese mit $\mathrm{GFT}^{+/+}$- und $\mathrm{GFT}^{+/}$-Tieren sowie untereinander verpaart. Aufgrund der geringen Verfügbarkeit von $\mathrm{GFT}^{-/-}$-Tieren, die ein verpaarungsfähiges Alter erreichten, konnten auch hier bisher nur wenige Daten gewonnen werden. Es zeigte sich jedoch, dass für beide Geschlechter jeweils etwa 50\% der Verpaarungen erfolgreich waren. Durch Verpaarung von $\mathrm{GFT}^{-/-}$-Männchen mit $\mathrm{GFT}^{+/+}$- und $\mathrm{GFT}^{+/-}-$Weibchen wurden Würfe erzielt, in denen zu etwa $50 \%$ der $\mathrm{GFT}^{-/-}$-Genotyp vertreten war.

Eine reine $\mathrm{GFT}^{-/-}$-Zucht war bisher aufgrund einer unzureichenden Verfassung der trächtigen $\mathrm{GFT}^{-/-}$-Weibchen nicht möglich. Entweder erfolgte eine Resorption in utero (aus einer äußerlich deutlich erkennbaren Schwangerschaft, die jedoch zu keinem Partus führte, zu schließen), oder die Neugeborenen verstarben unmittelbar nach der Geburt. 


\subsubsection{Blutbild}

Zur Charakterisierung von Leukozyten-Anzahl und -Populationen wurde von jeweils zwölf Tieren der Genotypen $\mathrm{GFT}^{+/+}$bzw. GFT ${ }^{-/-}$durch Färbung und Auszählung von Blutausstrichen nach Pappenheim (1912) ein Differentialblutbild erstellt (s. Tab. 4). Bei GFT'---Tieren ist die Anzahl der Leukozyten im Blut deutlich erhöht und beträgt $262 \%$ des Wertes aus den $\mathrm{GFT}^{+/+}$-Proben. Diese Erhöhung der Leukozyten-Zahl ergibt sich durch die stark erhöhte Neutrophilen-Zahl, die fast das Fünffache der ensprechenden Anzahl in Kontrollproben beträgt (s. Abb. 17).

Tab. 4: $\quad$ Differentialblutbild. (Mittelwert \pm SEM, $n=12$ pro Gruppe).

\begin{tabular}{|l|c|c|}
\hline \multicolumn{1}{|c|}{ Blutwert } & GFT $^{+++}$ & GFT $^{-1-}$ \\
\hline Hämatokrit [\%] & $48,5 \pm 1,1$ & $45,0 \pm 1,3$ \\
\hline Leukozyten $\left[\left.\mu\right|^{-1}\right.$ ] & $5421 \pm 317$ & $14206 \pm 1372$ \\
\hline Segmentkernige Neutrophile [\%] & $13,0 \pm 2,3$ & $26,9 \pm 2,8$ \\
\hline Stabkernige Neutrophile [\%] & $2,9 \pm 1,3$ & $2,8 \pm 1,2$ \\
\hline Gesamtzahl Neutrophile [ $\left.{ }^{-1}{ }^{-1}\right]$ & $841 \pm 169$ & $4184 \pm 677$ \\
\hline Eosinophile [\%] & $0,2 \pm 0,1$ & $0,3 \pm 0,2$ \\
\hline Basophile [\%] & $0,1 \pm 0,1$ & $0,0 \pm 0,0$ \\
\hline Lymphozyten [\%] & $82,6 \pm 3,1$ & $68,7 \pm 3,6$ \\
\hline Monozyten [\%] & $1,3 \pm 0,6$ & $1,3 \pm 0,6$ \\
\hline
\end{tabular}

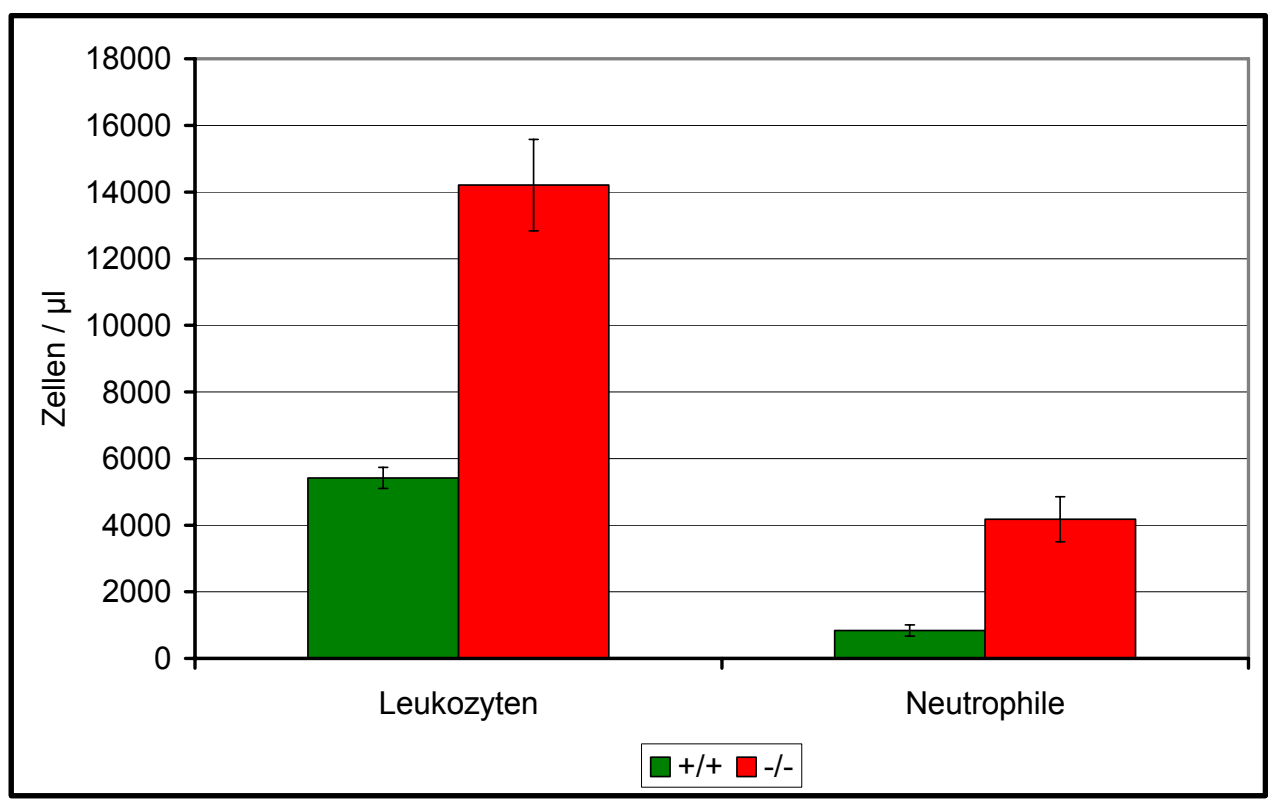

Abb. 17: Anzahl der Leukozyten bzw. der neutrophilen Granulozyten. (Mittelwert \pm SEM, $n=12$ ). 


\subsection{Nachweis des Knockouts auf Ebene der RNA und GDP- Fucose-Import-Aktivität}

Bisherige Versuche, Antikörper gegen den GDP-Fucose-Transporter herzustellen, sind, vermutlich aufgrund der hohen Hydrophobizität des Proteins, fehlgeschlagen. Daher kann der Nachweis des Knockouts nicht auf der Proteinebene sondern nur auf Ebene der Transkription und indirekt anhand der Proteinfunktion nachgewiesen werden.

\subsubsection{Expressionsanalyse durch Northern-Blot}

Zur Untersuchung der Genexpression wurde aus verschiedenen Organen von $\mathrm{GFT}^{+/+}$bzw. $\mathrm{GFT}^{-1-}$-Tieren die Gesamt-RNA präpariert und einer Northern-BlotAnalyse unterzogen. Die Transkripte des SLC35C1-Gens wurden mit einer radioaktiv markierten Sonde detektiert, die mit einem vorderen Abschnitt des ersten Exons vor der Insertionsstelle der Neo-Kassette hybridisiert (Primer: GFTF2 und -R4). Nach Autoradiographie und Dokumentation wurde die Sonde wieder von den Membranen gewaschen. Anschließend erfolgte die Hybridisierung mit einer $\beta$-Aktin-Sonde, um anhand dieses ubiquitär exprimierten Gens die RNAMenge und -Qualität zu kontrollieren (s. Abb. 18).

In den $\mathrm{GFT}^{-/}$-Proben ließ sich im Gegensatz zu den $\mathrm{GFT}^{+/+}$-Proben kein SLC35C1-Signal detektieren. Die $\beta$-Aktin-Expression hingegen zeigte sich praktisch unverändert. 


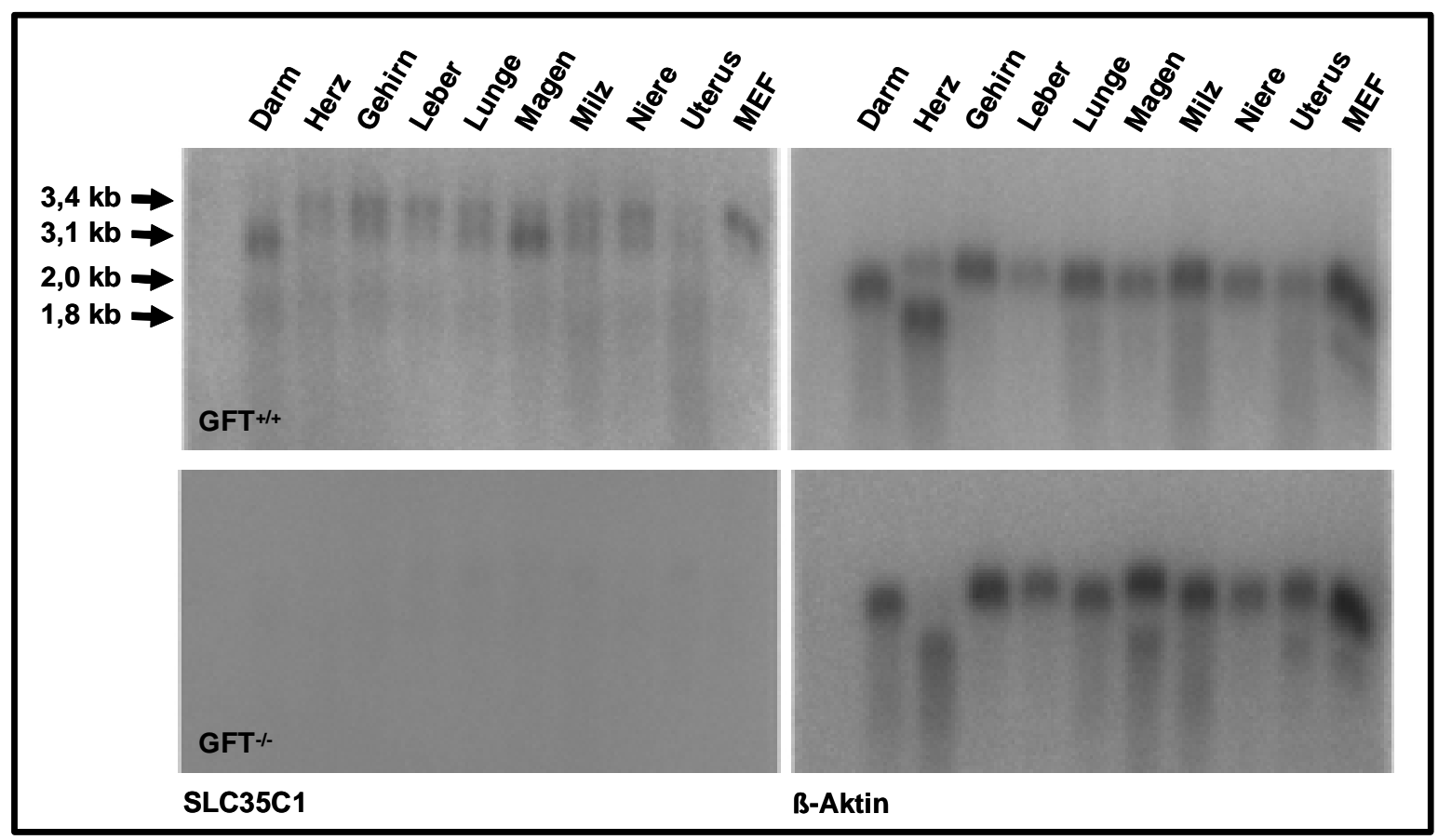

Abb. 18: Bandenmuster nach Northern-Blot. Eingesetzt wurden jeweils $8 \mu \mathrm{g}$ der GesamtRNA aus Geweben der Maus. Für SLC35C1 wurden mit der verwendeten Sonde vorwiegend Transkripte von 3,4 kb und 3,1 kb detektiert. Die $\beta$-Aktin-Transkripte wiesen eine Größe von 2,0 kb bzw. 1,8 kb auf.

\subsubsection{Zuckernukleotid-Import-Aktivität in Golgi-angereicherten Vesikeln aus Leberhomogenat}

Die Proteinaktivität des GFT wurde durch einen Assay ermittelt, der die Quantifizierung importierter Zuckernukleotide in isolierte mikrosomale Vesikel ermöglicht. Die Vesikel wurden durch Zellaufschluss und Ultrazentrifugation des Materials in einem Sucrose-Gradienten aus Leberhomogenat angereichert. Die Anreicherung wurde anhand der Golgi-spezifischen Galactosyltransferase-Aktivität ermittelt. Diese betrug in dem Golgi-haltigen Membranfeld, das von dem SucroseGradienten geerntet wurde, im Mittel das 8,9fache im Vergleich zur Aktivität im Leberhomogenat und variierte zwischen dem 6,0- und 12,8fachen.

Aliquots des Membranfelds, entsprechend $400 \mu \mathrm{g}$ Gesamtprotein, wurden mit radioaktiv markierter GDP-Fucose bzw. UDP-Galactose inkubiert. Der UDP- 
Galactose-Transporter diente als Golgi-spezifische, von dem GFT-Knockout nicht betroffener Kontrolltransporter.

Die absoluten Werte für die GDP-Fucose-Importaktivität in Vesikeln aus $\mathrm{GFT}^{+/+}$bzw. GFT ${ }^{-/}$-Leber lagen bei 1,118 vs. $0,064 \mathrm{pmol} /(\mathrm{mg}$ Protein $\cdot \mathrm{min})$. Die Aktivität in $\mathrm{GFT}^{-/-}$-Gewebe ist also gemäß dieser Werte auf 5,7\% reduziert. In $\mathrm{GFT}^{+/-}$-Gewebe ist sie praktisch unverändert (1,094 pmol/(mg Protein·min)).

Um präparationsbedingte Veränderungen der Aktivität, beispielsweise verursacht durch die z.T. sehr unterschiedliche Golgi-Anreicherung (s.o.) oder Integrität der Vesikel, zu berücksichtigen, wurde sie auf die in $\mathrm{GFT}^{-/-}$-Gewebe unverminderte UDP-Galactose-Importaktivität normalisiert (s. Abb. 19). Dieses Verhältnis lag in $\mathrm{GFT}^{+/+}$-Proben bei 5,89 vs. 0,20 in $\mathrm{GFT}^{-/-}$-Proben und war somit in Letzteren auf $3,3 \%$ reduziert.

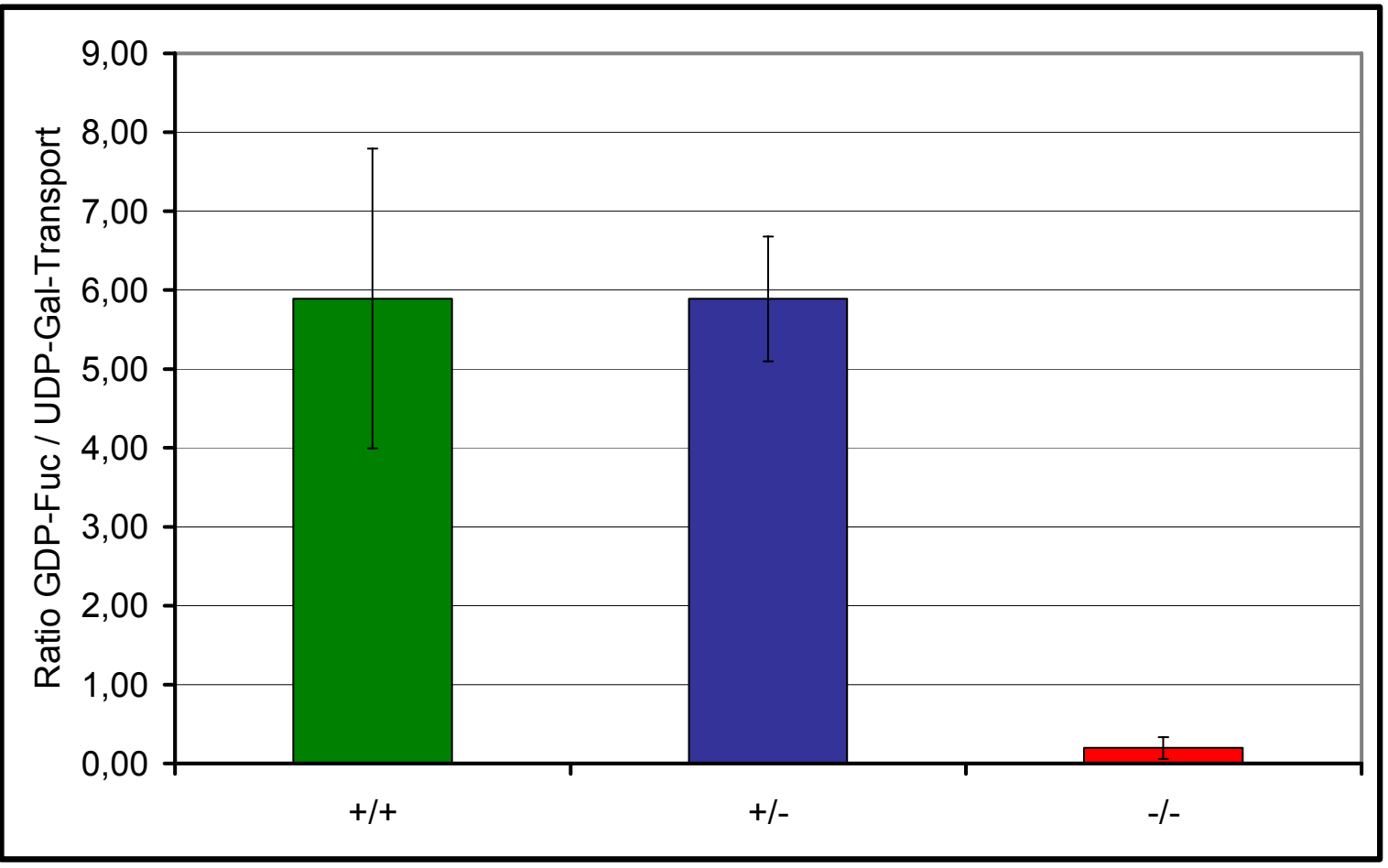

Abb. 19: Verhältnis der spezifischen GDP-Fucose- und UDP-GalactoseTransportaktivitäten. $\mathrm{n}\left(\mathrm{GFT}^{+/+}\right)=6, \mathrm{n}\left(\mathrm{GFT}^{+/}\right)=4, \mathrm{n}\left(\mathrm{GFT}^{-/}\right)=3$ (Mittelwert $\left.\pm \mathrm{SDM}\right)$. 


\subsection{Charakterisierung der Fucosylierung in primären Zellkulturen}

\subsubsection{Markierung fucosylierter Strukturen in primären embryonalen Fibroblasten durch Aleuria aurantia-Lektin}

Lektine sind zuckerbindende Strukturen, die nach ihrem jeweiligen Ursprungsorganismus benannt sind und für die Lokalisierung und Differenzierung verschiedener Glykokonjugate Verwendung finden. Für die erste qualitative Erfassung der Fucosylierungsrate in $\mathrm{GFT}^{-/}$-Zellen wurden primäre Fibroblasten aus Embryonen (MEF) präpariert und mit Hilfe des Aleuria aurantia-Lektins ( $A A L$ ),

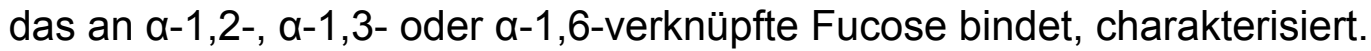

Die Zellen wurden fixiert und mit biotinyliertem AAL markiert. Dieses wiederum wurde durch Alkalische Phosphatase (AP)-gekoppelte Streptavidin-Moleküle als Signalverstärker detektiert. Bei der Umsetzung eines Farbsubstrats durch die AP bilden sich purpurfarbene Präzipitate an markierten Zellstrukturen, während nichtmarkierte Bereiche ungefärbt bleiben (s. Abb. 20).

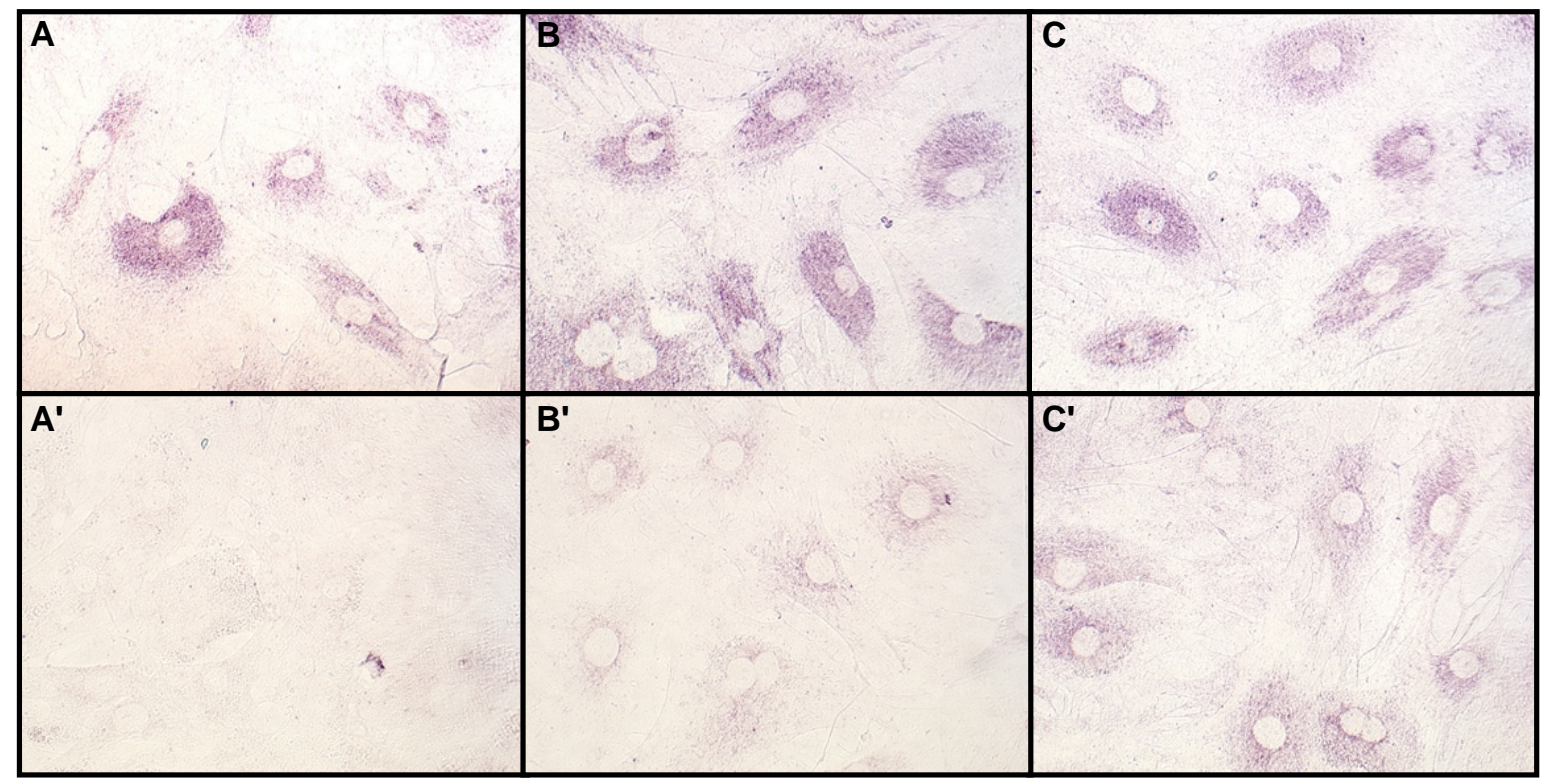

Abb. 20: Nachweis fucosylierter Strukturen in MEF durch Aleuria aurantia-Lektin. A, B, $C$ entspricht jeweils $\mathrm{GFT}^{+/+}, \mathrm{A}^{\prime}, \mathrm{B}^{\prime}, \mathrm{C}^{\prime}$ entspricht $\mathrm{GFT}^{-/-}$. Vor der Fixierung wurden die Zellen für $48 \mathrm{~h}$ ohne Zusatz von Fucose (A, $\left.A^{\prime}\right)$ bzw. mit Fucosesupplementiertem Medium (B, B': 1 mM; C, C': 10 mM) kultiviert (Objektiv: 50x). 
In $\mathrm{GFT}^{+/+}$-MEF waren perinukleär liegende Präzipitate deutlich zu erkennen, GFT ${ }^{-/-}$ -MEF hingegen blieben ungefärbt.

Gleichzeitig wurde mit diesem Ansatz untersucht, ob sich durch Supplementierung des Kulturmediums mit Fucose eine Refucosylierung in $\mathrm{GFT}^{-/-}-\mathrm{MEF}$ einstellen lässt. Die Zellen wurden für $48 \mathrm{~h}$ bis zur Fixierung in Fucose-haltigem Medium (1 mM bzw. $10 \mathrm{mM}$ ) inkubiert. Durch $1 \mathrm{mM}$ Fucose ließ sich bereits eine leichte Färbung erzeugen, nach Inkubation mit $10 \mathrm{mM}$ Fucose im Medium stellte sich nahezu eine Normalisierung der Expression entsprechender fucosylierter Strukturen ein.

\subsubsection{Quantitative Analyse der Fucosylierung durch Lens culinaris- Lektin-Affinitätschromatographie}

\subsubsection{Primäre embryonale Fibroblasten}

Das fucosebindende Lektin LCA stammt aus der Speiselinse (Lens culinaris). Dieses bindet an a-1,6-verknüpfte Core-Fucose in mannosereichen bi- und triantennären $\mathrm{N}$-Glykanen und ist unter anderem in Agarose-gekoppelter Form verfügbar. Säulen mit dieser Agarose wurden zur spezifischen Quantifizierung der entsprechenden Zuckerstrukturen aus Zellextrakten verwendet.

Zunächst wurden die Zellen durch Inkubation mit einem glucosearmen "Hungermedium" unter Zusatz von [2-- $\mathrm{H}$ ]Mannose metabolisch markiert. Aufgrund des Nährstoffmangels wird der markierte Zucker in erhöhter Rate aufgenommen und in Glykokonjugate inkorporiert. Nach Aufschluss der Zellen wurden die Glykoproteine durch mehrere Extraktionsschritte angereichert, ihr Proteinanteil mit Pronase, einer Protease-Mischung aus Streptomyces griseus, abgedaut und die resutierenden Glykopeptide mit LCA-Agarose inkubiert. Nach Auswaschen nichtgebundener Glykopeptide wurden die spezifisch gebundenen durch Verdrängung mit einer vergleichsweise hohen Konzentration des Haptens Methyl- $\alpha-D-$ mannopyranosid eluiert. Ihre Quantifizierung erfolgte durch Messung der Radioaktivität in den Elutionsfraktionen. Das ensprechende Elutionsprofil nach Durchführung dieses Protokolls mit MEF ist in Abbildung 21 und 22 dargestellt. 


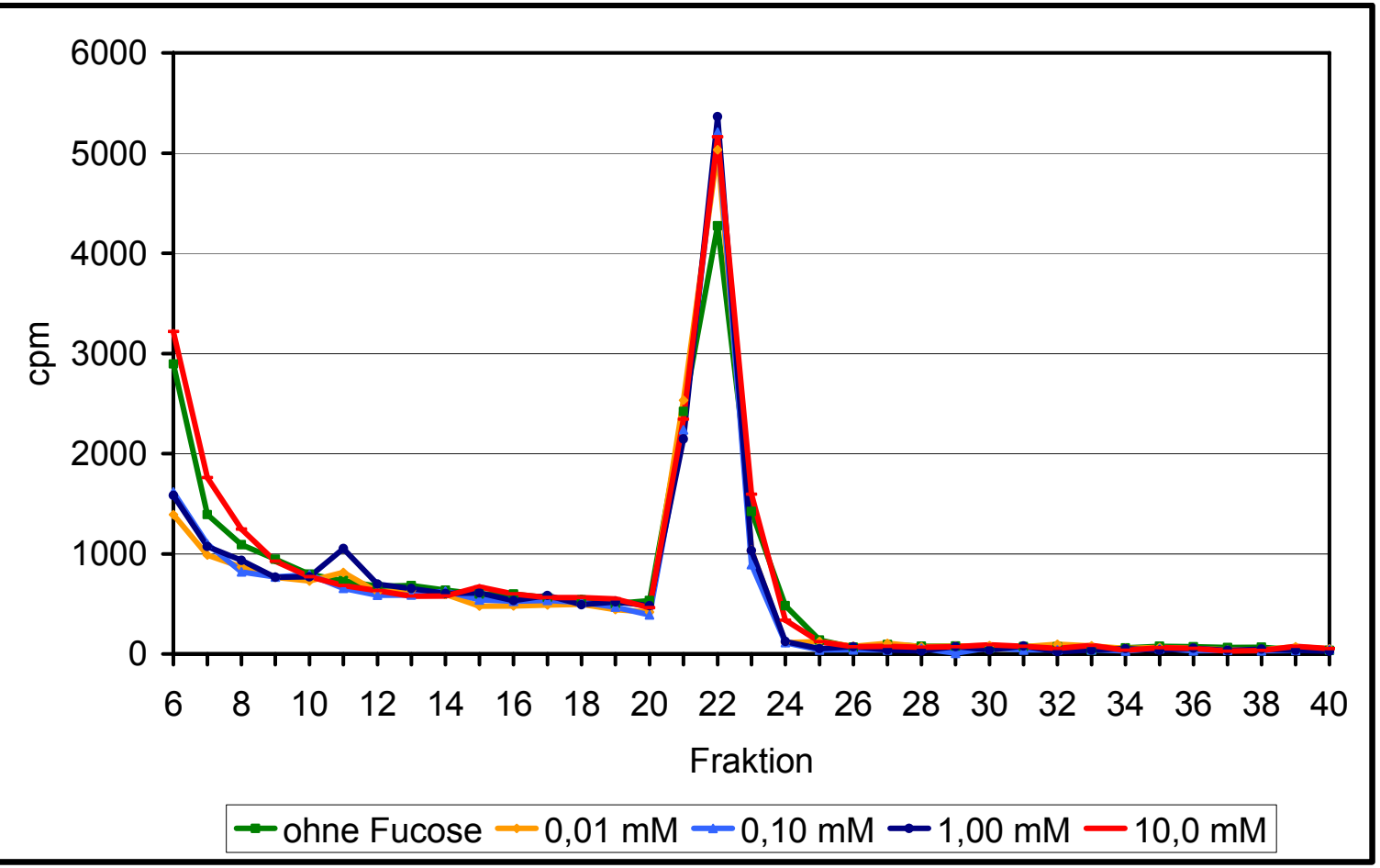

Abb. 21: Elutionsprofil der Lens culinaris-Affinitätschromatographie mit Extrakten aus $\mathrm{GFT}^{+/+}$-MEF. Es wurde jeweils ein Probenvolumen entsprechend $120.000 \mathrm{cpm}$ aufgetragen.

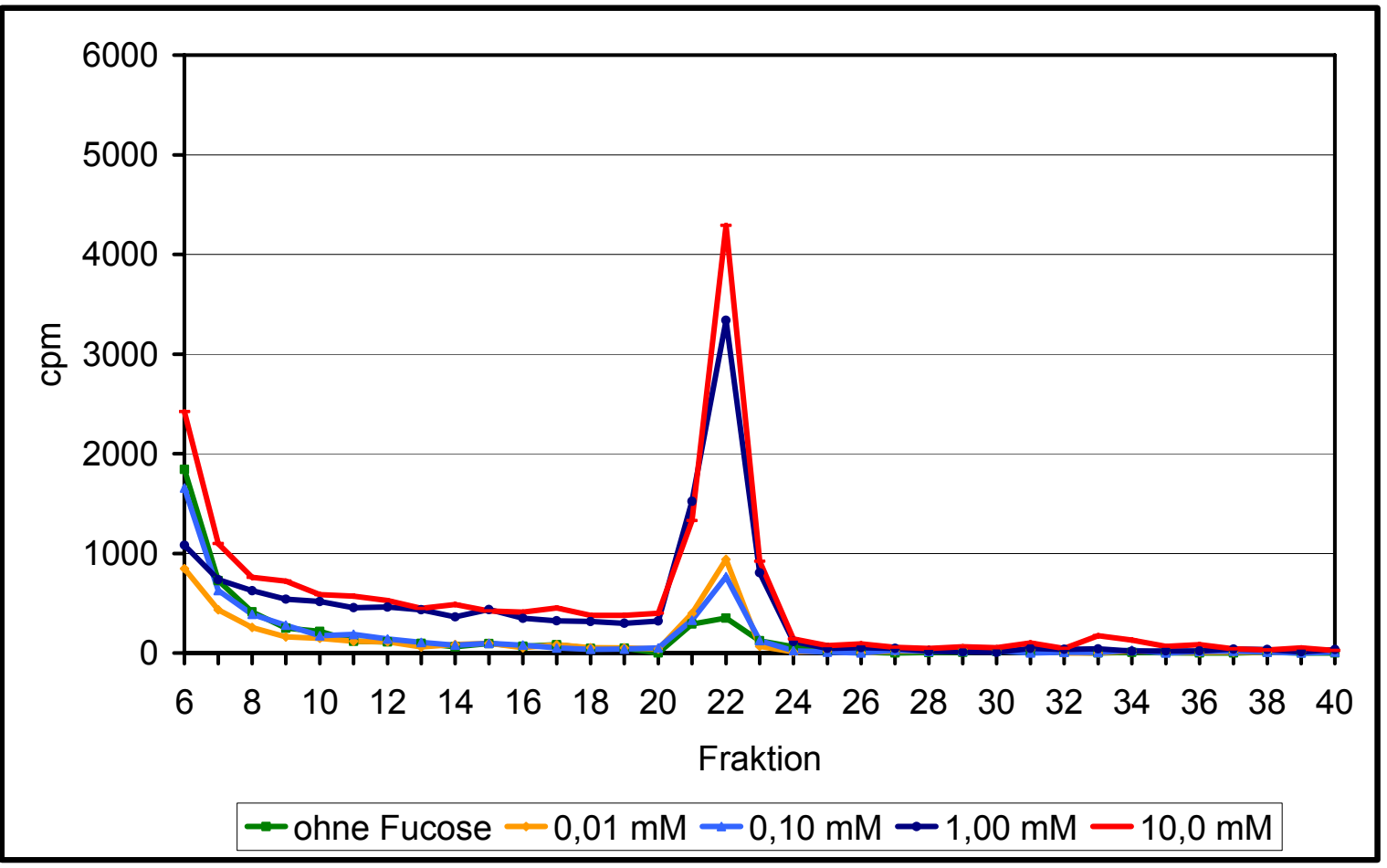

Abb. 22: Elutionsprofil der Lens culinaris-Affinitätschromatographie mit Extrakten aus $\mathrm{GFT}^{-1-}$-MEF. 
Die aus $\mathrm{GFT}^{+/+}-\mathrm{MEF}$ extrahierten und spezifisch an das Lektin gebundenen Glykopeptide stellen im Fall des in den Abbildungen 21 und 22 dargestellten, repräsentativen Experiments 8,4\% der insgesamt auf die Säule geladenen Radioaktivität dar (ohne Fucosebehandlung). Dieser Anteil lag bei GFT'--Proben bei $0,8 \%$, es ist also eine geringe Fucosylierung zu detektieren.

Mit dieser Methode konnte die dosisabhängige Refucosylierung in $\mathrm{GFT}^{-/-}$-MEF quantifiziert werden. Durch Supplementierung des Mediums mit 0,01 mM oder 0,1 mM Fucose konnte der Anteil spezifisch gebundener Glykopeptide nur leicht erhöht werden (1,4 bzw. 1,2\%). Ein deutlicher Effekt stellte sich jedoch durch 1 $\mathrm{mM}$ Fucose ein $(5,3 \%)$, der durch eine Konzentration von $10 \mathrm{mM}$ noch weiter auf drei Viertel des $\mathrm{GFT}^{+/+}$-Wertes gesteigert werden konnte $(6,3 \%)$.

\subsubsection{Primäre Hepatozyten}

Die unter 4.4.2.1 beschriebene Methode zur Quantifizierung der Fucosylierungsrate wurde neben den leicht zu präparierenden und verhältnismäßig anspruchslosen Fibroblasten für einen weiteren, völlig anders gearteten Zelltyp, primäre Hepatozyten, angewandt.

Die Präparation dieser Zellen erfolgte durch eine Leberperfusion mit EDTAhaltigem Puffer. Die Zellen bildeten auf Kollagen-beschichteten Kulturgefäßen innerhalb weniger Stunden ein charakteristisches parenchymartiges Muster aus (s. Abb. 23). Sie teilten sich unter diesen Bedingungen nicht weiter und konnten bis zu 14 Tagen in Kultur gehalten werden.

Für die Affinitätschromatographie hinreichende Mengen an markierten Glykopeptiden konnten erst nach Supplementierung des Markierungsmediums mit Insulin erzielt werden. Die Elutionsprofile waren ähnlich wie in MEF gestaltet (s. Abb. 24). In $\mathrm{GFT}^{+/+}$-Proben konnten 5,6 bzw. 5,9\% der Gesamtaktivität (ohne bzw. mit $10 \mathrm{mM}$ Fucose) an die Matrix binden. Für $\mathrm{GFT}^{-/-}$-Hepatozyten betrug dieser Anteil $0,9 \%$ ohne Fucose und 6,1\% mit $10 \mathrm{mM}$ Fucose. Hier ließ sich also eine vollständige Normalisierung der Fucosylierung erzielen. 


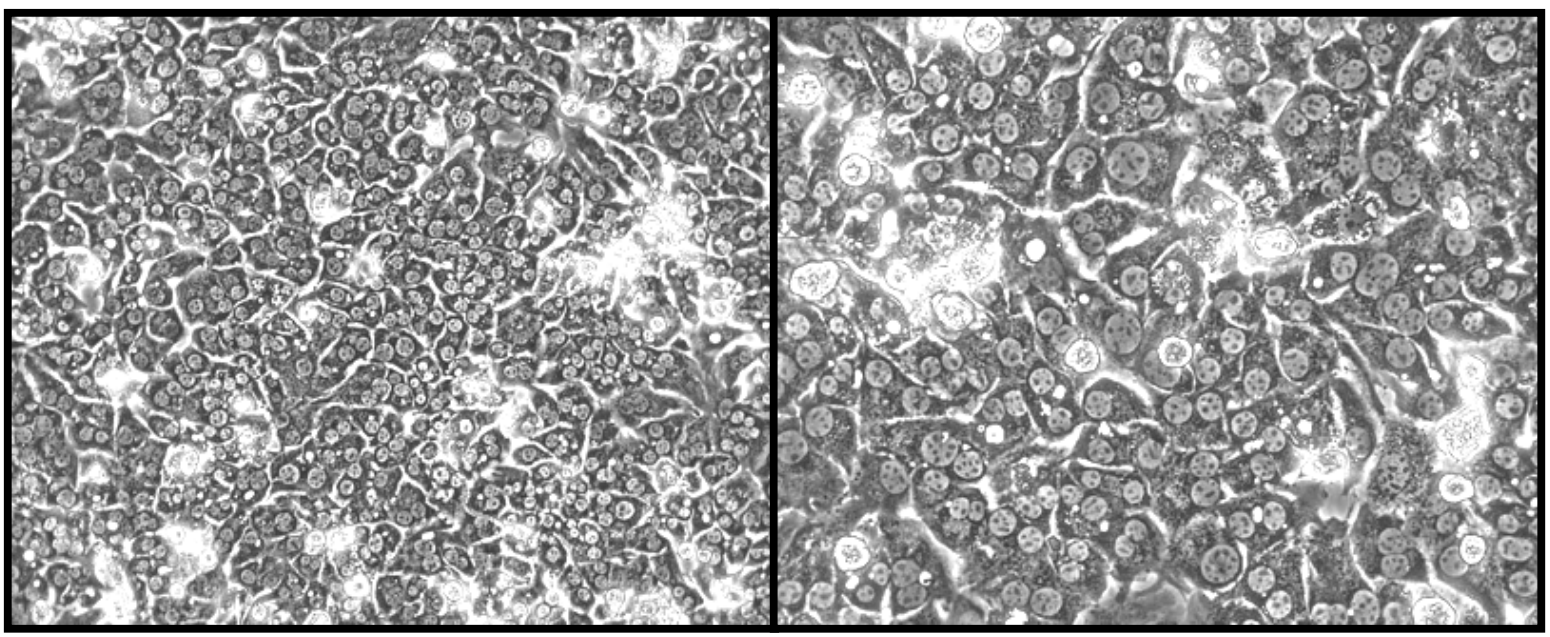

Abb. 23: Primäre Hepatozyten $72 \mathrm{~h}$ nach der Präparation. Die Zellen weisen eine parenchymartige Morphologie auf und sind überwiegend di- oder polynukleär. Die hellen Bereiche sind nur teilweise adhärente Zellen, die keinen Platz auf der Kulturfläche gefunden haben und in einer höheren Fokussierungsebene schwimmen (Objektive: links 10x, rechts 20x).

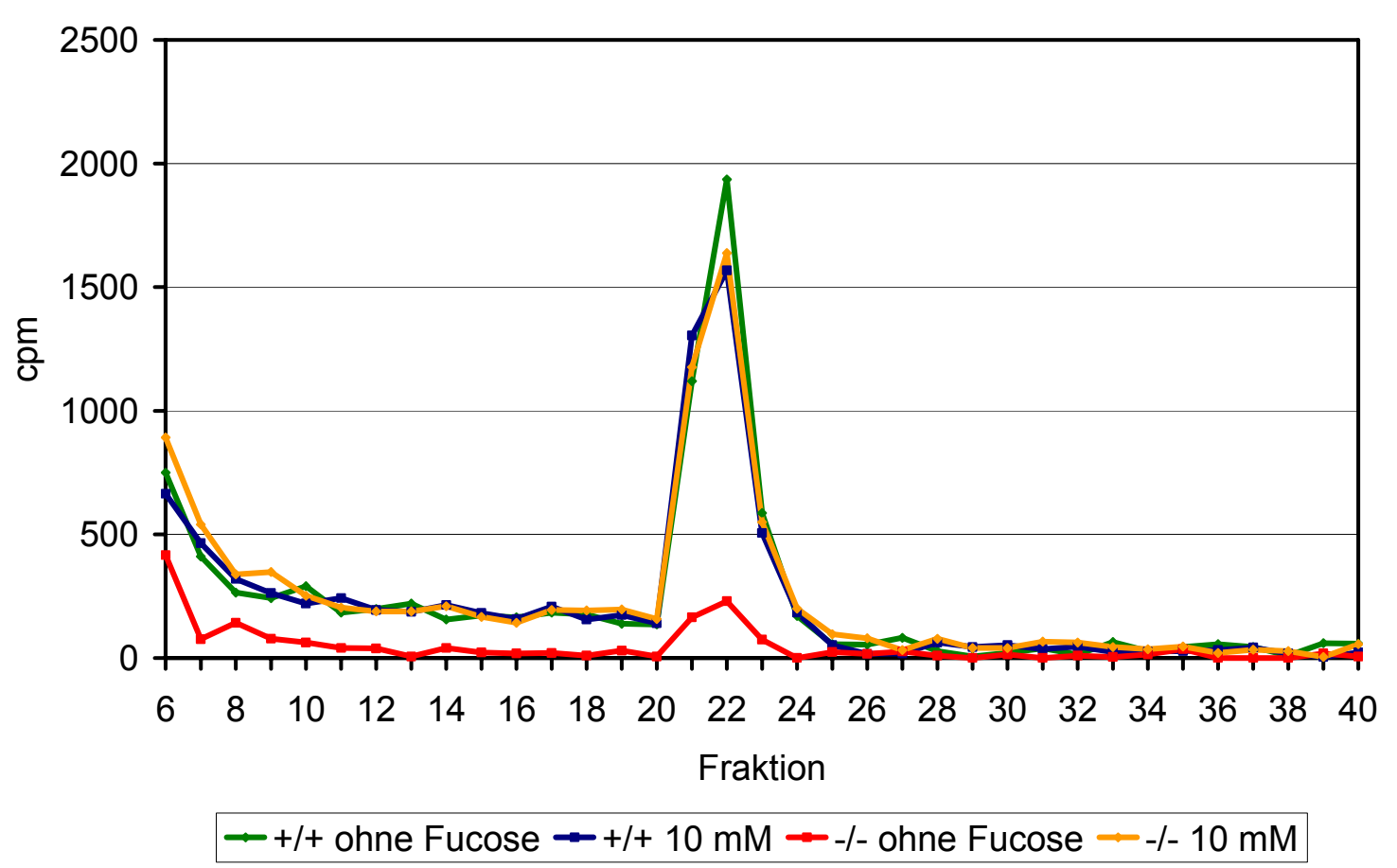

Abb. 24: $\quad$ Elutionsprofil der Lens culinaris-Affinitätschromatographie mit Extrakten aus Hepatozyten. Es wurde jeweils ein Probenvolumen entsprechend $70.000 \mathrm{cpm}$ aufgetragen. 


\subsubsection{Primäre Mesangialzellen}

Schließlich wurden primäre Zellkulturen eines dritten Zelltyps, der Mesangialzellen der Niere, etabliert und ihre Fucosylierungsrate analog zu 4.4.2.1 charakterisiert. Die Präparation erfolgte mit Hilfe eines Siebverfahrens, welches die Isolierung der Glomerula aus der Nierenrinde ermöglicht. Wurden diese Collagenase-behandelt und anschließend in Nährmedium kultiviert, konnte nach etwa fünf Tagen das Auswachsen von Mesangialzellen in die Peripherie beobachtet werden. Nach etwa 14 Tagen waren die Zellen konfluent und konnten passagiert werden.

Die Kontamination der Kulturen mit Fibroblasten wurde durch Verwendung eines D-Valin-haltigen Mediums ausgeschlossen. Bei gleichzeitiger, vorübergehender Absenkung des Serumgehaltes wurden Fibroblasten eliminiert, da sie im Gegensatz zu Mesangialzellen nicht das Enzym D-Aminosäure-Oxidase besitzen, das die Umwandlung von D- zu L-Valin katalysiert (Gilbert und Migeon, 1975). Weitere Zelltypen aus Glomerula wie beispielsweise Epithelzellen sind anspruchsvoller und benötigen weitere Mediumzusätze, so dass ihr Wachstum nach wenigen Passagen auszuschließen war. Nach etwa vier Passagen ergab sich ein homogenes Bild von spindelförmigen Mesangialzellen (s. Abb. 25).

Eine Markierung der Glykoproteine dieses Zelltyps mit [2- $\left.{ }^{3} \mathrm{H}\right]$ Mannose war im Gegensatz zu Hepatozyten unproblematisch. Bei der Elution der Glykopeptide von der LCA-Affinitätsmatrix fiel zunächst auf, dass in $\mathrm{GFT}^{+/+}$-Proben der Anteil der spezifisch gebundenen d.h. fucosylierten Glykopeptide geringer war als der aus entsprechenden Proben aus MEF und Hepatozyten (4,2 bzw. 4,9\% ohne bzw. mit $10 \mathrm{mM}$ Fucose). Bei GFT ${ }^{-/-}$-Proben lag dieser Anteil bei $0,8 \%$ ohne Fucose-Zusatz im Medium, bei 4,1\% unter $10 \mathrm{mM}$ Fucose. Also ist auch hier eine schwache Fucosylierung ohne Fucose-Supplementierung vorhanden, die sich durch Zusatz von $10 \mathrm{mM}$ Fucose in das Kulturmedium vollständig normalisieren lässt (s. Abb. 26). 


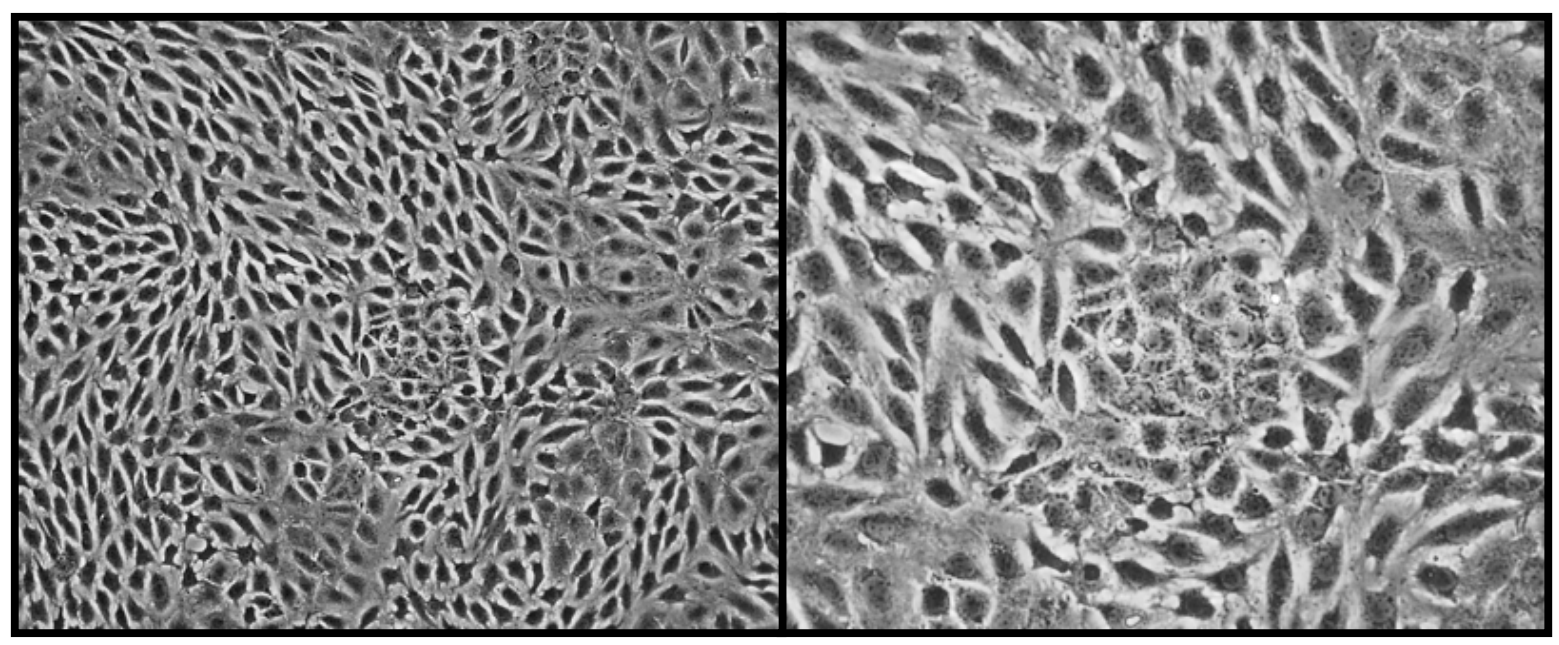

Abb. 25: Primäre Mesangialzellen. Die Zellen sind spindelförmig und bilden bei höherer Dichte kleine Hügel, die sogenannten "hillocks", aus (Objektive: links 10x, rechts 20x).

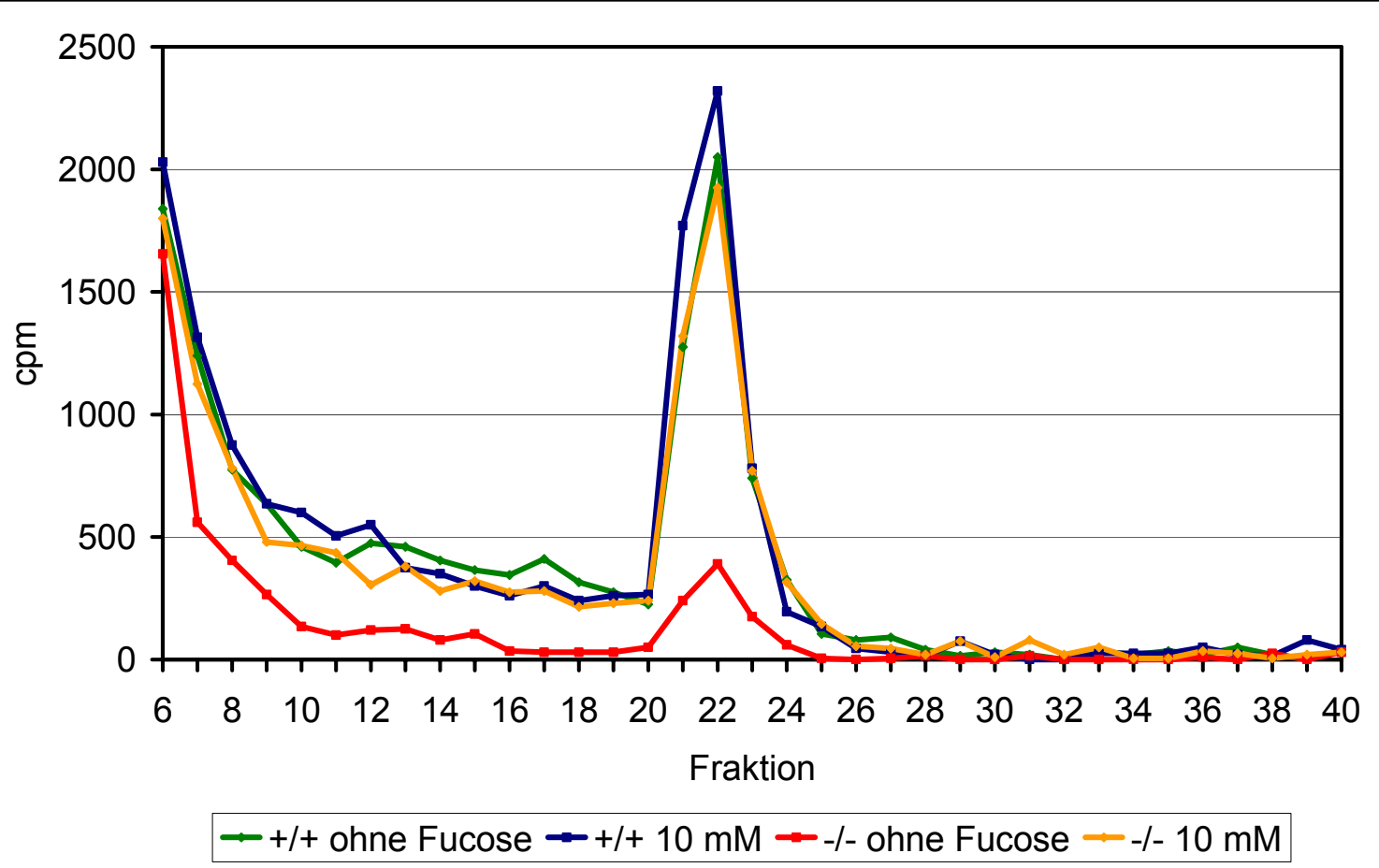

Abb. 26: Elutionsprofil der Lens culinaris-Affinitätschromatographie mit Extrakten aus Mesangialzellen. Es wurde jeweils ein Probenvolumen entsprechend 120.000 cpm aufgetragen. 
4.5

\section{Fucosylierung und Selektin-Liganden-Funktion auf Leukozyten}

\subsubsection{FACS-Analyse isolierter Leukozyten aus dem Knochenmark}

Die Expression fucosehaltiger Selektin-Liganden wurde in Zusammenarbeit mit Dr. Martin Wild, Yvonne Helmus und Sviatlana Yakubenia in der Abteilung von Prof. Dr. Dietmar Vestweber am Max-Planck-Institut für Molekulare Biomedizin Münster anhand von isolierten Leukozyten des Knochenmarks unter Verwendung der Durchflusszytometrie (FACS) charakterisiert. Die Auswahl der Leukozytenpopulation aus den Zellisolaten erfolgte anhand ihrer Morphologie (Größe und Granularität), die im FACS mit großer Genauigkeit erfasst wird.

Nach ihrer Präparation wurden die Knochenmarkszellen mit E- und P-Selektin-FcFusionsproteinen inkubiert, welche an die entsprechenden Selektin-Liganden auf der Leukozytenoberfläche binden. Die Detektion der gebundenen Selektine erfolgte mit einem Sekundärantikörper, welcher an das Fluorochrom Phycoerythrin (PE) gekoppelt war. Die Ergebnisse der sich daran anschließenden durchflusszytometrischen Analyse sind in Abbildung 25 dargestellt. Bei $\mathrm{GFT}^{+/+}$Proben ist ein deutlicher Peak entsprechend der PE-markierten Zellen zu erkennen. Dieser ist bei Verwendung eines E-Selektin-Fc-Fusionsproteins schwächer ausgeprägt, was jedoch auf die Qualität des Fusionsproteins selbst zurückzuführen ist. In den entsprechenden $\mathrm{GFT}^{-/}$-Proben ist keine $\mathrm{E}$ - und PSelektinbindung zu detektieren, die Peaks der gezählten Zellen überlappen praktisch vollständig mit der Negativkontrolle.

Analog wurde auch hier das Aleuria aurantia-Lektin (AAL) sowie als Positivkontrolle das an Sialinsäure bindende Maackia amurensis-Lektin (MAL II) eingesetzt. Der Nachweis der an die Zellen gebundenen biotinylierten Lektine erfolgte mit PE-gekoppeltem Streptavidin. Während die MAL II-Bindung an GFT ${ }^{-/}$Leukozyten normal war, zeigte sich eine deutliche Linksverschiebung des AALPeaks. Dieser überlappte jedoch nicht vollständig mit der Negativkontrolle, d.h. hier ist eine geringe Restbindung festzustellen. 


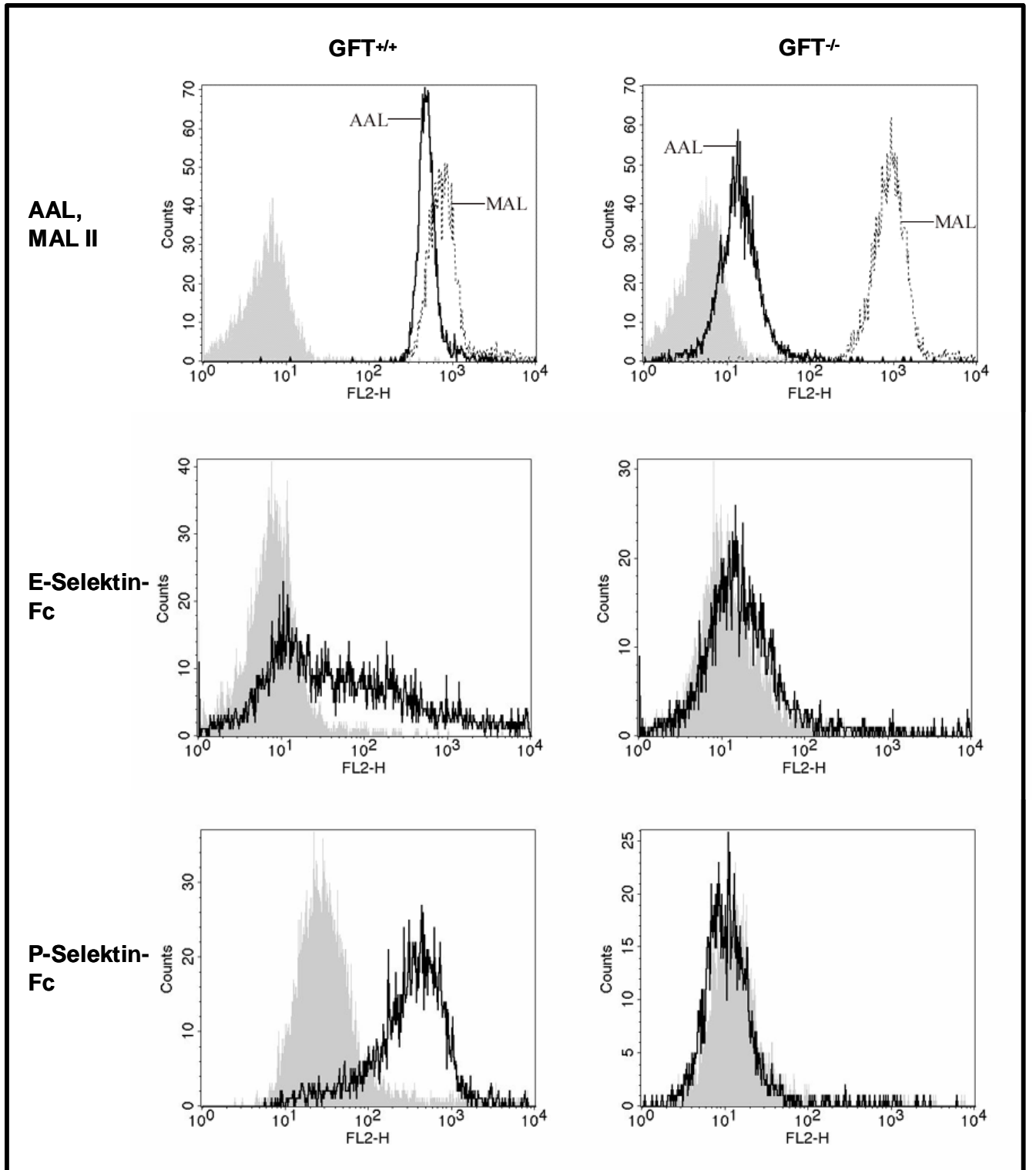

Abb. 27: Histogramme nach FACS-Analyse der Neutrophilen. Die Abszisse repräsentiert in logarithmischer Skalierung die Intensität der Fluoreszenz durch die gebundenen fluoreszierenden Marker, die Ordinate die Zellzahl. Der grau hinterlegte Bereich entspricht den EDTA-Negativkontrollen. 


\subsubsection{FACS-Analyse von Milzzellen nach Fucose-Supplementierung}

Die Untersuchungen zur Korrekturmöglichkeit der Hypofucosylierung von $\mathrm{GFT}^{-{ }^{-}}$Zellen (s. 4.4) wurden auch an Leukozyten der Milz durchgeführt. In diesem Fall erfolgte die Quantifizierung der Fucosylierung durch eine Lektin-abhängige durchflusszytometrische Analyse entsprechend 4.5.1. Die primären Milzzellen wurden vor der Analyse über Nacht (18 h) in normalem oder mit 10 mM Fucose supplementiertem Medium inkubiert.

Es zeigte sich auch hier eine auffällige Linksverschiebung des Peaks entsprechend der AAL-bindenden Zellen, die jedoch nicht zu einer vollständigen Übereinstimmung mit der Negativkontrolle führt. Unter Fucose-Behandlung verschiebt sich dieser Peak nach rechts, was eine Refucosylierung der Milzzellen indiziert.

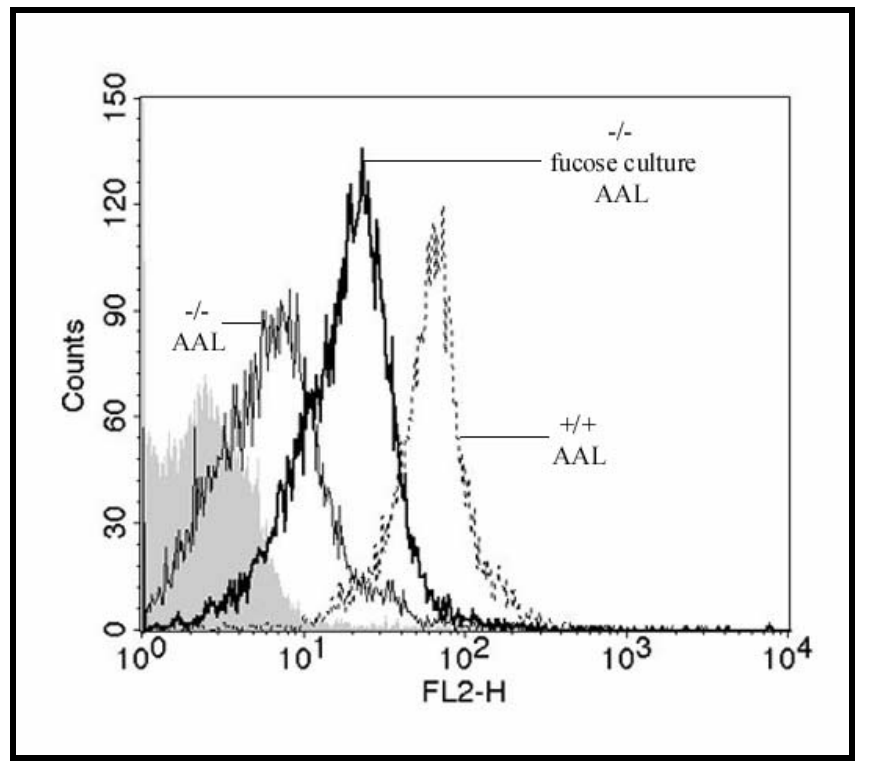

Abb. 28: Histogramm nach FACS-Analyse von Milzzellen. Die $\mathrm{GFT}^{-1}$-Milzzellen wurden für $24 \mathrm{~h}$ parallel ohne Fucose und mit Fucose-supplementiertem Medium (10 mM) inkubiert. 


\subsubsection{Leukozyten-Rollen in HEV der Peyer'schen Plaques}

Die Interaktionen von Leukozyten mit dem Gefäßendothel, welches die Bindung fucosylierter Selektin-Liganden an Selektine erfordert, wurde in Zusammenarbeit mit Dr. Markus Sperandio (Klinik für Kinder- und Jugendmedizin Heidelberg, Abt. IV Neonatologie) mit Hilfe der Intravitalmikroskopie in hochendothelialen Venolen (HEV) von Peyer'schen Plaques des Dünndarms dargestellt.

Die Leukozyten des narkotisierten Tieres wurden durch Rhodamin 6G fluoreszenzmarkiert, so dass ihr Durchflussverhalten in den HEV dünner Bereiche der Peyer'schen Plaques beobachtet werden konnte. Im Verlauf dieser Beobachtungen wurden Selektin- und Integrin-blockierende Antikörper injiziert, um deren Effekt bzw. die Abhängigkeit des Leukozytenrollens von den entsprenden Strukturen zu untersuchen.

Das Ausmaß des Rollens wird als die "Rolling flux fraction" (RFF) ausgedrückt. Diese entspricht dem Anteil der auf dem Endothel rollenden Leukozyten an der Gesamtzahl der das Gefäß passierenden Leukozyten. Alle in Abbildung 27 dargestellten Werte wurden jeweils in Prozent der RFF im unbehandelten $\mathrm{GFT}^{+/+}$Tier dargestellt.

Im unbehandelten $\mathrm{GFT}^{-/-}$-Tier ist die RFF auf $13,7 \%$ reduziert. Sie bleibt unverändert bei spezifischer Blockade von L-Selektin-Bindungsstellen, während die RFF in den HEV von $\mathrm{GFT}^{+/+}$-Tieren dadurch um etwa zwei Drittel auf $36,7 \%$ reduziert wird. Bei zusätzlicher Applikation eines P-Selektin-blockierenden Antikörpers verringert sich die RFF in beiden Fällen kaum signifikant weiter. Wird ausschließlich die fucosylierungsunabhängige $\alpha_{4} \beta_{7}$-Integrin-Bindung blockiert, so wird das Leukozytenrollen in $\mathrm{GFT}^{-/-}-\mathrm{HEV}$ vollständig unterbunden. Dies erfolgt in $\mathrm{GFT}^{+/+}$-HEV erst nach Blockade aller drei Epitope. 


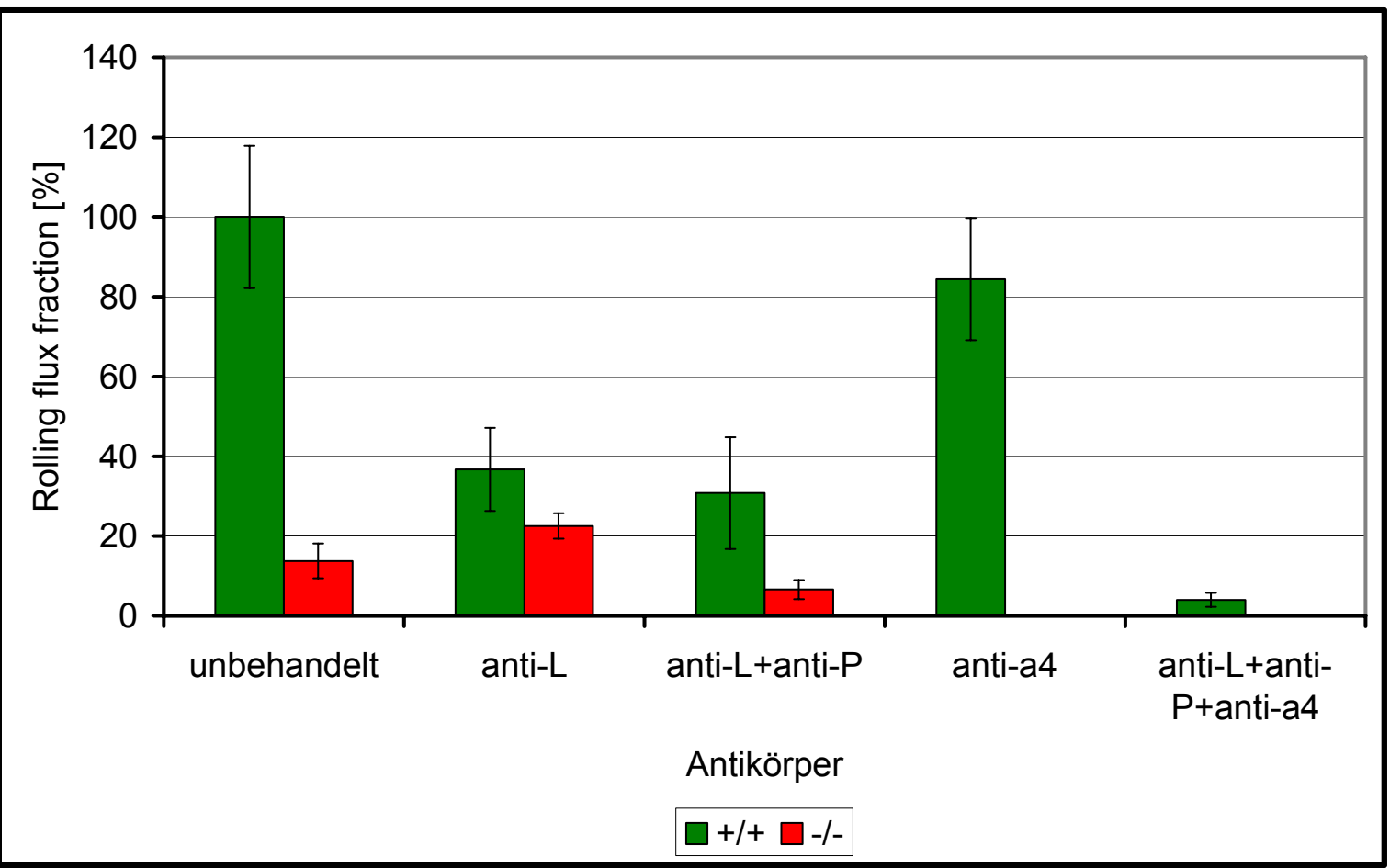

Abb. 29: $\quad$ "Rolling flux fraction" der Leukozyten in HEV der Peyer'schen Plaques in $\mathrm{GFT}^{+/+}$- und $\mathrm{GFT}^{-l-}$-Tieren. Die absoluten Werte wurden in Verhältnis zum Wert "+/+ unbehandelt" (=100\%) gesetzt (Mittelwert \pm SDM, $n=7$ pro Gruppe). 


\subsection{Histologie der Organe}

Für die histologische Charakterisierung wurden die Organe aus insgesamt vier Tieren pro Genotyp (GFT ${ }^{+/+}$bzw. $\mathrm{GFT}^{-/}$) präpariert, in Formaldehyd fixiert und in Paraffin eingebettet. Bei der Sektion der Paraffinblöcke wurden jeweils mehrere Schnittebenen gewählt, um Fehlschlüsse durch Beurteilung von nur kleinen Ausschnitten nach Möglichkeit zu vermeiden. Die Tiere wiesen ein Alter zwischen zwei und sechs Monaten auf, es wurden von jedem Genotyp jeweils gleichaltrige Geschwister verwendet.

Bei allen Präparationen wurde auf makroskopisch sichtbare Unterschiede in der Größe und Morphologie geachtet. Die Organe waren proportional zur verminderten Gesamtkörpergröße entsprechend kleiner. Auffällig war eine überproportionale Hypomorphie der Lymphknoten, die aus diesem Grund oft nur sehr schwer aufzufinden waren. Bei einigen $\mathrm{GFT}^{-/}$-Tieren zeigte sich die Milz leicht vergrößert. Darüber hinaus konnten keine besonderen anatomischen Auffälligkeiten beobachtet werden.

\subsection{1 Übersichtsfärbung der histologischen Präparate}

$3 \mu \mathrm{m}$-Sektionen der Paraffin-eingebetteten Organe wurden nach Anwendung der HE-Übersichtsfärbung beurteilt. Dabei wurden saure Gewebebestandteile, d.h. vor allem Nukleinsäuren in den Zellkernen, blau-violett angefärbt. Verschiedene andere Strukturen wie Kollagenfasern, Muskelfibrillen oder Erythrozyten zeigten durch Eosin eine rote Färbung. Für Sektionen der Lunge wurde zusätzlich eine kombinierte Elastica-Trichrom-Färbung angewandt (Erläuterungen: s. Abb. 33).

Die folgenden Farbtafeln (Abb. 30 bis 38) zeigen jeweils repräsentative Ausschnitte aus den HE-gefärbten Präparaten. Je nach Eignung zum Aufzeigen bestimmter Elemente wurden verschiedene Vergrößerungen gewählt (40x, 100x, 200x oder 400x). Pfeile markieren eine Auswahl charakeristischer und gegebenenfalls auffällig veränderter Elemente der einzelnen Organe bzw. Gewebe. 


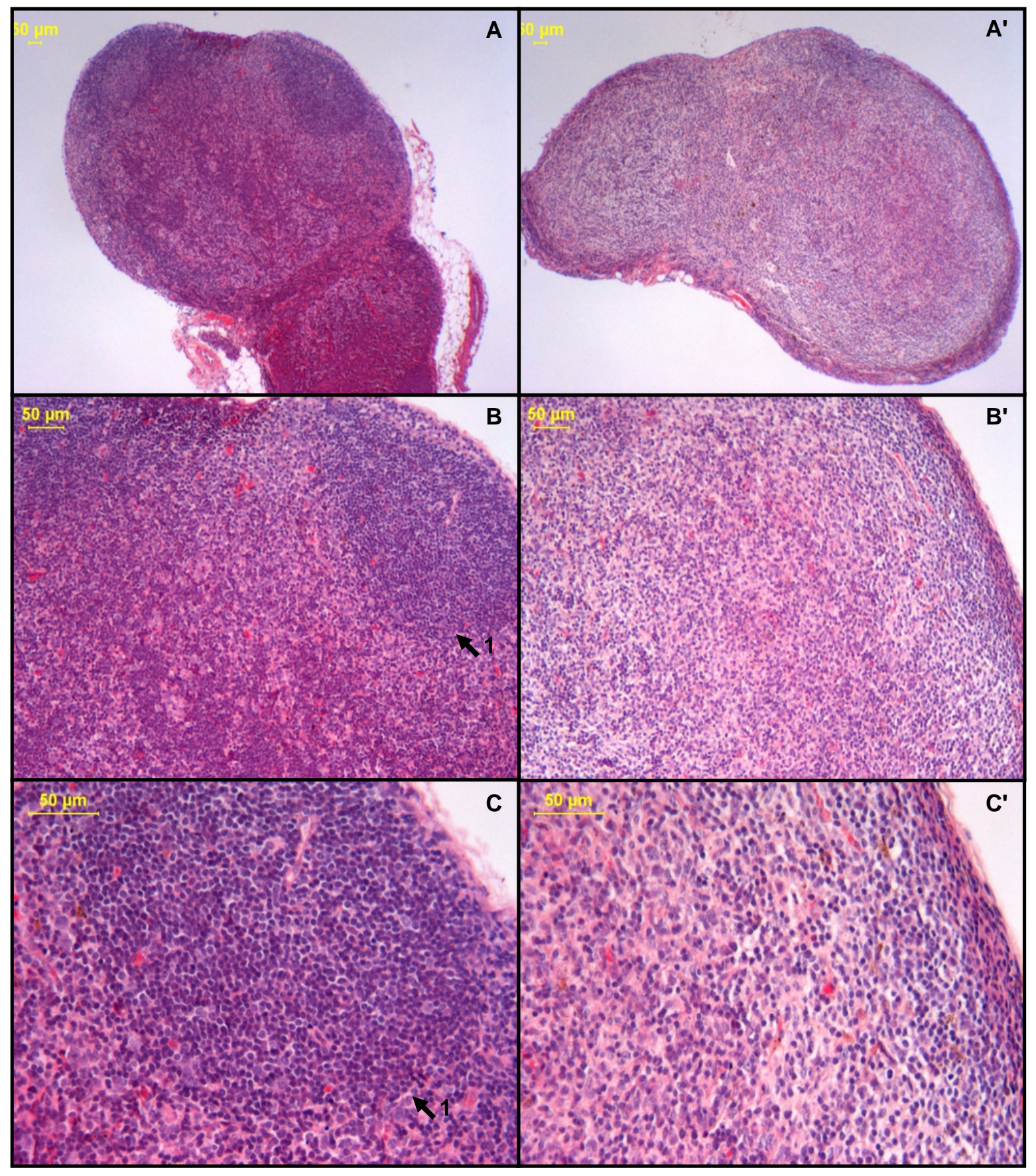

Abb. 30: Periphere Lymphknoten (inguinal). A, B, C entspricht jeweils $G^{+/+}, A^{\prime}, B^{\prime}, C^{\prime}$ entspricht $\mathrm{GFT}^{-/}$. A, $\mathbf{A}^{\prime}$ : $\mathrm{GFT}^{-/}$-Lymphknoten sind hypozellulär. B-C': Lymphfollikel sind in diesem $\mathrm{GFT}^{-/}$-Lymphknoten nicht vorhanden, bei $\mathrm{GFT}^{-/-}$-Präparaten generell seltener zu finden und dann weniger deutlich ausgeprägt als die Lymphfollikel in $\mathrm{GFT}^{+/+}$-Lymphknoten (1). 


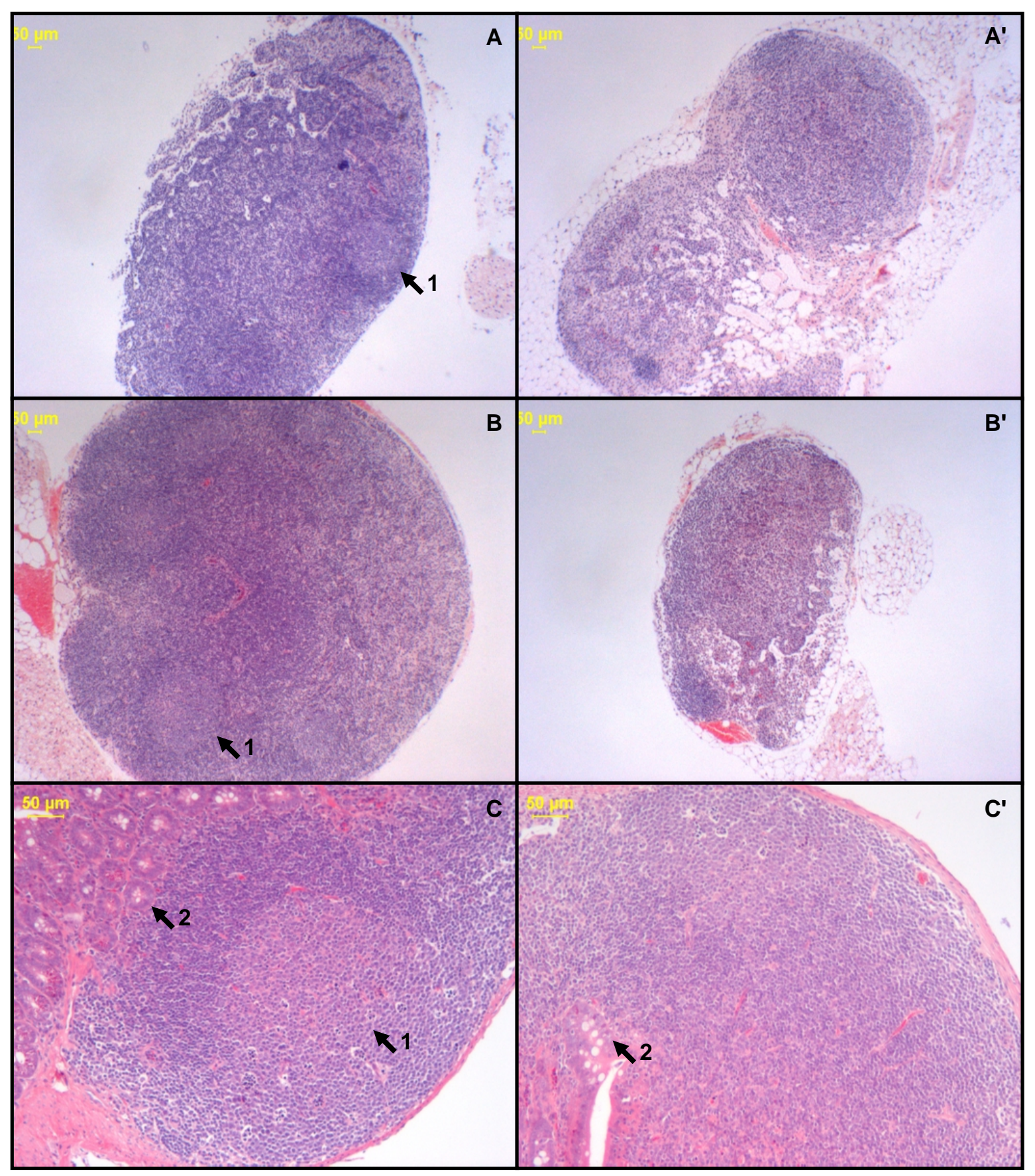

Abb. 31: $\quad$ Periphere Lymphknoten (axillär und aortal) und Peyer'sche Plaques. A, A': Auch in den axillären Lymphknoten aus $\mathrm{GFT}^{-1}$-Tieren zeigt sich eine geringere Zelldichte sowie das Fehlen sekundärer Lymphfollikel (1). B, B': Anhand dieser aortal gelegenen Lymphknoten wird darüber hinaus die häufig in $\mathrm{GFT}^{-1-}$-Tieren zu findende Hypomorphie deutlich. C, C': In den Peyer'schen Plaques, Dünndarmassoziierten lymphatischen Organen, ist die Hypozellularität bei $\mathrm{GFT}^{-{ }^{-}-\text {-Präparaten }}$ weniger deutlich als in anderen Lymphknoten ausgeprägt. Doch auch hier sind kaum Lymphfollikel auszumachen. An die Plaques angrenzend sind Darmkrypten zu erkennen (2). 


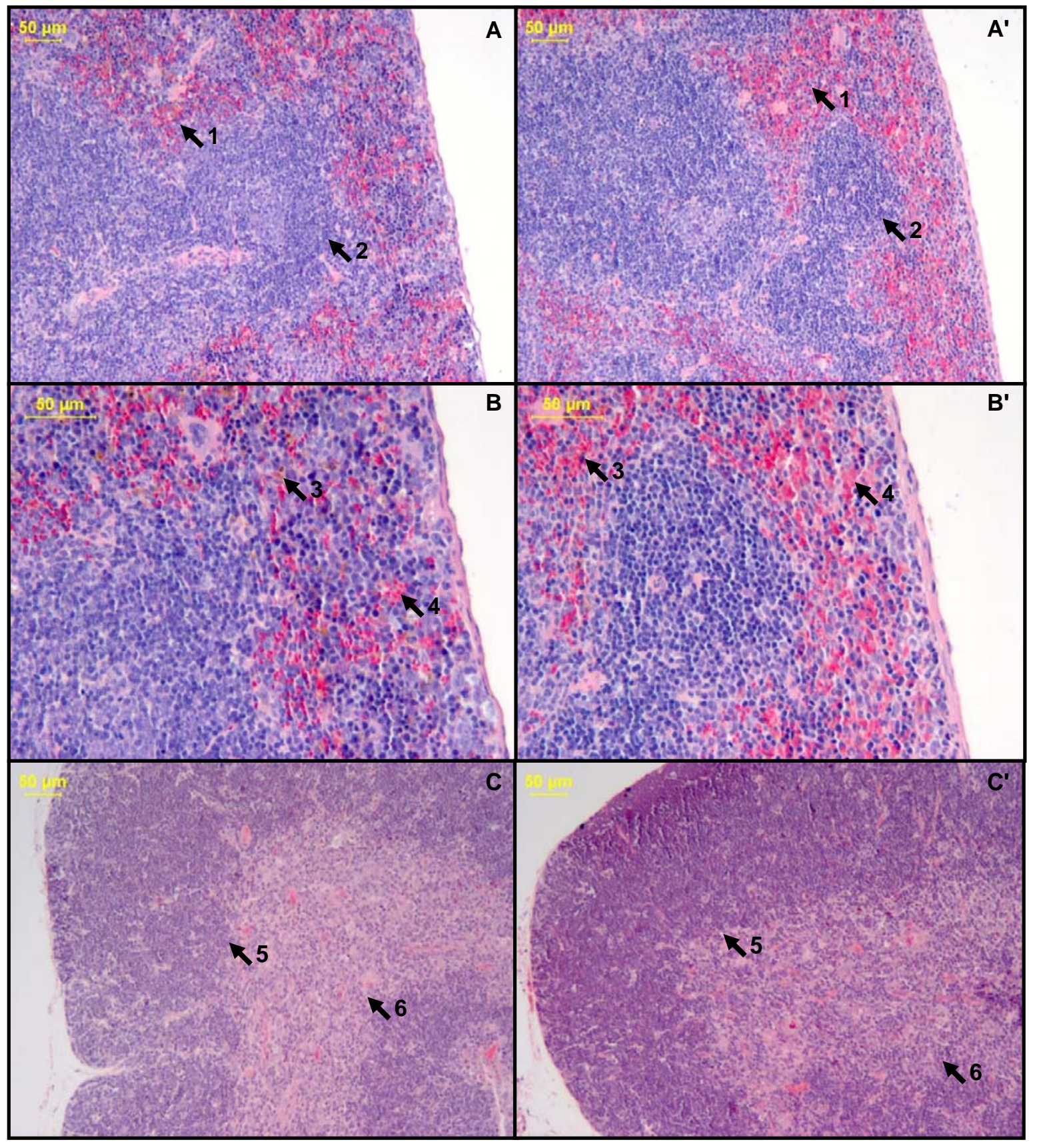

Abb. 32: Milz und Thymus. A, A': Die Architektur der Milz ist in $\mathrm{GFT}^{-1}$-Tieren nicht verändert. Rote Pulpa (1) und die lymphozytenreichen Malpighi'sche Körperchen (weiße Pulpa, 2) liegen in normalen Anteilen vor und sind klar voneinander abgegrenzt. B, B': In der roten Pulpa finden sich vereinzelt Makrophagen, die durch Pigmenteinschlüsse aus abgebauten Erythrozyten dunkel bis bräunlich gefärbt sind (3), sowie hellrot gefärbte Erythrozyten (4). C, C': Der Aufbau des Thymus erscheint ebenfalls unverändert. Die Rindenzone (5) ist lymphozytenreich und lässt sich gut von der lymphozytenärmeren Markzone (6) unterscheiden. 


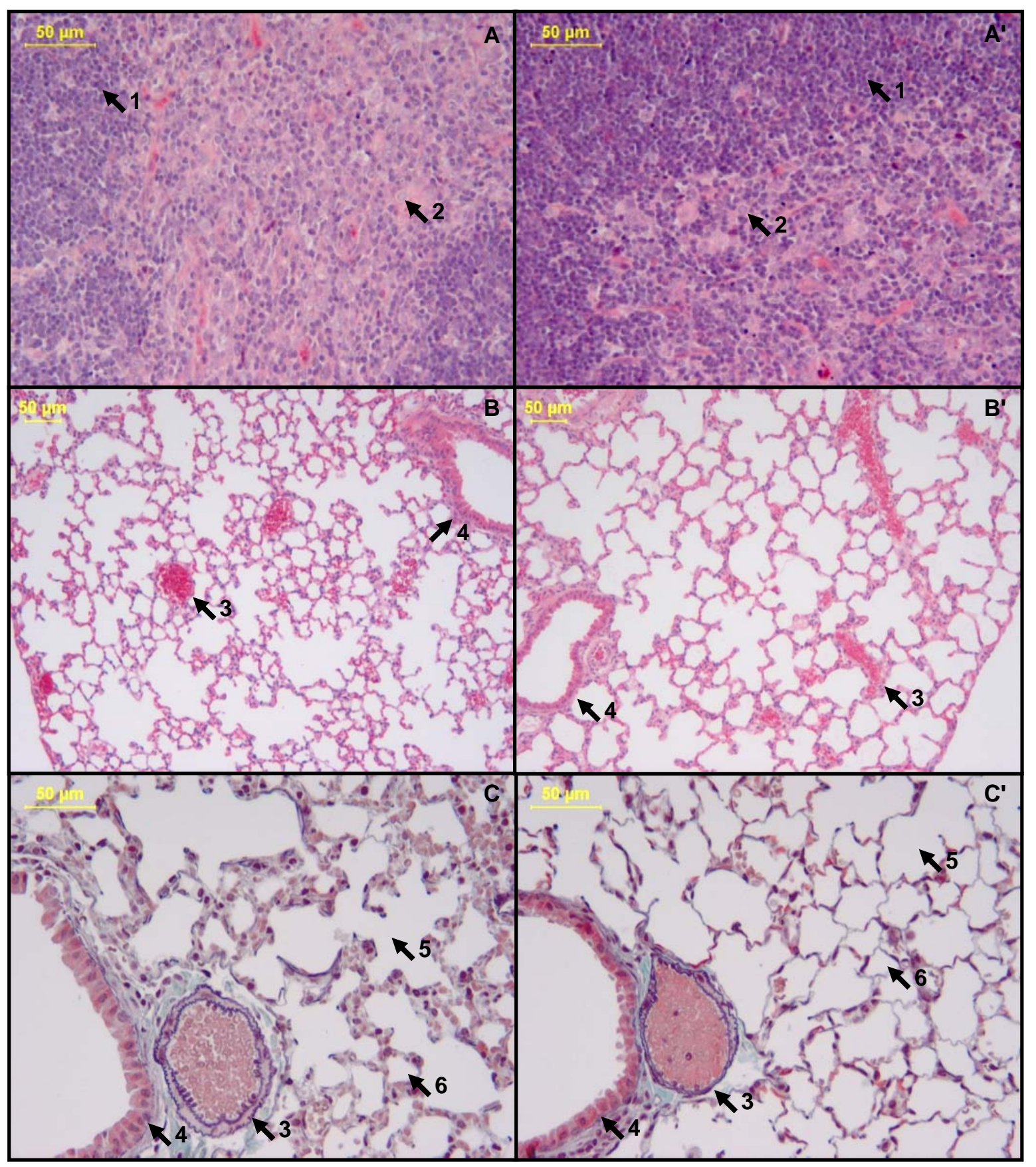

Abb. 33: Thymus, Lunge. A, A': In stärkerer Vergrößerung lassen sich im Thymusgewebe neben den Lymphozyten (1) die helleren Zellen des retikulären Bindegewebes (2) erkennen. B, B': Verteilung und Aufbau von Arterien (3) und Bronchien (4) im Lungengewebe erscheinen unauffällig. Die Alveolarräume jedoch sind in $\mathrm{GFT}^{-1-}$ Präparaten Emphysem-ähnlich dilatiert. C, C': In der kombinierten ElasticaTrichrom-Färbung der Lungensektionen wird besonders deutlich, dass die Alveolarwände dünner und zellärmer sind. Kollagenes Bindegewebe ist grünlich gefärbt. Elastische Fasern in den Wänden der Ductuli alveolares (5) und deren Aussackungen, den Alveolen (6), erscheinen violett. 


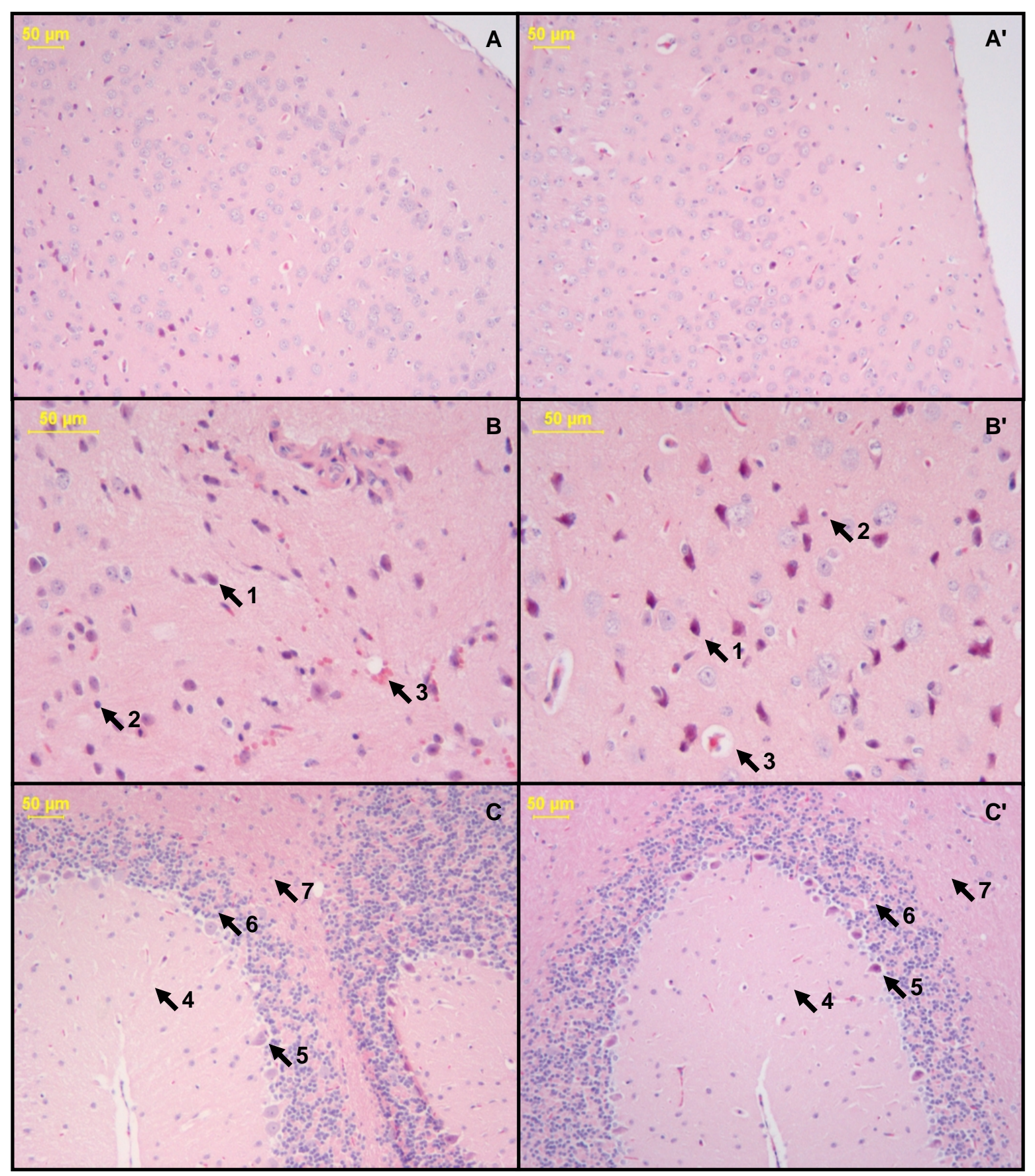

Abb. 34: Großhirnrinde und Kleinhirnrinde. A, A': Der Aufbau der Großhirnrinde erscheint in $\mathrm{GFT}^{-1-}$-Tieren normal. An der Oberfläche ist die zellarme Molekularschicht (Lamina molecularis) zu erkennen, darunterliegend die zellreichere äußere Pyramidenschicht (Lamina pyramidalis externa). B, B': In diesem Ausschnitt sind die stark angefärbten Pyramidenzellen (1), kleine Gliazellen (2) sowie Blutgefäße (3) zu erkennen. C, C': Auch die Schichtung der Kleinhirnrinde zeigt sich unauffällig. Außen liegt die Molekularschicht (4), darunter das Stratum gangliosum mit den charakteristischen Purkinje-Zellen (5), die Körnerschicht (6) sowie die weiße Substanz (Kleinhirnmark, 7). 


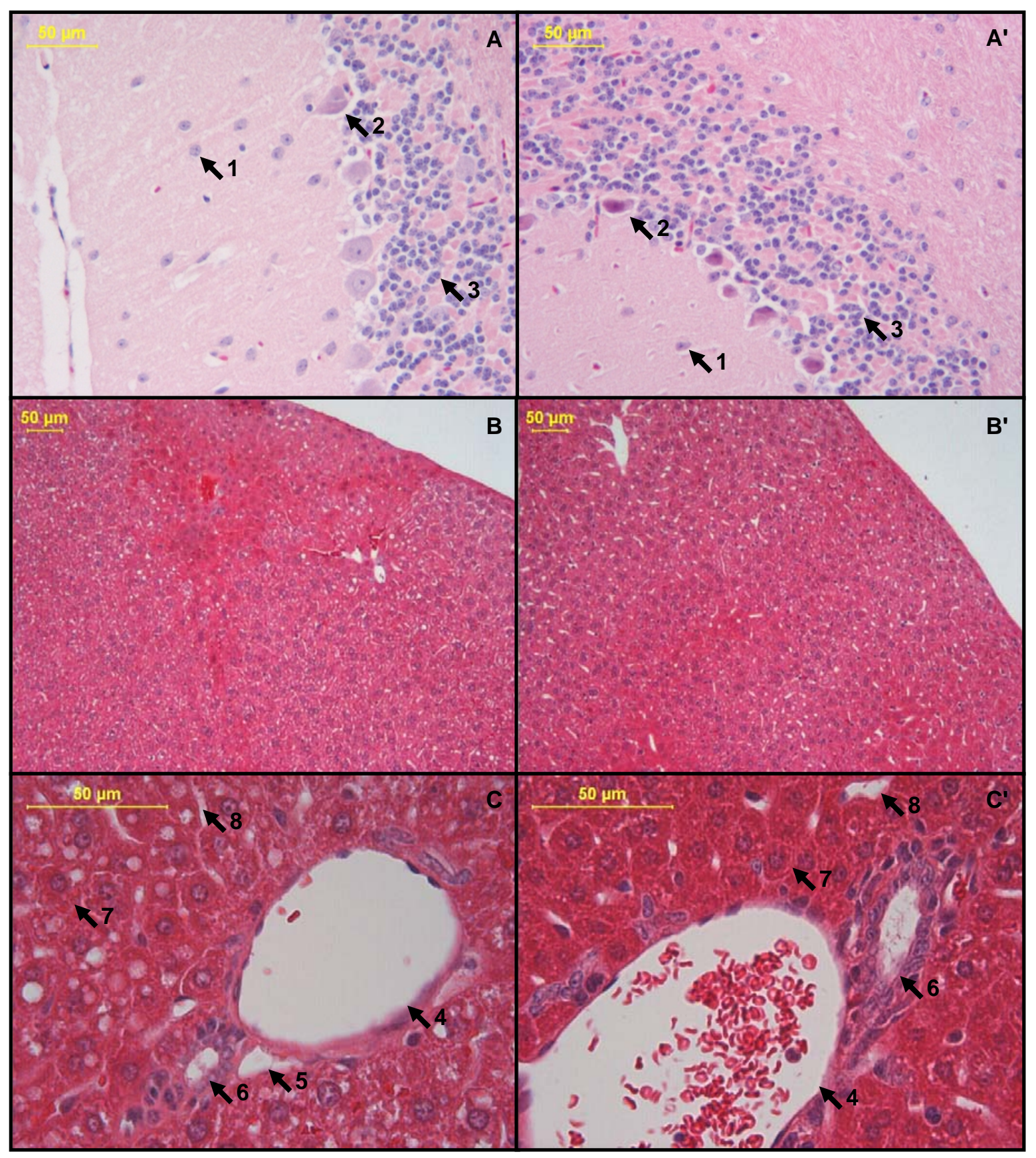

Abb. 35: Kleinhirnrinde, Leber. A, A': Bei stärkerer Vergrößerung lassen sich in der Kleinhirnrinde die für die einzelnen Schichten charakteristischen Zellen identifizieren: Korbzellen (1), Purkinje-Zellen (2) und Körnerzellen (3). B, B': Das Leberparenchym im Überblick. C, C': In den Periportalfeldern zwischen den Leberläppchen befindet sich die Glisson'sche Trias, bestehend aus jeweils einem kleinen Ast der Pfortader (4) und der Leberarterie (5) sowie einem Gallengang (6). Umliegend sind Hepatozyten (7), umgeben von Sinusoiden (8), zu erkennen. 


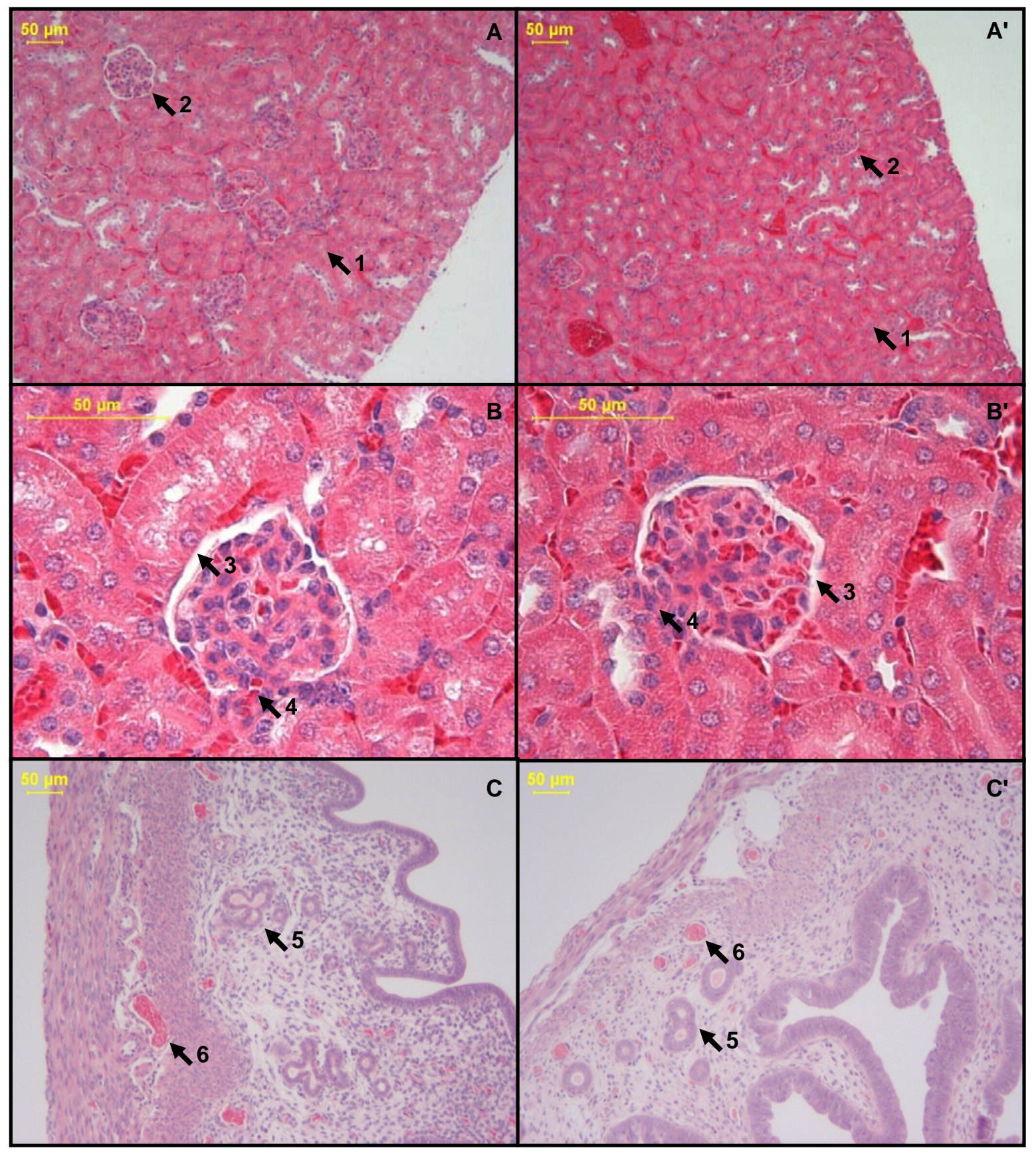

Abb. 36: Nierenrinde, Uterusepithel. A, A': Die Nierenrinde ist in $\mathrm{GFT}^{-1-}$-Tieren ebenfalls normal aufgebaut. Sie setzt sich aus dem Tubulussystem (1) und den dazwischenliegenden Glomerula (2) zusammen. B, B': Das Glomerulum ist von der Bowman'schen Kapsel (3) umgeben und hat einander gegenüberliegend einen Gefäßpol (4) und einen Harnpol. C, C': In der Uteruswand sind das luminal gelegene Endometrium mit Drüsenschläuchen (5) und das Myometrium mit Bündeln glatter Muskelzellen und Blutgefäßen (6) zu erkennen. 


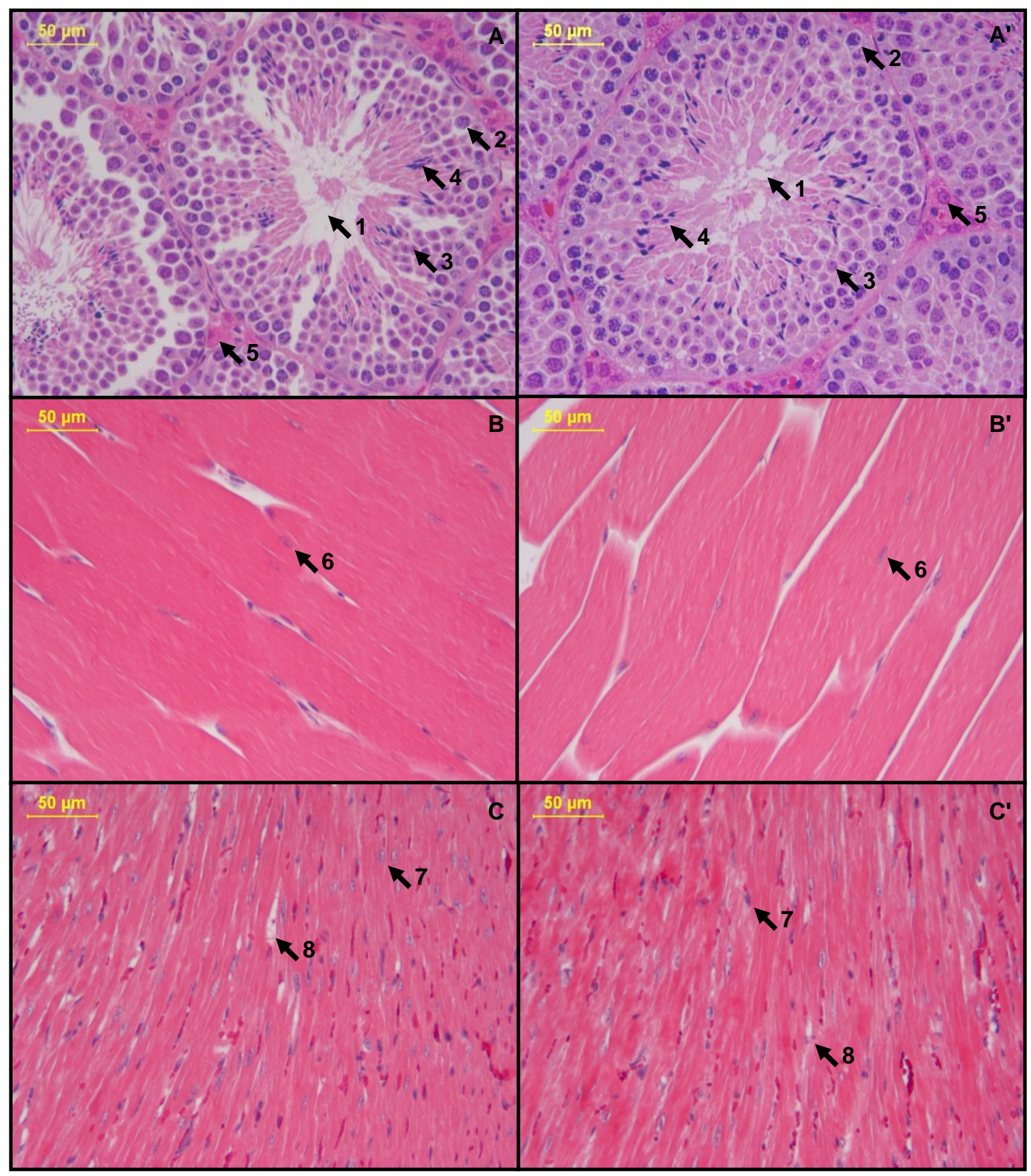

Abb. 37: Hoden, Skelettmuskulatur und Herzmuskulatur. A, A': Im Tubulus seminiferus (1) sind unterschiedliche Stadien der Spermienentwicklung zu sehen. Basal liegen die Spermatogonien (2), weiter lumenwärts die kleineren Spermatozyten (3) und die Spermien (4). In dem die Tubuli umgebenden Bindegewebe liegen die großen Leydig-Zellen (5). B, B': Die Myozyten der Skelettmuskulatur (hier längs geschnitten) weisen randständige Kerne (6) auf. C, C': Die deutlich kleineren Hermuskelzellen (ebenfalls längs geschnitten) haben einen mittelständigen Kern (7). Zwischen innen befindet sich lockeres Bindegewebe (8). 


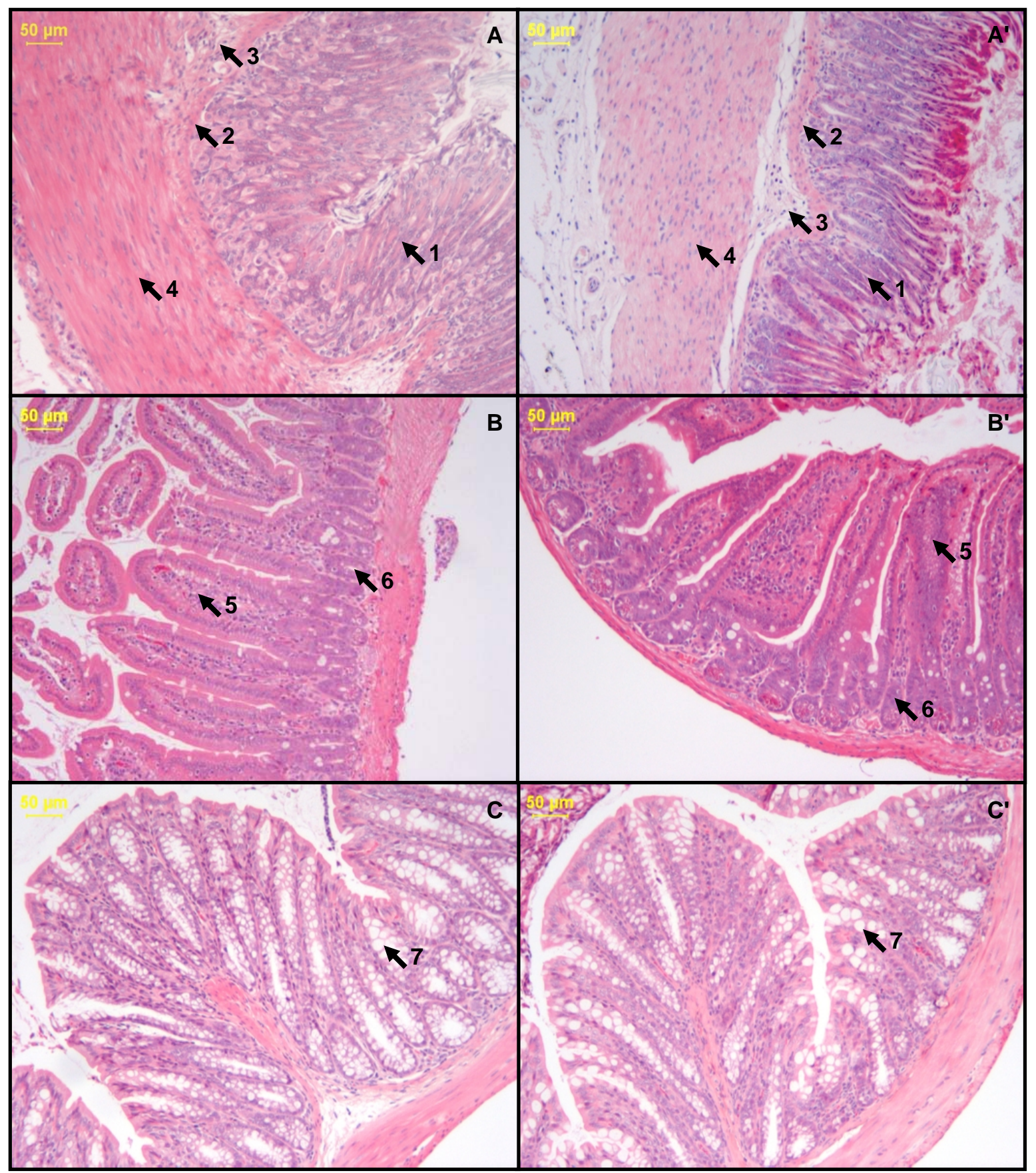

Abb. 38: Magen, Dünndarm und Dickdarm. A, A': Im Magen liegt luminal die Mukosa mit den sich einsenkenden Foveolae (1). Die Lamina muscularis mucosae (3) bildet die Grenze zur Submukosa (3), die von der Tunica muscularis propria (4) umgeben ist. B, B': Der Schichtenaufbau im Dünndarm entspricht prinzipiell dem des Magens. Die Mucosa besitzt hier fingerfömige Ausstülpungen, die Zotten (5), sowie tubulöse Drüsen, die Krypten (6). C, C': Im Dickdarm ziehen die Krypten sehr tief in die Lamina propria und sind reich an Becherzellen (7). 
Bei der Beurteilung der HE-gefärbten histologischen Präparate zeigten sich Auffälligkeiten in den Lymphknoten sowie in der Lunge. Die Lymphknoten in $\mathrm{GFT}^{-/}$ -Tieren sind deutlich zellärmer und zumeist kleiner im Vergleich zu Lymphknoten aus $\mathrm{GFT}^{+/+}$-Geschwistern. Die Lymphfollikel sind nur in verminderter Anzahl vorhanden und in ihrer Struktur schwach ausgeprägt.

In der Lunge der $\mathrm{GFT}^{-/}$-Tiere finden sich Emphysem-ähnliche Dilatationen der Alveolarräume. Die Alveolenwände sind auffallend dünn und zellarm sowie arm an elastischen Fasern. In den übrigen Organen der GFT ${ }^{-1-}$-Tiere sind anhand der HEgefärbten Präparate keine Auffälligkeiten festzustellen. Ihr Aufbau und die zelluläre Zusammensetzung entsprechen den Organen aus $\mathrm{GFT}^{+/+}$-Geschwistern.

\subsubsection{Morphometrische Analyse des Lungengewebes}

Die Fläche der Lungenalveolen wurde am Mikroskop mit Hilfe der Leica QWinSoftware ermittelt. Aus Präparaten von drei Tieren jedes Genotyps wurden jeweils drei repräsentative Ausschnitte ausgewertet. In $\mathrm{GFT}^{-/}$-Tieren war die mittlere Fläche der Alveolen auf das 1,8fache des Kontrollwertes erhöht (s. Abb. 39).

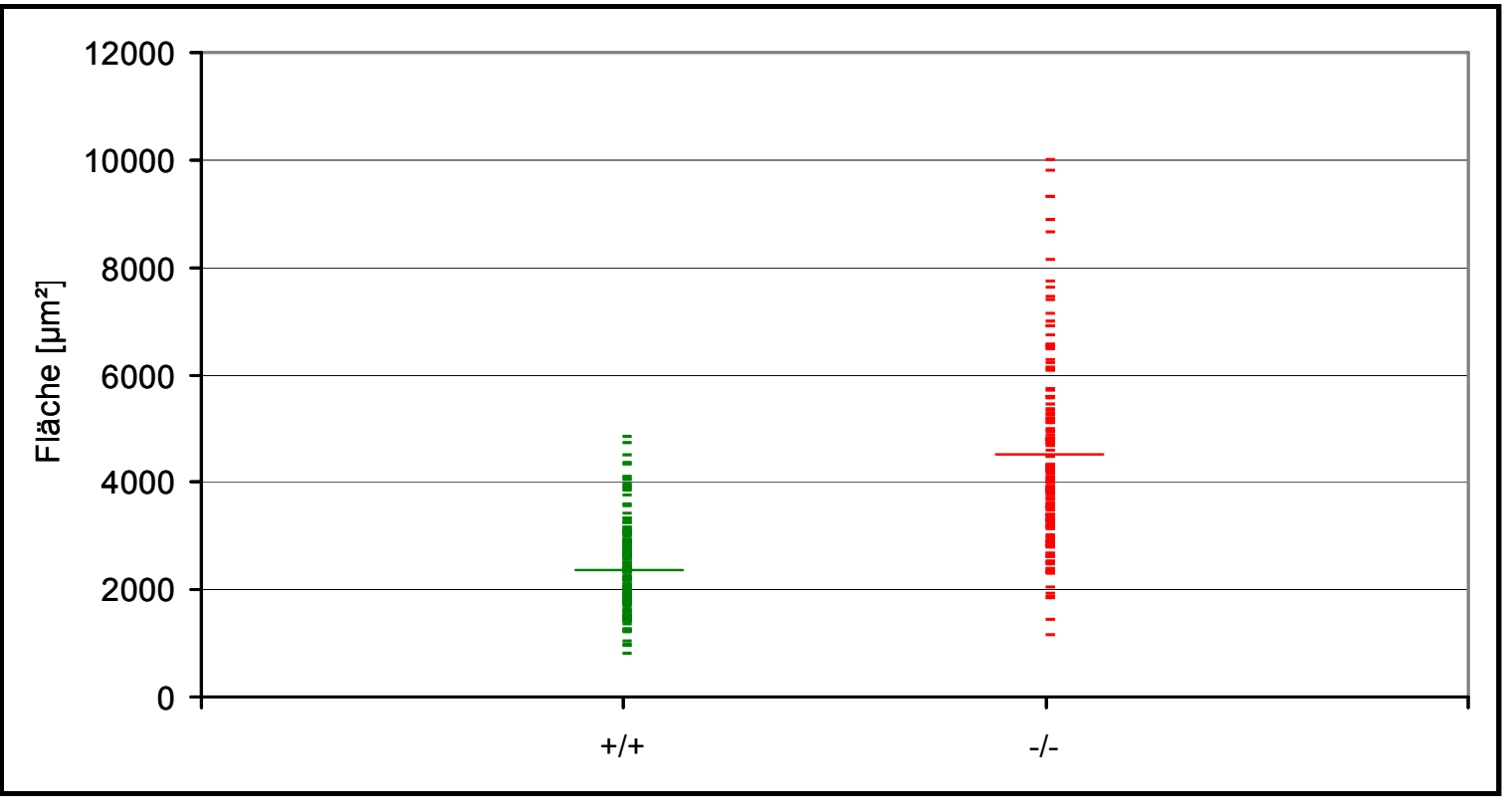

Abb. 39: Flächen der Alveolen. Dargestellt sind die Einzelwerte von insgesamt 150 Alveolen aus drei verschiedenen Tieren pro Gruppe. Die Mittelwerte (Balken) betrugen $2.420 \pm 825 \mu \mathrm{m}^{2}\left(\mathrm{GFT}^{+/+}\right.$) bzw. 4.354 $\pm 1.745 \mu \mathrm{m}^{2}\left(\mathrm{GFT}^{-/-}\right)$. 


\subsection{3 \\ Fluoreszenz-Markierung \\ glykosylierter \\ Strukturen \\ in histologischen Präparaten}

Unter Verwendung von Lektinen, die direkt oder indirekt an das grün fluoreszierende Fluorochrom FITC gebunden sind, wurden in den histologischen Präparaten aus Organen der $\mathrm{GFT}^{+/+}$- und $\mathrm{GFT}^{-/-}$-Tiere fucosylierte Strukturen sichtbar gemacht. Zur Lokalisierung der Zellen erfolgte eine Kernfärbung mit dem blau fluoreszierenden Fluorochrom DAPI.

Es wurden mehrere biotinylierte Lektine gegen Fucose in unterschiedlichen Bindungen ausgetestet: das Aleuria aurantia-Lektin (AAL, Bindung an $\alpha-1,2-$, $\alpha-$ 1,3- oder $\alpha$-1,6-verknüpfte Fucose), das Lotus tetragonolobus-Agglutinin (LTA, $\alpha$ verknüpfte Fucose) und das Lens culinaris-Agglutinin (LCA, $\alpha-1,6$-verknüpfte Core-Fucose in bi- und triantennären N-Glykanen). Die beste Bindung, anhand der $\mathrm{GFT}^{+/+}$-Präparate beurteilt, wurde mit AAL erzielt, das daraufhin für die Testung in allen Organen verwendet wurde. LCA wurde exemplarisch zusätzlich zu AAL für die Lymphknoten verwendet (s. Abb. 40), LTA für die Nierenrinde (s. Abb. 42).

Das Maackia amurensis-Lektin I (MAL I), welches an Glykokonjugate mit Gal- $\beta$ 1,3-LacNAc-Strukturen bindet, wurde als Kontroll-Lektin verwendet (s. Abb. 47). Negativkontrollen wurden nur mit Streptavidin-FITC, jedoch nicht zuvor mit einem biotinylierten Lektin inkubiert. 


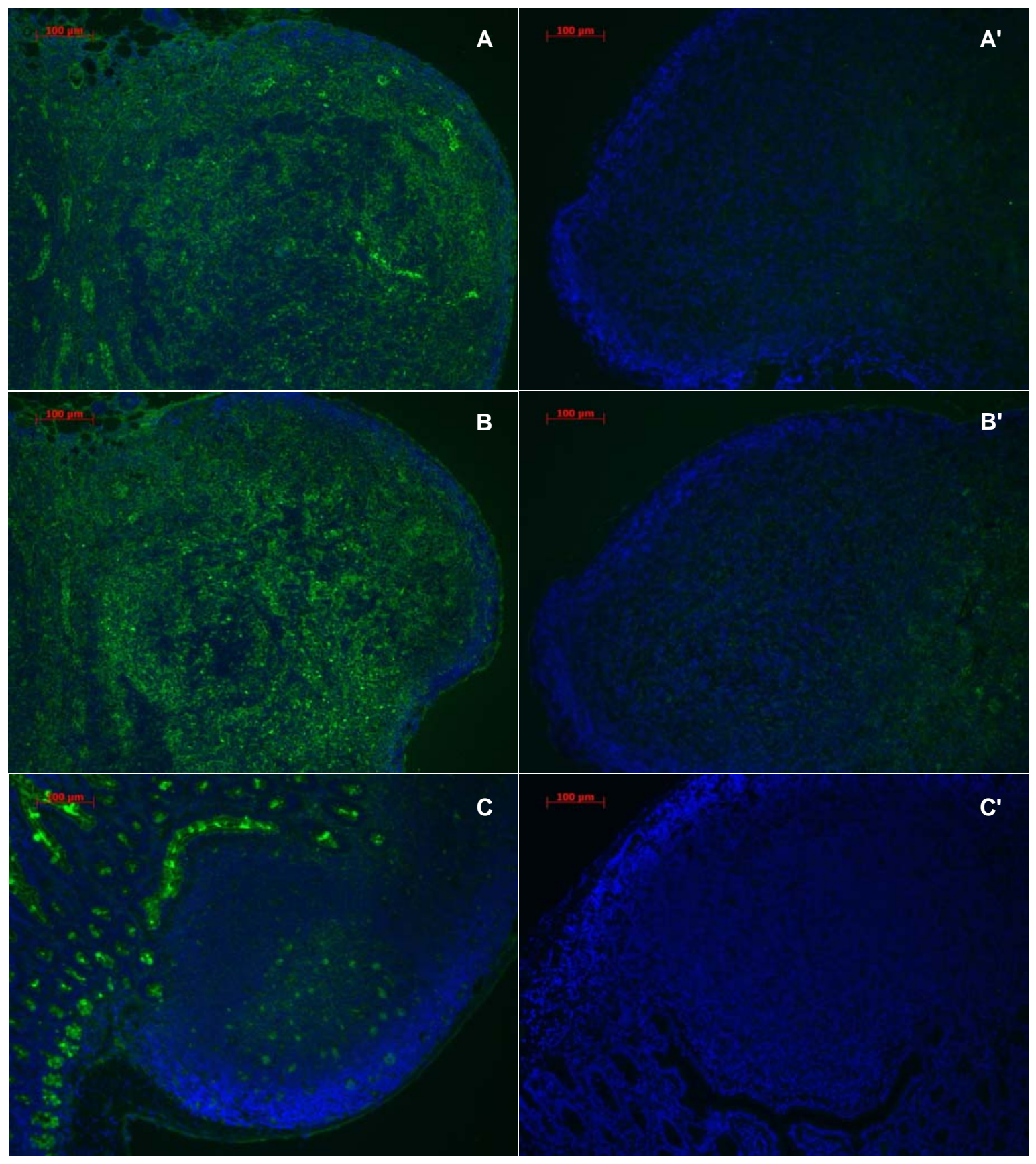

Abb. 40: Lymphknoten und Peyer'sche Plaques. A, B, C entspricht jeweils $G^{+/+}, A^{\prime}, B^{\prime}$, $\mathrm{C}^{\prime}$ entspricht $\mathrm{GFT}^{-1}$. Zellkerne sind blau dargestellt (DAPI), die markierten Zuckerstrukturen grün (FITC). A, A': Inguinale Lymphknoten, AAL. B, B': Inguinale Lymphknoten, LCA. C, C': Peyer'sche Plaques des Dünndarms, AAL. 


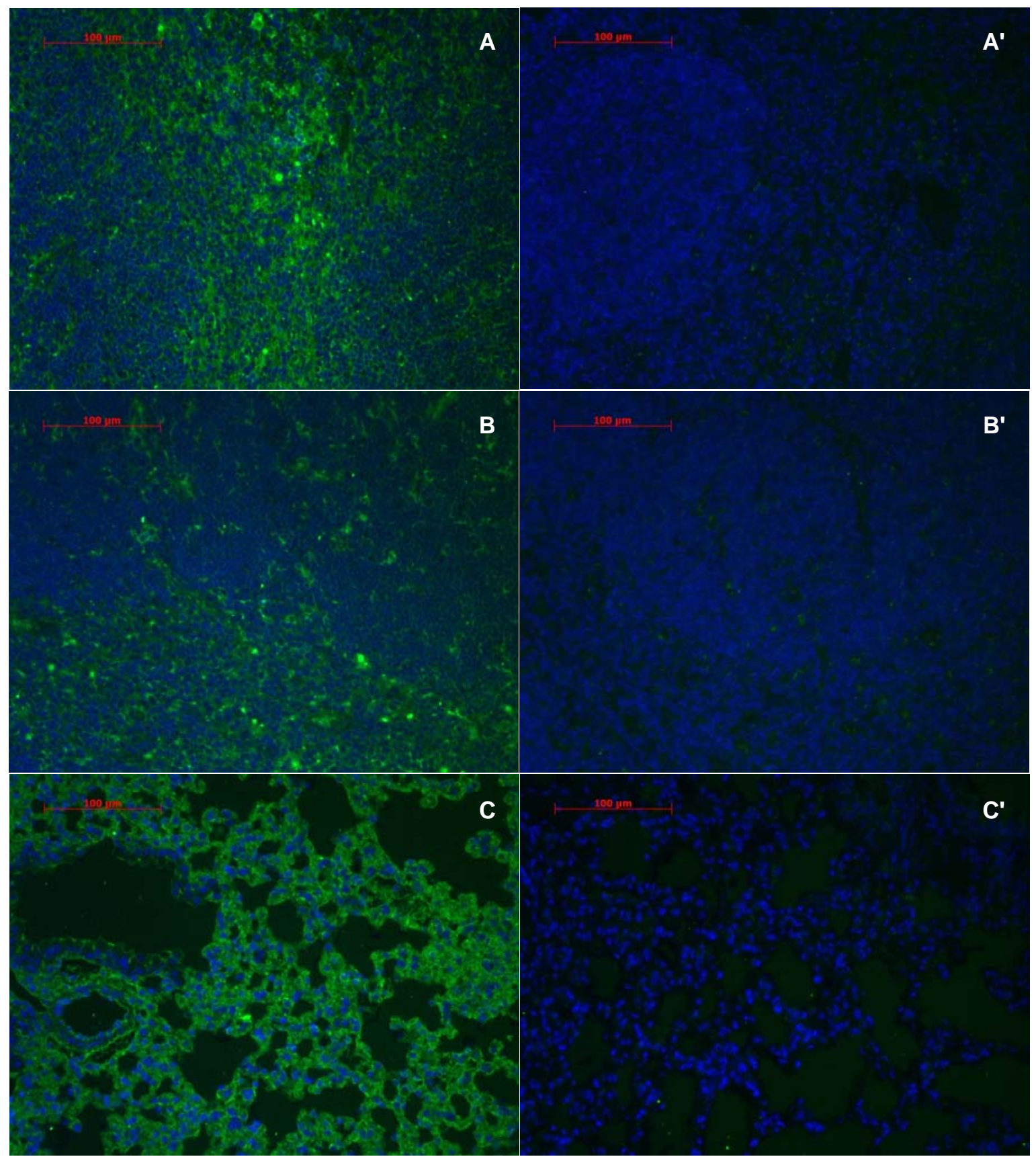

Abb. 41: Milz, Thymus und Lunge. A, A': Milz, AAL. B, B': Thymus, AAL. C, C': Lunge, AAL. 


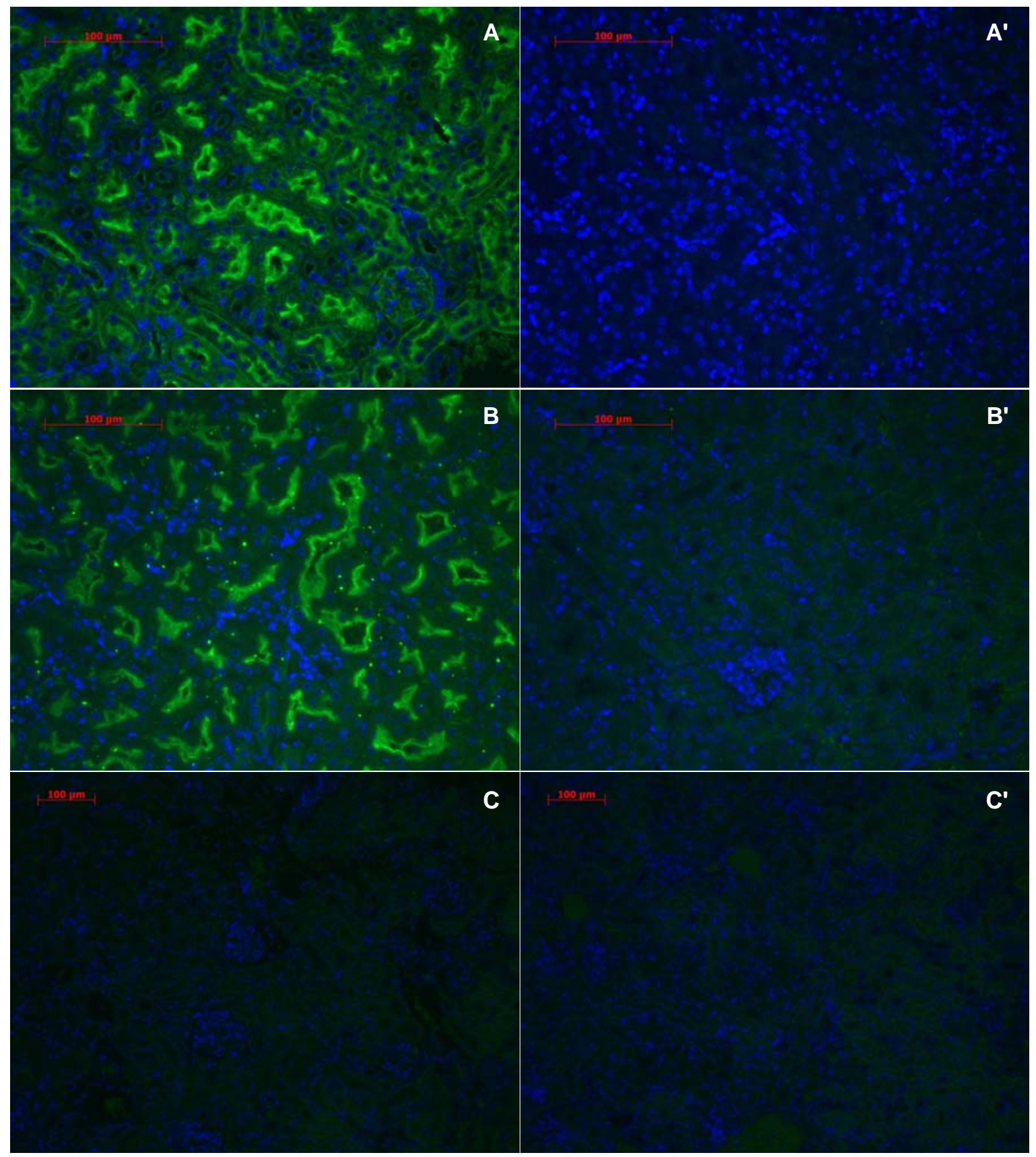

Abb. 42: $\quad$ Nierenrinde. A, A': AAL. B, B': LTA. C, C': Negativkontrolle. 


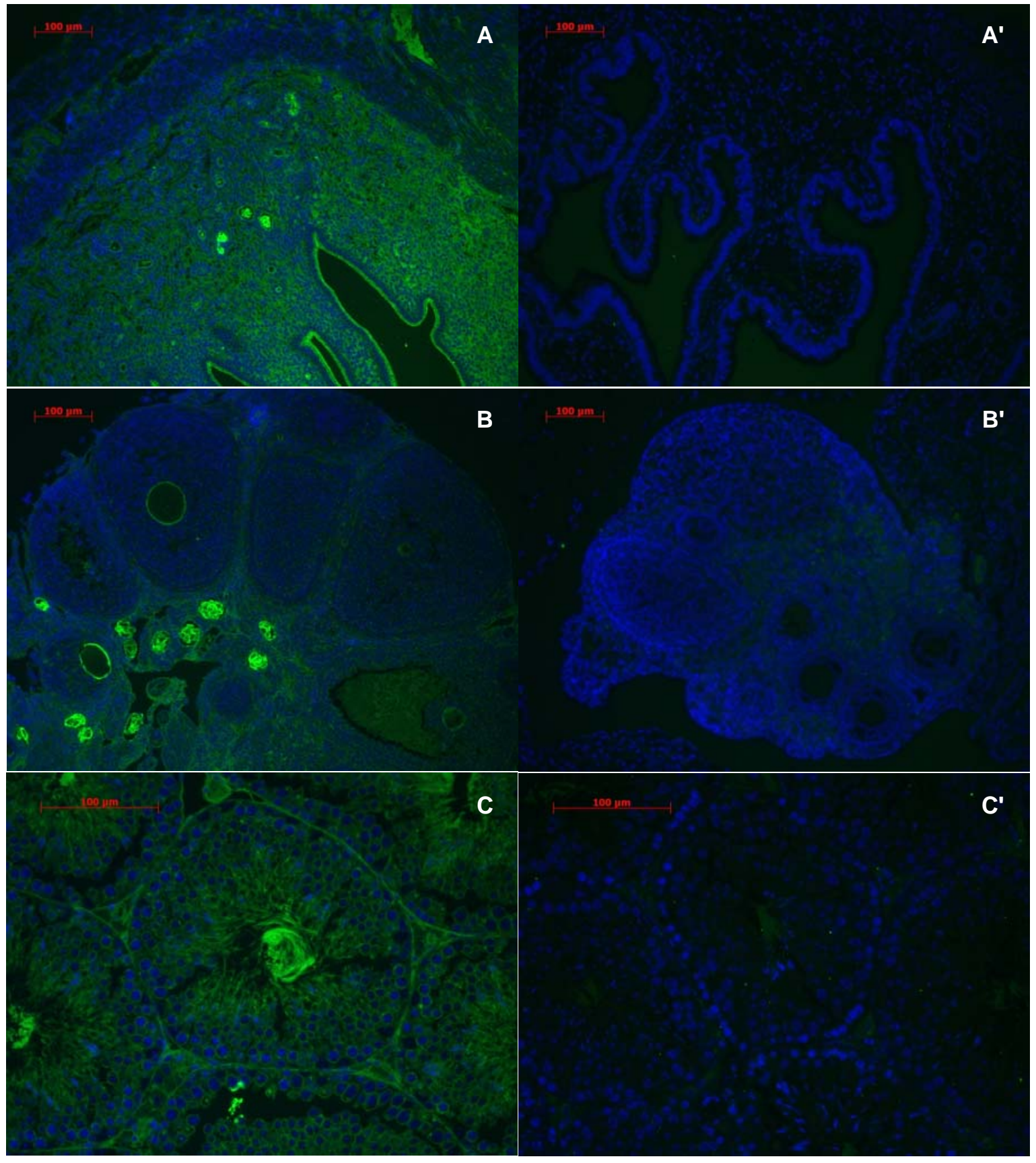

Abb. 43: $\quad$ Uterus und Hoden. A, A': Uteruswand, AAL. B, B': Ovar mit Follikeln, AAL. C, C': Tubulus seminiferus des Hodens, AAL. 


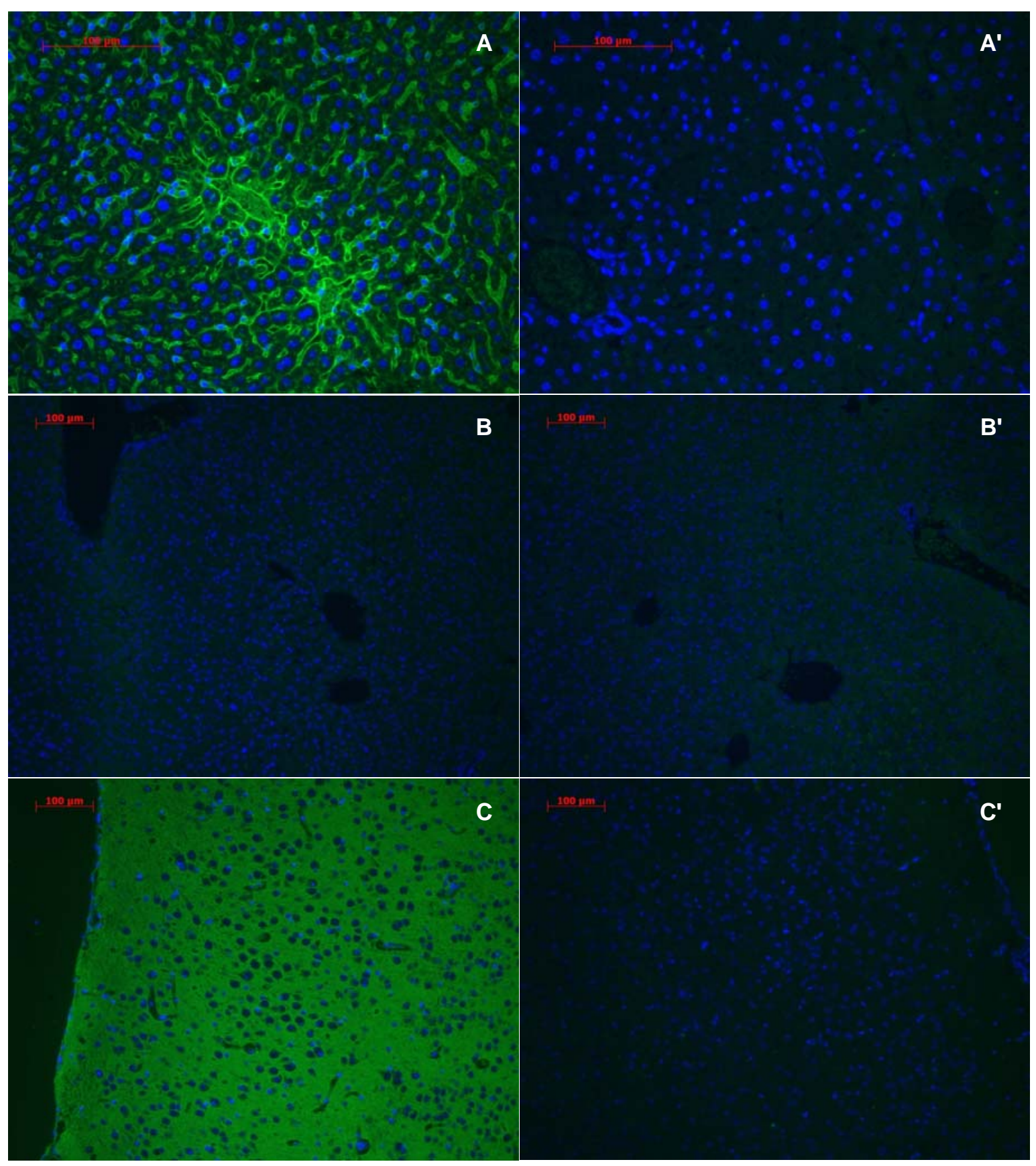

Abb. 44: Leber und Großhirnrinde. A, A': Leber mit Glisson'scher Trias, AAL. B, B': Leber, Negativkontrolle. C, C': Großhirnrinde, AAL. 


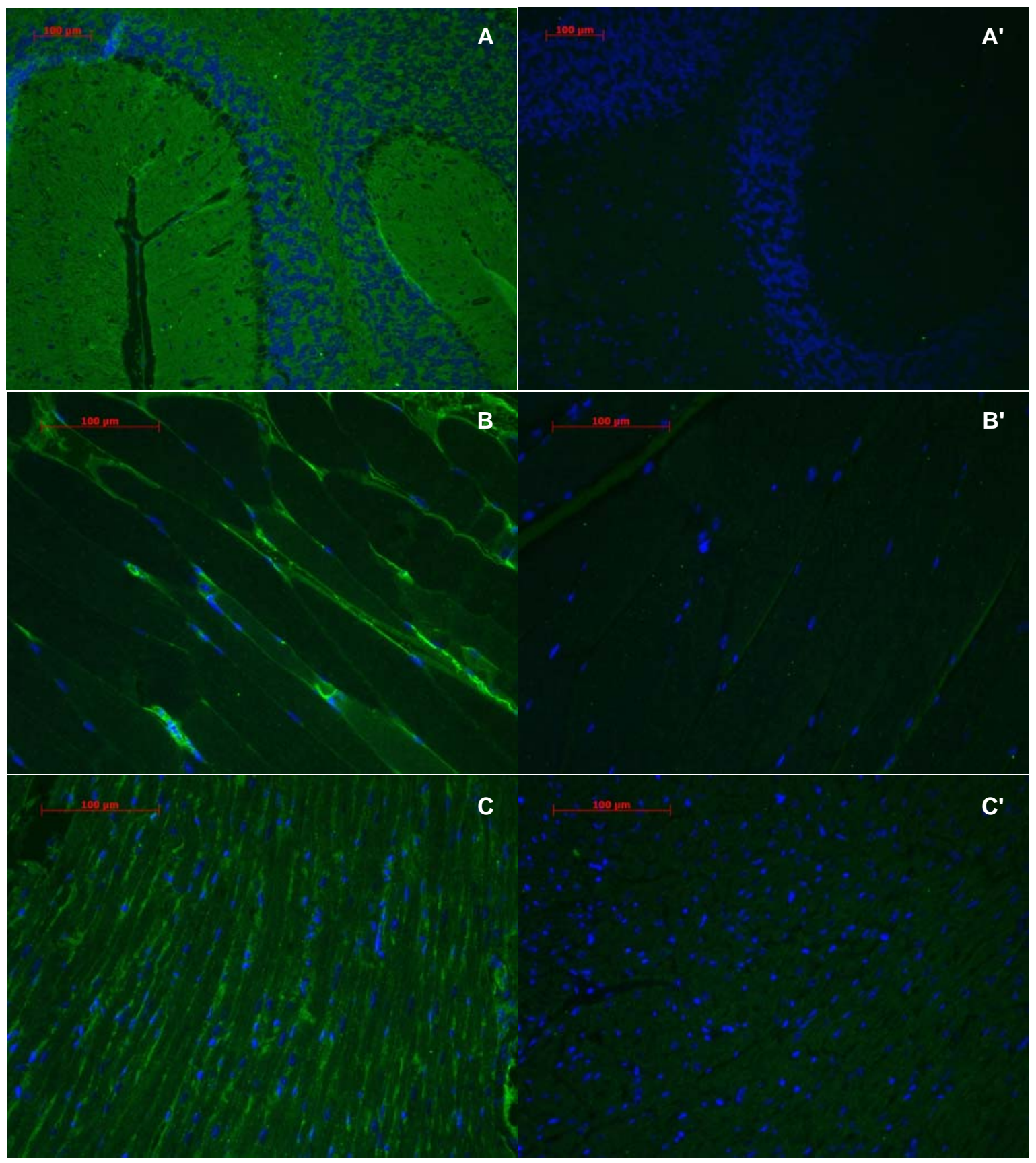

Abb. 45: Kleinhirn, Skelettmuskel und Herzmuskel. A, A': Kleinhirnwindung, AAL. B, B': Skelettmuskel, längs geschnitten, AAL. C, C': Herzmuskel, längs geschnitten, AAL. 


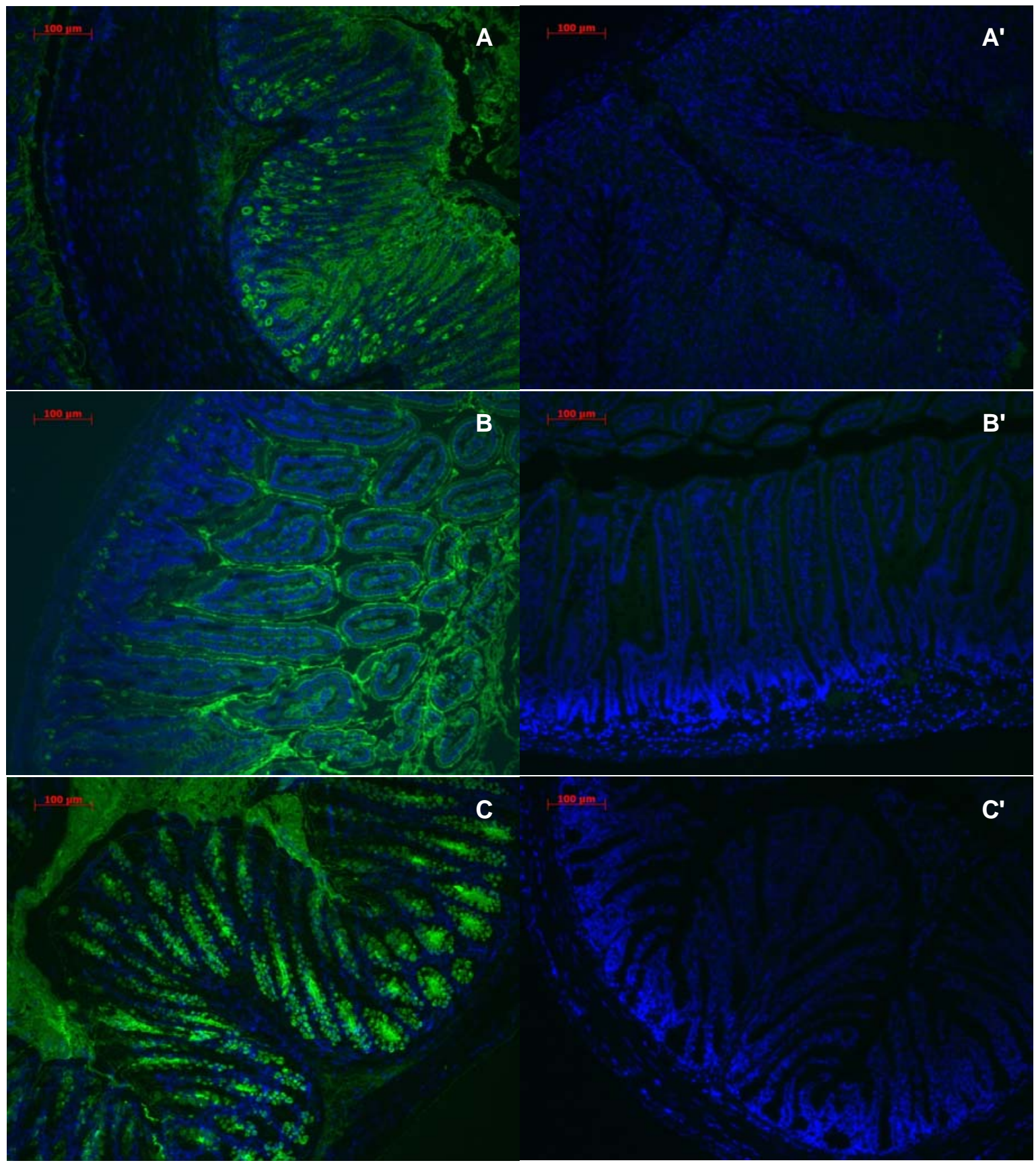

Abb. 46: Magen, Dünndarm und Dickdarm. A, A': Magenwand, AAL. B, B': Dünndarmwand, AAL. C, C': Dickdarmwand, AAL. 


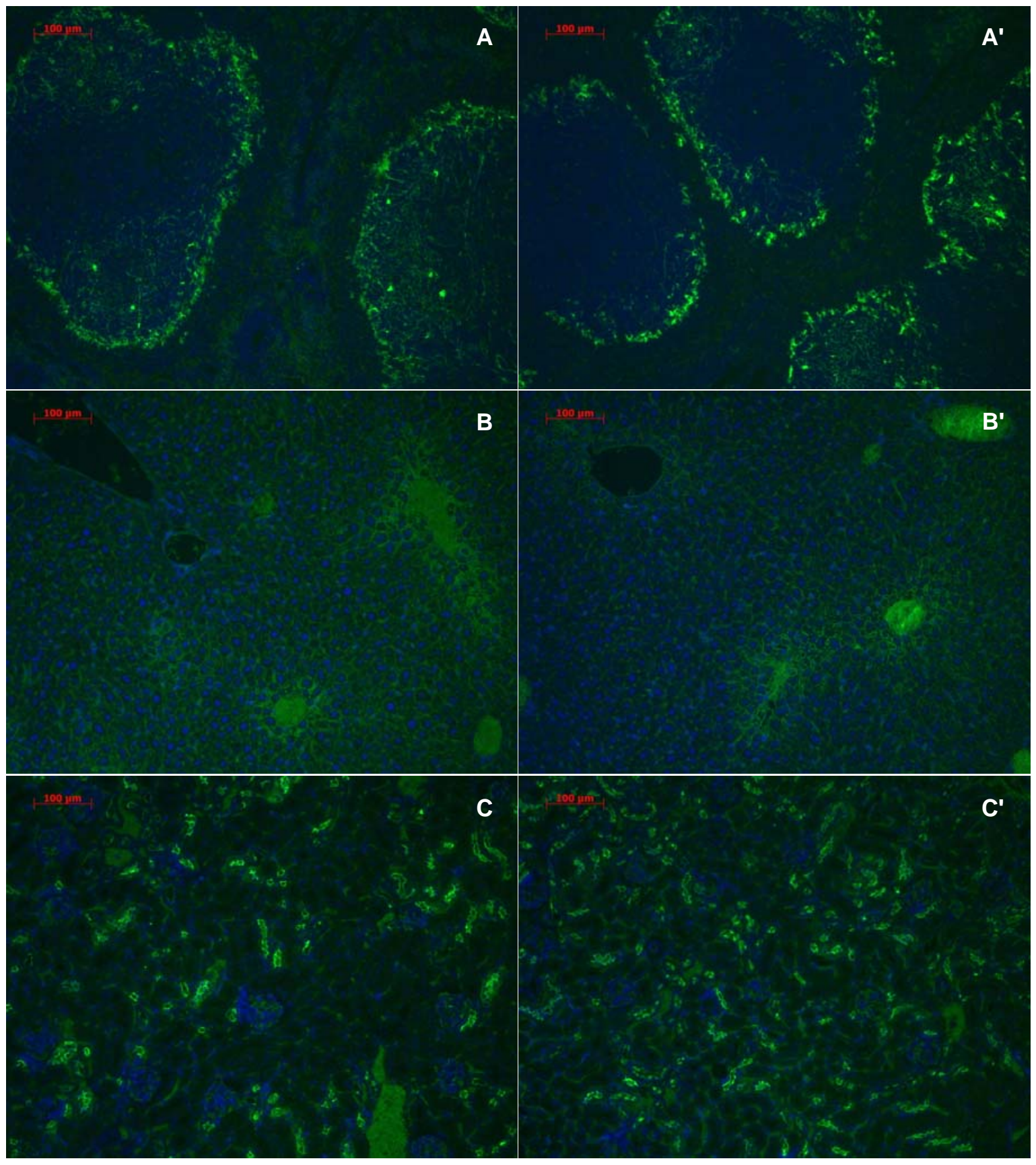

Abb. 47: MAL I-Kontrollfärbung in Milz, Leber und Niere. A, A': Milz, MAL I. B, B': Leber, MAL I. C, C': Nierenrinde, MAL I. 
In allen Geweben der $\mathrm{GFT}^{+/+}$-Organe konnte mit $\mathrm{AAL}$ eine strukturspezifische Fucosylierung dargestellt werden. Diese erstreckt sich hauptsächlich auf epitheliale Strukturen, was beispielsweise anhand des Tubulusepithels der Nierenrinde oder des Schleimhautepithels im Reproduktions- und GastrointestinalTrakt deutlich wird. Auffällig ist die starke und gleichmäßige Fucosylierung der gesamten Groß- und Kleinhirnrinde. Ein exemplarischer Vergleich mit anderen Fucose-bindenden Lektinen in Lymphknoten und der Niere zeigt ähnliche Fucosylierungsmuster.

Für alle $\mathrm{GFT}^{-/-}$-Organe konnte ausnahmslos gezeigt werden, dass die Fucosylierung entweder völlig fehlt oder auf ein Minimum reduziert ist, das sich nicht von den Negativkontrollen unterscheiden lässt.

Im Vergleich dazu führte die Behandlung mit MAL I, einem Lektin gegen fucosylierungsunabhängige Zuckerstrukturen, zu identischen Färbungsmustern in $\mathrm{GFT}^{+/+}$- und $\mathrm{GFT}^{-/-}$-Geweben. 


\section{$5 \quad$ Diskussion}

Der Fucosylierung von Glykoproteinen werden Funktionen im Rahmen vieler intraund interzellulärer Erkennungsprozesse und Interaktionen sowie Signaltransduktionswegen zugeschrieben. Die molekulare Ursache für die Erberkrankung CDG-Ilc konnte einem Defekt des humanen Golgi-GDP-FucoseTransporters zugeschrieben werden (Lübke et al., 2001; Lühn et al., 2001), der zu einer generellen Hypofucosylierung führt. Die Pathogenese ist jedoch weitgehend ungeklärt. Ein Mausmodell mit einem Total-Knockout des Golgi-GDP-FucoseTransporters soll hierüber sowie über die generelle Bedeutung von Fucose im Säugerorganismus Aufschluss geben. Der Phänotyp weist viele Parallelen zum Krankheitsbild von CDG-IIc auf. Die Tiere zeigen eine hohe postnatale Mortalität, Entwicklungsretardierung und eine Defizienz des Leukozyten-Rollens. Histologisch auffällig sind hypozelluläre und hypomorphe Lymphknoten sowie Emphysem-ähnliche Dilatationen der Lungenalveolen. In histologischen Präparaten der Organe ist mit Lektinen keine Fucosylierung nachweisbar. In primären Zellkulturen zeigt sich eine Restfucosylierung, die durch FucoseBehandlung auf das Niveau der Kontrollzellen normalisiert werden kann.

Die Insertion einer Neomycin-Resistenzkassette in das SLC35C1-Gen führt zu einem konstitutiven Total-Knockout des murinen Golgi-GDP-Fucose-Transporters

CDG-Ilc-Patienten weisen verschiedene Mutationen in dem für den Golgi-GDPFucose-Transporter (GFT) codierenden Gen SLC35C1 auf, die zu einem Aktivitätsverlust des Transporters führen. Kürzlich wurde ein Patient pakistanischer Abstammung mit Homozygotie für die Punktmutation G969A beschrieben (Helmus et al., 2006). Diese Mutation generiert ein vorzeitiges StopCodon, welches zu einem Verlust der zehnten Transmembrandomäne sowie der C-terminalen Domäne führt. In Fibroblasten dieses Patienten konnte gezeigt werden, dass das resultierende Protein mislokalisiert im ER zu finden und nicht aktiv ist. Eine Komplementation mit SLC35C1-Konstrukten verschiedener Länge 
führte zu dem Ergebnis, dass die zehnte Transmembrandomäne für eine korrekte Lokalisierung des GFT im Golgi-Apparat essentiell ist. Nur bei Vorliegen weiterer sechs Aminosäuren C-terminal dieser Domäne ist das Protein darüber hinaus auch funktional.

Der GFT der Maus weist, wie in eigenen Vorarbeiten im Verlauf der Diplomarbeit gezeigt werden konnte, eine hohe Homologie zum humanen GFT auf. Das murine SLC35C1-Ortholog ist zu 87\% im Vergleich zum humanen Ortholog konserviert und besteht ebenfalls aus zwei Exons, die für ein stark hydrophobes Protein mit zehn Transmembrandomänen codieren.

In der vorliegenden Arbeit sollte der GFT der Maus konstitutiv ausgeschaltet werden. Die Realisierung des vollständigen Funktionsverlust des Gens erfolgte durch die Insertion einer Neomycin-Resistenzkassette in inverser Orientierung in das erste Exon. Durch diese Modifikation des Gens wird der Leserahmen unmittelbar hinter dem für die dritte Transmembrandomäne codierenden Sequenzabschnitt unterbrochen. Somit ist davon auszugehen, dass die Transkription zu einem instabilen und nicht-funktionellen Produkt führt, welches im Falle einer Synthese sofort wieder degradiert werden sollte. Darüber hinaus beinhaltet dieser modifizierte Leserahmen ein Stop-Codon innerhalb der inserierten Kassette. Gemäß der o.g. Erkenntnisse aus der kürzlich beschriebenen CDG-Ilc-Mutation wäre selbst im Falle einer Translation des stark verkürzten Transkripts bis zu diesem Stop-Codon innerhalb des ersten Exons das resultierende Produkt, das nur die ersten drei Transmembranen umfassen würde, mislokalisiert und nicht aktiv.

Um das Vorliegen eines solchen Transkripts zu untersuchen, wurde die GesamtRNA aus verschiedenen Organen der $\mathrm{GFT}^{-/-}$-Tiere sowie entsprechender Kontrollen isoliert. Für eine Northernblot-Analyse dieser RNA wurde eine Sonde gewählt, die mit dem 5'-Ende des ersten Exons vor der Insertionsstelle der NeoKassette, also mit einem unveränderten Genabschnitt, hybridisiert. Während die Hybridisierung des Blots mit einer $\beta$-Actin-Kontrollsonde für $\mathrm{GFT}^{+/+}$- wie $\mathrm{GFT}^{-/}$RNA zu gleichen Bandenmustern führte, ließ sich das SLC35C1-Transkript nur in $\mathrm{GFT}^{+/+}$-Proben nachweisen. In $\mathrm{GFT}^{-/-}$-Organen liegt weder das Transkript normaler Länge noch eine um 1,4 kb, also um die inserierte Neo-Kassette, elongierte Form vor. 
Abgesehen von dem GFT ist bisher kein weiteres Protein beschrieben worden, das GDP-Fucose in den Golgi-Apparat oder andere Zellkompartimente transportieren kann. Diese Transportaktivität wurde in mikrosomalen Vesikeln aus Leberhomogenat mit Hilfe eines modifizierten Transportassays nach Perez et al. (1987) ermittelt. In GFT $^{-/-}$-Vesikeln war die GDP-Fucose-Importaktivität auf 5,7\% der Aktivität in $\mathrm{GFT}^{+/+}-$Vesikeln reduziert. Wurde diese Aktivität auf die unabhängige UDP-Galactose-Import-Aktivität normalisiert, um präparationsbedingte Variablen zu eliminieren, reduzierte sich der $\mathrm{GFT}^{-1-}$-Anteil auf $3,3 \%$ des $\mathrm{GFT}^{+/+}$-Wertes. Vergleichend dazu sei erwähnt, dass die GDP-FucoseImportaktivität beispielsweise bei dem türkischen CDG-Ilc-Patienten, dessen Punktmutation möglicherweise eine Restaktivität zulässt, auf 20\% der Kontrollen erniedrigt ist (Lübke et al., 1999).

Der GDP-Fucose-Import ist also in $\mathrm{GFT}^{-/-}$-Leber auf ein Minimum reduziert. Da keine spezifischen Inhibitoren für den GFT zur Verfügung stehen, existiert keine sichere Negativkontrolle für diesen Transportassay. Daher muss bei der Beurteilung dieses Ergebnisses davon ausgegangen werden, dass die minimale gemessene Menge an Radioaktivität in den Vesikeln nicht zwingend ein Hinweis für eine Restaktivität oder einen alternativen Transporter ist, sondern auch ein versuchsimmanentes Artefakt darstellen kann.

Die Transportaktivität in $\mathrm{GFT}^{+/}$-Vesikeln erwies sich als praktisch unbeeinträchtigt. Bei der Untersuchung der Aktivität in Fibroblasten der Eltern eines CDG-IlcPatienten mit Heterozygotie für das defekte Allel wurde im Fall des Vaters eine Verminderung auf etwa $60 \%$ festgestellt, was allerdings auch für den Kontrolltransporter zutraf (Lübke et al., 1999). Die Mutter zeigte eine unveränderte Transportaktivität. Diese Ergebnisse aus humanen und murinen Zellen sind also weitgehend übereinstimmend und führen $\mathrm{zu}$ dem Schluss, dass das Vorhandensein eines gesunden Allels für eine normale Transportaktivität ausreicht. 


\subsection{Der Phänotyp des $\mathrm{GFT}^{-{ }^{-}-\text {-Mausmodells ist mit dem }}$ Krankheitsbild von CDG-Ilc vergleichbar}

Ziel des Knockouts des GFT in der Maus war einerseits die Generierung eines Modells, welches zum Verständnis der generellen Bedeutung der Fucosylierung im Säugerorganismus beitragen soll. Andererseits sollte es tiefere Einblicke in die Pathogenese von CDG-Ilc ermöglichen. Letzteres setzt voraus, dass das Modell einen mit CDG-Ilc-Patienten vergleichbaren Phänotyp hat.

Das Genom von Mus musculus steht dem humanen Genom sehr nahe. Der Großteil der physiologischen Prozesse funktioniert in beiden Organismen nach den gleichen Prinzipien unter Beteiligung entsprechender orthologer Proteine mit hoher Homologie zueinander. Dennoch verbleibt trotz Kenntnis der vollständigen Genome ein gewisses Maß an Unsicherheit bei der Vorhersage eines Effektes eines spezifischen Knockouts, da dieser durch ein noch nicht identifiziertes Protein kompensiert werden könnte, welches nur in der Maus, nicht aber im Menschen existiert. Daher war zunächst zu zeigen, dass eine GFT-Defizienz in der Maus einen mit CDG-Ilc vergleichbaren Phänotyp zur Folge hat.

Der klinische Phänotyp der $\mathrm{GFT}^{-/}$-Maus ist durch eine hohe postnatale Mortalitätsrate bei einem normalen Geburtenverhältnis gekennzeichnet. In der konventionellen Tierhaltung war nach der ersten Lebenswoche ein Drittel, nach vier Wochen ein weiteres Drittel der GFT $^{-/}$-Tiere verstorben. In SPF-Haltung zeigte sich prinzipiell eine ähnliche Entwicklung, jedoch überlebten hier bis zum Alter von vier Wochen etwa $8 \%$ mehr. Besonders zu erwähnen ist die gesteigerte Sterblichkeit in der Phase des Absetzens vom Muttertier und der damit verbundenen Nahrungsumstellung.

Die Tiere zeigten eine stark verzögerte Gewichtsentwicklung im Vergleich zu heterozygoten und Wildtyp-Geschwistern. Diejenigen Tiere, die ein Alter von mehreren Monaten erreichten, waren auch dann noch deutlich untergewichtig.

Äußerlich fallen mangelnde Fellpflege sowie eine gekrümmte Körperhaltung auf, was physischen oder psychische Stress anzeigt. Die motorischen Fähigkeiten der $\mathrm{GFT}^{-/-}$-Tiere sind eingeschränkt, sie sind deutlich weniger aktiv als ihre Geschwister. Ihr Verhalten ist durch zwanghafte und wiederholte Bewegungen gekennzeichnet. 
$\mathrm{GFT}^{-/-}$-Tiere sind fertil, allerdings waren nur etwa 50\% der bisherigen Verpaarung erfolgreich. $\mathrm{GFT}^{-/}$-Weibchen erwiesen sich als nicht in der Lage, ihre Nachkommen prä- wie postnatal hinreichend zu versorgen. Für diejenigen Verpaarungen, bei denen es zu keiner Befruchtung kam, ist aufgrund der beschriebenen Verfassung von $\mathrm{GFT}^{-/}$-Tieren nicht auszuschließen, dass der Grund nicht beispielsweise in einem spezifischen Defekt der Keimzellen durch eine Fucosylierungdefizienz sondern in einem mangelnden physischen Zustand des verpaarten $\mathrm{GFT}^{-/-}$-Tieres bestand.

Bei Erstellung eines Blutbildes fiel die starke Erhöhung der Leukozyten-Zahl auf. Die Zahl der Neutrophilen ist auf fast das Fünffache des Normalwertes erhöht.

Das Krankheitsbild von CDG-Ilc ist durch schwere Entwicklungsverzögerungen, vermindertes Wachstum, Mikrozephalie, Hypotonie sowie wiederkehrende, lebensbedrohliche Infektionen bei einer persistierenden Leukozytose geprägt. Das GFT $^{-/-}$-Modell stimmt demnach in vielen Punkten mit dem CDG-Ilc-Phänotyp überein.

CDG-Ilc-Patienten weisen einen immunologischen Defekt aufgrund eines stark verminderten Leukozyten-Rollens auf, welcher die dauerhafte Leukozytose bzw. insbesondere eine Neutrophilie zur Folge hat. Diese Neutrophilie ist auch in $\mathrm{GFT}^{-/-}$ -Mäusen zu beobachten. Die genaue Todesursache der Tiere bleibt bislang ungeklärt, jedoch legt der zwar moderate, jedoch vorhandenen Unterschied der Überlebensfähigkeit in Tierhaltungen mit unterschiedlichem Hygienestatus einen Zusammenhang mit der Immunkompetenz der Tiere nahe. In der verwendeten konventionellen Tierhaltung wurden Keime wie beispielsweise das Maus-HepatitisVirus (MHV) und Pasteurella pneumotropica nachgewiesen. Die spezifiziert pathogenfreie (SPF-) Haltung ist zwar, wie der Name sagt, nicht gänzlich frei von pathogenen Keimen, jedoch sind diese auf ein definiertes, vergleichsweise geringes Maß beschränkt. Die Belastung der Tiere durch Infektionen ist also in konventioneller Haltung deutlich höher als in SPF-Haltung und kann somit eine erhöhte Sterblichkeit bei GFT ${ }^{-/}$-Tieren erklären, deren Immunabwehr durch einen Defekt der Leukozytenadhäsion als eine Voraussetzung für die Infektbekämpfung geschwächt ist.

Weitere Übereinstimmmungen zwischen CDG-Ilc-Patienten und GFT ${ }^{-/-}$-Mäusen liegen in der Entwicklungsverzögerung sowie mangelnden motorischen Fähigkeiten. Es existieren Anzeichen, dass, ähnlich wie bei den Patienten, auch in 
GFT $^{-/-}$-Mäusen neurokognitive Fähigkeiten gestört sind. Eine konkrete Aussage dazu lässt sich jedoch erst nach systematischer Durchführung von Verhaltenstests treffen, die aus genannten Gründen (s. 4.2.3) bisher noch nicht möglich waren.

5.3

GFT $^{-I-}$-Mäuse weisen einen Defekt der Expression und Funktion von Selektin-Liganden auf

Fucosereste sind ein essentieller Bestandteil von Lewis-Antigenen, deren Funktionsspektrum sich auch auf die Vermittlung von Zell-Zell-Erkennungs- und Adhäsionsvorgängen im Rahmen des Leukozyten-Rollens erstreckt. Wie Untersuchungen von Marquardt et al. (1999a) an Leukozyten eines CDG-IlcPatienten erwiesen haben, liegt die Ursache für das auffälligste Symptom der Erkrankung, eine akute persistierende Leukozytose, in dem Fehlen dieser Strukturen.

Das Leukozyten-Rollen ist Teil des mehrstufigen Prozesses der LeukozytenRekrutierung. Die Annäherung (Margination) und der erste Kontakt zwischen Leukozyten und dem Gefäßendothel, das "Einfangen" der Leukozyten, wird durch rein rheologische Faktoren beeinflusst (Ley und Tedder, 1995). Aufgrund der relativ niedrigen Flussgeschwindigkeit und des geringen Durchmessers werden fast alle Leukozyten in postkapillären Venolen an entzündetem Gewebe adhärent (Kunkel et al., 2000). Auf die Margination folgt ein vorübergehender Kontakt zu den Endothelzellen in Form eines Rollens der Leukozyten, das vorwiegend durch die Bindung von Selektinen an ihre Liganden vermittelt wird (Kansas, 1996). Durch membranständige Faktoren auf der Endotheloberfläche in entzündetem Gewebe wie beispielsweise Chemokine kommt es zur Aktivierung von Integrinen auf der Oberfläche rollender Leukozyten. Die Subpopulationen der Leukozyten exprimieren verschiedene Chemokin-Rezeptoren, was neben der Kontextabhängigen Expression entsprechender Chemokine zu einer Spezifität der Aktivierung beiträgt (Rossi und Zlotnik, 2000). Aus der Bindung der Integrine an ihre Liganden auf dem Endothel, Mitglieder der Immunglobulin-Superfamilie, folgt eine Stabilisierung der Adhäsion und der Arrest des Rollens (Kunkel et al., 2000). Schließlich erfolgt die Transmigration (Diapedese) der Leukozyten zwischen den Endothelzellen hindurch in das entzündete Gewebe (Burns et al., 1997). 
Die Bezeichnung "Selektin" leitet sich aus den Begriffen Selektion und Lektin ab. In der Familie der Selektine werden drei Adhäsionsmoleküle der Lektin-Klasse zusammengefasst, die spezifisch Kohlenhydratstrukturen erkennen und auf Blutzellen sowie Zellen des Blutgefäßsystem exprimiert werden. Sie sind entsprechend ihres Expressionsortes benannt: L-Selektin wird ausschließlich und konstitutiv auf Leukozyten exprimiert; P-Selektin ist in den $\alpha$-Granula der Blutplättchen (Platelets) sowie in den Weibel-Palade-Körpern der Endothelzellen gespeichert und wird nach Stimulation durch proinflammatorische Substanzen zur Oberfläche mobilisiert; eine E-Selektin-Expression auf Endothelzellen wird durch Cytokine wie TNF- $\alpha$ und Interleukine sowie durch Lipopolysaccharid induziert (Vestweber und Blanks, 1999).

Alle Selektine erkennen eine bestimmte sialylierte Kohlenhydrat-Struktur auf ihren Liganden, im Wesentlichen bestehend aus dem Sialyl-Le ${ }^{\mathrm{x}}-$ Molekül und seinen Isomeren (Rosen, 1993). Das alleinige Vorhandensein dieses Epitops genügt für eine geringe Affinität der Selektine, was u.a. durch eine Bindung von Selektinen an entsprechend chemisch modifiziertes BSA demonstriert wurde (Berg et al., 1992). Im Fall der L-Selektin-Liganden ist eine Sulfatierung der determinanten Gruppe für eine hochaffine Bindung erforderlich. Der Fucosylanteil dieser Epitope ist jedoch in jedem Fall für die Selektin-Ligand-Bindung von essentieller Bedeutung (Vestweber und Blanks, 1999).

In CDG-Ilc-Patienten ist das Leukozyten-Rollen aufgrund einer Defizienz der Selektin-Liganden gestört (Marquardt et al., 1999a). Entsprechend wurden die Expression sowie die Funktion der Liganden in $\mathrm{GFT}^{-/-}$-Mäusen bestimmt. Die Expression von E- und P-Selektin-Liganden, die im Gegensatz zu L-SelektinLiganden auf der Leukozytenoberfläche exprimiert werden, ließ sich in vitro an isolierten Leukozyten ermitteln. Bei FACS-Analysen war keine Bindung von Selektin-Fc-Konstrukte an E- oder P-Selektin-Liganden auf GFT ${ }^{-/}$-Zellen nachweisbar.

Die funktionelle Charakterisierung der Selektin-Liganden erfolgte anhand des Modells der Peyer'schen Plaques aus dem Dünndarm. Durch Intravitalmikroskopie konnte das Rollen der Leukozyten auf dem Endothel hochendothelialer Venolen (HEV) beobachtet und quantifiziert werden. HEV sind postkapilläre Venolen, die sich durch ihre cuboidalen, "hohen" Endothelzellen sowie die konstitutive Expression von chemoattraktiven Substanzen auszeichnen 
(Butcher et al., 1999). Diese Merkmale gewährleisten eine effiziente Rekrutierung von Lymphozyten in lymphatisches Gewebe, die sich in ihren Grundzügen entsprechend der beschriebenen mehrstufigen Kaskade gestaltet. Die Interaktionen zwischen Leukozyten und HEV in Peyer'schen Plaques werden hauptsächlich von L-Selektin vermittelt, das daher auch als Lymphozyten-HomingRezeptor bezeichnet wird, sowie von $\alpha_{4} \beta_{7}$-Integrin und P-Selektin (Sperandio et al., 2001). Letzteres wird in geringer Menge aufgrund der bei dem experimentellen Eingriff erfolgenden Gewebeschädigung exprimiert.

Im Verlauf des Versuchs zeigte sich zunächst eine deutliche Reduktion des Leukozyten-Rollens in Peyer'schen Plaques von GFT'---Tieren auf etwa ein Siebtel der Kontrollen. Durch spezifische Blockade der drei verschiedenen Adhäsionsmoleküle mittels Applikation von Antikörpern konnte gezeigt werden, dass dieses verbleibende Rollen ausschließlich auf die Integrin-vermittelte, also fucosylierungsunabhängige Adhäsion zurückzuführen ist. Diese Ergebnisse zeigen, dass der GFT für die Expression funktioneller Selektin-Liganden essentiell ist.

5.4

Lymphknoten und Lunge GFT-defizienter Mäuse zeigen histopathologische Veränderungen

Der GFT-Knockout in der Maus ermöglicht es, auf zellulärer Ebene Einblicke in Organe eines Säugerorganismus mit einer generellen, d.h. nicht nur auf einzelne Verknüpfungsarten beschränkten, Fucosylierungdefizienz zu erlangen. Zu drei anderen fucosylierungsdefizienten Mausmodellen wurden histologische Befunde publiziert, die im Folgenden zusammengefasst werden sollen.

Ist die de novo-Biosynthese von GDP-Fucose durch Ausschalten des FX-Proteins gestört, kommt es zu einer persistierenden Diarrhoe (Smith et al., 2002). Die Darmwand des absteigenden Teils des Colons zeigte eine starke Verdickung und Krypten-Abszesse mit inflammatorischen Zellinfiltraten. Weitere histologische Befunden zu diesem Modell wurden nicht publiziert.

Die Fucosyltransferase VII katalysiert den Transfer a-1,3-verknüpfter Fucose und wird in Leukozyten exprimiert. Fut7-defiziente Mäuse haben hypozelluläre 
Lymphknoten mit nur rudimentär angelegten Primärfollikeln (Weninger et al., 2000).

In Fut8-defizienten Mäusen ist die a-1,6-Fucosylierung betroffen (Wang et al., 2005). Eine histopathologische Analyse ergab eine Emphysem-ähnliche Störung in der Lunge.

Für eine eingehende histologische Analyse der $\mathrm{GFT}^{-/-}$-Tiere wurden alle wichtigen Organe präpariert und mit Hilfe von Übersichtsfärbungen der Präparate beurteilt. Bei diesem Modell zeigten sich Auffälligkeiten in den Lymphknoten sowie in der Lunge. Der Darm sowie die übrigen Organe waren nicht betroffen.

Periphere Lymphknoten in $\mathrm{GFT}^{-/-}$-Tieren sind hypozellulär und zumeist hypomorph. Lymphfollikel sind nur selten zu finden und dann auch nur sehr schwach ausgeprägt. Dieser Befund deckt sich also mit den Ergebnissen aus Fut7-defizienten Mäusen und lässt sich durch die Defizienz funktionaler SelektinLiganden erklären, die für ein effizientes Homing der Lymphozyten in den HEV der Lymphknoten erforderlich sind. In Peyer'schen Plaques waren zwar ebenfalls kaum Lymphfollikel auszumachen, die Hypozellularität war hier jedoch schwächer ausgeprägt. Dieser Befund lässt sich durch die bereits unter 5.3 beschriebene teilweise Vermittlung der Leukozytenadhäsion durch das $\alpha_{4} \beta_{7}$-Integrin erklären, das von dem GFT-Defekt nicht beeinflusst wird.

In der Lunge der $\mathrm{GFT}^{-/}$-Tiere fielen Emphysem-ähnliche Dilatationen der Alveolarräume auf, die sich morphometrisch bestätigen ließen. Dieses Ergebnis wiederum deckt sich mit dem Befund Fut8-defizienter Mäuse. Dort wurde dieser Phänotyp auf eine Störung des TGF(transforming growth factor) $\beta$-Signalwegs zurückgeführt, der eine Überexpression von Metalloproteasen und schließlich einen Mangel an Proteinen der extrazellulären Matrix zur Folge hat. Durch eine Anfärbung elastischer Fasern in der $\mathrm{GFT}^{-{ }^{-}}$-Lunge wurde gezeigt, dass deren Anteil tendenziell vermindert sind. Wie der Pathomechanismus gestaltet und ob auch hier der TGF $\beta$-Signalweg gestört ist, bleibt noch zu klären.

Für CDG-Ilc-Patienten sind u.a. Störungen der neuronalen Entwicklung beschrieben worden. Alle Betroffenen leiden unter kortikaler Atrophie und Mikrozephalie, ihre geistige Entwicklung ist retardiert. Daher wäre möglicherweise auch im Gehirn von $\mathrm{GFT}^{-/-}$-Tieren ein Phänotyp zu erwarten gewesen. Dieses zeigte jedoch weder äußere Auffälligkeiten bezüglich der Größe noch Veränderungen der Architektur und Zellverteilung. Für ein abschließendes Urteil 
müssen jedoch noch weitere Präparationen mit beispielsweise einer anderen als der bisher verwendeten sagittalen Schnittebene sowie Spezialfäbungen zur Darstellung bestimmter Strukturen und Moleküle durchgeführt werden.

Auch die Architektur und die zelluläre Zusammensetzung der übrigen Organe unterschieden sich nicht zwischen $\mathrm{GFT}^{-/-}$-Tieren und ihren Geschwistern, soweit dies anhand der HE-gefärbten Präparate zu beurteilen war.

\section{$5.5 \mathrm{GFT}^{-1-}$-Zellen und -Gewebe weisen eine ausgeprägte Hypofucosylierung auf}

Die Fucosylierung in $\mathrm{GFT}^{-/-}$-Zellen und -Geweben sowie Kontrollen wurde in verschiedenen Modellen charakterisiert. Ein erster funktioneller Nachweis des GFT-Knockouts erfolgte durch eine Lektin-Markierung von primären embryonalen Fibroblasten (MEF). Hier zeigte sich deutlich das Fehlen von $\alpha-1,2-, \alpha-1,3-$ oder $\alpha-$ 1,6-verknüpften Fucoseresten, an die das verwendete Aleuria aurantia-Lektin $(\mathrm{AAL})$ bindet.

Eine quantitative Erfassung fucosylierter Strukturen erfolgte durch affinitätschromatographische Analyse $\left[2-{ }^{3} \mathrm{H}\right]$ Mannose-markierter Glykopeptide mit Lens culinaris-Lektin (LCA), welches an bi- und triantennären N-Glykane mit $\alpha-1,6$ verknüpfter Core-Fucose bindet und in Agarose-gekoppelter Form verfügbar ist. In $\mathrm{GFT}^{-/-}$-MEF zeigte sich eine klare Reduktion des Anteil dieser N-Glykane an allen mannosylierten N-Glykanen. Er machte etwa ein Zehntel des entsprechenden Anteils in Kontroll-MEF aus.

Weiterhin wurde die Kultur von zwei weiteren primären Zelltypen etabliert, die sich sowohl in ihrem Ursprungsorgan und -keimblatt als auch ihrem Stoffwechsel unterscheiden. Hepatozyten entstammen dem Entoderm und nehmen etwa 80\% des Lebervolumens ein. Sie stellen die Funktionseinheit der Leber dar und besitzen neben sekretorischen und metabolischen Eigenschaften auch die Fähigkeit zur Speicherung von Zuckern in Form von Glykogen. Glykogenspeicherung und Gluconeogenese unterliegen der strengen hormonollen Regulation durch Insulin und Glukagon (Klover und Mooney, 2004). Dementsprechend war eine effiziente metabolische Markierung der Glykoproteine 
in Hepatozyten mit dem Zucker $\left[2-{ }^{3} \mathrm{H}\right]$ Mannose nur unter Insulin-Behandlung möglich.

Mesangialzellen sind mesodermalen Ursprungs, stellen etwa ein Drittel der Gesamtzahl aller Zellen im Glomerulum dar und haben eine zentrale Bedeutung für den Erhalt der Struktur und die Funktion des Ultrafiltrationsapparates der Niere (Haas et al., 1999). Ihr Funktionsspektrum ist breit gefächert und umfasst die Synthese extrazellulärer Matrix, Kontraktion bei entsprechender Stimulation, Makrophagenfunktionen sowie die Produktion von Wachstumsfaktoren und Zytokinen (Lee, 1995).

Die LCA-affinitätschromatographische Analyse [2- $\left.{ }^{3} \mathrm{H}\right]$ Mannose-markierter Glykopeptide zeigte auch für diese Zelltypen ein ähnliches Ergebnis wie in MEF. Der Anteil fucosylierter und somit LCA-bindender Glykopeptide war in $\mathrm{GFT}^{-/}$-

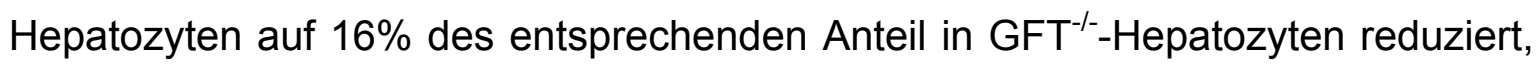
im Fall der Mesangialzellen waren es $19 \%$.

Vergleicht man die Fucosylierungsraten in den drei verschiedenen Zelltypen untereinander, wiesen MEF den größten Anteil von LCA-Liganden an allen markierten Glykopeptiden auf, Mesangialzellen die wenigsten. Die Menge an LCALiganden in den $\mathrm{GFT}^{-/-}$-Zellen war jedoch in allen drei Zelltypen in etwa gleich.

Schließlich wurde auch in Milzzellen die Fucosylierung untersucht. In diesem Fall erfolgte eine Verwendung von AAL, dessen Bindung durch die Kopplung eines Fluoreszenzmarkers und eine anschließende FACS-Analyse nachgewiesen wurde. Es zeigte sich eine deutliche Reduktion des Anteils AAL-bindender Zellen. Auf einem kleinen Anteil der Zellen war jedoch noch eine Restfucosylierung detektierbar.

Zusammenfassend lässt sich also sagen, dass die Fucosylierung, soweit dies anhand des für diesen Ansatz verwendeten Lektins LCA zu beurteilen ist, in vier verschiedenen Zelltypen aus $\mathrm{GFT}^{-/}$-Organen deutlich reduziert ist. Es lässt sich jedoch eine konstante Restfucosylierung detektieren, deren Ursprung noch unklar ist und die von dem ausgeschalteten GFT unabhängig sein muss.

Darüber hinaus wurde die Fucosylierung in histologischen Schnitten der Organe mit verschiedenen Lektinen und Fluoreszenzmarkierung charakterisiert. Hierbei wurde vor allem AAL verwendet, da es ein breit gefächertes Bindungsspektrum hat und die beste Bindung in Kontrollpräparaten zeigte. Vergleiche mit anderen Lektinen führten prinzipiell zu vergleichbaren Resultaten. Unter Verwendung eines 
Kontroll-Lektins, welches an Gal- $\beta$-1,3-LacNAc-Strukturen, also von dem Knockout nicht betroffene Glykokonjugate, bindet, zeigten sich identische Glykosylierungsmuster in $\mathrm{GFT}^{+/}$- und $\mathrm{GFT}^{-/}$-Organen. Mit Hilfe der Fucosespezifischen Lektine ließ sich jedoch in $\mathrm{GFT}^{-/}$-Organen praktisch keine Fucosylierung nachweisen. Die Intensität einer leichten Hintergrund-Fluoreszenz entspricht derjenigen in Negativkontrollen und ist somit als unspezifisch zu interpretieren.

Gleichzeitig wurde durch diese Färbungen deutlich, wie groß das Ausmaß der Fucosylierung im Säugerorganismus ist. Die Expression der Lektin-Epitope ist vor allem auf Oberflächenstrukturen nachzuweisen, z.B. in den Tubuli der Niere, auf der Zona pellucida der Oozyte sowie auf den Epithelien von Lunge, Uterus und Darmzotten. Ebenso auffällig ist die ausgeprägte und gleichmäßige Fucosylierung des Neuropils in der Groß- und Kleinhirnrinde. Im Folgenden sollen kurz die bisherigen Erkenntnisse zur Fucosylierung in diesen Strukturen dargestellt werden.

Die Schleimhautepithelien des Respirations-, Reproduktions- und Gastrointestinaltraktes sind reich an Proteinen des Mucin-Typs, die von sekretorischen Zellen abgegeben werden und hydrophob sowie O-glykosyliert sind (Gendler und Spicer, 1995). Die Oligosaccharid-Anteile stellen 50-80\% der Mucin-

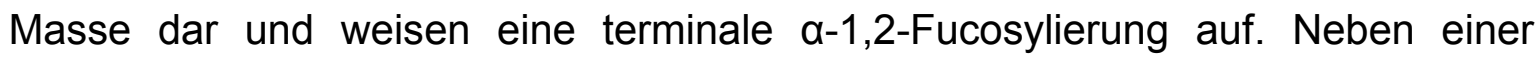
Gewährleistung der Viskosität des Epithelschleims werden den Mucinen u.a. Funktionen bei Interaktionen zwischen Wirtszellen und pathogenen wie kommensalen Bakterien zugeschrieben (Falk et al., 1995; Bry et al.,1996).

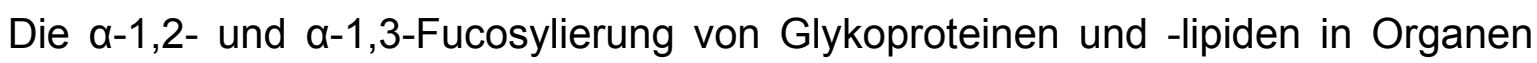
des weiblichen und männlichen Reproduktionstraktes wurde mit verschiedenen Prozessen in Verbindung gebracht. So haben gemäß Fenderson et al. (1984) a1,3-fucosylierte Glykane eine Bedeutung für die Morula-Kompaktion und darüber hinaus für Interaktionen zwischen Spermium und Ei (Dell et al., 1999). Die a-1,2Fucosylierung wird im Uterusepithel zyklusabhängig dynamisch reguliert und ist in den Vorgang der Blastozysten-Implantation involviert (Kimber und Lindenberg, 1990). Sie ist ebenso in den Tubuli seminiferi des Hodens und im Nebenhoden zu finden, wo ihr eine Beteiligung an der Spermienreifung zugeschrieben wird (Millette et al., 1987; Sandhoff et al., 2005). 
Eine Fucosylierung der Tubuli in der Niere wurde zwar beschrieben (Schulte und Spicer, 1983), ihr konnten bislang jedoch keine speziellen Funktionen zugeordnet werden.

Histochemische Analysen von neuronalem Gewebe deuten auf eine Beteiligung von Fucose an ontogenetischen Prozessen im Nervensystem im Rahmen des axonalen Wachstums und der Faszikulation, der Neuronenwanderung, Synaptogenese und Myelinisierung hin (Zanetta, 1998). Ferner hat sie Einfluss auf Gedächtnisfunktionen (Jork et al., 1986) sowie auf die Stabilität von Synapsin la und lb (Murrey et al., 2006).

In Teilen wurden die genannten Funktionen von Fucosylresten in den

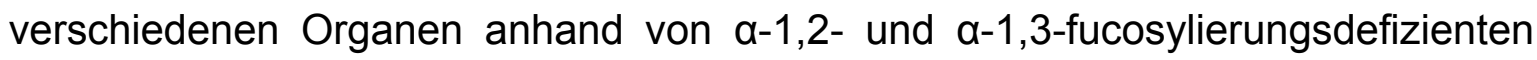
Mäusen untersucht. Entgegen den Erwartungen, die sich aus dem bisherigen Kenntnisstand und der erwähnten Literatur ergeben, zeigten Fut1-und Fut2defiziente Mäuse keine gastrointestinalen Abnormalitäten (Hurd et al., 2005) und waren fertil (Domino et al., 2001). In Fut9-defizienten Mäusen fehlt SSEA-1 (Stage specific embryonic antigen 1), ein $\alpha-1,3-$ fucosyliertes Le ${ }^{x}$-Epitop, das in der frühen Embryonalentwicklung sowie in Primordialfollikeln exprimiert wird und bisher mit der Morula-Kompaktion in Zusammenhang gebracht wurde. Doch auch diese Tiere weisen eine normale Entwicklung und Fertilität auf (Kudo et al., 2004).

In $\mathrm{GFT}^{-1-}$-Mäusen konnte mit $\mathrm{AAL}$ das Fehlen alle beschriebener Fucosylierungsmuster gezeigt werden. Dennoch sind auch diese Tiere fertil, sie haben keine erkennbaren gastrointestinalen Probleme, und auch in anderen Organsystemen sind, von Lymphknoten und Lunge abgesehen, histologisch keine Auffälligkeiten ersichtlich, die im Übrigen Hinweise auf die noch unbekannte Todesursache geben könnten.

Alle fucosylierungsdefizienten Mausmodelle, den GFT-Knockout eingeschlossen, weisen also einen schwächeren Phänotyp auf, als er nach dem bisherigen Kenntnisstand zu fucosylierungsabhängigen Prozessen zu erwarten gewesen wäre (s. auch 1.1.2). Somit stellt sich die Frage nach der tatsächlichen Funktion fucosylierter Strukturen in den einzelnen Geweben, der momentan nur mit Hypothesen begegnet werden kann. Eine Möglichkeit besteht darin, dass sich die Bedeutung der Fucosylreste lediglich auf unterstützende, jedoch nicht essentielle Funktionen beschränkt. Da unklar ist, ob ein alternativer Mechanismus existiert, um zumindest kleinste Mengen GDP-Fucose über die Golgi-Membran zu 
transportieren, wäre ebenfalls das Vorhandensein einer sehr schwachen Restfucosylierung denkbar, die einen schwerwiegenderen Phänotyp verhindern kann. Diese würde möglicherweise durch die Lektin-Färbung in den Geweben nicht hinreichend erfasst werden, könnte jedoch die Ergebnisse der Affinitätschromatographie für Glykopeptide aus $\mathrm{GFT}^{-/-}$-Zellen erklären.

Für die Charakterisierung der O-Fucosylierung, also der direkten Verknüpfung von Fucose mit Proteinanteilen, stehen keine entsprechende Lektine oder Antikörper zur Verfügung. Ihre Analyse soll massenspektrometrisch anhand eines Markerproteins, das z.B. durch Überexpression in MEF gewonnen wird, durchgeführt werden, entsprechende Arbeiten für diesen verhältnismäßig aufwändigen Ansatz sind zur Zeit noch nicht abgeschlossen. Bisher lässt sich jedoch aus dem Phänotyp der GFT $^{-/}$-Mäuse schließen, dass die O-Fucosylierung nicht oder nur sehr geringfügig betroffen ist. Eine vollständige Defizienz auch der O-verknüpften Fucosereste hätte einen dem Protein-O-Fucosyltransferase 1Knockout ähnlichen Phänotyp erwarten lassen, der zu einem Absterben der Embryonen in utero führt (Shi und Stanley, 2003; s. 1.3.3).

5.6 Die Fucosylierungsrate in $\mathrm{GFT}^{-l-}$-Zellen lässt sich durch FucoseSupplementation normalisieren

Mindestens drei der CDG-Ilc-Patienten zeigen unter Fucose-Therapie klinische Verbesserungen sowie eine Re-Expression von Selektin-Liganden auf Neutrophilen. Die kausale Beziehung zwischen der Verbesserung des Gesundheitszustandes und der Fucose-Behandlung zeigte sich auch darin, dass sich bereits eine Woche nach Absetzen der Therapie im Fall des türkischen Patienten ein vollständiger Verlust der Selektin-Liganden einstellte und parallel dazu der Leukozyten-Spiegel wieder drastisch anstieg (Lühn et al., 2001). Aufgrund des unterschiedlichen Ansprechens auf eine Fucose-Therapie und einer Korrelation mit verschiedenen Mutationen wurde zunächst angenommen, der Therapieerfolg sei auf eine je nach Mutationstyp noch vorhandene Restaktivität des GFT zurückzuführen (Hirschberg, 2001).

Diese Arbeit hingegen zeigt nun, dass auch in primären Zellkulturen aus Organen von Mäusen mit einem konstitutiven Total-Knockout des GFT durch Fucose- 
Supplementation eine Anhebung der Fucosylierungsrate erzielt werden kann, die, zumindest mit unphysiologisch hohen Fucose-Konzentrationen, bis zur Normalisierung reicht. In vivo ist eine auffällig hohe Sterblichkeit von $\mathrm{GFT}^{-{ }^{-}}$Nachkommen u.a. in der Phase des Abstillens zu beobachten. Muttermilch ist reich an Fucose, in humaner Muttermilch liegt der Gehalt bei $660 \mathrm{mg} / \mathrm{l}$ (Miller et al., 1994). Somit ist diese Phase mit dem Absetzen von einer "Fucose-Therapie" vergleichbar.

Welche Faktoren diese Refucosylierung vermitteln, ist nach dem derzeitigen Kenntnisstand ungeklärt. Lühn et al. (2001) haben auf der Suche nach dem humanen GFT ein als ORF-11 bezeichnetes Gen aus Caenorhabditis elegans identifiziert, das in transfizierten Patienten-Fibroblasten etwa 10\% der Fucosylierung wiederherstellen konnte. Das GFT-Orthologe aus C. elegans, ORF7, erzielte $40-50 \%$ Refucosylierung. Wie sich später zeigte, entspricht ORF-11 dem Transporter SLC35B4 mit Spezifität für UDP-Xyl und UDP-GIcNAc, jedoch nicht für GDP-Fucose (Ashikov et al., 2005). Das humane Ortholog führte zu keiner Komplementation in Patienten-Fibroblasten (M. Wild, unpublizierte Daten). Innerhalb der SLC35-Familie (s. 1.1.4) weist das Mitglied SLC35C2 mit 25,5\% Sequenzübereinstimmung die größte Homologie zum GFT auf. Chen et al. (2005) konnten anhand der gain-of-function-CHO-Mutante LEC11B, die die a-1,3Fucosyltransferase exprimiert, zeigen, dass das Genprodukt von SLC35C2 die a1,3-Fucosylierung in LEC11B-Zellen supprimiert. Der Mechanismus dieser Suppression ist unbekannt, die Autoren spekulieren, dass es sich um einen GDPFucose-Transporter handeln könnte, der in einem anderen als dem GolgiKompartiment lokalisiert ist und somit die GDP-Fucose-Verfügbarkeit im GolgiApparat indirekt reduziert.

Eine dritte Möglichkeit wäre der Transport von GDP-Fucose durch einen anderen Nukleotidzucker-Transporter, der bei einem Überangebot von GDP-Fucose auf der zytosolischen Seite und einem Mangel im Golgi-Lumen diesen Nukleotidzucker zusätzlich zu seinem Hauptsubstrat transportieren kann. Konkrete Anhaltspunkte gibt es für diese Hypthese nicht, sie erscheint jedoch angesichts der Identifikation von anderen Multisubstrat-Nukleotidzucker-Transportern in den letzten Jahren (Muraoka et al., 2001; Segawa et al., 2002; Suda et al., 2004; Ashikov et al., 2005) nicht vollkommen unplausibel. 
Schließlich ist bei Überlegungen bezüglich eines alternativen GDP-FucoseTransportmechanismus die O-Fucosylierung zu berücksichtigen. Dieser Art der Fucosylierung kommt im Rahmen von Signaltransduktionswegen bereits im Verlauf der Embryonalentwicklung eine entscheidende Bedeutung zu (s. auch 1.1.2 und 1.1.3). Die O-Fucosylierung des Notch-Rezeptors ist essentiell für dessen Aktivierung durch Liganden auf Nachbarzellen. Der aktivierte Rezeptor übermittelt Signale in den Zellkern, die durch Regulation der Expression verschiedener Gene über das Schicksal der betreffenden Zelle in Abhängigkeit des Schicksals der Nachbarzellen entscheiden. Die Defizienz des Notch1-Proteins führt in der Maus zu embryonaler Letalität am Tag E11 und schweren Defekten in der Koordination der Somiten-Segmentierung (Conlon et al., 1995). Heterozygote Tiere weisen Lern- und Gedächtnisstörungen auf (Costa et al., 2003). Im Menschen äußern sich Störungen des Notch-Signalwegs z.B. in Form der Alagilleund CADASIL-Syndrome, die mit mentaler Retardierung und Demenz assoziiert sind (Li et al., 1997; Joutel et al., 1996). Eine Defizienz der O-Fucosyltransferase 1 (O-Fuc-T-1) betrifft neben Notch weitere Signaltransduktionsrezeptoren wie z.B. auch Nodal (s. 1.1.2), homozygote Tiere sterben während der mittleren Embryonalentwicklung am Tag E10 (s. 1.3.3; Shi und Stanley, 2003).

Erst kürzlich wurde gezeigt, dass beide O-Fucosyltransferasen entgegen früherer Annahmen im ER lokalisiert und aktiv sind. Daraus ergibt sich die Frage, ob sie: 1) zumindest in Teilen von der Aktivität des GFT abhängen, indem GDP-Fucose durch einen retrograden Transport aus dem Golgi-Apparat in das ER gelangt, oder 2) ausschließlich durch einen eigenen Transporter im ER mit ihrem Substrat GDPFucose versorgt werden (s. Abb. 48). Für 1) sprechen die Ergebnisse der Charakterisierung eines Knockouts des GFT-Orthologs in Drosophila (Ishikawa et al., 2005). Die Mutanten weisen einen Phänotyp ähnlich Notch1-heterozygoter Mutanten auf, d.h. sie sind überlebensfähig, haben aber u.a. die für einen NotchDefekt charakteristischen Kerben (engl. notch) in ihren Flügeln. Für die zweite Hypothese spricht eine Arbeit über den O-Fucosylierungsstatus in CDG-IlcFibroblasten, der gemäß der Aussage der Autoren nicht betroffen ist (Sturla et al., 2003). 


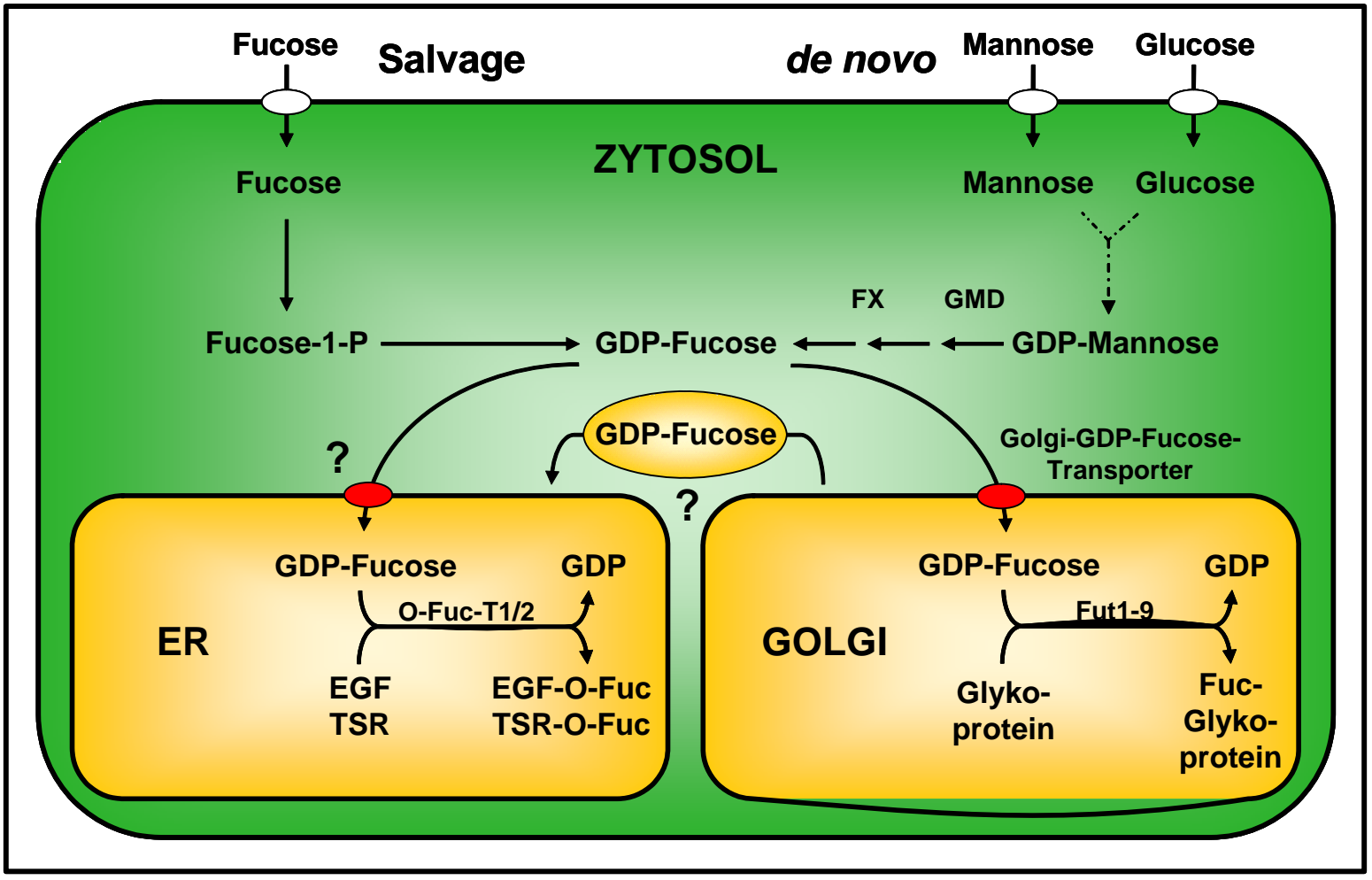

Abb. 48: Schematische Darstellung der Proteinfucosylierung in ER und Golgi-Apparat. GDP-Fucose wird zu etwa 90\% durch de novo-Synthese und zu etwa 10\% über den Salvage-Pathway im Zytosol bereitgestellt. Der Transport in den Golgi-Apparat erfolgt durch den GFT. Wie GDP-Fucose in das ER gelangt, ist bislang unbekannt.

Aus dem Phänotyp GFT-defizienter Mäuse kann man schließen, dass die OFucosylierung in diesem Modell nicht oder nur zu einem sehr geringen Teil betroffen ist. Sie weisen einen bedeutend milderen Phänotyp als die o.g. O-Fuc-T1-defizienten Mäuse auf. Darüber hinaus sind $\mathrm{GFT}^{-1-}$-Zellen mit Fucose therapierbar, was im Gegensatz zur unklaren Situation der CDG-Ilc-Patienten mit Punktmutationen im SLC35C1-Gen in diesem Fall nicht auf eine potentielle Restaktivität des GFT zurückgeführt werden kann. Dies ist also ein entscheidender Hinweis darauf, dass es neben dem GFT einen alternativen Transportmechanismus für GDP-Fucose in die Zellkompartimente gibt. 
Mit dem Total-Knockout des GFT in der Maus steht ein Modell zur Verfügung, anhand dessen viele ontologische und homöostatische Prozesse im Säugerorganismus auf ihre Fucosylierungsabhängigkeit hin untersucht und überprüft werden können.

Der für die Lunge beschriebene Phänotyp in $\mathrm{GFT}^{-/}$-Mäusen gleicht demjenigen in Fut8-defizienten Mäusen. Für dieses Modell wurde eine Störung des TGF $\beta 1$ Signalwegs nachgewiesen (Wang et al., 2005). Darüber hinaus haben die Autoren die Abhängigkeit weiterer Wachstumsfaktor-Signalwege von der in Fut8defizienten Mäusen betroffenen Core-Fucosylierung beschrieben (Wang et al., 2006). Es ist zu prüfen, ob diese Prozesse auch in $\mathrm{GFT}^{-{ }^{-}-}$-Mäusen gestört sind und ob sie neben dem Lungen-Phänotyp auch die Wachstum-Retardierung der Mäuse erklären können.

Erste Untersuchungen von Glykosphingolipiden (GSL) aus Hoden in Kooperation mit Dr. Roger Sandhoff (Abteilung für Zelluläre und Molekulare Pathologie, DKFZ, Heidelberg) haben das vollständige Fehlen von Fucosylresten erwiesen. Dieses Ergebnis muss durch weitere Versuche bestätigt werden und soll Aufschluss über die Abhängigkeit der Spermiogenese von fucosylierten GSL geben.

In Bezug auf die Selektin-Funktionen sind verschiedene weitere Ansätze geplant. In Zusammenarbeit mit Dr. Markus Sperandio (Klinik für Kinder- und Jugendmedizin Heidelberg, Abt. IV Neonatologie) sollen die intravitalmikroskopischen Untersuchungen des Leukozytenrollens für die Charakterisierung der Selektin-Funktionen während der Embryonalentwicklung angewandt werden. In der Abteilung von Prof. Dr. Dietmar Vestweber (MaxPlanck-Institut für Molekulare Biomedizin Münster) sollen anhand der GFT ${ }^{-I_{-}}$-Maus verschiedene Entzündungsmodelle untersucht werden.

Wichtig für das weitere Verständnis des Phänotyps der $\mathrm{GFT}^{-/-}$-Maus ist auch die Charakterisierung der O-Fucosylierung. Entsprechende Arbeiten zur Überexpression eines Markerproteins in MEF nach retroviraler Transduktion werden zur Zeit in unserer Arbeitsgruppe durchgeführt. Die Aufreinigung dieses Proteins, eines Thrombospondin-Repeats aus F-Spondin, sowie die massenspektrometrische Analyse der O-Fucosylierung werden in Kooperation mit Dr. Jan Hofsteenge (Friedrich Miescher Institut, Basel) durchgeführt. 
Darüber hinaus können primäre Zellkulturen aus $\mathrm{GFT}^{-/-}$-Tieren dazu genutzt werden, weitere Hinweise auf einen alternativen Transportmechanismus zu erlangen. Da die GFT-Aktivität ausgeschaltet ist, kann ein positiver bzw. negativer Effekt auf die Fucosylierungsrate in $\mathrm{GFT}^{-/}$-Zellen unter Fucose-Supplementierung bei gezielter Über- bzw. Unterexpression eines Transporters auf dessen Aktivität zurückgeführt werden. 


\section{$6 \quad$ Zusammenfassung}

In der vorliegenden Arbeit wurde ein Mausmodell für die humane Erberkrankung CDG-Ilc, die durch einen Defekt des Golgi-GDP-Fucose-Transporters verursacht wird, generiert. Der konstitutive Total-Knockout des Golgi-GDP-FucoseTransporters der Maus erfolgte durch die Insertion einer NeomycinResistenzkassette in das erste Exon und ließ sich durch Untersuchungen der Genexpression sowie der GDP-Fucose-Importaktivität in Golgi-Vesikel nachweisen.

Der Phänotyp Golgi-GDP-Fucose-Transporter-defizienter Mäuse weist in entscheidenden Punkten Parallelen zum Krankheitsbild von CDG-IIc-Patienten auf. Die Tiere zeigen eine ausgeprägte Entwicklungsverzögerung. Sie sind deutlich kleiner und untergewichtig im Vergleich zu gesunden Geschwistern, versterben zu einem Großteil während der ersten Lebenswochen und zeigen Auffälligkeiten in Bezug auf ihr Verhalten und motorische Leistungen.

Es ist eine ausgeprägte Neutrophilie festzustellen. Auf der Oberfläche der Leukozyten konnten, ebenso wie bei CDG-IIc-Patienten, keine fucosylierten Selektin-Liganden detektiert werden, die für das Rollen von Leukozyten auf dem Gefäßendothel essentiell sind. In vivo war kein Selektin-abhängiges LeukozytenRollen nachzuweisen. Dies erklärt unter anderem die Hypozellularität und Hypomorphie der Lymphknoten in defizienten Mäusen. Darüber hinaus ergab die histologische Charakterisierung der Organe pathologische Veränderungen der Lunge in Form einer Dilatation der Alveolen.

In verschiedenen primären Zellkulturen sowie in histologischen Präparaten der Organe konnte das weitgehende bzw. vollständige Fehlen von terminaler Fucose in unterschiedlichen Bindungsarten nachgewiesen werden. Diese Fucosylierungsdefizienz ließ sich durch Zugabe von Fucose in Zellkulturen korrigieren. Der verhältnismäßig milde Phänotyp, eine Restfucosylierung in primären Zellkulturen sowie die Möglichkeit einer Korrektur der Hypofucosylierung durch Fucose-Supplementierung geben einen entscheidenden Hinweis darauf, dass ein bisher noch nicht identifizierter Transportmechanismus für GDP-Fucose existiert. Das vorliegende Modell bietet nun die Möglichkeit, diesen Mechanismus sowie fucosylierungsabhängige Prozesse im Säugerorganismus zu identifizieren und zu charakterisieren. 


\section{$7 \quad$ Literaturverzeichnis}

Adams JC, Tucker RP (2000). The thrombospondin type 1 repeat (TSR) superfamily: diverse proteins with related roles in neuronal development. Dev Dyn 218:280-99.

Alwine JC, Kemp DJ, Stark GR (1977). Method for detection of specific RNAs in agarose gels by transfer to diazobenzyloxymethyl-paper and hybridization with DNA probes. Proc Natl Acad Sci U S A 74:5350-4.

Anderson DC, Springer TA (1987). Leukocyte adhesion deficiency: an inherited defect in the Mac-1, LFA-1, and p150,95 glycoproteins. Annu Rev Med 38:175-95.

Artavanis-Tsakonas S, Rand MD, Lake RJ (1999). Notch signaling: cell fate control and signal integration in development. Science 284:770-6.

Ashikov A, Routier F, Fuhlrott J, Helmus Y, Wild M, Gerardy-Schahn R, Bakker H (2005). The human solute carrier gene SLC35B4 endcodes a bifunctional nucleotide sugar transporter with specifity for UDP-xylose and UDP-Nacetylglucosamine. J Biol Chem 280:27230-5.

Becker DJ, Myers JT, Ruff MM, Smith PL, Gillespie BW, Ginsburg DW, Lowe JB (2003). Strain-specific modification of lethality in fucose-deficient mice. Mamm Genome 14:130-9.

Beltran-Valero de Bernabe D, Currier S, Steinbrecher A, Celli J, van Beusekom E, van der Zwaag $B$, Kayserili $H$, Merlini L, Chitayat D, Dobyns WB, Cormand $B$, Lehesjoki AE, Cruces J, Voit T, Walsh CA, van Bokhoven H, Brunner HG (2002). Mutations in the O-mannosyltransferase gene POMT1 give rise to the severe neuronal migration disorder Walker-Warburg syndrome. Am J Hum Genet 71:1033-43.

Bendahmane M, Abou-Haila A (1997). Characterization of glycoconjugates in the epididymal epithelium and luminal fluid during postnatal development of the mouse. Cell Tissue Res 287:611-9.

Berg EL, Magnani J, Warnock RA, Robinson MK, Butcher EC. Comparison of Lselectin and E-selectin ligand specificities: the L-selectin can bind the Eselectin ligands sialyl $\mathrm{Le}^{\mathrm{x}}$ and sialyl $\mathrm{Le}^{\mathrm{a}}$. Biochem Biophys Res Commun 184:1048-55.

Bradley A, Evans M, Kaufman MH, Robertson E (1984). Formation of germ-line chimaeras from embryo-derived teratocarcinoma cell lines. Nature 309:2556.

Brändli AW, Hansson GC, Rodriguez-Boulan E, Simons K (1988). A polarized epithelial cell mutant deficient in translocation of UDP-galactose into the Golgi complex. J Biol Chem 263:16283-90. 
Brockhausen I, Schutzbach J, Kuhns W (1998). Glycoproteins and their relationship to human disease. Acta Anat (Basel) 161:36-78.

Bry L, Falk PG, Midtvedt T, Gordon JI (1996). A model of host-microbial interactions in an open mammalian ecosystem. Science 273:1380-3.

Burda P, Borsig L, de Rijk-van Andel J, Wevers R, Jaeken J, Carchon H, Berger EG, Aebi M (1998). A novel carbohydrate-deficient glycoprotein syndrome characterized by a deficiency in glucosylation of the dolichol-linked oligosaccharide. J Clin Invest 102:647-52.

Burns AR, Walker DC, Browns ES, Thurmon LT, Bowden RA, Keese CR, Simon SI, Entman ML, Smith CW (1997). Neutrophil transendothelial migration is independent of tight juctions and occurs preferentially at tricellular corners. J Immunol 159:2893-903.

Butcher EC, Williams M, Youngman K, Rott L, Briskin M (1999). Lymphocyte trafficking and regional immunity. Adv Immunol 72:209-253.

Campbell ID, Bork P (1993). Epidermal growth factor-like modules. Curr Opin Struct Biol 3:385-92.

Capecchi MR (1989). The new mouse genetics: altering the genome by gene targeting. Trends Genet 5:70-6.

Chantret I, Dupre T, Delenda C, Bucher S, Dancourt J, Barnier A, Charollais A, Heron D, Bader-Meunier B, Danos O, Seta N, Durand G, Oriol R, Codogno $P$, Moore SE (2002). Congenital disorders of glycosylation type Ig is defined by a deficiency in dolichyl-P-mannose:Man7GlcNAc2-PP-dolichyl mannosyltransferase. J Biol Chem 277:25815-22.

Chantret I, Dancourt J, Dupre T, Delenda C, Bucher S, Vuillaumier-Barrot S, Ogier de Baulny H, Peletan C, Danos O, Seta N, Durand G, Oriol R, Codogno P, Moore SE (2003). A deficiency in dolichyl-P-glucose:Glc1Man9GIcNAc2PP-dolichyl alpha3-glucosytransferase defines a new subtype of congenital disorders of glycosylation. J Biol Chem 278:9962-71.

Chen W, Tang J, Stanley P (2005). Suppressors of alpha(1,3)fucosylation identified by expression cloning in the LEC11B gain-of-function $\mathrm{CHO}$ mutant. Glycobiology 15:259-69.

Conlon RA, Reaume AG, Rossant J (1995). Notch1 is required for the coordinate segmentation of somites. Development 121:1533-1545.

Costa RM, Honjo T, Silva AJ (2003). Learning and memory deficits in Notch mutant mice (2003). Curr Biol 13:1348-1354.

Coughenour LL, Mclean JR, Parker RB (1977). A new device for the rapid measurement of impaired motor function in mice. Pharmacol Biochem Behav 6:351-3. 
Crawley JN (1999). Behavioral phenotyping of transgenic and knockout mice: experimental design and evaluation of general health, sensory functions, motor abilities, and specific behavioral tests. Brain Res 835:18-26.

De Praeter CM, Gerwig GJ, Bause E, Nuytinck LK, Vliegenthart JF, Breuer W, Kamerling JP, Espeel MF, Martin JJ, De Paepe AM, Chan NW, Dacremont GA, Van Coster RN (2000). A novel disorder caused by defective biosynthesis of $\mathrm{N}$-linked oligosaccharides due to glucosidase I deficiency. Am J Hum Genet 66:1744-56.

Dell A, Morris HR, Easton RL, Patankar M, Clark GF (1999). The glycobiology of gametes and fertilization. Biochim Biophys Acta 1473:196-205.

Delves PJ (1998). The role of glycosylation in autoimmune disease. Autoimmunity 27:239-53.

Domino SE, Zhang L, Gillespie PJ, Saunders TL, Lowe JB (2001). Deficiency of reproductive tract alpha(1,2)fucosylated glycans and normal fertility in mice with targeted deletions of the FUT1 or FUT2 alpha(1,2)fucosyltransferase locus. Mol Cell Biol 21:8336-45.

Doucey MA, Hess D, Cacan R, Hofsteenge J (1998). Protein C-mannosylation is enzyme-catalyzed and uses dolichyl-phosphate-mannose as a precursor. Mol Biol Cell 9:291-300.

Eckhardt M, Gotza B, Gerardy-Schahn R (1999). Membrane topology of the mammalian CMP-sialic acid transporter. J Biol Chem 274:8779-87.

Etzioni A, Frydman M, Pollack S, Avidor I, Phillips ML, Paulson JC, GershoniBaruch R (1992). Brief report: recurrent severe infections caused by a novel leukocyte adhesion deficiency. N Engl J Med 327:1789-92.

Etzioni A, Tonetti M (2000). Fucose supplementation in leukocyte adhesion deficiency type II. Blood 95:3641-3.

Falk PG, Bry L, Holgersson J, Gordon JI (1995). Expression of a human alpha1,3/4-fucosyltransferase in the pit cell lineage of FVB/N mouse stomach results in production of Leb-containing glycoconjugates: a potential transgenic mouse model for studying Helicobacter pylori infection. Proc Natl Acad Sci U S A 92:1515-9.

Fenderson BA, Zehavi U, Hakomori S (1984). A multivalent lacto-N-fucopentaose III-lysyllysine conjugate decompacts preimplantation mouse embryos, while the free oligosaccharide is ineffective. J Exp Med 160:1591-6.

Fenderson BA, Holmes EH, Fukushi Y, Hakomori S (1986). Coordinate expression of $X$ and $Y$ haptens during murine embryogenesis. Dev Biol 114:12-21.

Frank CG, Grubenmann CE, Eyaid W, Berger EG, Aebi M, Hennet T (2004). Identification and functional analysis of a defect in the human ALG9 gene: 
definition of congenital disorder of glycosylation type IL. Am J Hum Genet 75:146-150.

Freeze $\mathrm{HH}$ (2001). Update and perspectives on congenital disorders of glycosylation. Glycobiology 11:129R-143R.

Frydman M, Etzioni A, Eidlitz-Markus T, Avidor I, Varsano I, Shechter Y, Orlin JB, Gershoni-Baruch R (1992). Rambam-Hasharon syndrome of psychomotor retardation, short stature, defective neutrophil motility, and Bombay phenotype. Am J Med Genet 44:297-302.

Fukuda M (1996). Possible roles of tumor-associated carbohydrate antigens. Cancer Res 56:2237-44.

Gendler SJ, Spicer AP (1995). Epithelial mucin genes. Annu Rev Physiol 57:60734.

Gilbert SF, Migeon BR (1975). D-valine as a selective agent for normal human and rodent epithelial cells in culture. Cell 5:11-7.

Gonzalez de Peredo A, Klein D, Macek B, Hess D, Peter-Katalinic J, Hofsteenge J (2002). C-mannosylation and O-fucosylation of thrombospondin type 1 repeats. Mol Cell Proteomics 1:11-8.

Gossler A, Doetschman T, Korn R, Serfling E, Kemler R (1986). Transgenesis by means of blastocyst-derived embryonic stem cell lines. Proc Natl Acad Sci U S A 83:9065-9.

Grubenmann CE, Frank CG, Hulsmeier AJ, Schollen E, Matthijs G, Mayatepek E, Berger EG, Aebi M, Hennet T (2004). Deficiency of the first mannosylation step in the $\mathrm{N}$-glycosylation pathway causes congenital disorder of glycosylation type lk. Hum Mol Genet 13:535-42.

Haas CS, Schocklmann HO, Lang S, Kralewski M, Sterzel RB (1999). Regulatory mechanisms in glomerular mesangial cell proliferation. J Nephrol 12:40515.

Hallgren P, Lundblad A, Svensson S (1975). A new type of carbohydrate-protein linkage in a glycopeptide from normal human urine. J Biol Chem 250:53124.

Hansske B, Thiel C, Lübke T, Hasilik M, Höning S, Peters V, Heidemann PH, Hoffmann GF, Berger EG, von Figura K, Körner C (2002). Deficiency of UDP-galactose:N-acetylglucosamine beta-1,4-galactosyltransferase I causes the congenital disorder of glycosylation type Ild. J Clin Invest 109:725-33.

Harris RJ, Leonard CK, Guzzetta AW, Spellman MW (1991). Tissue plasminogen activator has an O-linked fucose attached to threonine-61 in the epidermal growth factor domain. Biochemistry 30:2311-4. 
Helmus Y, Denecke J, Yakubenia S, Robinson P, Lühn K, Watson DL, McGrogan PJ, Vestweber D, Marquardt T, Wild MK (2006). Leukocyte adhesion deficiency II patients with a dual defect of the GDP-fucose transporter. Blood 2006 Feb 2 (Epub ahead of print).

Hidalgo A, Ma S, Peired AJ, Weiss LA, Cunningham-Rundles C, Frenette PS (2003). Insights into leukocyte adhesion deficiency type 2 from a novel mutation in the GDP-fucose transporter gene. Blood 101:1705-12.

Hiraishi K, Suzuki K, Hakomori S, Adachi M (1993). Le(y) antigen expression is correlated with apoptosis (programmed cell death). Glycobiology 3:381-90.

Hirschberg CB, Robbins PW, Abeijon C (1998). Transporters of nucleotide sugars, ATP, and nucleotide sulfate in the endoplasmic reticulum and Golgi apparatus. Annu Rev Biochem 67:49-69.

Hirschberg CB (2001). Golgi nucleotide sugar transport an leukocyte adhesion deficiency II. J Clin Invest 108:3-6.

Hofsteenge J, Müller DR, de Beer T, Loffler A, Richter WJ, Vliegenthart JF (1994). New type of linkage between a carbohydrate and a protein: C-glycosylation of a specific tryptophan residue in human RNase Us. Biochemistry 33:13524-30.

Hofsteenge J, Huwiler KG, Macek B, Hess D, Lawler J, Mosher DF, PeterKatalinic $J$ (2001). C-mannosylation and O-fucosylation of the thrombospondin Type 1 module. J Biol Chem 276: 6485-98.

Hogan B, Constantini F, Lacy E (1986). Manipulating the Mouse. A Laboratory Manual. Cold Spring Harbor Laboratory Press, New York.

Hogan B, Beddington R, Constantini F, Lacy E (1994). Manipulating the Mouse Embryo. A Laboratory Manual. Second Edition. Cold Spring Laboratory Press, New York.

Homeister JW, Thall AD, Petryniak B, Maly P, Rogers CE, Smith PL, Kelly RJ, Gersten KM, Askari SW, Cheng G, Smithson G, Marks RM, Misra AK, Hindsgaul O, von Andrian UH, Lowe JB (2001). The alpha(1,3)fucosyltransferases FucT-IV and FucT-VII exert collaborative control over selectin-dependent leukocyte recruitment and lymphocyte homing. Immunity 15:115-26.

Hooper M, Hardy K, Handyside A, Hunter S, Monk M (1987). HPRT-deficient (Lesch-Nyhan) mouse embryos derived from germline colonization by cultured cells. Nature 326:292-5.

Hurd EA, Holmen JM, Hansson GC, Domino SE (2005). Gastrointestinal mucins of Fut2-null mice lack terminal fucosylation without affecting colonization by Candida albicans. Glycobiology 15:1002-7. 
Imbach T, Burda P, Kuhnert P, Wevers RA, Aebi M, Berger EG, Hennet T (1999). A mutation in the human ortholog of the Saccharomyces cerevisiae ALG6 gene causes carbohydrate-deficient glycoprotein syndrome type-lc. Proc Natl Acad Sci U S A 96:6982-7.

Imbach T, Schenk B, Schollen E, Burda P, Stutz A, Grünewald S, Bailie NM, King MD, Jaeken J, Matthijs G, Berger EG, Aebi M, Hennet T (2000). Deficiency of dolichol-phosphate-mannose synthase-1 causes congenital disorder of glycosylation type le. J Clin Invest 105:233-9.

International Human Genome Sequencing Consortium (2004). Finishing the euchromatic sequence of the human genome. Nature 431:931-45.

Ishida N, Kawakita M (2004). Molecular physiology and pathology of the nucleotide sugar transporter family (SLC35). Eur J Physiol 447:768-75.

Ishikawa HO, Higashi S, Ayukawa T, Sasamura T, Kitagawa M, Harigaya K, Aoki K, Ishida N, Sanai Y, Matsuno K (2005). Notch deficiency implicated in the pathogenesis of congenital disorder of glycosylation Ilc. Proc Natl Acad Sci U S A 102:18532-7.

Jaeken J, Stibler H, Hagberg B (1991). The carbohydrate-deficient glycoprotein syndrome. A new inherited multisystemic disease with severe nervous system involvement. Acta Paediatr Scand Suppl 375:1-71.

Jaeken J, Schachter H, Carchon H, De Cock P, Coddeville B, Spik G (1994). Carbohydrate deficient glycoprotein syndrome type II: a deficiency in Golgi localised N-acetyl-glucosaminyltransferase II. Arch Dis Child 71:123-7.

Jaeken J, Artigas J, Barone R, Fiumara A, de Koning TJ, Poll-The BT, de Rijk-van Andel JF, Hoffmann GF, Assmann B, Mayatepek E, Pineda M, Vilaseca MA, Saudubray JM, Schluter B, Wevers R, Van Schaftingen E (1997). Phosphomannomutase deficiency is the main cause of carbohydratedeficient glycoprotein syndrome with type I isoelectrofocusing pattern of serum sialotransferrins. J Inherit Metab Dis 20:447-9.

Johansen PG, Marshall RD, Neuberger A (1961). Carbohydrates in protein. The preparation and some of the properties of a glycopeptide from hen egg ovalbumin. Biochem J 78: 518-27.

Joutel A, Corpechot C, Ducros A, Vahedi K, Chabriat H, Mouton P, Alamowitch S, Domenga V, Cecillion M, Marechal E, Maciazek J, Vayssiere C, Cruaud C, Cabanis EA, Ruchoux MM, Weissenbach J, Bach JF, Bousser MG, Tournier-Lasserve E (1996). Notch3 mutations in CADASIL, a hereditary adult-onset condition causing stroke and dementia. Nature 383:707-10.

Jork R, Grecksch G, Matthies H (1986). Impairment of glycoprotein fucosylation in rat hippocampus and the consequences on memory formation. Pharmacol Biochem Behav 25:1137-44. 
Joyner AL (1993). Gene Targeting. A Practical Approach. IRL Press at Oxford University Press, New York.

Kansas GS (1996). Selectins and their ligands: Current concepts and controversies. Blood 88:3259-87.

Karsan A, Cornejo CJ, Winn RK, Schwartz BR, Way W, Lannir N, GershoniBaruch R, Etzioni A, Ochs HD, Harlan JM (1998). Leukocyte Adhesion Deficiency Type II is a generalized defect of de novo GDP-fucose biosynthesis. Endothelial cell fucosylation is not required for neutrophil rolling on human nonlymphoid endothelium. J Clin Invest 101:2438-45.

Kentzer EJ, Buko A, Menon G, Sarin VK (1990). Carbohydrate composition and presence of a fucose-protein linkage in recombinant human pro-urokinase. Biochem Biophys Res Commun 171:401-6.

Kim S, Westphal V, Srikrishna G, Mehta DP, Peterson S, Filiano J, Karnes PS, Patterson MC, Freeze HH (2000). Dolichol phosphate mannose synthase (DPM1) mutations define congenital disorder of glycosylation le (CDG-le). J Clin Invest 105:191-8.

Kimber SJ, Lindenberg S (1990). Hormonal control of a carbohydrate epitope involved in implantation in mice. J Reprod Fertil 89:13-21.

Kleene R, Berger EG (1993). The molecular and cell biology of glycosyltransferases. Biochim Biophys Acta Rev Biomembr 1154:283-325.

Klover PJ, Mooney RA (2004). Hepatocytes: critical role for glucose homeostasis. Int J Biochem Cell Biol 36:753-8.

Kobata A (1998). A retrospective and prospective view of glycopathology. Glycoconj J 15:323-31.

Körner C, Lehle L, von Figura K (1998). Carbohydrate-deficient glycoprotein syndrome type 1: correction of the glycosylation defect by deprivation of glucose or supplementation of mannose. Glycoconj J 15:499-505.

Körner C, Knauer R, Stephani U, Marquardt T, Lehle L, von Figura K (1999a). Carbohydrate deficient glycoprotein syndrome type IV: deficiency of dolichyl-P-Man:Man(5)GlcNAc(2)-PP-dolichyl mannosyltransferase. EMBO J 18:6816-22.

Körner C, Linnebank M, Koch HG, Harms E, von Figura K, Marquardt T (1999b). Decreased availability of GDP-L-fucose in a patient with LAD II with normal GDP-D-mannose dehydratase and FX protein activities. J Leukoc Biol 66:95-8.

Kornfeld R, Kornfeld S (1985). Assembly of asparagine-linked oligosaccharides. Annu Rev Biochem 54:631-64. 
Krakower CA, Greenspon SA (1951). Localization of the nephrotoxic antigen within the isolated renal glomerulus. AMA Arch Pathol 51:629-39.

Kranz C, Denecke J, Lehrman MA, Ray S, Kienz P, Kreissel G, Sagi D, PeterKatalinic J, Freeze HH, Schmid T, Jackowski-Dohrmann S, Harms E, Marquardt T (2001). A mutation in the human MPDU1 gene causes congenital disorder of glycosylation type If (CDG-If). J Clin Invest 108:16139.

Kudo T, Kaneko M, Iwasaki H, Togayachi A, Nishihara S, Abe K, Narimatsu H (2004). Normal embryonic and germ cell development in mice lacking $\alpha-1,3-$ fucosyltransferase IX (Fut9) which show disappearance of stage-specific embryonic antigen 1. Mol Cell Biol 24:4221-8.

Kunkel EJ, Dunne JL, Ley K (2000). Leukocyte-arrest during cytokine-dependent inflammation in vivo. J Immunol 164:3301-8.

Lee GS (1995). Mesangial cell culture: its role in the understanding of the pathogenesis of glomerular disease. Ann Acad Med Singapore 24:851-5.

Leelavathi DE, Estes LW, Feingold DS, Lombardi B (1970). Isolation of a Golgirich fraction from rat liver. Biochim Biophys Acta 211:124-38.

Ley K, Tedder TF (1995). Leukocyte interactions with vascular endothelium: New insights into selectin-mediated attachment and rolling. J Immunol 155:5258.

Li L, Krantz ID, Deng Y, Genin A, Banta AB, Collins CC, Qi M, Trask BJ, Kuo WL, Cochran J, Costa T, Pierpont ME, Rand EB, Piccoli DA, Hood L, Spinner NB (1997). Alagille syndrome is caused by mutations in human Jagged 1, which encodes a ligand for Notch1. Nat Gen 16:243-51.

Lowe JB (1994). Carbohydrate recognition in cell-cell interaction. In: Fukuda M, Hindsgaul $O$ (Hrsg.), Molecular Glycobiology, Oxford University Press, Oxford, pp. 163-205.

Lowe JB (1997). Selectin ligands, leukocyte trafficking, and fucosyltransferase genes. Kidney Int 51: 1418-26.

Lübke T, Marquardt T, von Figura K, Körner C (1999). A new type of carbohydrate-deficient glycoprotein syndrome due to a decreased import of GDP-fucose into the golgi. J Biol Chem 274:25986-9.

Lübke T, Marquardt T, Etzioni A, Hartmann E, von Figura K, Körner C (2001). Complementation cloning identifies CDG-Ilc, a new type of congenital disorders of glycosylation, as a GDP-fucose transporter deficiency. Nat Genet 28:73-6.

Lühn K, Wild MK, Eckhardt M, Gerardy-Schahn R, Vestweber D (2001). The gene defective in leukocyte adhesion deficiency II encodes a putative GDPfucose transporter. Nat Genet 28:69-72. 
Luo Y, Haltiwanger RS (2005). O-fucosylation of Notch occurs in the endoplasmic reticulum. J Biol Chem 280:11289-94.

Luo Y, Nita-Lazar A, Haltiwanger RS (2006a). Two distinct pathways for Ofucosylation of epidermal growth factor-like or thrombospondin type 1 repeats. J Biol Chem 2006 Feb 7 (Epub ahead of print).

Luo Y, Koles K, Vorndam W, Haltiwanger RS, Panin VM (2006b). Protein Ofucosyltransferase 2 adds O-fucose to thrombospondin type 1 repeats. $J$ Biol Chem 2006 Feb 7 (Epub ahead of print).

Maly $P$, Thall AD, Petryniak B, Rogers CE, Smith PL, Marks RM, Kelly RJ, Gersten KM, Cheng G, Saunders TL, Camper SA, Camphausen RT, Sullivan FX, Isogai Y, Hindsgaul O, von Andrian UH, Lowe JB (1996). The $\alpha(1,3)$ fucosyltransferase Fuc-TVII controls leukocyte trafficking through an essential role in L-, E-, and P-selectin ligand biosynthesis. Cell 86:643-53.

Mansouri A (1998). Gene Targeting by Homologous Recombination in Embryonic Stem Cells. In: Cell Biology. A Laboratory Handbook. Second Edition. Vol. 3. Academic Press, San Diego.

Marquardt T, Brune T, Lühn K, Zimmer KP, Körner C, Fabritz L, van der Werft N, Vormoor J, Freeze HH, Louwen F, Biermann B, Harms E, von Figura K, Vestweber D, Koch HG (1999a). Leukocyte adhesion deficiency II syndrome, a generalized defect in fucose metabolism. J Pediatr 134:681-8.

Marquardt T, Lühn K, Srikrishna G, Freeze HH, Harms E, Vestweber D (1999b). Correction of leukocyte adhesion deficiency type II with oral fucose. Blood 94:3976-85.

Martinez-Duncker I, Mollicone R, Candelier JJ, Breton C, Oriol R (2003). A new superfamily of protein-O-fucosyltransferases, alpha2-fucosyltransferases, and alpha6-fucosyltransferases: phylogeny and identification of conserved peptide motifs. Glycobiology 13:1C-5C.

Martinez-Duncker I, Dupre T, Piller V, Piller F, Candelier JJ, Trichet C, Tchernia G, Oriol R, Mollicone R (2005). Genetic complementation reveals a novel human congenital disorder of glycosylation of type II, due to inactivation of the Golgi CMP-sialic acid transporter. Blood 105:2671-6.

McDowell G, Gahl W (1997). Inherited disorders of glycoprotein synthesis: Cell biological insights. Proc Soc Exp Biol Med 215:145-57.

McPherson MJ, Quirke P, Tayler GR (1991). PCR I: A Laboratory Approach. IRL Press at Oxford University Press, London.

Meredith MJ (1988). Rat hepatocytes prepared without collagenase: prolonged retention of differentiated characteristics in culture. Cell Biol Toxicol 4:40525. 
Miller JB, Bull S, Miller J, McVeagh P (1994). The oligosaccharide composition of human milk: temporal and individual variations in monosaccharide components. J Pedatr Gastroenterol Nutr 19:371-6.

Millette CF, Cardullo RA, Armant DR, Gerton GL (1987). Fucosylation events during mammalian spermatogenesis. Ann N Y Acad Sci 513:58-73.

Moloney DJ, Shair LH, Lu FM, Xia J, Locke R, Matta KL, Haltiwanger RS (2000a). Mammalian Notch1 is modified with two unusual forms of O-linked glycosylation found in epidermal growth factor-like modules. $\mathrm{J}$ Biol Chem 275:9604-11.

Moloney DJ, Panin VM, Johnston SH, Chen J, Shao L, Wilson R, Wang Y, Stanley $\mathrm{P}$, Irvine KD, Haltiwanger RS, Vogt TF (2000b). Fringe is a glycosyltransferase that modifies Notch. Nature 406:369-75.

Münster AK, Eckhardt M, Potvin B, Mühlenhoff M, Stanley P, Gerardy-Schahn R (1998). Mammalian cytidine 5'-monophosphate $\mathrm{N}$-acetylneuraminic acid synthetase: a nuclear protein with evolutionarily conserved structural motifs. Proc Natl Acad Sci USA 95:9140-5.

Muraoka M, Kawakita M, Ishida N (2001). Molecular characterization of human UDP-glucuronic acid/UDP-N-acetylgalactosamine transporter, a novel nucleotide sugar transporter with dual substrate specifity. FEBS Lett 495:87-93.

Murrey HE, Gama Cl, Kalovidouris SA, Luo WI, Driggers EM, Porton B, HsiehWilson LC (2006). Protein fucosylation regulates synapsin la/lb expression and neuronal morphology in primary hippocampal neurons. Proc Natl Acad Sci U S A 103:21-6.

Niehues R, Hasilik M, Alton G, Körner C, Schiebe-Sukumar M, Koch HG, Zimmer $\mathrm{KP}$, Wu R, Harms E, Reiter K, von Figura K, Freeze $\mathrm{HH}$, Harms HK, Marquardt T (1998). Carbohydrate-deficient glycoprotein syndrome type lb. Phosphomannose isomerase deficiency and mannose therapy. $\mathrm{J}$ Clin Invest 101:1414-20.

Pappenheim A (1912). Zur Blutzellenfärbung im klinischen Bluttrockenpräparat und zur histologischen Schnittpräparatfärbung der hämatopoetischen Gewebe nach meiner Methode. Folia Haematol 13:337-44.

Paulson JC, Colley KJ (1989). Glycosyltransferases. Structure, localization, and control of cell type-specific glycosylation. J Biol Chem 264:17615-18.

Perez M, Hirschberg CB (1987). Transport of sugar nucleotides into the lumen of vesicles derived from rat liver rough endoplasmic reticulum and Golgi apparatus. Methods Enzymol 138:709-15.

Peters V, Penzien JM, Reiter G, Körner C, Hackler R, Assmann B, Fang J, Schäfer JR, Hoffmann GF, Heidemann PH (2002). Congenital disorder of 
glycosylation IId (CDG-IId) - a new entity: clinical presentation with DandyWalker malformation and myopathy. Neuropediatrics 33:27-32.

Puglielli L, Hirschberg CB (1999). Reconstitution, identification, and purification of the rat liver golgi membrane GDP-fucose transporter. J Biol Chem 274:35596-600.

Robertson EJ (1987). Teratocarcinomas and embryonic stem cells: A Practical Approach. IRL Press at Oxford University Press, London.

Rosen SD (1993). Cell surface lectins in the immune system. Semin Immunol 5:237-47.

Rossi D, Zlotnik A. The biology of chemokines and their receptors. Annu Rev Immunol 18:217-42.

Saiki RK, Bugawan TL, Horn GT, Mullis KB, Erlich HA (1986). Analysis of enzymatically amplified beta-globin and HLA-DQ alpha DNA with allelespecific oligonucleotide probes. Nature 324:163-6.

Saiki RK, Gelfand DH, Stoffel S, Scharf SJ, Higuchi R, Horn GT, Mullis KB, Erlich HA (1988). Primer-directed enzymatic amplification of DNA with a thermostable DNA polymerase. Science 239: 487-91.

Sajdel-Sulkowska EM (1998). Immunofluorescent detection of CD15-fucosylated glycoconjugates in primary cerebellar cultures and their function in glialneuronal adhesion in the central nervous system. Acta Biochim Pol 45:78190.

Sambrook J, Fritsch E F, Maniatis T (1989). Molecular Cloning, a laboratory manual, second edition. Cold Spring Harbor Laboratory Press, New York.

Sandhoff R, Geyer R, Jennemann R, Paret C, Kiss E, Yamashita T, Gorgas K, Sijmonsma TP, Iwamori M, Finaz C, Proia RL, Wiegandt H, Gröne HJ (2005). Novel class of glycosphingolipids involved in male fertility. J Biol Chem 280:27310-8.

Satoh J, Kim SU (1994). Differential expression of Lewis(x) and sialyl-Lewis(x) antigens in fetal human neural cells in culture. $J$ Neurosci Res 37:466-74.

Scanlin TF, Glick MC (1999). Terminal glycosylation in cystic fibrosis. Biochim Biophys Acta 1455:241-53.

Schenk B, Imbach T, Frank CG, Grubenmann CE, Raymond GV, Hurvitz H, RaasRotschild A, Luder AS, Jaeken J, Berger EG, Matthijs G, Hennet T, Aebi M (2001). MPDU1 mutations underlie a novel human congenital disorder of glycosylation, designated type If. J Clin Invest 108:1687-95.

Schiffer SG, Foley S, Kaffashan A, Hronowski X, Zichittella AE, Yeo CY, Miatkowski K, Adkins HB, Damon B, Whitman M, Salomon D, Sanicola M, 
Williams KP (2001). Fucosylation of Cripto is required for its ability to facilitate nodal signaling. $\mathrm{J}$ Biol Chem 276:37769-78.

Schulte BA, Spicer SS (1983). Histochemical evaluation of mouse and rat kidneys with lectin-horseradish peroxidase conjugates. Am J Anat 168:345-62.

Sears $\mathrm{P}$, Wong $\mathrm{CH}$ (1998). Enzyme action in glycoprotein synthesis. Cell Mol Life Sci 54:223-52.

Segawa H, Kawakita M, Ishida N (2002). Human and Drosophila UDP-galactose transporters transport UDP- $N$-acetylgalactosamine in addition to UDPgalactose. Eur J Biochem 269:128-38.

Shao L, Moloney DJ, Haltiwanger R (2003). Fringe modifies O-fucose on mouse Notch1 at epidermal growth factor-like repeats within the ligand-binding site and the Abruptex region. J Biol Chem 278:7775-82.

Shi S, Stanley P (2003). Protein O-fucosyltransferase 1 is an essential component of Notch signaling pathways. Proc Natl Acad Sci U S A 100:5234-9.

Sinowatz F, Plendl J, Kolle S (1998). Protein-carbohydrate interactions during fertilization. Acta Anat (Basel) 161:196-205.

Smith PL, Myers JT, Rogers CE, Zhou L, Petryniak B, Becker DJ, Homeister JW, Lowe JB (2002). Conditional control of selectin ligand expression and global fucosylation events in mice with a targeted mutation at the FX locus. $J$ Cell Biol 158:801-15.

Southern EM (1975). Detection of specific sequences among DNA fragments separated by gel electrophoresis. J Mol Biol 98:503-17.

Sperandio M, Forlow SB, Thatte J, Ellies LG, Marth JD, Ley K (2001). Differential requirements for core2 glucosaminyltransferase for endothelial L-selectin ligand function in vivo. J Immunol 167:2268-74.

Spiro RG (1969). Characterization and quantitative determination of the hydroxylysine-linked carbohydrate units of several collagens. J Biol Chem 244: 602-12:

Spiro RG (2002). Protein glycosylation: nature, distribution, enzymatic formation, and disease implications of glycopeptide bonds. Glycobiology 12:43R-56R.

Sturla L, Etzioni A, Bisso A, Zanardi D, De Flora G, Silengo L, De Flora A, Tonetti M (1998). Defective intracellular activity of GDP-D-mannose-4,6dehydratase in leukocyte adhesion deficiency type II syndrome. FEBS Lett 429:274-8.

Sturla L, Puglielli L, Tonetti M, Berninsone P, Hirschberg CB, De Flora A, Etzioni A (2001). Impairment of the Golgi GDP-L-fucose transport and unresponsiveness to fucose replacement therapy in LAD II patients. Pediatr Res 49:537-42. 
Sturla L, Rampal R, Haltiwanger RS, Fruscione F, Etzioni A, Tonetti M (2003). Differential terminal fucosylation of $\mathrm{N}$-linked glycans versus protein $\mathrm{O}$ fucosylation in leukocyte adhesion deficiency type II (CDG IIc). J Biol Chem 278:26727-33.

Suda T, Kamiyama S, Suzuki M, Kikuchi N, Nakayama K, Narimatsu H, Jigami Y, Aoki T, Nishihara S (2004). Molecular cloning and characterization of a human multisubstrate specific nucleotide-sugar transporter homologous to Drosophila fringe connection. J Biol Chem 279:26469-74.

Tan J, Dunn J, Jaeken J, Schachter H (1996). Mutations in the MGAT2 gene controlling complex $\mathrm{N}$-glycan synthesis cause carbohydrate-deficient glycoprotein syndrome type II, an autosomal recessive disease with defective brain development. Am J Hum Genet 59:810-7.

Tatu U, Helenius A (1997). Interactions between newly synthesized glycoproteins, calnexin and a network of resident chaperones in the endoplasmic reticulum. J Cell Biol 136:555-65.

Ten Hagen KG, Bedi GS, Tetaert D, Kingsley PD, Hagen FK, Balys MM, Beres TM, Degand P, Tabak LA (2001). Cloning and characterization of a ninth member of the UDP-GalNAc:polypeptide N-acetylgalactosaminyltransferase family, ppGaNTase-T9. J Biol Chem 276:17395-404.

Thiel C, Schwarz M, Hasilik M, Grieben U, Hanefeld F, Lehle L, Von Figura K, Körner C (2002). Deficiency of dolichyl-P-Man:Man7GlcNAc2-PP-dolichyl mannosyltransferase causes congenital disorder of Glycosylation-lg. Biochem J 367:195-201.

Thiel C, Schwarz M, Peng J, Grzmil M, Hasilik M, Braulke T, Kohlschütter A, von Figura K, Lehle L, Körner C (2003). A new type of congenital disorders of glycosylation (CDG-li) provides new insights into the early steps of dolichollinked oligosaccharide biosynthesis. J Biol Chem 278:22498-505.

Van Schaftingen E, Jaeken J (1995). Phosphomannomutase deficiency is a cause of carbohydrate-deficient glycoprotein syndrome type I. FEBS Lett 377:31820.

Van der Weyden L, Adams DJ, Bradley A (2002). Tools for targeted manipulation of the mouse genome. Physiol Genomics 11:133-64.

Varki A (1993). Biological roles of oligosaccharides: all of the theories are correct. Glycobiology 3:97-130.

Vestweber D, Blanks JE (1999). Mechanisms that regulate the function of the selectins and their ligands. Physiol Rev 79:181-213.

Wang Y, Shao L, Shi S, Harris RJ, Spellman MW, Stanley P, Haltiwanger RS (2001). Modification of epidermal growth factor-like repeats with O-fucose. J Biol Chem 276:40338-45. 
Wang H, Tachibana K, Zhang Y, Iwasaki H, Kameyama A, Cheng L, Guo J, Hiruma T, Togayachi A, Kudo T, Kikuchi N, Narimatsu H (2003). Cloning and characterization of a novel UDP-GalNAc:polypeptide Nacetylgalactosaminyltransferase, pp-GalNAc-T14. Biochem Biophys Res Commun 300:738-44.

Wang X, Inoue S, Gu J, Miyoshi E, Noda K, Li W, Mizuno-Horikawa Y, Nakano M, Asahi M, Takahashi M, Uozumi N, Ihara S, Lee SH, Ikeda Y, Yamaguchi Y, Aze Y, Tomiyama Y, Fujii J, Suzuki K, Kondo A, Shapiro SD, Lopez-Otin C, Kuwaki T, Okabe M, Honke K, Taniguchi N (2005). Dysregulation of TGFbeta1 receptor activation leads to abnormal lung development and emphysema-like phenotype in core fucose-deficient mice. Proc Natl Acad Sci U S A 102:15791-6.

Wang X, Gu J, Ihara H, Miyoshi E, Honke K, Taniguchi N (2006). Core fucosylation regulates epidermal growth factor receptor-mediated intracellular signaling. J Biol Chem 281:2572-7.

Weninger W, Ulfman LH, Cheng G, Souchkova N, Quackenbush EJ, Lowe JB, von Andrian UH (2000). Specialized contributions by alpha(1,3)fucosyltransferase-IV and FucT-VII during leukocyte rolling in dermal microvessels. Immunity 12:665-76.

Wu X, Rush JS, Karaoglu D, Krasnewich D, Lubinsky MS, Waechter CJ, Gilmore $\mathrm{R}$, Freeze HH (2003). Deficiency of UDP-GlcNAc:dolichol phosphate Nacetylglucosamine-1 phosphate transferase (DPAGT1) causes a novel disorder of glycosylation type lj. Hum Mutat 22:144-50.

Wu X, Steet RA, Bohorov O, Bakker J, Newell J, Krieger M, Spaapen L, Kornfeld S, Freeze HH (2004). Mutation of the COG complex subunit gene COG7 causes a lethal congenital disorder. Nat Med 10:518-23.

Yanagidani S, Uozomi N, Ihara Y, Miyoshi E, Yamaguchi N, Taniguchi N (1997). Purification and cDNA cloning of GDP-L-Fuc:N-acetyl- $\beta$-D-glucosaminide: $\alpha$ 1-6 fucosyltransferase ( $\alpha$ 1-6 FucT) from human gastric cancer MKN45 cells. J Biochem 121:626-32.

Yorek MA, Dunlap JA (2002). Effect of increased concentration of D-glucose or Lfucose on monocyte adhesion to endothelial cell monolayers and activation of nuclear factor-kappaB. Metabolism 51:225-34.

Yoshida A, Kobayashi K, Manya H, Taniguchi K, Kano H, Mizuno M, Inazu T, Mitsuhashi H, Takahashi S, Takeuchi M, Herrmann R, Straub V, Talim B, Voit T, Topaloglu H, Toda T, Endo T (2001). Muscular dystrophy and neuronal migration disorder caused by mutations in a glycosyltransferase, POMGnT1. Dev Cell 1:717-24.

Zanetta JP (1998). Structure and Functions of Lectins in the Central and Peripheral Nervous System. Acta Anatomica 161:180-95. 
$8 \quad$ Anhang

\title{
8.1 Nukleotid- und Aminosäuresequenzen des GFT
}

\author{
8.1.1 Partielle Nukleotidsequenz der cDNA des murinen GDP-Fucose- \\ Transporters (ohne 3'-Ende)
}

\begin{abstract}
GAATTCGGCTCGTGGCAACCGCAGGGCCTTGCTCCGGTCAGGCCCCTGTCCGTGTCCCTC GAGACGCCTTCCTGAGCCTCGGTGATCTCCCTGCAGCACGCCCTCCTTTCGGCTCTGCGG GTGCTTCCGGGGGTTCCCGCAGCCCATGCTTCCCACGCGGTCCGCGTCCAGTTATTTCCT CCTCCGCTCCGTCCTTCCTTCGCTCTCTCGCTTCCTTTCTCCCTGCGACTCACGTGTCCC CTGTCCTCAAACTGGCCATGGCTGTCAAAGCCCACATCCTTAGTTAGGCCCCTTCTCCCT TCCCTGGGTCTTGTTTCGTGACACCACCTCCCTCCCCCGCCCCGGGAGCGAGCAAGATGA GGAGCGGTGCACCTCGGCAAATCCGGAAGCAGAACTTCATCCAAGAAGGAGGGGACCGAT AGGTCATCCCATGTGACAGTTGAAGGCTGCAGCCACAGACCCTAGCTGCTTGAAGCCCTG TAGTCCAGGGACTGCTTCTGGCCGTAAGGTGACCCAGCTCTTCTGCCACATGAACAGGG CGCCTCTGAAGCGGTCCAGGATCCTGCGCATGGCGCTGACTGGAGTCTCTGCTGTCTCCG AGGAGTCAGAGAGCGGGAACAAGCCATTTCTGCTCCGGGCTCTGCAGATCGCGCTGGTGG TCTCTCTCTACTGGGTCACCTCCATTTCCATGGTATTCCTCAACAAGTACCTGCTGGACA GCCCCTCCCTGCAGCTGGATACCCCCATTTTTGTCACCTTCTACCAATGCCTGGTGACCT CACTGCTGTGCAAGGGCCTCAGCACTCTGGCCACCTGCTGCCCCGGCATGGTAGACTTCC CCACCCTAAACCTGGACCTCAAGGTGGCCCGAAGTGTGCTGCCGCTGTCAGTGGTCTTTA TCGGCATGATAACCTTCAATAACCTCTGCCTCAAGTACGTAGGGGTGCCCTTCTACAACG TGGGACGCTCGCTCACCACCGTGTTCAACGTTCTTCTCTCCTACCTGCTGCTCAAACAGA 1020 CCACTTCCTTCTATGCCCTGCTCACCTGCGGCGTCATCATTGGTGGTTTCTGGCTGGGTA 1080 TAGACCAAGAAGGAGCTGAGGGAACCTTGTCCCTGACGGGCACCATCTTCGGGGTGCTGG 1140 CCAGCCTCTGCGTCTCCCTCAATGCCATCTATACCAAGAAGGTGCTCCCTGCAGTAGACC 1200 ACAGTATCTGGCGCCTAACCTTCTATAACAATGTCAATGCCTGCGTGCTCTTCTTGCCCC 1260 TGATGATAGTGCTGGGCGAGCTCCGTGCCCTCCTGGCCTTCACTCATCTGAGCAGTGCCC 1320 ACTTCTGGCTCATGATGACGCTGGGTGGCCTGTTTGGCTTTGCCATCGGCTATGTGACAG 1380 GACTGCAGATCAAATTCACCAGTCCCCTGACCCATAACGTGTCAGGCACGGCCAAGGCCT 1440 GTGCACAGACAGTGCTGGCCGTGCTCTACTACGAAGAGATTAAGAGCTTCCTGTGGTGGA 1500 CAAGCAACCTGATGGTGCTGGGTGGCTCCTCCGCCTACACCTGGGTCAGGGGCTGGGAGA 1560 TGCAGAAGACCCAGGAGGACCCCAGCTCCAAAGATGGTGAGAAGAGTGCTATCAGGGTG 1620 GAGCTCCTTCAGGGAGCCAGGGCTGAGCTCGGGTGGGGCCTGCCCAGCACGGAAGGCTTC 1680 CCATAGAGCCTACTGGGTATGGCCCTGAGCAATAATGTTTACATCCTTCTCAGAAGACCA 1740 TCTAAGAAGAGCCAGGTTCTTTCCTGATAATGTCAGAAAGCTGCCAAATCTCCTGCCTGC 1800 CCCATCTTCTAGTCTTGGGAAAGCCCTACCAGGAGTGGCACCCTTCTGCTCCTCCTGGG 1860 CCTGTCTACCTCCTATGGTCTCTGGGGTTGGGGCCAGCTGCACTCTTTGGGCACTGGACT 1920 GATGAAGTGATGTCTTACTTTCTACACAAGGGAGATGGGTTGTGACCCTACTATAGCTAG 1980 TTGAAGGGAGCTGTGTAACCCCACATCTCTGGGGCCCTGGGCAGGTAGCATAATAGCTAG 2040 GTGCTATTAACATCAATAACACTTCAGACTACCTTTGGAGGCAGTTGGGAGCTGAGCCGA 2100
\end{abstract}




\subsection{2}

\section{Aminosäuresequenz des murinen Golgi-GDP-Fucose- Transporters}

$\begin{array}{lr}\text { MNRAPLKRSRILRMALTGVSAVSEESESGNKPFLLRALQIALVVSLYWVT } & 50 \\ \text { SISMVFLNKYLLDSPSLQLDTPIFVTFYQCLVTSLLCKGLSTLATCCPGM } & 100 \\ \text { VDFPTLNLDLKVARSVLPLSVVFIGMITFNHLCLKYVGVPFYNVGRSLTT } & 150 \\ \text { VFNVLLSYLLLKTTSFYLLTCGVIIGGFLGIDQEAEGTLLTGTIF } & 200 \\ \text { GVLASLCVFLNAIYTKVLPAVDHSIWRLTFYNNVNACVLFLPLMIVLGE } & 250 \\ \text { LRALLAFTHLSSAHFWLMMTLGGLFGFAIGYVTGLQIKFTSPLTHNVSGT } & 300 \\ \text { AKACAQTVLAVLYYEEIKSFLWTTSNLMVLGGSAYTWRGWEMQKTQED } & 350 \\ \text { PSSKDGEKSAIRV. } & 363\end{array}$

\subsection{Sequenzen der verwendeten Oligonukleotide}

Sämtliche Oligonukleotid-Sequenzen sind in $5^{\prime} \rightarrow 3^{\prime}$-Orientierung angegeben.

\subsubsection{Genotypisierungs-PCR}

GFT-F1:

GCG TTG CAA GTT CAG CCG AG

GFT-R1:

CCG TCG ACG GTA TCG ATA AGC

GFT-R2:

GTG TGT TGG TCA AGA GTG TAA CC

\subsubsection{Southern-Sonde}

GFT-F1: $\quad$ s.o.

GFT-R3: $\quad$ CCA GCT CGC AGG CCG TTG C

\subsubsection{Northern-Sonde}

GFT-F2: $\quad$ CTG GCC GTA AGG TGA CCC AG

GFT-R4: $\quad$ CTG AAG GAG CTC ACA CCC TG 


\section{Danksagung}

Herrn Prof. Dr. Dr. h.c. Kurt von Figura danke ich für die Vergabe des überaus interessanten Themas. Seine immerwährende Diskussionsbereitschaft und Anregungen, auch nach unserem Umzug nach Heidelberg und seinem Antritt des Präsidentenamtes der Universität Göttingen, haben maßgeblich zum Erfolg beigetragen.

Bei Herrn Prof. Dr. Gerhard Braus bedanke ich mich für die bereitwillige Übernahme des Korreferats.

Herrn Prof. Dr. Christian Körner danke ich für das Vertrauen in meine Arbeit, die Betreuung und Diskussionsbereitschaft sowie das freundschaftliche Verhältnis in seiner Arbeitsgruppe.

Für das freundschaftliche Klima innerhalb der Arbeitsgruppe möchte ich mich weiterhin bei Christian Thiel, Jürgen Lübbehusen, Virginia Bauersfeld, Nina Rind, Anette Schneider und Yonghong Li bedanken. Der gleiche Dank gilt den Mitgliedern der Gruppe vor dem Umzug, Frau Sander, Martin Hasilik und Jan Rindermann. Gerne denke ich an die "guten alten Göttinger Zeiten" zurück.

Herzlichen Dank auch allen anderen Mitarbeitern sowohl der Stoffwechselabteilung der Kinderklinik in Heidelberg als auch der damaligen Göttinger Abteilung für die Hilfsbereitschaft und das freundliche Arbeitsklima.

Darüber hinaus danke ich allen auch außerhalb der Arbeitsgruppe, die mir bei dem Erlernen neuer Methoden ihre Zeit und Hilfe geschenkt haben, darunter Torben Lübke, Ellen Eckermann, Elisabeth Munk, Christian Morath, Barbara Rodenbeck und Heidi Raschke.

Mein Dank gilt auch Herrn Prof. Dr. Gröne für seinen fachlichen Rat bei der Auswertung meiner histologischen Präparate.

Dr. Martin Wild und Dr. Markus Sperandio danke ich für die hervorragenden Kooperationen.

Dem Evangelischen Studienwerk e.V. Villigst danke ich für die finanzielle Förderung meiner Promotion sowie für das freundschaftliche Klima im Haus Villigst.

Ganz besonders danke ich meinem geliebten Schatz Marcel für die Geduld, Unterstützung und vor allem für das große Verständnis.

Der größte Dank gilt meinen Eltern und meiner Schwester für die Liebe und Unterstützung in all den Jahren. 


\section{Lebenslauf}

Am 18. Januar 1979 wurde ich als zweites Kind meiner Eltern Ingrid Hellbusch, geb. Schöler, und Hans-Peter Hellbusch in Delmenhorst geboren. Von 1985 bis 1989 besuchte ich die Grundschule, von 1989 bis 1991 die Orientierungsstufe in Harpstedt. Meinen anschließenden Besuch des Gymnasiums Wildeshausen schloss ich 1998 mit der allgemeinen Hochschulreife ab.

Im Oktober 1998 begann ich das Studium der Biologie an der Georg-AugustUniversität zu Göttingen. Die mündliche Diplom-Hauptprüfung erfolgte im November 2001 im Hauptfach Biochemie und den Nebenfächern Mikrobiologie und Organische Chemie. Die Anfertigung meiner Diplomarbeit erfolgte am Zentrum Biochemie und Molekulare Zellbiologie, Institut für Biochemie II der Georg-August-Universität zu Göttingen unter Leitung von Herrn Prof. Dr. Kurt von Figura. Die Abgabe der Diplomarbeit mit dem Titel "Klonierung des murinen GolgiGDP-Fucose-Transporters und Herstellung von Gene-Targeting-Vektoren zur Generierung eines Mausmodells für Congenital Disorder of Glycosylation-Ilc (CDG-IIc)" erfolgte im Oktober 2002.

Im November 2002 begann ich am gleichen Institut unter der Anleitung von Herrn Prof. Dr. Kurt von Figura in der Arbeitsgruppe von Herrn PD Dr. Christian Körner den experimentellen Teil der vorliegenden Dissertation mit dem Thema "Ein Knockout-Mausmodell für Congenital Disorder of Glycosylation-Ilc: Defizienz des Golgi-GDP-Fucose-Transporters". Im Jahr 2004 wechselte ich mit der Arbeitsgruppe von Herrn Prof. Dr. Christian Körner an die Universitätsklinik für Kinder- und Jugendmedizin Heidelberg, wo die Weiterführung des experimentellen Teils dieser Arbeit erfolgte. Seit Dezember 2003 bin ich Stipendiatin des Begabtenförderungswerkes Evangelisches Studienwerk e.V. Villigst. Im September 2005 erhielt ich ein Reisestipendium der "Society for the Study of Inborn Errors of Metabolism" (SSIEM) für den Besuch des 42. SSIEMSymposiums in Paris. 